\title{
OFFICE OF NAVAL RESEARCH
}

Contract No. NR 099-404/2-75

\section{ADVANCED RESEARCH PROGRAMS ADMINISTRATION \\ Order No. 2944 \\ Reporting Period From \\ February to August 1975}

TIN-STEAM MHD POWER SYSTEM - VOLUME ॥

by

M. Petrick, Project Scientist

B. K. Snyder, R. Hantman, T. Kassner,

L. Carlson, and T. Zinneman

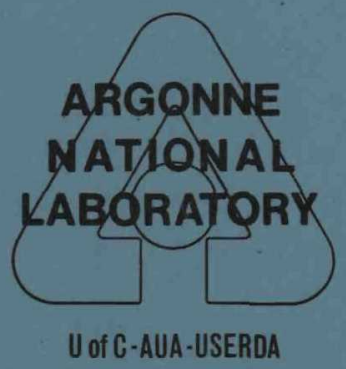

Engineering Division

September 1975 


\section{DISCLAIMER}

This report was prepared as an account of work sponsored by an agency of the United States Government. Neither the United States Government nor any agency Thereof, nor any of their employees, makes any warranty, express or implied, or assumes any legal liability or responsibility for the accuracy, completeness, or usefulness of any information, apparatus, product, or process disclosed, or represents that its use would not infringe privately owned rights. Reference herein to any specific commercial product, process, or service by trade name, trademark, manufacturer, or otherwise does not necessarily constitute or imply its endorsement, recommendation, or favoring by the United States Government or any agency thereof. The views and opinions of authors expressed herein do not necessarily state or reflect those of the United States Government or any agency thereof. 


\section{DISCLAIMER}

Portions of this document may be illegible in electronic image products. Images are produced from the best available original document. 
The facilities of Argonne National Laboratory are owned by the United States Government. Under the terms of a contract (W-31-109-Eng-38) between the U. S. Energy Research and Development Administration, Argonne Universities Association and The University of Chicago, the University employs the staff and operates the Laboratory in accordance with policies and programs formulated, approved and reviewed by the Association.

\section{MEMBERS OF ARGONNE UNIVERSITIES ASSOCIATION}

The University of Arizona Carnegie-Mellon University Case Western Reserve University The University of Chicago University of Cincinnati Illinois Institute of Technology University of Illinois Indiana University Iowa State University The University of Iowa
Kansas State University The University of Kansas Loyola University Marquette University Michigan State University The University of Michigan University of Minnesota University of Missouri Northwestern University University of Notre Dame
The Ohio State University Ohio University The Pennsylvania State University Purdue University Saint Louis University Southern Illinois University The University of Texas at Austin Washington University Wayne State University The University of Wisconsin

\section{NOTICE}

This report was prepared as an account of work sponsored by the United States Government. Neither the United States nor the United States Energy Research and Development Administration, nor any of their employees, nor any of their contractors, subcontractors, or their employees, makes any warranty, express or implied, or assumes any legal liability or responsibility for the accuracy, completeness or usefulness of any information, apparatus, product or process disclosed, or represents that its use would not infringe privately-owned rights. Mention of commercial products, their manufacturers, or their suppliers in this publication does not imply or connote approval or disapproval of the product by Argonne National Laboratory or the U. S. Energy Research and Development Administration. 
OFFICE OF NAVAL RESEARCH

Contract No. NR 099-404/2-75

ADVANCED RESEARCH PROGRAMS ADMINISTRATION

Order No. 2944

REPORTING PERIOD FROM

February to August 1975

TIN-STEAM MHD POWER SYSTEM - VOLUME II ${ }^{\star}$

by

M. Petrick, Project Scientist

B. K. Snyder

R. Hantman

T. Kassner

L. Carlson

T. Zinneman

Argonne National Laboratory

Engineering Division

September 1975

This report was prepared as an account of work sponsored by the United States Government. Neither the United States nor the United States Energy their emplovelopment Administration, nor any of subcontractors, not any of their contractors, warranty, expreas or implomployes, makes any liabillty of responsibility for the assumes any legal or usefulness of any information, appar, completeness infringe privately owned rights.

*Work performed under the auspices of the United States Energy Research and Development Administration. 
I. Introduction

II. $1 \mathrm{MW}$ (therma1) Prototype Power

System Description

III. Program Plan Description

Materials and Reaction Kinetics Studies

Component Development and Testing

Program Schedule

IV. Management Plan

V. Budget

References: References are listed at the end of each section

\section{APPENDICES}
A. 1 MW(thermal) Tin-Water MHD Prototype Power System Conceptual System Design Description
B. Tin-Water MHD Program Plan Task Descriptions (abridged)
C. Tin-Water MHD Program Plan Cost Estimate Criteria and Work Sheets 
SECTION I

Introduction

During fiscal year 1975 Argonne National Laboratory, under an agreement with the Defense Advanced Research Projects Agency (DARPA) has engaged in conceptual studies of a tin-water MHD Prototype Power System. This system has several advantages that make it especially attractive for application in large submersibles. In addition to being compatible with present day light water reactors and having the potential for producing very substantial reductions in weights and volumes for given power levels when compared to present-day systems, it also possesses the potential for increased system reliability and reduced noise levels, since the few rotating parts are of small size and will rotate at relatively low velocity.

The FY 75 activities included cycle and system studies, pre-conceptual design studies and development of detailed program plans. Volume I describes the results of the cycle and system studies and tin-water oxidation studies conducted in FY 75.

This volume, Volume II, concerns itself with the description of a conceptual reference design for a $1 \mathrm{MW}$ (thermal) $\mathrm{Sn}-\mathrm{H}_{2} \mathrm{O} \mathrm{MHD}$ Prototype Power System, the program plan for the $R \& D$, design and construction of such a system and time schedules and budgets corresponding thereto.

A summary of the conceptual reference design of the prototype power system, its major features and operational characteristics are given in Section II; the details are given in appendix A, the System Design Description which describes the system, its components, operation and design parameters in great detail.

Section III describes the overall program plan. It contains subsections which describe, in detail, the materials and reaction-kinetics studies program and the component development and testing program. 
Also, the overa11 program schedule is presented. Salient program feature such as constraints, critical paths, manpower loadings and program buildup are discussed.

The management plan, including an organtzation chart is given in Section IV. Section V presents the overall program budgets by category for each of the four fiscal years, 1976 through 1979, for both a single stage system and a double stage system. Also included is an analysis of some budgetary characteristics of the program.

As indicated previously, the Conceptual System Design Description of the $1 \mathrm{MW}$ Prototype Power System is presented in Appendix A. This is the reference design upon which the program plan, task descriptions and, the program budgets were based. It describes a two-stage system. However, provisions are incorporated which would permit construction of only portions of the system required for operation of a single stage. Appendix B contains the major program task descriptions upon which the program schedules and cost estimates were based. This is an abridged version of the task descriptions. The full document includes subtask descriptions and completion criteria for each task and subtask. Appendix $C$ contains the detailed cost estimate sheets upon which the program budgets were based. Also included is a description of the criteria employed in cost estimating. 
SECTION II

\section{MW (Therma1) Sn-H 2 O MHD Prototype \\ Power System Description}

The focal point of the $\mathrm{Sn}-\mathrm{H}_{2} \mathrm{O}$ MHD program is the construction of a $1 \mathrm{MW}(t)$ prototype power system. All activites, including the materials and reaction kinetics studies, component development and testing and system and cycle studies are dedicated to that objective.

The completed plant, in addition to serving as a demonstration of the viability of the $\mathrm{Sn}-\mathrm{H}_{2} \mathrm{O}$ MHD principle will provide experfence with the operational characteristics of such a system. The system will be extensively instrumented and the system parameters thus measured will provide input for analytical models which will be useful in designing advanced systems for shipboard and other possible applications. The completed facility will also be used as a test bed for component testing and refinement within its capability for accepting modifications.

No attempt has been made, in carrying out the conceptual design of this system and its components, to comply with spatial limitations that would influence sizes and configurations of components in an actual application.

The prototype power system as described in Appendix A will occupy a space approximately twenty feet wide by forty to fifty feet long by twenty feet high. The actual space occupied will depend upon whether a single or double stage system is constructed. A twenty foot by fifteen foot control room will be located adjacent to the power system. The entire power system will be contained in a framed, sheet metal enclosure on all four sides. The power system will be sited in a crane-equipped high bay area.

The conceptual design upon which the program plan is based is described in great detail in the System Design Description, which is Appendix A of 
this report. Figure 2 in that appendix (reproduced on the next page) defines the full system, consisting of two MHD generator stages with regenerative heating between stages. It is possible to establish, analytically, two stage cycle characteristics after having demonstrated, operationally, the basic characteristics of a single stage MHD system. For that reason the single stage option is being presented as a means of minimizing program cost. Referring to Fig. 2, the single stage system would consist of all components to the left of, and Including the Primary $\mathrm{Hx}$-Boiler plus Regenerative $\mathrm{Hx}$ 非 and all components to its right.

Most components of the system can be classified as conventional steam plant equipment such as the regenerative heat exchangers, condenser, condensate and feedwater pumps, etc. The largest component is the Primary Hx-Boiler, which w 111 be approximately three feet in diameter and twenty feet high. It simulates the primary fluid system of a water cooled reactor. The specialized components are those associated with the two phase mixture of tin and steam. They are the injector-mixer, nozzle, separatordiffuser, MHD generator and superconducting magnet. These are the components (except for the magnet) which will require developmental and testing effort. The electrical power that will be generated will be dissipated in an electrical heat dump coupled directly to the generator. Reject heat from the condenser and other heat sources will be dissipated in air or water cooled facilities provided at the site.

Current planning is based on the use of low-carbon steel for most system components. However, material studies to be conducted will determine whether high alloy steels will be required to resist the erosive or corrosive attack by the flowing tin and tin-steam mixtures. Commercial sources of construction will be sought for all components of the system wherever 


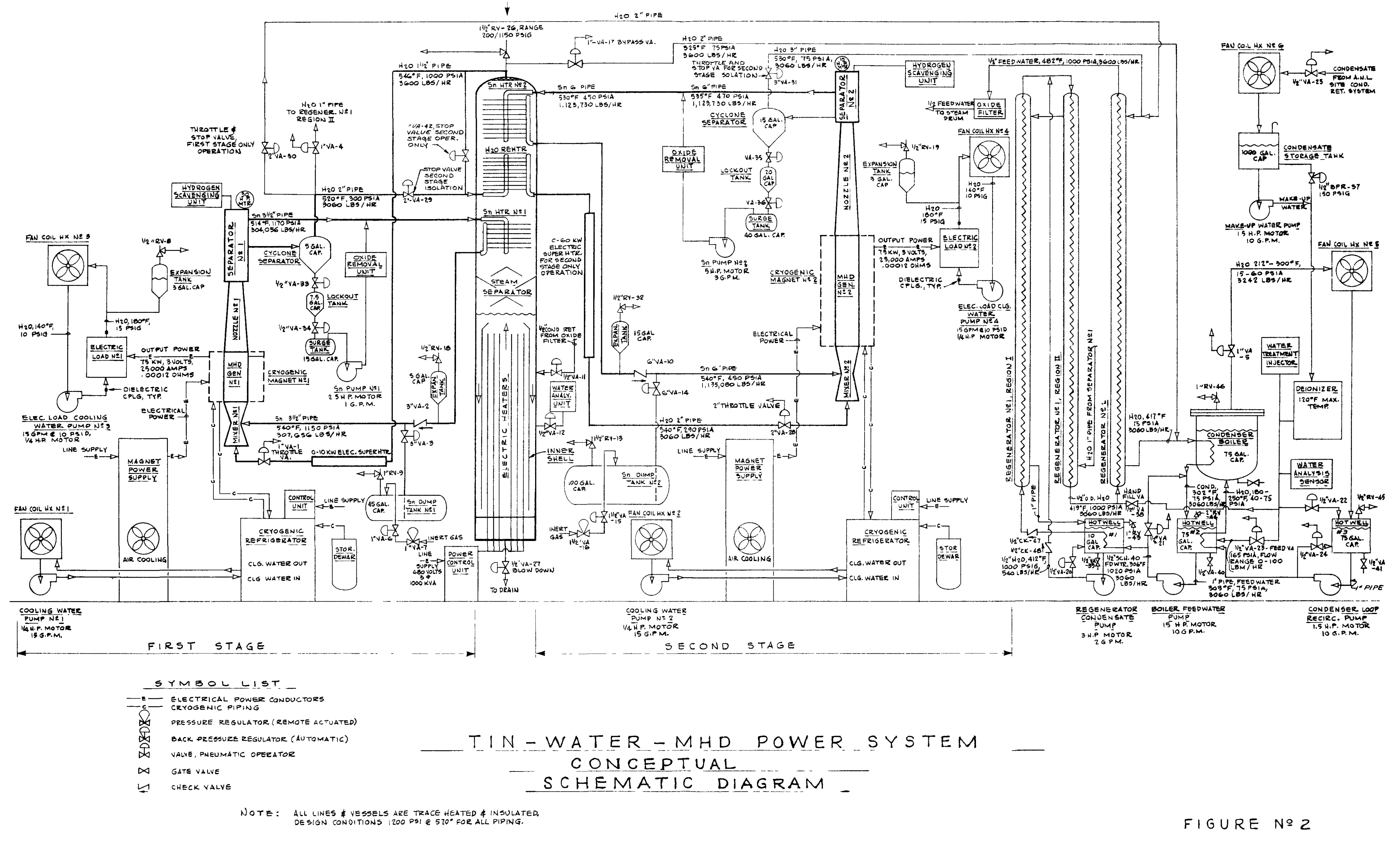


possible. It is contemplated that some of the developmental model construction will be accomplished at ANL shops.

The complete power generation system will be built to applicable codes and standards to every possible extent. The program plan includes periodic design and safety reviews and the system will be thoroughly checked and tested before operation.

Following is a brief outline description of the system: Approximately one megawatt of thermal energy is supplied by electrical heaters simulating a light water reactor to produce saturated steam at 1000 psi and $546^{\circ} \mathrm{F}$ for the modified, closed Rankine cycle. Although this pressure and temperature formed the basis for the reference design, parametric studies as described in Volume I indicate that a lower system pressure has advantages in terms of cycle performance for the pure LMMHD system. The MHD power generation system consists of the following subsystems
1. Makeup water
2. Heat rejection
3. Boiler feedwater
4. Steam generator
5. MHD Stage 1
6. MHD Stage 2
7. Miscellaneous components (piping, structure, insulation, controls and instrumentation).

The makeup water, feedwater, heat rejection, steam generation and miscellaneous subsystem components will conform to standard boilerplant design practice wherever possible.

The two MHD stages represent new development components and technology as follows:

Each of the two MHD stages consists of a tin-reheat heat exchanger, a tin-steam mixer, a MHD channel, a two-phase steam expansion nozzle, a tin-steam separator and other auxiliary equipment. The steam flows in 
series arrangement through the two MHD stages. It is the working fluid for the cycle.

The two separate liquid tin streams which recirculate in each MHD stage provide the electrical conductance within the MHD generator channels. Steam is mixed with the tin within the mixing device in the form of small bubbles dispersed in the continuous tin phase. The small bubbles expand in the decreasing pressure fleld through the MHD channel and perform work in forcing the liquid tin through the opposing magnetic force field. The intimate contact of the small bubbles with the liquid tin allows good heat transfer from the tin to the steam and results in nearly isothermal heat transfer within the MHD channe1. The isothermal expansion feature increases the efficiency of this cycle over that of a Rankine cycle in which expansion is isentropic. The two-phase convergent nozzle accelerates the mixture into the separator to facilitate separation of the tin and steam. The separator concept employs a rotating member upon whose inner surface the high velocity stream is tangentially impinged. Centrifugal force effects the separation of the steam from the tin with little fluid friction loss. A motor or turbine coupled to the rotating member will be used for startup and to furnish supplemental torque as may be required to assist in pumping the tin back to the mixer.

Complete information on the details of construction, operation and system parameters such as pressures, temperatures, pipe sizes and flow rates is contained in Appendix A. It should be kept in mind that the conceptual design presented therein, although theoretically feasible, is subject to optimization and refinement in future design phases.

The instrumentation, control, data acquisition and data processing provisions are important aspects of the prototype power system. In the full system there are over one hundred parameters that will be monitored and/or controlled. This is beyond the realm of "hands-on" control. 
The System Design Description, Appendix A, describes in detail the provisions for caring for these requirements. A brief review of the subject follows:

The function of the $\mathrm{Sn}-\mathrm{H}_{2} \mathrm{O}$ MHD instrumentation and control system is to monftor and control all system parameters necessary for the efficlent and safe operation of the facility under all possible operating conditions. The system must be flexible enough to accomodate plant changes which typically occur in the operation of a test or demonstration facility.

Various parameters to be monitored and controlled include temperature, pressure, flow, and liquid levels of components and piping in both the tin and steam systems as well as the cryogenic system associated with the superconducting magnets. Although standard off-the-shelf instrumentation can be used for the water and steam system, the tin system presents some interesting problems. Tin is naturally corrosive to many materials, expecially those containing nickel. Thus, to monitor the pressure, flow and Iiquid levels in the tin system, the exposed elements must be something other than stainless steel or inconel as found in many transducers. It appears that tantalum is a suitable material, especially at the low temperatures involved. Commercially available, differential and gauge pressure transducers using tantalum appear suitable for instrumenting the tin system.

The control and operation of the facility will take place from the control room which will be located adjacent to, but separated from the vault containing the tin and steam systems. Manual controls will be provided for the initial start-up and operation of the system. A computerized data acquisition system will be used for the logging, alarm scanning, and display of all system parameters. This system will consist of a small minicomputer with a real-time operating system, dual disk pack, magnetic tape unit, alpha-numeric CRT terminal, plotting scope with hard copy unit, analog multiplexer and analog to digital converter, and a 
digital input/output system. As experience is obtained from the operation of the facility, the computer programing system will be expanded to provide supervisory control of all parameters. 
SECTION III

Program Plan Description

The program work plan is based on a four year schedule encompassing fiscal years 1976 through 1979. The detailed activity schedule for this plan is presented in a program plan network, Fig. III-1.

The program plan network is based on the conceptual reference design described in the Conceptual System Design Description, Appendix A. The program plan allows for two possible courses of action. One would pursue the design and construction of a two stage system similar to the one defined in Fig. 2, Appendix AB. The other would comprise a single stage system having only one MHD generator and its associated equipment. The two systems are quite similar with regard to the design of the components that would be employed in each. Many of the components would be needed for both systems. In additton, the essential difference between the two systems is the number of components rather than the design features of the components. Furthermore, it is contemplated that the $R \& D$ efforts will be relatively little affected by the choice of either a one-stage or a two-stage system. Therefore, while the choice between a single or double stage system will affect labor and material costs it will have no significant effect on the time schedule, and thus, the network is appropriate to either system.

Because of the short time frame for completion of the program the $R \&$ D activities are extensively integrated. Within the $R \& D$ program parallel efforts involving component tests in air-water, tin-water and NaK-nitrogen test facilities will be pursued simultaneously.

At the same time preliminary design will proceed on some of the steam components, particularly the Primary Hx-Boiler, which is a long lead-time item. 
As the program proceeds into the design and construction phases of the $1 \mathrm{MW}$ prototype power system the tasks and activities are those typical of a construction program and, therefore, require no further explanation here. That is not the case with the materials and reaction kinetics and component development and testing phases of the program which are therefore described in detail in the two immediately following subsections.

\section{Materials and Reaction Kinetics Studies}

The FY 75 oxidation rate studies reported in Volume I established preliminary tin-water reaction rates typical of the laboratory equipment employed. The results of these studies indicate that, while the rate of $\mathrm{Sn} \mathrm{O}_{2}$ production in the MHD Prototype Power System will be relatively smal1, further activities devoted to this matter will be required as follows :

1. A natural circulation tin-steam test loop will be constructed in FY 76. This facility will be used to verify the reaction rate measurements made in the laboratory facility, where individual steam bubbles are passed through a column of tin, with those in the natural circulation loop, where a flowing two-phase mixture is created. The two-phase mixture will be akin to that in the MHD generator in that comparable vold fractions will be used. The fluids in the loop will be driven by the buoyancy forces created by the injection of superheated steam bubbles into the lower part of the vertical leg of a tin flow circuit. The steam will then be separated from the tin in a drum, condensed and discharged into a holding tank for sampling.

Hydrogen produced by the chemical reaction will be cooled and sampled for quantity. In addition, a material test section will be provided in the vertical leg of the loop in order to study corrosion effects on various candidate materials for the tin-steam MHD systems. 
By the end of FY 76 it is anticipated that the oxidation rates will be firmly established, confirming the viability of the $\mathrm{Sn}-\mathrm{H}_{2} \mathrm{O}$ system. 2. Methods for trapping or filtering out of the system, tin oxide which has been formed by system operation will be explored. This will include various ideas for valving filters in and out of the system.

3. The possibility of insitu regeneration of trapped $\mathrm{Sn} \mathrm{O}_{2}$ by reduction with dry hydrogen will be explored. For this purpose, the kinetics of reduction of $\mathrm{Sn} \mathrm{O}_{2}$ by hydrogen will be determined as a function of temperature, the hydrogen dew point and flow rate.

By early FY 78 it is contemplated that the small scale tests conducted in FY 77 will have determined the feasibility of the recombination process and will permit construction of a full scale unit to start.

Another aspect of the materials research program will be the testing of alumina as an electrically insulating material suitable for construction of MHD generator ducts. No major developmental program is anticipated, however, the material chosen must withstand the chemical and mechanical effects of flowing tin and steam at high temperatures. It must have good thermal stress resisting qualities and must possess sufficient strength and fabricability to permit its integration into MHD duct structures.

The scheduling of these activities is shown in the overall program schedule presented in Fig. III-1 elsewhere in this section.

\section{Component Development and Testing}

The early thrust of the tin-water MHD program in fiscal years 76 and 77 will be the development of the specialized components for the $1 \mathrm{MW}$ Prototype Power System, namely the separator-diffusor, nozzle, injectormixer and MHD generator. These components are described along with the Prototype Power System in Appendix A. Their development will entail analytical 
studies, design and fabrication of models and testing in several factlities designed and constructed for that purpose.

The component development and testing program described below corresponds with that program as outlined on the overall program schedule presented in Fig. III-1 elsewhere in this section.

\section{Separator-Diffuser Development}

The first of the component test facilities to be constructed will be an air-water loop for testing the separator-diffuser, two-phase nozzle, and injector-mixer. Tests in this facility will be directed toward obtaining basic information and design guidelines. In FY 76 the majority of effort will be applied to the separator-diffuser. The concept being developed at ANL involves impinging the high velocity two phase mixture, which has expanded through the MHD generator and is then accelerated through the nozzle, tangentially on the inner periphery of a rotating drum. The centrifugal force on the mixture will cause the two phases to separate while at the same time the tangential impingement at near synchronous velocity will minimize fluid friction losses. The device will incorporate a collection and diffusion feature by which the liquid phase is brought up in pressure (at the expense of velocity head) sufficient to circulate it around the system. The air water facility will be used to experimentally develop the information necessary to verify the concept and to provide the basis for design of the power system component. The air water tests will run through FY 77. The air-water facility will consist of a water pump, reservoir tank, flow-calibration tank, air compressor, piping, valves and necessary instrumentation. It will accomodate various models of injector-mixers, two-phase nozzles and separator diffusers. It will have torque, flow rate and mixture-characteristics measurement capabilities and will test self-circulation possibilities. 
In FY 78 further testing of the separator-diffuser will be conducted in a tin-steam blow-down facility in order to establish the design parameters for the actual prototype power system fluids. This test facility will be described later in this section.

\section{Mixer-Nozzle Development}

The injector-mixer and nozzle concepts will be tested in the airwater facility in FY 77. The primary objectives of the injector-mixer development program will be to assure mixture uniformity, homogeniety and void fraction control. Sophisticated instrumentation incorporated in the test facilities will be required to measure these characteristics. The major consideration in the nozzle development program will be to achieve the required two-phase flow acceleration with minimal energy loss and minimal degradation of the two-phase fluid.

The injector-mixer and nozzle concepts will be further developed and refined in $\mathrm{NaK}-\mathrm{N}_{2}$ and tin-steam tests in conjunction with the MHD generator development program.

MHD Generator Development

The MHD generator development program will concentrate on two major objectives. One of these is the definition of behavior concerning the scaling-up of power (and mass flow). The other is the definition of the behavior of the tin-steam mixture in an actual MHD system including a mixer, generator and separator-diffuser.

A comparison of generator parameters already studied at ANL with those required for the 1 MWt prototype power system is shown in Table III-1. The major considerations of larger scale generators indicate that lower two-phase velocity slip-losses will result due to the higher flow velocities used. In addition, reduced electrical end losses will result 
from the use of higher generator aspect ratios, and the insulator wall shunting effect will be lessened. The other two-phase flow components associated with the generator should scale according to established dimensionless parameters. For the most part, no adverse effects in scaling-up are expected. Conceptual design of the MHD generator will begin in FY 76.

As seen in Table III-1 the power density of the proposed 1 MWt prototype power system is an order of magnitude higher than current experimental levels. The effects of higher pressure gradients and power densities will be explored in a $\mathrm{NaK}-\mathrm{N}_{2}$ blowdown test facility to be designed and constructed in FY 77. This facility will employ high pressure bottled inert gas to pressurize the room temperature liquid metal from a reservoir tank into an injector mixer model where it will mix with nitrogen gas at the same pressure to form the correct two-phase mixture flowing at the proper velocity for entry into the MHD generator. From the generator the mixture will flow to an elevated holding tank equipped with a simple impingement type separator. The nitrogen gas w1ll be vented after all NaK vapor has been removed. The tanks will be sized for two minute operation, as will the single heat-sink type electromagnet to be used in connection with the MHD generators. At the end of each run the NaK will be drained by gravity from the holding tank to the reservoir in preparation for the next test run. Because this is a batch process, flow instrumentation will be simply a matter of measuring NaK displacements and metering gas flows in addition to measuring the generator power outputs.

An initial series of tests will be conducted in FY 77 on a $15 \mathrm{KWe}$ generator to develop the necessary instrumentation and experience with the facility and to test generator design principles. In FY 78, generator tests of up to 100 KWe will be conducted in order to confirm power scale-up behavior. 


\section{TABLE III-1}

COMPARISON OF GENERATOR PARAMETERS ALREADY STUDIED WITH THOSE REQUIRED FOR 1 MWt

PROTOTYPE $\mathrm{Sn}-\mathrm{H}_{2} \mathrm{O}$ SYSTEM

\section{Key Performance Parameters}

Generator Pressure Ratio

Generator Pressure Gradient (psi/in)

Generator Inlet Liquid/Gas Density Ratio

Power Density $\left(\mathrm{KW} / \mathrm{M}^{3}\right)$

Magnetic Field (Tesla)

Liquid Velocity (ft/sec)

Aspect Ratio

(Gen. Length/Electrode Spacing)

Mixture Quality

Cross-Sectional Area Aspect Ratio

(Avg. Electrode Spacing/Insulator

Spacing)

Voltage (volts)

Curr

amps)
Generator Tests

Completed (Nomina1)

$$
.1 \rightarrow .4
$$

$2 \rightarrow 5$

150

$8 \times 10^{3}$

$0.6 \rightarrow 1.2$

$30(\max )$

$0 \rightarrow .012$

$0 \rightarrow 1.0$

$0 \rightarrow 6 \times 10^{3}$
$\mathrm{Sn}-\mathrm{H}_{2} \mathrm{O} 1 \mathrm{MWt}$

Generator Requirements

$.25 \rightarrow .40$

$15 \rightarrow 20$

190

$60 \rightarrow 80 \times 10^{3}$

50

$7 \rightarrow 10$

$.008 \rightarrow .012$

$$
\begin{aligned}
4 & \rightarrow 8 \\
3 & \rightarrow 6 \\
10^{4} & \rightarrow 5 \times 10^{4}
\end{aligned}
$$


A preliminary test of $\mathrm{Sn} \mathrm{H}_{2} \mathrm{O}$ mixture characteristics in a LMMHD flow system will be performed in FY 77. The reaction-kinetics loop will be modified for this purpose. A power level of up to $5 \mathrm{KW}$ will be achieved.

In order to define the behavior of the tin-steam mixture in an actua 1 MHD system including a mixer, generator and separator-diffuser a $40 \mathrm{KWe}$ tin-steam blowdown facility will be designed and constructed. Conceptual design of this facility will start in FY 76, with construction scheduled for FY 77 and operation in FY 78. This work will proceed once it has been firmly established that the $\mathrm{Sn} 0_{2}$ production rate is sufficiently low for a practical system.

The tin-steam blowdown facility will employ a package-type high pressure steam boiler discharging steam into a model injector-mixer into which liquid tin is also injected from an inert-gas-pressurized reservoir tank. The two-phase tin-steam mixture thus produced will flow through the MHD generator being tested. The generator will comprise a duct with field compensating bus bars, power leads, power dissipation load and simple heat-sink type electromagnet suitable for two minute operation. The two-phase mixture will then flow through a convergent nozzle into a model separator-diffuser. After separation the steam will be exhausted to atmosphere while the tin will discharge into an elevated dump tank equipped with instrumentation for measurement of velocity and pressure heads. At the end of each run the tin will be drained by gravity from the dump tank to the reservoir in preparation for the next test run. Flow rate determination for the tin can be by batch weight determination. Inert gas and steam flow measurement will be by conventional means.

In addition to establishing the operating parameters of the MHD components being tested these tests will reveal any problems such as deposition of $\mathrm{Sn} \mathrm{O}_{2}$ on the generator electrodes, rotary separator, etc. Destgn modifications can then be incorporated before completion of the design of the 1 MWt prototype power system. 
The generator development outlined above will be complemented by ongoing support from the Office of Naval Research. This work will consist of additional basic experimental studies in $\mathrm{NaK}-\mathrm{N}_{2}$ and $\mathrm{Na}-\mathrm{Ar}$ facilities. Theoretical modeling of the flow and electrical characteristics of the generator will also continue. The $\mathrm{NaK}-\mathrm{N}_{2}$ facility is presently undergoing modifications to allow the doubling from present levels of pressure and 1iquid velocities. This work to be conducted in FY 76 will develop many of the concepts needed for the $\mathrm{Sn}-\mathrm{H}_{2} \mathrm{O}$ system, as discussed in the above. Simultaneously, a Na-Ar test facility presently under construction at ANL, will allow testing up to $1000^{\circ} \mathrm{F}$. This will be the first experimental effort at such elevated temperatures.

\section{Program Schedule}

The program schedule is presented in the Program Plan Network, Fig. III-1, which is a detailed schedule of significant tasks and acitvities over the life of the program. Its basis is the conceptual reference design for the $1 \mathrm{MW}$ (therma1) MHD Prototype Power System and associated research and development activities.

The program plan network was developed from detailed task descriptions. An abridged version of the task descriptions appears in Appendix $C$. The network contains inputs from many considerations, most of which are interrelated. The governing consideration for FY 76 is the $\$ 300,000$ budget which has been established by DARPA.* This provides for only a modest $R \& D$ effort, cycle and system studies and only minimal effort on preliminary design of some steam system components.

* P-7412-C, Amendment II, "A Proposal for Two Phase Liquid Metal MHD Development - FY 76 Program for Development of a Tin-Water MHD System." Submitted by Argonne National Laboratory, Argonne, Illinols, May 1975. 
A decision should be made by the fourth quarter of FY 76 whether to proceed with a single or double stage system so preliminary design can be completed for some of the long lead-time components.

The budget limitation for $F Y 76$ will require an unusually rapid activity scale-up in FY 77 as can be seen on the program plan network. Supplemental FY 76 funds, if made available by mid-year, would permit a more orderly activity scale-up. Furthermore, in this particular phase of the program containing fewer time-dependent activities than others, acceleration of the program would be quite favorable.

FY 77 plans call for a rapid and significant scale-up of $R \& D$ activities. Parallel efforts are devoted to the design and construction of model MHD components and three experimental facilities in which to test them.

The results of the FY $77 \mathrm{R} \& \mathrm{D}$ program will determine the performance of the MHD components, 1.e. injector-mixer, nozzle, separator-diffuser and generator, to the point where completion of scaled-up generator tests early in FY 78 will enable a decision to proceed with construction of the 1 MW power facility.

Final design of the steam system and 1 ts components will proceed in FY

77. This is necessary so as not to delay the completion of the 1 MW facility. Preliminary design of the tin system will be completed and a start

will be made on the final design in FY 77 . The tin system design is scheduled to coincide with availability of results from the $R \& D$ program which define component configurations and preferred materials of construction.

By early FY 77 system and component design will have progressed to the point that preliminary electrical control and instrumentation design can begin in earnest.

The data processing system design must also start at this time to provide for installation in time for ten months of computer programing. 


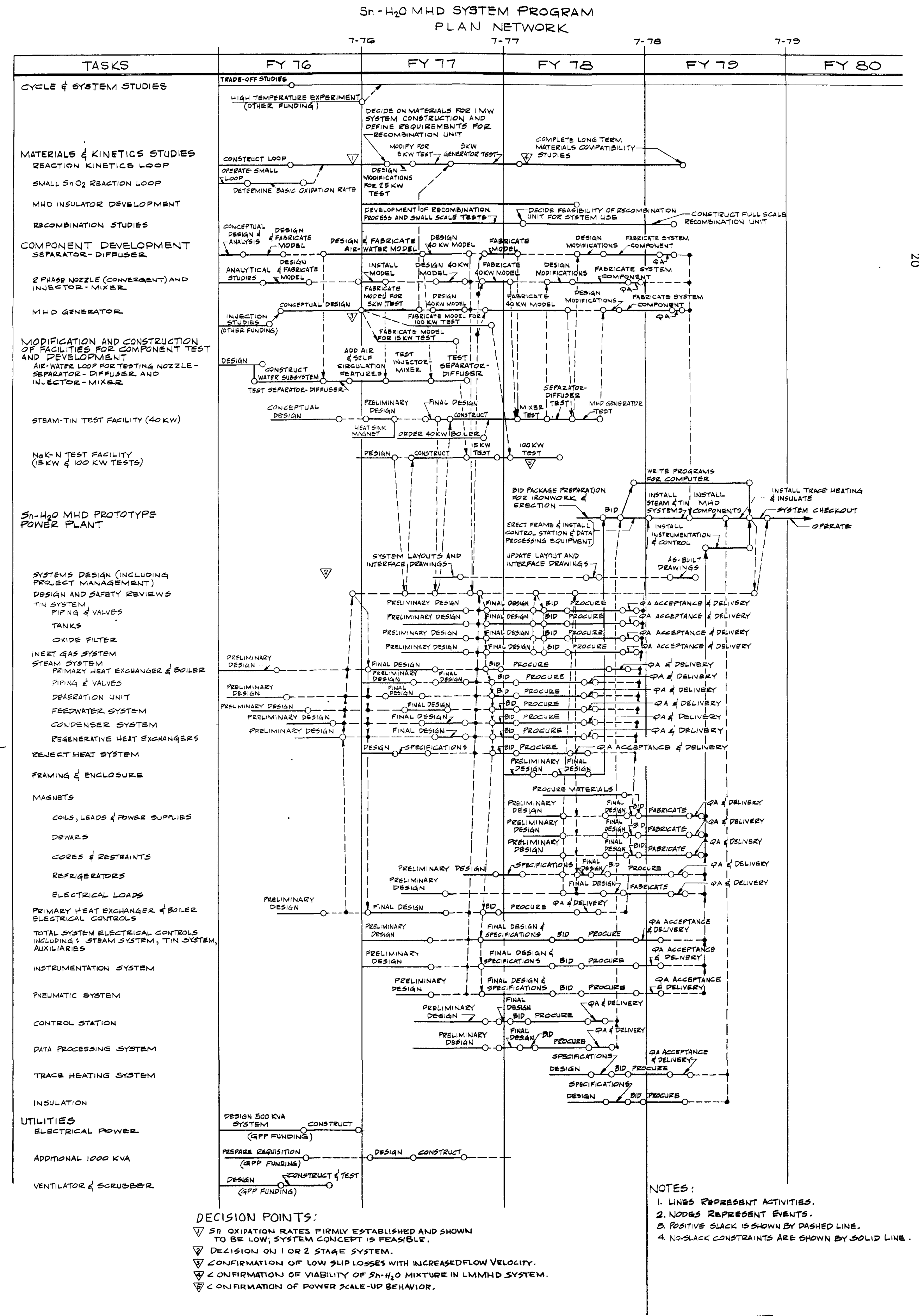

FIGURE III-I 
Since the control station will accomodate the data processing equipment, design of this facility must proceed along with that of the data processing system.

The completion of design of the mafority of the 1 MW power system components is scheduled to coincide with the decision point of the $R \& D$ program so that if a favorable conclusion is reached at that time all will be in readiness to commit construction money early in FY 78 .

FY 77 and FY 78 comprise some inherently time-dependent activities which would be difficult to accelerate. Among these are the long Eerm materials compatibility studies. On the other hand, development and testing of MHD components could possibly be accelerated by increasing the manpower leve1. The resultant incremental and successive fiscal year funding levels would benefit the program schedule by permitting earlier results from the $R \&$ $D$ efforts which feed into the design of the 1 MW system components. Typical of this is the MHD generator development which must be completed before design of the superconducting magnets can be finalized. For the same reason final design of the framing system cannot be completed until the final configurations of the components are known. Both of these units are on critical paths.

Because FY 78 will have a number of long term procurements the best possibility for accelerating the program in that year would be in increasing the manpower required to speed some final design completions and to expedite the processing of bids and contracts.

FY 79 is, in great part, concerned with installation of the 1 MW power system. However, fabrication of the separator-diffuser and MHD generator system components will st11l be underway in early FY 79. This is true also of the superconducting magnets whose final design completion is constrained by the need to first determine sizes and configurations of the MHD generators. 
In the interest of maintaining the schedule as planned, it will be important to provide the requisite manpower levels to accomplish this. Because the time schedule for the fabrication and installation activities taking place in FY 79 were based on conventional manpower loadings employed in the trades, it can be concluded that acceleration could be accomplished by increasing the manpower loadings within reason.

Analysis of the program plan network will show that there is a virtual critical path shared by the separator-diffuser and MHD generator testing and development programs which lead into the superconducting magnet design and thence into the Power System installation. This emphasizes the prominence that the MHD generator and separator-diffuser testing and development will have in the overall program. 


\section{SECTION IV}

\section{Program Management Plan}

The Sn- $\mathrm{H}_{2} \mathrm{O}$ MHD System program is being carried out within the Engineering Division of Argonne National Laboratory. To ensure an orderly and efficient application of effort to the program and to ensure timely completion of the tasks described, the extablished, proven procedures within the Engineering Division will be applied to the planning, scheduling, reporting and periodic detailed programmatic reviews. Specific attention will be devoted to program control features such as the use of approved test plans, a frequently updated system design description, progress reports, work plans, formal design reviews and other established management tools.

Abundant resources exist at ANL among the many divisions for scientific, engineering and technical assistance. Facilities, equipment and manpower available at the Laboratory will be utilized wherever possible, especially in $R$ \& $D$ activities.

Support organizations at the Laboratory such as Procurement, Shops, Quality Assurance, Safety and others will be utilized during the design and construction stages.

Dr. Michael Petrick, Associate Birector for Advanced Programs in the Engineering Division has overall responsibility for the program. In this capacity he will devote $20 \%$ of his time to the project. Dr. Robert Hantman is responsible for the research and development programs while Mr. Burton Snyder is responsible for system and component design and construction. Both Dr. Hantman and Mr. Snyder will devote full time to their responsibilities. Project manpower requirements will be provided by the Engineering Division and other Laboratory organizations as needed. The organizational structure for this program is shown in Fig. IV-I. 
FIGURE IV-1

ORGANIZATION CHART

for

$\mathrm{Sn}-\mathrm{H}_{2} \mathrm{O}$ MHD SYSTEM PROGRAM MANAGEMENT

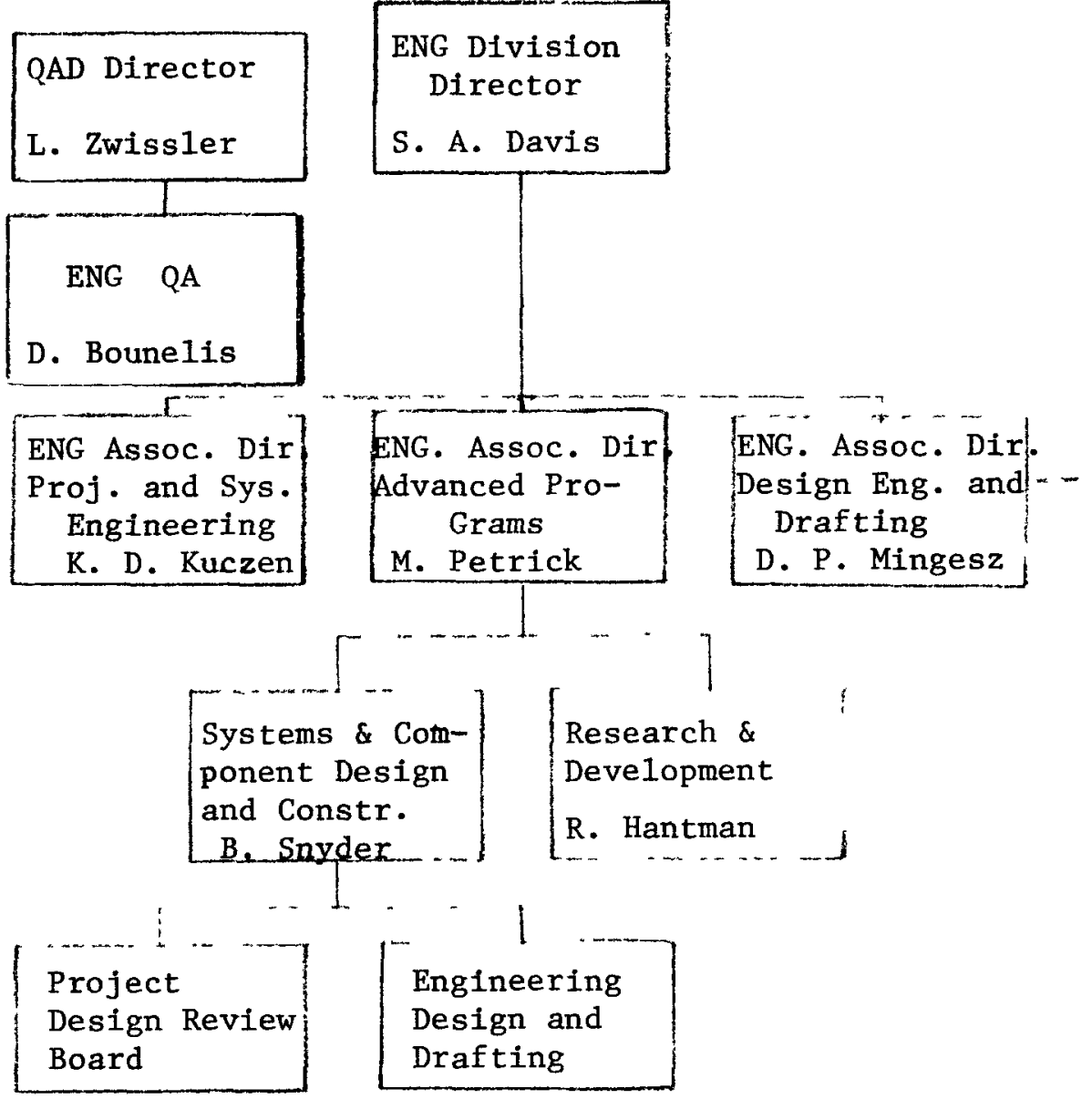




\section{SECTION V}

Budget

The overall program costs are summarized in Tables $\mathrm{V}-1$ and $\mathrm{V}-2$. Table V-1 shows a total projected program cost of $\$ 6,235,000$ for a system having a single MHD stage. Table V-2 shows a total projected program cost of $\$ 7,679,000$ for a system having two MHD stages.

The two-stage system would operate with a higher cycle efficiency than that of a single stage system because of its greater steam expansion range. However, it is possible to establish, analytically, two-stage system cycle characteristics after having demonstrated, operationally, the basic characteristics of a single-stage MHD system. As can be seen from the cost summaries the cost advantage of a single stage system over a two stage system is estimated to be $\$ 1,444,000$.

The costs shown in the tables are taken from detailed cost estimate work sheets which can be found in Appendix C. These cost estimates were based on detailed task descriptions which can be found in Appendix B. The detailed task descriptions were developed from the conceptual system (Fig. 2, Appendix A) which was established as the reference design for purposes of planning and estimating and from the $R$ \& D program which will be required to develop the special materials, components and systems for such a system. It should be pointed out that the reference design parameters such as pressures, temperatures, flow rates and even component and subsystem configurations will be subject to change as the $R \& D$ program and parametric studies progress. It is felt, however that regardless of future changes that will occur to the reference design the cost of any such system of similar power level will not vary significantly from the one we have chosen as the basis of our cost estimate. 
TABLE $\quad V-1$

$\underline{\mathrm{Sn}}-\mathrm{H}_{2}$ O MHD SYSTEM PROGRAM, TIME SCHEDULE, AND COST SUMMARY FOR A SINGLE

GENERATOR STAGE (a11 costs in thousands of dollars)

$\begin{array}{lllll}\text { FY } 76 & \text { FY } 77 & \text { FY } 78 & \text { TOTAL }\end{array}$

Cycle \& System Studies

$$
11.9
$$

50

55

60

177

Materials \& Kinetics Studies

48

475

200

100

823

Component Test Program

107.2

550

265

120

1042

Facilities, Air $-\mathrm{H}_{2} \mathrm{O}$

Tests, Liquid Metal

Comp. Tests

Component Development

85.4

375

200

660
Injector-Mixer, Sep.-
Diff., Nozzle, MHD
Gen.

1 MWt Proto. Power System

Design
Const.
Operation

General Program

Project Management

Design Reviews, Lab.

Services
32.5

317

475

55

15.0

300

* Was reported as 6285 in letter to $W$. Chapman dated 6-25-75 
TABLE $\mathrm{V}-2$

${\underline{\mathrm{Sn}}-\mathrm{H}_{2}}_{2} 0$ MHD SYSTEM PROGRAM, TIME SCHEDULE, AND COST SUMMARY FOR 2 GENERATOR STAGES

(a11 costs in thousands of dollars)

$\begin{array}{lllllllll}\text { FY } & 76 & \text { FY } & 77 & \text { FY } & 78 & \text { FY } & 79 & \text { TOTALS }\end{array}$

Cycle \& System Studies

11.9

50

55

60

177

Materials \& Kinetics Studies

48.0

475

200

100

823

Component Test Program

107.2

550

265

120

1042

Facilities, Air $-\mathrm{H}_{2} \mathrm{O}$ Tests,

Liquid Metal Comp. Tests

Component Development

85.4

Injector-Mixer, Separator, N ozzle, MHD Gen.

1 MWt Proto. Power System

Design

Const.

Operation

General Program

Project Mgt., Design

Reviews, Lab. Services
32.5

$$
370
$$$$
490
$$

15.0

$$
\begin{array}{r}
389 \\
2653
\end{array}
$$

70
845

3767

126

239

TOTALS

300

2364

3832

1183

$7679 *$

* Was reported as $\$ 7492$ in letter to $W$. Chapman dated 6-25-75. 
The detailed task descriptions also formed the basis for the program plan network, Fig. III-1, thus providing the correlation between tasks and time schedules which is necessary when determining escalation factors for cost estimates. Cost estimates were developed in accordance with standard procedures established and employed by the Engineering Division. A detailed explanation of the criteria used in developing the cost estimates can be found in Appendix $C$.

The $R \& D$ portion of the overall program which comprises the first four program categories listed in the tables constitutes $43 \%$ of total program cost for the single stage system and $35 \%$ of total program cost for the two stage system. $R \& D$ cost for either system is the same, since only a change in quantity of components is involved. Component development, which includes considerable design and construction of test models, is actually a sizeable contribution to the Power System design and construction program. When considered in this light $R \& D$ costs would become a smaller percentage of total program cost than is indicated.

Referring to the 1 MWt Prototype Power System, design costs are $28.7 \%$ of construction costs and $11.5 \%$ of total program costs for the single stage system or $22.4 \%$ of construction costs and $11 \%$ of total program costs for the two stage system.

Cost of design, procurement and installation of electrical, instrumentation and data processing equipment for the single-stage system is estimated at $\$ 455,000$. This 1 s $14 \%$ of total design and construction cost for a single-stage system.

The same costs for a two-stage system would be $\$ 544,000$ which is $12 \%$ of total design and construction cost for such a system. These are considered to be reasonable relationships for the types of systems considered. 
ARGONNE NATIONAL LABORATORY

9700 South Cass Avenue

Argonne, I1linois 60439

1 MW (THERMAL) TIN-WATER MHD

PROTOTYPE POWER SYSTEM

CONCEPTUAL

SYSTEM DESIGN DESCRIPTION 
SYSTEM DESIGN DESCRIPTION

\author{
OF THE
}

1 MW (THERMAL) TIN-WATER MHD

PROTOTYPE POWER SYSTEM

AUGUST 1975

Argonne National Laboratory

9700 South Cass Avenue

Argonne, Illinois 60439

Prepared by:
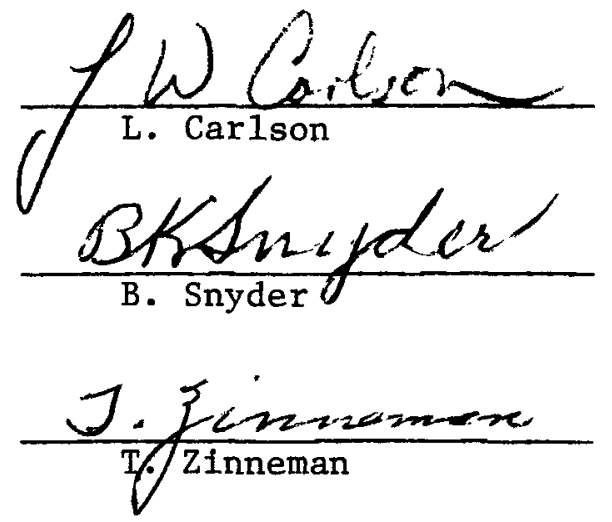

Approved by:

M. Petrick 

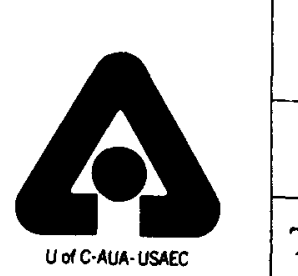

\section{ARGONNE NATIONAL LABORATORY}

\section{NOTIFICATION OF SPECIFICATIONS REVISION}

Title Conceptual System Design Description of the $1 \mathrm{MWt} \mathrm{Sn}-\mathrm{H}_{2} \mathrm{O} \mathrm{MHD}$ Prototype Power System
*Document No.

\section{Page___ of}

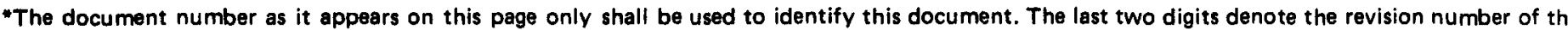
document (see Revision Authorization block below).

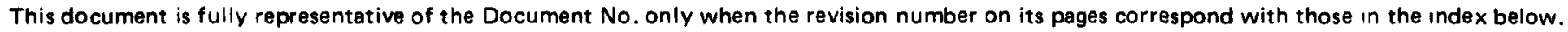

(INDEX)

INDEX OF PAGE REVISIONS

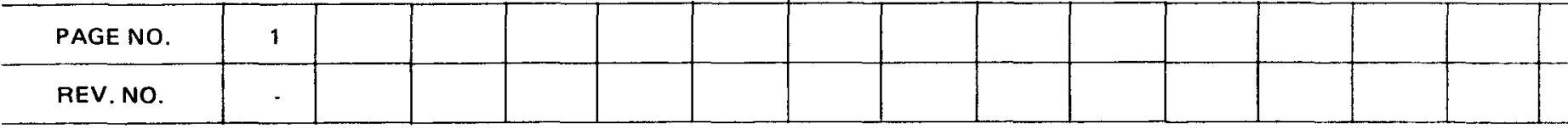

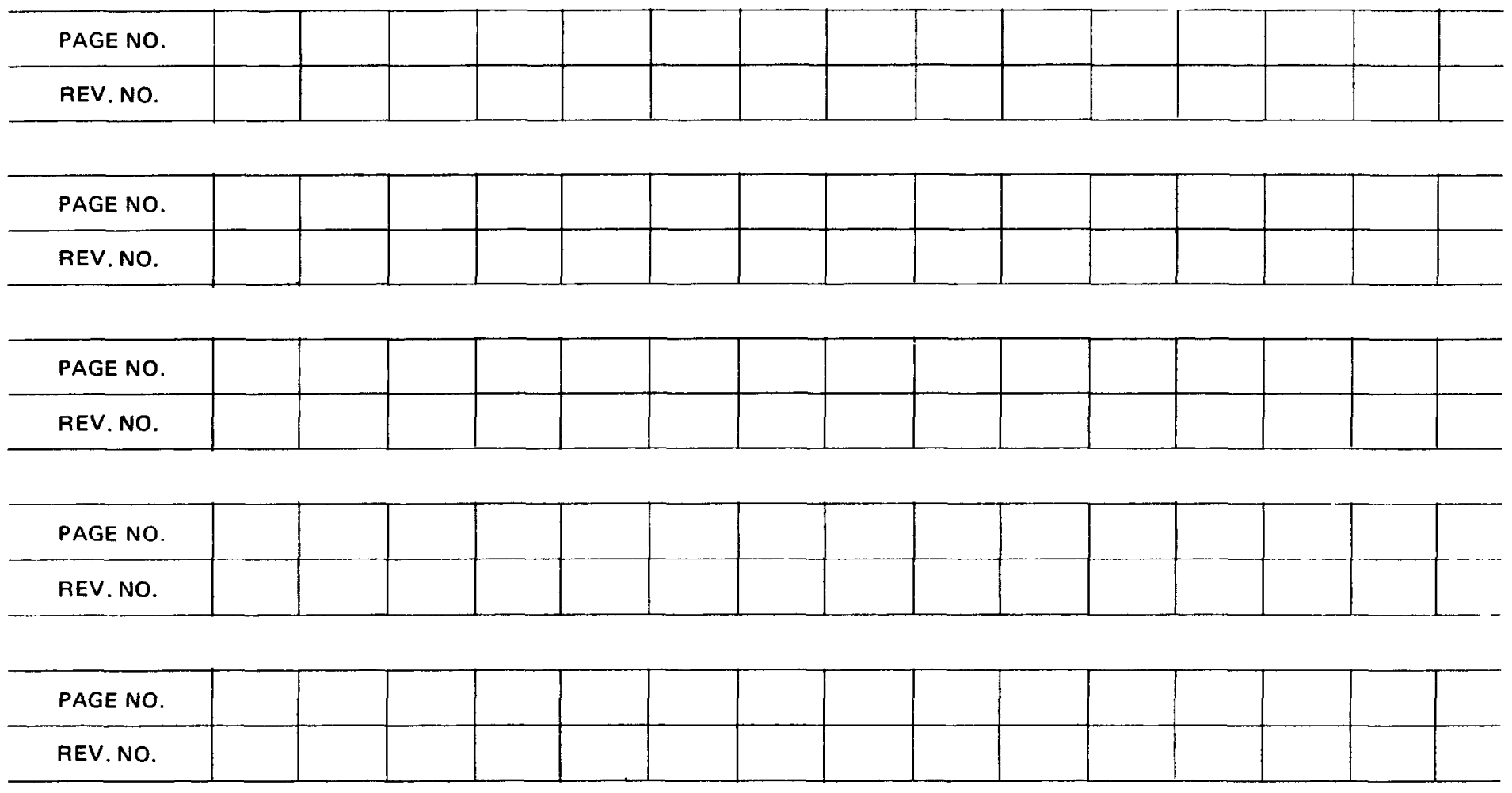

REVISION AUTHORIZATION

\begin{tabular}{|c||c|c|c|c|c|c|c|c|c|c|}
\hline $\begin{array}{c}\text { REVISION } \\
\text { NUMBER }\end{array}$ & 00 & 01 & 02 & 03 & 04 & 05 & 06 & 07 \\
\hline $\begin{array}{c}\text { DCN } \\
\text { NUMBER }\end{array}$ & - & & & & & & & \\
\hline DATE & & & & & & & & \\
\hline $\begin{array}{c}\text { APPROVED } \\
\text { BY }\end{array}$ & & & & & & & & & \\
\hline
\end{tabular}


Approval Page

i

Revision Page

ii

Table of Contents

Introduction

$\mathrm{v}$

1. Functions and Design Requirements I-1

1.1 General I-1

1.2 Instrumentation and Controls I-9

$\begin{array}{lll}1.3 & \text { Electrical System } & \text { I-16 }\end{array}$

$\begin{array}{ll}1.4 \text { Codes and Standards } & \text { I-22 }\end{array}$

2. Design Description II-1

2.1 Makeup Water System II-1

2.2 Heat Rejection System II-3

$\begin{array}{lll}2.3 & \text { Boiler Feedwater System } & \text { II-4 }\end{array}$

$\begin{array}{ll}2.4 \text { Steam Generator Assembly } & \text { II-7 }\end{array}$

2.5 MHD Stage 1 System $\quad$ II-10

$\begin{array}{lll}2.6 & \text { MHD Stage } 2 \text { System } & \text { II-18 }\end{array}$

2.7 Misc. System Components II-23

3. System Limitations, Set Points and Precautions III-1

4. Operation IV-1

4.1 Startup $\quad$ IV -1

$\begin{array}{lll}4.2 & \text { Steady State } & \text { IV-2 }\end{array}$

4.3 Shutdown IV -3

5. Casualty Events and Recovery Procedures V-1

6. Maintenance VI-1 
Appendix AA - References

$A-1$

Appendix $A B$ - Drawings (Figures)

$A-2$

Appendix AC - Instrument list

A-3 
INTRODUCTION

Argonne National Laboratory has concluded the conceptual design phase of a closed Rankine cycle two stage magnetohydrodynamic (MHD) power generation system which uses liquid tin and steam as the working fluids. Input heating power level to the system will be approximately one megawatt. The power will be supplied by electrical heaters for this prototypical system, though nuclear power could be utilized in the intended application. The system which will be described has two MHD generators which operate in series with respect to the steam flow. Each MHD generator will have a separate tin flow loop. It should be kept in mind that, although the two-stage system has been described and used as the reference design, systems having only one MHD generator stage or combinations of MHD and steam-turbine stages are also possible. It is also emphasized that the physical features of the system components described herein, as well as their operational characteristics, are representative of one particular cycle concept. In addition, cycle studies conducted subsequent to the selection of the reference design; some of which are described in Volume I, and others which will be conducted in the future, will probably significantly change the reference system herein and affect its components and their characteristics. Also the component testing and development program will serve to refine the accuracies of component operational characteristics as stated in the reference design.

The Tin-Water mHD Prototype Power System will be constructed at Argonne National Laboratory. It will occupy a space approximately twenty feet wide by forty to fifty feet long by twenty feet high. The actual space occupied will depend upon whether a single or double stage system is constructed. A twenty foot by fifteen foot control room will be located adjacent to the power system. The entire power system will be contained in a framed, sheet metal enclosure The power system will be sited in a crane-equipped high bay area.

No attempt has been made in designing this system and its components, to comply with spatial limitations that would influence sizes and configurations in an actual power plant. 
The particular Rankine cycle which is envisioned for this system will ho superheated steam extraction after the first stage MHD separator to heat feed-

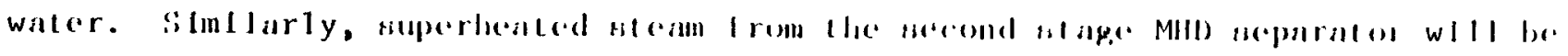

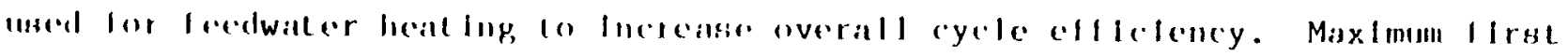
stage steam operating pressure wi11 be 1000 psia (saturated); maximum first stage tin pressure will be 1170 psia at $545^{\circ} \mathrm{F}$. The expected second stage steam operating pressure will be 300 psta (at $540^{\circ} \mathrm{F}$ ); maximum second stage tin pressure is expected to be 450 psia (at $540^{\circ} \mathrm{F}$ ). Design pressure for all piping and vessels excepting hot wells and the condenser/boiler, will be 1200 psig at $570^{\circ} \mathrm{F}$; the hot wells and condenser/boiler will have 100 psig design pressure rating at $330^{\circ} \mathrm{F}$. The planning for this MHD power system, including cost estimation has been based on the use of low carbon steel for the entire system. However, the ultimate choice of materials will be determined by a materials research program.

The thermodynamic cycle diagram for the proposed two-stage tin-water MHD power system is depicted in Figure 1. In this temperature-versus-entropy diagram, the cycle is conceived as follows:

Subcooled feedwater, at an initial pressure of approximately 75 psia and temperature of $303^{\circ} \mathrm{F}$ (state point 12), is pumped at constant entropy to 1000 psia (state point 1). The liquid feedwater is heated at a constant pressure of 1000 psia (by regeneration and electric heating) to the saturated liquid state (state point 3). The feedwater is evaporated at a constant pressure of 1000 psia in the electrically heated steam generator to the saturated vapor state (state point 4). At state point 4, liquid tin at 1000 psia and $545^{\circ} \mathrm{F}$ is mixed with the steam to form a two-phase electrically-conductive bubbly mixture. The two phase mixture traverses the first stage MHD generator and generates electric power between state point 4 and state point 5. System pressure decreases from 1000 psia at state poin 4 to approximately 445 psia at state point 5 at the outlet of the first stage generator; the corresponding temperature drop of the tin-steam mixture is $25^{\circ} \mathrm{F}$. Even though the steam expands in volume and does work in forcing the 
the steam during the expansion such that the process is nearly isothermal and the enthalpy of the steam at state point 5 is actually greater than the enthalpy of the steam at state point 4 .

From state point 5 to state point 6 , the liquid tin-steam mixture is accelerated by further expansion of the steam (in decreasing pressure to 300 psia at $\left.500^{\circ} \mathrm{F}\right)$. At state point 6 , the steam flow is separated from the first stage tin flow which is traveling at high velocity (i.e., $175 \mathrm{ft} / \mathrm{sec}$ ). The first stage tin flow is collected and diffused down in velocity to recover dynamic head as static head ( 1170 psia) so the first stage tin flow can be reheated (not shown in the diagram) and reinjected with steam at state point 4. The steam at state point 6 is divided into two streams. A small portion of the steam flow (12 to 15\%) is bled through heat exchangers to reheat the feed water (discussed fully later). The remainder of the steam ( 85 to $88 \%$ ) is reheated to state point 7 (290 psia and $540^{\circ} \mathrm{F}$ ). At state point 7 , the steam is mixed with tin (at 290 psia and $540^{\circ} \mathrm{F}$ ) from the second stage tin 10op. The two phase mixture of tin and steam traverses the second stage MHD generator between state point 7 and state point 8 (112 psia, $530^{\circ} \mathrm{F}$ ), therein generating electrical power. From state point 8 to state point 9 , the liquid tin-steam mixture is accelerated by further expansion of the steam in decreasing pressure (to $75 \mathrm{psia}$ and $530^{\circ} \mathrm{F}$ ) to a velocity of approximately $100 \mathrm{ft} / \mathrm{sec}$. At state point 9, the second stage steam and tin flows are separated. The second stage tin flow is collected and diffused down in velocity to convert kinetic energy into static head ( $470 \mathrm{psia})$ so the tin flow can be reinjected with the steam at state point 7. The steam which is separated from the tin at state point 9 is desuperheated to state point $9^{\prime}$ and supplies heat to the feedwater between state points $2^{\prime}$ and $2^{\prime \prime}$. Further desuperheating of the steam to state point 10 and condensation to state point 11 occurs in the heat rejection system. The saturated liquid condensate at state point 11 ( 75 psia) is subcooled to state point 12 , whereupon the main steam cycle is completed as described. 
The bleed steam from state point 6 is desuperheated to state point 13 to lueat the feedwater from state point $1^{\prime}$ to state point $2^{\prime}$; this bleed steam is condensed from state point 13 to state point 14 to heat the maln feedwater stream from state point 1 to state point $1^{\prime}$. The bleed condensate at state point 14 is subcooled from state point 14 ( 300 psia saturated) to state point 15 (300 psia and $312^{\circ} \mathrm{F}$ ) before being pumped isentropically to 1000 psia to rejoin the main feedwater stream at state point $2\left(1000\right.$ psia and $\left.415^{\circ} \mathrm{F}\right)$. Electrical heat input to the system is required only between state points $2 "$ and state point 4. 


\section{SECTION I}

\section{FUNCTIONS AND DESIGN REQUIREMENTS}

\subsection{General.}

The preceding discussion of the thermodynamics of the two stage tinsteam MHD Rankine cycle now will be related directly to the functional aspects of the system design as shown in the process diagram that is presented as Figure 2. The process diagram depicts, schematically, those components and the piping interrelationships which are required to accomplish the thermodynamic cycle which has just been described. The process diagram will be followed from component-to-component describing functions and design requirements in the same sequence as in the thermodynamic diagram of Figure 1.

The boiler feedwater pump, which is located in the lower right hand corner of Figure 2, draws condensate at approximately 75 psia and $303^{\circ} \mathrm{F}$ and at a flow rate of $10 \mathrm{gpm}$ from the hotwe11(非) below the condenser/boiler. The boiler feedwater pump pressurizes the feedwater to 1000 psia (state points 12 to 1 ). The flow rate of feedwater that is required by the steam generator (approximately 7 to $8 \mathrm{gpm}$ ) at $1000 \mathrm{psia}$ is controlled by the liquid water level in the steam generator. The feedwater flow is regulated by opening or closing bypass valve 21 that allows a portion of the pumped feedwater to recirculate back to (非) hotwell. The main feedwater flow (3060 $\mathrm{lbm} / \mathrm{hr}$ at steady flow conditions) from the boiler feedwater pump passes through a cooling coil in the regenerator condensate hotwel1 (\#1). The feedwater is heated slightly (approx. $1^{\circ} \mathrm{F}$ ) in the "11 hotwe1I; however, the main function of the feedwater flow through the cooling coil in the regenerator condensate hotwell is to 
subcool (approx. $5^{\circ} \mathrm{F}$ ) the condensate (state points 14 to 15 ) to supply NPSH for the regenerator condensate pump.

The feedwater next flows through a check valve (非7) and through regenerator number 1 , region I (state points 1 to $1^{\prime}$ ), wherein the bleed flow condenses to heat the feedwater (state points 13 to 14 ) from $307^{\circ} \mathrm{F}$ to $407^{\circ} \mathrm{F}$. Bleed condensate is pumped from the regenerator hotwe 11 (\#1) to 1000 psia, at a flow rate which is controlled by the (\#1) hotwell 11quid leve1, and recombined with the main feedwater flow between region $]$ and region II of regenerator $\# 1$. The combined feedwater flow $(3600$. $/ \mathrm{hr}$ ) is further heated in flowing through regenerator $\# 1$, region II (state points $1^{\prime}$ to $2^{\prime}$ ) from $407^{\circ} \mathrm{F}$ to $419^{\circ} \mathrm{F}$, wherein the bleed flow is desuperheated (state points 6 to 13 ) from $520^{\circ} \mathrm{F}$ to $417^{\circ} \mathrm{F}$. The feedwater is finally reheated to $482^{\circ} \mathrm{F}$ in flowing thorugh regenerator $\$ 2$ (state points $2^{\prime}$ to $2^{\prime \prime}$ ) by the exhaust steam from the second stage separator (state points 9 to $9^{\prime}$ ). An oxide filter cartridge is provided to remove tin oxide from the feedwater before it is reinjected into the steam generator. A maximum pressure drop of 10 psid will be permitted before the oxide filter is replaced.

The steam generator is the large vertically oriented cylindrical apparatus depicted near the center of Figure 2. The function of the steam generator is to produce a net output of approximately $1 \mathrm{lbm} / \mathrm{sec}$ $(3600 \mathrm{lbm} / \mathrm{hr})$ of saturated steam at $1000 \mathrm{psia}$. It also heats feedwater from state points $2^{\prime \prime}$ to $3\left(482^{\circ} \mathrm{F}\right.$ to $\left.546^{\circ} \mathrm{F}\right)$ and evaporates this feedwater from state points 3 to 4 . The steam generator also has the functions to reheat tin which flows in the two tin loops and to reheat the steam passing from stage 1 to stage 2 (state points 6 to 7). 
Reheating tin and steam is accomplished by reflux condensing of the 1000 psia saturated steam on the external surfaces of the heat exchangers. The net throughput of saturated steam at 1000 psia is routed through an electrically heated superheater ( 0 to $10 \mathrm{KW}$ capacity) that superheats the steam by a few ( 0 to 10 ) degrees Fahrenheit (not shown in Figure 1) to eliminate liquid water carry over and thereby insure that the steam flowmeter will accurately measure steam flow rate. (See P\&I diagram, Figure 23.)

Steam at 1000 psia saturated and $3600 \mathrm{lbm} / \mathrm{hr}$ flow rate flows through throttle valve 非 into the first stage mixer (state point 4 ). The throttle valve is sized for a maximum pressure drop of 5 psid at full flow and full open. The purpose of the first stage mixer is to mix the $3600 \mathrm{lbm} / \mathrm{hr}$ steam flow with the first stage tin flow $(308,000 \mathrm{lbm} / \mathrm{hr})$ to produce a bubbly two phase mixture of small steam bubbles uniformly dispersed within a continuous tin phase that has been accelerated to approximately 50 feet/second (which is the mean flow velocity through the MHD stage 1 generator).

The stage $1 \mathrm{MHD}$ generator applies a strong magnetic field ( 4 to 6 Tesla) perpendicular to the two phase tin-steam flow. Because the tin is electrically conductive, a direct current (2-4 volts, 20,000-30,000 amps) is induced perpendicular to both the magnetic field and flow directions by the interaction of the magnetic field with this moving conductor. The magnetic force field interaction with the flowing two phase fluid causes a corresponding pressure loss (from 1,000 psia to 450 psia) to occur along the axis of the MHD generator. 
The tin within the MHD generator acts as a heat source for the steam and supplies thermal energy during the steam expansion such that the resulting process through the stage $1 \mathrm{MHD}$ generator is nearly 1sothermal (from $545^{\circ} \mathrm{F}$ to $520^{\circ} \mathrm{F}$, state points 4 to 5 ). The velocity of the tinsteam mixture within the MHD generator will be held constant (at $50 \mathrm{ft} / \mathrm{sec}$ by increasing flow area to avoid axial potential gradients that could induce energy robbing eddy currents. The velocity of the tin-steam mixture is increased in the nozzle (state points 5 to 6 ) from $50 \mathrm{ft} / \mathrm{sec}$ to $175 \mathrm{ft} / \mathrm{sec}$. The nozzle is a convergent duct that increases the tin-steam mixture velocity, with low slip, by expansion of the stream to lower pressure (from 450 psia to 300 psia) at nearly constant temperature (approx. $520^{\circ} \mathrm{F}$ ).

The two phase tin-steam mixture is separated in the separator (at state point 6). The tin which is at high velocity (e.g., $175 \mathrm{ft} / \mathrm{sec}$ ) is decelerated in a diffuser to approximately $5 \mathrm{ft} / \mathrm{sec}$ to convert kinetic energy into static pressure head (1170 psia) so that it can be routed back to the mixer at state point 4 . The steam stream is split into two parts at state point 6. Part of the steam (.12 to $.151 \mathrm{bm} / \mathrm{sec})$ is routed through valve $\$ 4$ as bleed off from the stage 1 separator to the regenerators in order to reheat the feedwater; the remainder of the steam (.85 to $.88 \mathrm{lbm} / \mathrm{sec}$ ) is routed through the steam reheater (state points 6 to 7,300 psia at $520^{\circ} \mathrm{F}$ to 290 psia at $540^{\circ} \mathrm{F}$ ) which is 10 ated within the steam generator shell. The first stage tin flow which was separated from the steam at state point 6 is reheated in another heat exchanger that is also located within the steam generator shell. 
Provision is made in the process diagram (Figure 2) for secondary separation of tin and steam coming from the first stage primary separator. A secondary cyclone type separator will be used to separate an intentional overflow of tin ( 1 gal/min) which will be pumped in a side stream of the main first stage tin 1oop. This side stream of tin will have approximately one percent of the flow rate of the main tin flow to keep the system full during operation and make up for carryover in the separator, and also to allow for loss from reaction of tin with steam. The tin side stream will incorporate a 10 micron rated filter element of heat cleaned glass to remove the tin oxide particles on a continuous basis equal to the oxide generation rate in the main stream. The side stream of tin will drop out of the bottom of the cyclone separator into a lockout tank which collects this tin until the lockout tank is full. Then, the batch of tin is dumped out of the lockout tank into a surge tank (at regular intervals). The tin is continuously pumped at a constant flow rate from the surge tank through the filter system to re-enter the main tin flow stream. Electric power that is generated in the first stage MHD device will be dissipated within a variable resistance load. The resistance load will be water cooled and will comprise part of a pumped water system that will further dissipate the thermal energy, that is generated in the resistive load, by using an air cooled heat exchanger.

The second stage MHD loop has components which perform functions in a manner that is identical to the first stage MHD loop. Component sizes are larger to accommodate larger volume flows. The steam that is 
reheated in the heat exchanger within the shell of the steam generator assembly (state points 6 to 7 ) flows through an electrically heated superheater which is used when the second stage is operated without the first stage (i.e., during checkout). Otherwise, this superheater is inoperative. The steam is throttled to the desired operating pressure of the second stage before admission to the second stage mixer which mixes the second stage tin flow (315 1bm/sec at $450 \mathrm{psia}$ and $540^{\circ} \mathrm{F}$ ) with the steam $\left(.85 \mathrm{lbm} / \mathrm{sec}\right.$ at $290 \mathrm{psia}$ and $\left.540^{\circ} \mathrm{F}\right)$. The mixer's function is to form a homogeneous mixture of small steam bubbles within a continuous liquid tin phase while accelerating the mixture up to the inlet velocity $(50 \mathrm{ft} / \mathrm{sec})$ required in the MHD channel. The mixer must be capable of forming the homogeneous dispersed bubble phase over a range of inlet void fractions (perhaps from .4 to .6).

The two phase tin-steam mixture flows through the second stage MHD channel and generates power by the interaction of the flowing electricall: conductive tin with the crossed magnetic field. This electrical power is dissipated in a second (identical) variable resistance water cooled load and heat exchanger circuit as depicted in Figure 2. Steam expansion to lower pressure (from 290 to 112 psia) within the second stage generator (state points 7 to 8 ) is at nearly constant temperature (540 to $530^{\circ} \mathrm{F}$ ) due to the high heat transfer rate capability and high heat capacity of the tin.

The two phase tin-steam mixture is accelerated in the second stage nozzle at low slip (between state points 8 to 9) from an inlet veloci near $50 \mathrm{ft} / \mathrm{sec}$ to an exit velocity near $100 \mathrm{ft} / \mathrm{sec}$. This higher velocity imparts sufficient kinetic energy to the tin so that when the tin is 
separated in the second stage separator and diffused down in velocity (to $5 \mathrm{ft} / \mathrm{sec}$ ) sufficient static pressure head ( $470 \mathrm{psia}$ ) is recovered to allow recirculation of the second stage tin back through a reheater (located within the steam generator shell) and into the second stage mixer. The steam from the second stage separator (at 75 psia and $530^{\circ} \mathrm{F}$ ) at a flowrate of $.85 \mathrm{lbm} / \mathrm{sec}$ flows through a cyclone separator with the excess tin that is intentionally spilled from the second stage separator. The steam is routed out of the top of the cyclone to regenerator $\#^{2}$ shell side for reheating feedwater. The excess tin drops out of the bottom of the cyclone separator into a lockout tank. When the lockout tank is filled, it automatically drops the tin into the surge tank. A tin pump is used to recirculate tin in this side stream at a rate of 3 gallons per minute (approximately one percent of the main second stage tin flow) back into the main tin stream.

The steam from the outlet of the second stage cyclone separator (flowrate of $30601 \mathrm{bm} / \mathrm{hr}$ ) is desuperheated from $520^{\circ} \mathrm{F}$ to $430^{\circ} \mathrm{F}$ at a constant pressure of 75 psia in going through regenerator 非 (shell side). The heat load of approximately $45 \mathrm{kw}$ heats the feedwater from approximately 420 to $480^{\circ} \mathrm{F}$. This steam is further desuperheated and condensed to 75 psia saturated liquid within the condenser/boiler. In desuperating and condensing the steam, approximately $900 \mathrm{kw}$ of thermal energy is rejected by boiling water on the shell side of the condenser/boiler at nominal design operating pressures up to 60 psia. The saturated steam which is generated in the condenser boiler at a rate of approximately $3240 \mathrm{lbm} / \mathrm{hr}$ is throttled by valve number 5 to control boiling pressure in the condenser boiler. Thus, valve number 5 can be used to control 
(tune) the outlet pressure of the second stage MHD loop which, in turn, will have some effect on the outlet pressure of the first stage MHD 10op.

The saturated steam that is generated in the condenser/boiler is condensed in an air cooled heat exchanger (number 5). The condensing pressure in the air cooled heat exchanger is controlled by air flow rate and ambient air temperature in the air-cooled heat exchanger. A multiple speed blower motor and inlet air damper will be used to control air flow rate to maintain condensing temperature and pressure within the required ranges of $212^{\circ} \mathrm{F}$ to $300^{\circ} \mathrm{F}$ and 15 psia to $60 \mathrm{psia}$. The condensate from the air cooled heat exchanger (\#5) flows by gravity into a hotwe11 (非). Feedwater for this heat rejection system is pumped into the shell side of the condenser/boiler through the internal cooling coil of the main boiler feedwater hotwell (\$2). The boiler feedwater is subcooled (state points 11 to 12 ) by approximately $5^{\circ} \mathrm{F}$ to provide increased NPSH for the boiler feedwater pump. The heat rejection system feedwater flow (approximately $3240 \mathrm{lbm} / \mathrm{hr}$ ) into the shell side of the condenser boiler is controlled by a liquid level controller that modulates valve number 24 to change the bypass flow of water back into the hotwe11 (\#2).

Make-up water for the two stage MHD steam system and also the heat rejection system will be supplied from the Argonne process and building heating steam system. The steam will be condensed at a rate of approximately $1001 \mathrm{bm} / \mathrm{hr}$ in an air cooled heat exchanger (\#6) and stored in stainless steel tank. Sufficlent tank capacity (1000 gallons) will 
available to completely fill the dry MHD steam-water system and heat rejection system. The stored condensate will have total dissolved solids (TDS) of less than $10 \mathrm{ppm}$ and $\mathrm{a}$ ph between 7 and 8 . Upon demand, the stored condensate will be pumped through a mixed bed demineralizer at a flow rate up to $10 \mathrm{gpm}$ to polish the makeup water to less than 1 ppm TDS. An automatic back pressure regulator (valve \#37) will maintain 150 psig makeup water supply pressure whenever the makeup water pump is operating; the excess flow (over demand) will be recirculated back into the storage tank.

Water analysis will be made of both makeup water and boiler water such that water treatment chemicals can be added to the makeup water. Boiler water will be blown down out of the bottom of the steam generator assembly at periodic intervals as required to maintain water purity through operation of the makeup water system.

\subsection{Instrumentation and Control}

\subsubsection{Genera1}

The operation of the $\mathrm{Sn}-\mathrm{H}_{2} \mathrm{O}$ MHD facility requires monitoring and control of a large number of system parameters. These parameters include temperature, pressure, flow, and liquid levels of components and piping in both the tin and steam systems aswell as the cryogenic system associated with the superconducting magnets. The purities of the system make-up water and the boiler water and the volume of hydrogen liberated from any tin oxidation will also be monitored. 
The control and operation of the facility will take place from the control room which will be located adjacent to, but separated from the vault containing the tin and steam systems. Manual controls will be provided for the initial start-up and operation of the system. A computerized data acquisition system will be used for the logging, alarm scanning, and display of a11 system parameters. Eventually, the systems will be expanded to provide supervisory control of the entire system.

\subsubsection{Function}

The function of the $\mathrm{Sn}-\mathrm{H}_{2} \mathrm{O} \mathrm{MHD}$ instrumentation and control system is to monitor and control all system parameters necessary for the efficient and safe operation of the facility under all possible operating conditions. Fail-safe and interlocked modes of operation of the various instrument and control subsystems shall be utilized to protect the facility and personnel from the consequences of component or power failure as well as operator error. Automatic control and data logging are to be used as much as possible to simplify operations. However, manual override and readout of key parameters shall be provided as back-up during emergency or faulted conditions.

\subsubsection{Design Requirements}

The instrumentation and control system should be designed with the following requirements in mind.

a. Installation of instruments (thermowells, pressure taps, flowmeters, etc.) within a component must meet the applicarre code for that component. 
b. All pneumatic lines should be of heavy wall metallic construction.

c. The control center must not be located in the same room as the high pressure tin and steam systems.

d. All electrical power lines must be in metallic conduit. Electrical signal lines must be in metallic conduit or duct as much as possible.

e. Instrument sensors shall be selected to be consistent with the input requirements of the data acquisition system whenever possible.

f. Actuators and circuits shall be designed to be fail safe.

g. Solid state electronic devices shall be used to the maximum extent possible.

h. Critical isolation valves sha11 have valve position indicators.

i. Spare thermocouples and heaters shall be provided throughout the trace heating system.

j. Instruments and controllers shall be installed to permit ease of periodic calibration and maintenance. This shall include reasonable access to devices and provisions for calibration signal test points. Spare parts inventory requirements shall be prepared and implemented.

\subsubsection{System Configuration}

The P\&I diagram for the $\mathrm{Sn}-\mathrm{H}_{2} \mathrm{O}$ MHD system is shown in Figure 23. The flow diagram of the entire system, Figure 2, augments the P\&I diagram by providing the process parameter values expected at the various sensor and control element locations. The 
instrument and component numbering system is common to the flow diagram and the P\&I diagram to facilitate understanding of the system operation.

All instrumentation for monitoring and controlling the operation of the MHD facility will be located in a control room adjacent to the vault containing the MHD system. Remote manual controls will be used to control all equipment. All safety interlocks will be hard-wired. A graphic panel will display the layout of the MHD system and contain controls and indicator lamps for a11 valves.

The control room will also contain a small real-time data acquisitio and control computer and associated peripherals which include a teletype terminal, magnetic tape unit, dual disk pack (2.4 million words), colored CRT display terminal, plotting scope, and a hard copy drum type plotter. In addition, the system will contain a 256 channel A/D converter, several D/A converters, and a digital input/output system for providing on/off control and status information.

Inftially, the computer will be used only for the logging, displaying, and alarming of all parameters assoclated with the operation of the facility. As more and more experience is obtained from the operation of the facility, the computer can be programmed to provide supervisory control of the various systems. 


\subsubsection{Temperature Instrumentation and Contro1}

All remote indications of temperatures in the $\mathrm{Sn}-\mathrm{H}_{2} \mathrm{O}$ MHD system will be provided by the rmocouples. Chromel/Alumel (type K) thermocouples will be utilized for the measurement of noncryogenic temperatures and Copper/Constantan (type T) thermocouples for measurement of temperatures in the cryogenic range. All thermoelements will be specified to meet the ANSI Special Limits of Error requirements. Thermocouples will be either mounted in thermowells or attached to the surfaces of pipes. Each thermocouple will be connected to a reference temperature compensating junction using extension wire of the same material as the thermocouple. Local indications of temperature will be provided by dial-type thermometers.

Thermocouples will also be used to monitor the temperature of several heater elements in the boiler. Limit controllers w111 be used to shut off power to the heaters in the event of overtemperature, which could be caused by low boiler water level.

Since the trace heating system has not been designed, the thermocouples and temperature controllers for this system are not shown on the P\&I diagram. However, each trace heating circuit will be independent and consist of two pairs of type $K$ thermocouples ( 1 used and 1 spare), two heating elements ( 1 used and 1 spare) and an indicating controller. The controller will feature local as we11 as computer adjustable setpoints. 
1.2.6 Pressure Instrumentation and Control

Pressure measurements throughout the $\mathrm{Sn}-\mathrm{H}_{2} \mathrm{O}$ MHD system will be made by using strain gage or force balance type transducers. Both absolute and differential measurements are required. The readouts will be converted to engineering units by the computer and displayed on the CRT terminal. Several local indications of pressure will be made available by the use of Bourdon tube pressure gages.

Absolute pressure measurements in the steam-water system will be made with strain gage transducers. Differential pressures will also be measured with strain gage transducers, whenever possible. However, the force balance type with remote seals may have to be used in the high temperature portions of the system.

Pressure measurements in the tin system, both absolute and differential, will be made by the force balance type transducer with remote seals. The seal diaphragm will be made of tantalum which is compatible with a tin environment.

\subsubsection{Leve1 Instrumentation and Control}

The level of fluids in all vessels containing water or tin must be monitored and in some cases, controlled. Fourteen level indicator and/or control points are shown on the P\&I diagram.

The level in vessels containing water will be monitored by continuous indicating, capacitance type probes. Probe length 
will vary from 10 to 40 inches, depending on the vessel size. A sight gage will be used for local indication on the 1000 gallon condensate storage tank.

The level in vessels containing tin will be monitored by measuring head pressure. Force balance differential pressure transducers with remote seals will be used. The remote seals will utilize a tantalum diaphragm.

All level indications will be displayed on the CRT terminal. Limit controllers with adjustable set points will be used to control fill and drain valves where required.

\subsubsection{Flow Instrumentation and Control}

Flow measurements throughout the $\mathrm{Sn}-\mathrm{H}_{2} \mathrm{O}$ MHD system will be made by using flow tubes with differential pressure transducers. The differential pressure transducers will be of the strain gage or force balance type, as discussed under the section on pressure transducers. Flow readouts, converted to engineering units by the computer, will be displayed on the CRT terminal.

\subsubsection{Miscellaneous Instrumentation}

Some specialized instrumentation will be required for monitoring parameters other than temperature, pressure, level, and flow. Purity and pH monitors will be used to analyze the make-up water and boiler water. Vibration monitors will be used to detect excessive motion of the separator. The amount of hydrogen liberated from the oxidation of tin must be monitored. 


\subsection{Electrical System}

\subsubsection{General}

The $\mathrm{Sn}-\mathrm{H}_{2} \mathrm{O} \mathrm{MHD}$ system w11l require approximately $1500 \mathrm{KVA}$ of electric power for operation of the steam boiler, various motors, auxiliary steam and tin heating systems, and miscellaneous apparatus including instrumentation, controls, and data acquisition equipment. Al1 equipment, apparatus, and materlals shall conform to the latest standards of the American National Standards Institute, the Institute of Electrical and Electronic Engineers, and the National Electrical Manufacturing Association.

\subsubsection{Function}

The main function of the $\mathrm{Sn}-\mathrm{H}_{2} \mathrm{O}$ MHD electric power system is to provide power for the operation of:

a. $1000 \mathrm{KW}$ of resistive heating elements for the steam boiler.

b. Various motors of horsepower ratings from $1 / 2 \mathrm{hp}$ to $30 \mathrm{hp}$.

c. Superheaters and trace heating for steam lines.

d. Immersion heaters and trace heating for tin piping and components.

e. Various other 480-, 280-, and 120-volt power for auxiliary equipment, lighting, controls instrumentation, and the data acquisition system.

\subsubsection{Design Requirements}

The general design requirements of the electrical system are:

a. All circuit breakers shall have adequate interrupting capacity 
b. The position of operating handles, levers, etc., shall clearly indicate to the operator whether a circuit breaker or switch is open or closed.

c. 480-V, 3-phase, 60-Hz power shall be used for motors of $1 / 2$ hp up to $100 \mathrm{hp.} \mathrm{A} \mathrm{supply} \mathrm{of} \mathrm{120/208-V,} \mathrm{3-phase,}$ 60-Hz power shall be provided for bullding lighting, instrumentation, and miscellaneous small loads.

d. In general, motor disconnect switches shall be provided at motors served by a motor control center when the motor is "out of sight" of its starter. These switches shall be horsepower-rated, unfused safety switches with provisions for padlocking in their open and closed positions.

e. In general, 120-V, 1-phase, 60-Hz power shall be used for controls.

f. A11 480-V, 277-V, 208-V, and 120-V electrical equipment enclosures are to be grounded by a green-colored, insulated wire, included with the power supply wires.

g. Nameplates installed on equipment and devices shall read clearly for explicit identification. Instruction nameplates shall be installed where specific instructions or caution is needed.

\section{$1.3 .413 \mathrm{kV}$ System}

A total of $1500 \mathrm{KVA}$ of electrical power will be required for the $\mathrm{Sn}-\mathrm{H}_{2} \mathrm{O}$ MHD facility. The existing distribution panel and feeder provides only $250 \mathrm{KVA}, 100 \mathrm{KVA}$ of which is used for normal building requirements. The additional power requirements will 
be provided for in two stages. Initially, a 500 KVA 13,000/480 volt transformer will be installed on a concrete pad south of Building 310. The $13 \mathrm{KV}$ primary feeder will be extended from the existing pole line, using direct-burial underground cable. The output of this transformer will go directly to the 600

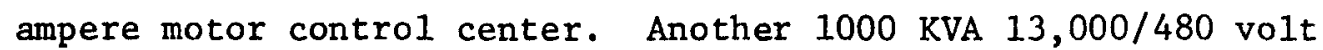
transformer will be installed at a later date to provide power to the 1600 amp motor control center. The same $13 \mathrm{KV}$ primary feeder will be used.

\subsubsection{Motor Control Centers}

Two 3-phase 480-volt wall mounted motor control centers of the indoor metal-enclosed type will be required. One control center, for the boiler heating elements, will have a main bus rating of 1600 amperes, while the other control center, for all other heating elements, motors, power supplies, etc. will have a main bus rating of 600 amperes. Both circuit breaker and fuse type combination starters will be used, the fuse type being primarily used for the heating elements. Both control centers will be of the NEMA Class 1 type and use Type A wiring. A single-line diagram depicting both control centers is shown in Figure 24.

\subsubsection{Motor Requirements}

Combination starters for motors ranging in size from $1 / 2 \mathrm{hp}$ to $30 \mathrm{hp}$ will be required. A tentative list of motor requirements is shown below. 


\begin{tabular}{|c|c|c|c|c|c|}
\hline Motor & Size & & Phase & Volta & age \\
\hline Separator - Stage 1 & 30 & hp & $3 \phi$ & 480 & $\mathrm{~V}$ \\
\hline Separator - Stage 2 & 10 & hp & 36 & 480 & $\mathrm{~V}$ \\
\hline Tin Pump - Stage 1 & 3 & hp & 36 & 480 & V \\
\hline Tin Pump - Stage 2 & 5 & $h_{p}$ & $3 \phi$ & 480 & V \\
\hline Cooling Pump No. 1 & $1 / 2$ & hp & $3 \phi$ & 480 & $\mathrm{~V}$ \\
\hline Cooling Pump No. 2 & $1 / 2$ & hp & $3 \phi$ & 480 & $\mathrm{~V}$ \\
\hline Cooling Pump No. 3 & $3 / 4$ & hp & $3 \phi$ & 480 & $\mathrm{~V}$ \\
\hline Cooling Pump No. 4 & $3 / 4$ & hp & $3 \phi$ & 480 & V \\
\hline Condenser loop pump & $11 / 2$ & hp & 36 & 480 & V \\
\hline Make-up Water Pump & 2 & hp & $3 \phi$ & 480 & V \\
\hline Regenerator Condensate Pump & 3 & hp & $3 \phi$ & 480 & V \\
\hline Boiler Feed Pump & 15 & hp & 36 & 480 & $\mathrm{~V}$ \\
\hline Fan Coil Hx. No. 1 & 1 & $\mathrm{hp}$ & 36 & 480 & $\mathrm{~V}$ \\
\hline Fan Coil Hx. No. 2 & 1 & hp & $3 \phi$ & 480 & $\mathrm{~V}$ \\
\hline Fan Coil Hx. No. 3 & 10 & hp & $3 \phi$ & 480 & $\mathrm{~V}$ \\
\hline Fan Coil Hx. No. 4 & 10 & hp & $3 \varnothing$ & 480 & $\mathrm{~V}$ \\
\hline Fan Coil Hx. No. 5 & 25 & $\mathrm{hp}$ & $3 \phi$ & 480 & $\mathrm{~V}$ \\
\hline Fan Coil Hx. No. 6 & 1 & hp & $3 \phi$ & 480 & $\mathrm{~V}$ \\
\hline
\end{tabular}

\subsubsection{Steam System Heating Requirements}

of the $1500 \mathrm{KVA}$ power provided for the $\mathrm{Sn}-\mathrm{H}_{2} \mathrm{O}$ MHD system, approximately $1000 \mathrm{KVA}$ will be required for the steam boiler heater assembly. This assembly consists of $7215 \mathrm{KW}$ resistive heating elements. The heating elements will be divided into 12 circuits of 6 heaters each. On/off control will be provided for all 12 circuits. In addition, 2 of the circuits will 
contain motor-driven powerstats to provide a fine adjustment of total heater current. Local meter readout as well as computer readout of heater currents will be provided.

A $10 \mathrm{KW}$ superheater for stage 1 and a $60 \mathrm{KW}$ superheater for stage 2 are tentatively planned for the steam system. In addition, it is tentatively planned to use trace heating on several of the steam lines. The amount of power and the number of circuits required will be determined during the preliminary design when the piping system is more definitive.

\subsubsection{Tin System Heating Requirements}

The tin systems are heated electrically to raise their temperatures from ambient to tin-loading temperature (about $550^{\circ} \mathrm{F}$ ) and to maintain the system at or above $500^{\circ} \mathrm{F}$ during shutdowns. The temperature rise of the systems shall be controlled to occur as uniformly as feasible to minimize thermal stresses.

Electrical resistance heating of the piping systems is accomplished with heater cables consisting of a single-conductor heater wire embedded in magnesium oxide inside a stainless steel sheath. The cable is helically wound around the pipe and held in place by stainless steel bands. The nominal heater circuit voltage is 208. Type $\mathrm{K}$ Chromel/Alumel thermocouples are installed on the pipes for control and monitoring of pipe temperatures. Stainless steel foll is wrapped over the heater cables, thermocouples, and pipe to improve heat transfer. Convention high-temperature pipe insulation, with penetrations for the heater 
cable leads and thermocouple leads, is installed on the pipeline. Heater cables are also used on valves and other oddshaped equipment.

The tin dump tanks and surge tanks will contain internal as well as external resistive heating elements. The tentative internal heater requirements are listed below.

Heating Element

Dump Tank No. 1

Dump Tank No. 2

Surge Tank No. 1

Surge Tank No. 2

\begin{abstract}
Power
\end{abstract}
$5 \mathrm{~kW}$

$10 \mathrm{~kW}$

$3 \mathrm{KW}$

$6 \mathrm{KW}$
Voltage $480 \mathrm{~V}$ $480 \mathrm{~V}$ $480 \mathrm{~V}$ $480 \mathrm{~V}$

The number of circuits and lengths of wire required per circuit for the pipe heating system w111 be determined during the preliminary design when the piping system becomes more definitive.

\subsubsection{Miscellaneous Systems}

A $15 \mathrm{KVA}$ 480V/208-120V electrostatically-shielded transformer will be used to provide "clean" power for the instrumentation and data acquisition systems. In addition, a "clean" ground wire w1ll be provided which is separate from the normal "dirty" or power ground.

A 30 KVA 480V/208-120V transformer and panel board has been tentatively provided to allow for illumination requirements in the control room as well as the areas containing the MHD equipment. 
A $45 \mathrm{KVA} 480 \mathrm{~V} / 208-120 \mathrm{~V}$ transformer has also been tentatively provided to handle all miscellaneous equipment to provide power outlets throughout the areas.

\subsection{Codes and Standards}

1.4.1 The piping systems will be designed and constructed according to ANSI B31.1-1973.

1.4.2 Al1 pressure containing vessels and components will be designed and constructed according to the ASME Boiler and Pressure Vessel Code, Section VIII, Division 1, 1974, including 1974 Summer and 1974 Winter Addenda.

1.4.3 Heat exchangers will be designed and constructed according to the latest Tubular Exchangers Manufacturers Association (TEMA) standards.

1.4.4 Wherever applicable all equipment, apparatus and materials sha11 conform to the latest issue of standards of the American National Standards Institute, The Institute of Electrical and Electronic Engineers and the National Electrical Manufacturers Association. 


\section{DESIGN DESCRIPTION}

The components which are depicted in the Process Diagram of Figure 2 can be grouped into subsystems as follows: (1) Makeup Water System, (2) Heat Rejection System, (3) Boiler Feedwater System, (4) Steam Generator Assembly, (5) MHD Stage 1 System, (6) MHD Stage 2 System, and (7) Miscellaneous System Components. The functions and design requirements (i.e., design pressure and temperature and flowrates) have been discussed in the previous section for the major components in these subsystems. The following paragraphs will describe the physical characteristics of these subsystems and the major component parts as they have been concelved at the present time.

\subsection{Makeup Water System}

Steam is obtained from the Argonne process and steam heating supply, condensed and stored to supply makeup water to this proposed facility. A manual shut-off valve (not shown) of one-half inch nominal size will be used as the primary isolation valve between the MHD Power System and the Argonne Steam System. A remotely operable $1 / 2$ inch steam stop valve (非25) will be used to supply steam for refilling the storage system with condensate during operation as required.

An aircooled heat exchanger (Fan Coil HX $\# 6$ ) will be used to condense the steam. It must be capable of operation with 200 psia, $382^{\circ} \mathrm{F}$ steam at a heat load of $100,000 \mathrm{Btu} / \mathrm{hr}$. A single speed blower of $4500 \mathrm{cfm}$ with a 1 hp motor coupled to a $24^{\prime \prime} \times 24^{\prime \prime} \times 2^{\prime \prime}$ finned core is estimated to be adequate. 
The water storage tank for this facility will be a 1000 gallon stainless steel tank having an atmospheric pressure rating; it will always be vented to atmosphere. This tank will be of cylindrical shape with essentially flat heads. A half inch pipe water inlet and vent will be near the top. Half inch pipe bosses will be provided near the top and bottom of the sidewall for a sight gauge. A $1 / 2$ inch pipe inlet and 1 inch pipe outlet will be located near the bottom of the tank for the pump inlet and recirculating water return line.

The makeup water pump will supply $10 \mathrm{gpm}$ of water at $150 \mathrm{psid}$ and will require a 1-1/2 horsepower motor. A bronze impeller and casing is adequate. A pump with an NPSH requirement of 5 feet of head, or less, should be provided.

Valve \#37 is an automatic back pressure regulator (1/2" size) set for 150 psig. The mixed bed deionizer must be capable of polishing $10 \mathrm{ppm}$ makeup water at flowrates up to $10 \mathrm{gpm}$, to an equivalent TDS of less than $1 \mathrm{ppm}$. The physical characteristics of this unit have not been established. A case design pressure of 200 psig and a maximum operating temperature of $120^{\circ} \mathrm{F}$ can be specified at the present time.

The water treatment injector has not been specified at the present time. It should, however, be a standard avallable commercial unit that will have treatment capabilities that can compensate for conditions as indicated by boiler water and makeup water analysis units. 


\subsection{Heat Rejection System}

Provision is made for the rejection of approximately $900 \mathrm{KW}$ of heat from this facility. The condensing steam from the second stage MHD system rejects heat by boiling water in a condenser/boiler. This steam is throttled to control back pressure, condensed in an air cooled heat exchanger, collected in a hot well, and pumped back through to the condenser/boiler.

The condenser/boiler she11 (see Figure 3) will be a 75 gallon tank (22" diameter by $50^{\prime \prime}$ high) rated at 100 psig and $330^{\circ} \mathrm{F}$ operating conditions. Internal spiral coils of $1 / 2$ inch heavy wall tubing connect to two (2) inch schedule 80 inlet and outlet pipe headers to provide surface area of $80 \mathrm{ft}^{2}$. The internal tubing coils are located at the bottom end of the tank. Two 1 inch pipe connections are located in the top head of the pressure shell for a pressure relief valve and for the steam outlet. A half inch pipe connection is located in the top head for a liquid level control. The two inch pipe headers (2) are located in the side wall of the vessel and are positioned with the tubing coils so the condensate will drain by gravity. Two $1 / 2$ inch pipe connections are located in the bottom head for the water inlet and for a manual drain.

A one inch throttle valve $(\not 15)$ is used to adjust the steam pressure in the shell side of the condenser/boiler by servo control from a remote setpoint controller.

The air cooled heat exchanger will be sized to dissipate one megawatt of thermal energy at a maximum design pressure of 60 psig and design temperature of $300^{\circ} \mathrm{F}$. Blower capacity up to $33,000 \mathrm{cfm}$ will be provided 
by either a multiple speed 25 hp motor or by multiple parallel blowers equipped with automatic outlet shutter doors. Inlet damper control of the air flow will be required for fine adjustment of air flow and consequent condensing temperature and pressure. A 4 ft by 4 ft by 4 inch heat exchanger core is estimated to be required.

The hot well (\#3) (see Figure 4) for the heat rejection system condensate will be a 75 gallon tank rated at 100 psig and $340^{\circ} \mathrm{F}$. It will incorporate a two inch liquid condensate inlet and three $1 / 2^{\prime \prime}$ pipe connections (for pressure relief and readings) in the top head, and two $1 / 2$ inch and one, 1 inch pipe connections at the bottom head for the outlet to the pump, and manual drain. Two $1 / 2$ inch pipe connections on the side wall will be used for liquid level monitoring and control. A $1 / 2$ " pipe connection on the side vall is to be used for recirculation return.

The heat rejection system pump will circulate up to $10 \mathrm{gpm}$ of condensate from hot well \#3 at pressures up to 75 psid. The liquid level control on the condenser/boiler she1l will open or close the $1 / 2$ inch bypass valve (\#24) to maintain liquid level. A NPSH of $5 \mathrm{ft}$ of head or less is required of this pump which can be of bronze construction. A $1.5 \mathrm{hp}$ electric motor will be required.

\subsection{Boiler Feedwater System}

Boiler feedwater is drawn from the condenser hotwell (\$2) and is recirculated by pump through three regenerator heat exchangers, an oxide filter and discharged into the steam generator. Makeup water of high purity is added into the hotwell (\#2) to compensate for blowdown, reaction of steam with tin, and leakage of steam from within the steam system. 
The boiler feedwater hotwel1 (\#2) is a 75 gallon tank rated for 100 psig and $340^{\circ} \mathrm{F}$ (see Figure 4). A $20 \mathrm{ft}$ length of heavy wall one (1) inch tube is coiled in a helix at the bottom inside the hot we11 (非) to act as a feedwater chiller; it provides additional NPSH for the boiler feedwater pump. The hotwel1 (\#2) will have two 2 inch pipe penetrations on the top head for condensate inlet and a pressure relief valve, two $1 / 2$ inch pipe connections on the bottom head and side wall which connect to the internal heat transfer coll, two $1 / 2$ inch pipe connections in the side wall for liquid level control, and two $1 / 2$ inch pipe connections on the bottom head, for an outlet to the boiler feedwater pump and also a hand drain valve.

The boiler feedwater pump will supply $10 \mathrm{gpm}$ of water at a head pressure of 1200 psid. A fifteen horsepower motor will be used to power the pump. The impeller and casing must be made of materials which are resistant to tin attack; a high chrome steel, or a heavy chrome plate on internal surfaces is suggested. The pump must operate with an NPSH requirement of 10 psid or less.

The bleed condensate hotwel1 (\#1) is a 10 gallon tank rated for 100 psig and $340^{\circ} \mathrm{F}$ (see Figure 5). A $10 \mathrm{ft}$ length of heavy wall $1 / 2$ inch diameter tubing is coiled in a helix at the bottom inside the hot well (\#1) to act as a condensate chiller that provides additional NPSH for the bleed condensate pump. Hotwell $\left.\right|_{1} 1$ will have two $11 / 4$ inch pipe connections on the top head (for the condensate inlet and a PRV), two $1 / 2$ inch pipe connections to the internal chiller coil located in the bottom had and side wall, two $1 / 2$ inch pipe connections for liquid level control located on the side wall, and three $1 / 2$ inch pipe connections located 
on the bottom head (for the pump inlet, bypass flow return, and manual drain valve).

The regenerator condensate pump will supply 2 gpm at 1200 psid head pressure. A three horsepower motor is required. The Impeller and casing must be capable of withstanding tin attack because there is no assurance at the present time that tin will not carry through with the steam and feedwater. A high chrome steel or a heavy chrome plate on internal surfaces is suggested. The pump must operate with an NPSH requirement of 10 psid or less.

The two units of regenerator $\# 1$ (regions $I$ and II) are identical in construction (see Figure 6). The outer shell of each of these counterflow shell and tube units is approximately 20 feet long and consists of a section of $11 / 4$ inch schedule 80 pipe welded between two pipe tees, two tube sheets, and two concentric reducers $(11 / 4$ to $1 / 2$ inch pipe). Three $1 / 2^{\prime \prime}$ oD heavy wall tubes are welded into each tube sheet. The tubes are wrapped with .050 inch diameter wire, on a $1 \mathrm{ft}$ helical pitch, which is spot welded to the tube at regular intervals. The tubes are twisted one or two turns in their twenty foot length to allow for differential thermal expansion between tubes and she 11 by column buckling. Design pressure is 1200 psig and design temperature is $570^{\circ} \mathrm{F}$ for both the tubes and the shell.

Regenerator \#2 is also approximately 20 feet long and consists of a section of $31 / 2$ inch schedule 80 plpe welded between two reducing tees ( $31 / 2$ inch run, 3 inch 1 eg), two tube sheets and two concentric reducer ( $1 / 2$ inch to $31 / 2$ inch pipe) (see Figure 7). Nineteen 1/2" diameter heavy wall tubes are welded between the two tube sheets inside the shell. 
The tube sheets and tubes are twisted one turn in the $20 \mathrm{ft}$ distance to allow the tubes to buckle to accommodate differential thermal expansion. The tubes are welded into the tube sheets using a trepanned weld preparation on the outside face of the tube sheet. Design pressure is 1200 psig and design temperature is $570^{\circ} \mathrm{F}$ for both the tubes and the she11.

An oxide filter system will be incorporated into the feedwater system. It will consist of a sufficient number of cartridge elements to handle the design flowrate of $3600 \mathrm{lb} / \mathrm{hr}$ (approx. $9 \mathrm{gpm}$ ) with a filtration to 10 micron particle size with a pressure drop less than 10 psid at a system pressure level of $1000 \mathrm{psia}$ and temperatures up to $500^{\circ} \mathrm{F}$.

\subsection{Steam Generator Assembly}

The assembly is shown in Figure 8. Electric heating power is used to vaporize the feedwater and provide a net steam output of approximately I Ib/sec $(3600 \mathrm{Ib} / \mathrm{hr})$ at $1000 \mathrm{psia}$ and $546^{\circ} \mathrm{F}$. Some of the steam which is generated condenses within the assembly on three different heat exchangers to reheat two tin streams and one steam stream.

The outside shell of the steam generator is 3 feet in diameter and is 16 feet high. The bottom closure is a cylindrical tubesheet; the top closure is a semi-elliptical head. The steam generator will be rated at $1200 \mathrm{psig}$ and $570^{\circ} \mathrm{F}$ design conditions. Wall thickness of the outer shell will be approximately $13 / 8$ inch. The unit will be of all welded construction (no flange joints on the shell). 
The electric power of one megawatt will be dissipated in 72 resistance heaters that are contained within tubular wells that are welded to the bottom tubesheet. Each of the electric heaters will be one $(1.000 \pm$ .002) inch diameter, will have an eight (8) foot heated length and a one (1) foot unheated length at the end where both electrical leads are fastened. The tubular wells which house the heaters will have thick walls (e.g., 0.2 inch) with inside diameters of $1.020+000-004$ inch. The heater wells w111 be back-side butt-welded to the trepanned tube sheet. The matching holes in the tube sheet will be reamed after welding to ensure easy heater insertion. The electric heater and wel1 assembly will be built with a 3 inch equilateral triangular pitch (see Figure 9). The heater well assembly will be supported on the top end with a minimum flow restriction brace to the inner shell.

The inner shell, which is seven (7) feet long, is a cylinder with a wall thickness of $1 / 8$ to $1 / 4$ inch and an outside diameter that leaves a two inch annular gap out to the pressure shell. Radial webs are welded to the inner shell at three equally spaced locations (both top and bottom) to attach the inner shell to the pressure she11.

A "bullseye" type steam separator, located in the axial mid-region of the steam generator, will be fashioned from $1 / 4$ inch plate formed into conical sections. The separator will be welded together with spacer struts and will be welded to the inside wall of the pressure shell.

Tin heater 非 (see FIgure 10) will have $31 / 2$ inch pipe headers (schedule 80) for the inlet and outlet; the inlet header is located coaxial to the steam generator, and the outlet header axis is located 
parallel to the steam generator axis near the pressure shell. Approximately forty (40) $\mathrm{ft}^{2}$ of heat exchanger area is provided by parallel flow passages of $1 / 2$ " pipe sections (schedule 80 ) bent into spiral shapes and welded to the headers at each end. The heat exchanger is supported on the headers and by hangers welded to the pressure shell.

The steam reheater (see Figure 11) will be located above tin heater $\# 1$ and will have two inch schedule 80 pipe headers; the inlet header will be coaxial to the steam generator and the outlet header axis will be parallel at a location near the pressure she11. Approximately forty (40) $\mathrm{ft}^{2}$ of heat exchanger area is provided by parallel flow passages of $1 / 2$ " pipe sections (schedule 80 ) bent into spiral shapes and welded between headers. The steam reheater is supported on the headers and by hangers which are welded to the pressure shell.

Tin heater 非 (see F1gure 12) located near the top of the steam generator assembly will have 6 inch schedule 80 pipe headers; the inlet header is nearly coaxial to the steam generator and the outlet header is parallel to the axis and is located near the pressure shell. Approximately $80 \mathrm{ft}^{2}$ of heat exchanger area is provided by parallel flow passages of 1 inch $x .109$ wall tubing, bent into spiral shapes and welded between headers. The tin heater is supported on the headers and by hangers which are welded to the pressure shell.

The entire steam generator assembly will be supported by an external skirt that is welded to the pressure shell at a point approximately one-third of the distance down from the top head. A four point suspension will be used. 


$$
\text { II- }-10
$$

There will be 73 penetrations in the bottom tube sheet (see Figure 9) 72 of these wi 11 be $1.040 " \pm .010^{\prime \prime}$ diameter for insertion of heaters; the middle penetration will be mating to $1 / 2$ inch pipe for blowdown and draining. Two $31 / 2$ inch pipe penetrations in the side wall will be required for tin heater $\# 1$ inlet and outlet headers. Two 2 inch pipe penetrations will be required for the steam reheater headers. Four $1 / 2$ inch pipe penetrations will be required for tin heater $\# 2$ headers. A single 1 1/2 inch penetration on the top head wil1 be required for the steam outlet. Two 6 inch pipe penetrations will be required in the side wall of the vessel for liquid level control, feedwater inlet and water analysis. Additional penetrations (not defined at the present time) will be used for instrumentation.

\subsection{MHD Stage 1 System}

Electrical power is extracted from the magnetohydrodynamic device through which liquid tin and steam flow. The apparatus which are required to accomplish the tin-steam mixing and separating, fill and cleanup operations are described in the following narrative.

The electrically heated steam superheater will supply up to $10 \mathrm{KW}$ of power to dry the steam coming from the steam generator. The steam generator produces saturated steam at 1000 psia (nominal design conditions), this steam can become slightly "wet" after traversing some length of piping. In order to get an accurate flow measurement of steam at the inlet to the stage 1 mixer, the steam will be superheated. The superheater will consist of a 9 foot long standard heater ( 1 inch OD inconel sheath, as used in the boiler) centered in a two inch schedule 80 pipe section (see Figure 13). At one end of the pipe section a $2 \times 2 \times 11 / 2 "$ tee is welded to permit steam to enter via the leg and the electrical heater to penetrate along the run. The 
electric heater will have an unheated portion to a position beyond the steam inlet. The end closure at the tee will be flanged to permit removal of the electric heater. Radial spiders will keep the heater centered within the pipe. The end of the superheater opposite the tee will have a $2^{\prime \prime}$ to $11 / 2^{\prime \prime}$ reducer to mate with the steam line into the mixer.

The tin-steam first stage mixer has rectangular shaped channels which converge from $11 / 2$ " by $3^{\prime \prime}$ dimensions to 1 " by 2 " dimensions. One hundred and twenty-eight tubes ( $1 / 8^{\prime \prime}$ OD by $.015^{\prime \prime}$ wal1) converge from the large channel into the small channel, where they are fastened into the curved tubesheet (see Figure 14). The tin flows through the inside of the tubes. The rectangular inlet channel has a transition section from the $31 / 2$ inch schedule 80 pipe which feeds tin to the mixer. Steam flows into the mixer (outside of the tubes) from the side direction into the region where the tubes are splayed apart. This region allows the steam to be distributed uniformly in a lateral direction before it turns and flows axially along the tubes in the cusp regions formed between tubes (see Section A, Figure 14). The external pressure boundaries of the mixer will be formed from plate, welded together and stiffened with external rings as required to withstand the design pressure of $1200 \mathrm{psig}$ at $570^{\circ} \mathrm{F}$.

The first stage rectangular MHD channel has not been defined at the present time except in approximate inside dimensions and by known fluid dynamic constraints which set operating pressure levels. The inlet dimensions are approximately $0.5^{\prime \prime}$ by 4 ". Length is approximately 
40". Outlet dimensions are approximately $2.5^{\prime \prime}$ by $4 "$. The channel will operate with an inlet void fraction range between 0.5 and 0.65 and an outlet void fraction range between 0.75 to 0.85 , to maintain the required electrical conductivity characteristics of the two phase fluld mixture. The cryogenic refrigeration system, magnets, magnet power supply and air cooled heat exchanger for the refrigerator (Fan coil $\mathrm{HX} \# 1$ ) have not been defined at the present time.

Electrical power from the first stage MHD generator will be dissipated inside a variable resistance water cooled load (see Figure 15). Water is circulated through the load by a pump, heated in the load, and cooled in an air cooled heat exchanger. The variable resistance load for the MHD power will be a water cooled vertical copper pipe 1/2" ID by 5 feet long connected electrically between bus bars. Concentric around the water cooled pipe will be another heavy wall copper pipe that allows an $1 / 8$ inch annular gap. The outer copper pipe is brazed to the bottom bus bar and is sealed with a bellows to the top bus bar. Sodiumpotassium alloy $(\mathrm{NaK})$ is admitted to the annulus to vary the length of inner pipe which is electrically shorted and to thereby change the circuit resistance. The pipe wall thicknesses and lengths will be designed to operate within known heat flux limitations as well as the resistance range which is required for loading the MHD generator at the required power levels.

A three gallon expansion tank rated at 60 psig accommodates volume change of the water coolant in heating and provides pressurization to suppress bolling. The expansion tank has $1 / 2$ inch pipe connections 
on the top and bottom heads for the water connection, a pressure relief valve, gas pressurizer and pressure gauge. Two liquid leve1 $1 / 2$ inch pipe connections are required in the side walls of the tank.

The fan coil heat exchanger (\#3) will be a 24 inch by 24 inch by 2 inch core with a one (1) horsepower motor and a blower delivering $6000 \mathrm{cfm}$ of air.

The pump will deliver 20 feet of head at 15 gallons/minute with a case pressure rating of 100 psig; a 3/4 horsepower motor is required.

The electrical load is electrically isolated from the rest of the water coolant circuit by using electrical insulators (e.g., MICARTA) between pipe sections. Piping is $1 / 2$ inch schedule 40 .

The first stage nozzle for the example conceptual design is of all welded plate box type construction (see Figure 16). The side plates are constant width rectangles with machined indexing grooves. The top and bottom plates are trapezoldal in shape. The inlet dimensions are 2.5 inch by 4 inch which converge to the outlet dimensions of 2.5 inch by 1.74 inch over an axial distance of approximately 18 inches. Stiffener plates are welded at axial intervals as required to maintain dimensional control at a pressure rating of $1200 \mathrm{psig}$ and at a temperature rating of $570^{\circ}$. Because the nozzle function is intimately tied into the operational characteristics of the separator, nozzle design will change according to separator design requirements. 
The tin-steam separators will be developmental devices. Several conceptual separator designs are under consideration. The most promising separator design features a rotating inverted open bow1 (see Figure 17) into which the high velocity two-phase mixture of tin and steam is injected.

The two foot diameter bowl rotates at a peripheral velocity equivalent to the injection velocity (175 ft/sec). A "pony" motor of 30 horsepower will be used to spin the system. Centrifugal force separates the liquid tin from the steam. A stationary pitot "scoop", having an inlet hole diameter of $1 / 2$ inch is positioned inside the bow 1 below the liquid tin surface. Tin flows into the tin scoop and diffuses down in velocity (from $175 \mathrm{ft} / \mathrm{sec}$ to $5 \mathrm{ft} / \mathrm{sec}$ ) to convert kinetic energy into static pressure. It may be possible to modify a commercial pump (Kobe), which uses the pitot scoop principle, for this application. Kobe pumps achieve approximately 50 percent head recovery. By redesign of the diffuser, which is incorporated in the scoop, a considerable increase (approx. 75\%) in head recovery is expected. Model testing of this concept using water and air (or other inert two phase mixtures) is strongly suggested as part of the preliminary design phase of the project effort.

A second two-phase mixture separator, which will be considered further, is the JPL type separator (Ref. \#1) which was developed for LMMHD applications. This separator requires a conical upstream nozzle to accelerate the two phase mixture. In this design, the two phase mixture impinges upon a nearly conical shape surface of revolution. The liquid tin collects and flows along the surface of revolution. The gas is forced 
out an annular manifold. Skimmer blades strip the tin film in a two stage separation operation. The tin from the first stage skimmer flows through an annular diffuser into a collection manifold. (A first stage skimmer collection efficiency of over $90 \%$ (mass ratio of 1iquid) was obtained by JPL with sodium in argon.) The tin from the second stage skimmer goes through a second diffuser into a manifold which directs the tin back to the nearly conical surface of revolution where it is injected along the surface to decrease skin friction, increase recovered head, and increase overall collection efficiency. An overall collection efficiency greater than $99 \%$ using sodium in argon was obtained with a pressure head recovery of $50 \%$. The head recovery would have to be substantially increased (to $75 \%$ ) in this device in order to make a workable thermodynamic cycle.

A third type of two-phase mixture separator, which may be considered further during preliminary design, consists of a cyclone separator leading directly from the outlet of the MHD generator (in this case, the two phase mixture may or may not be accelerated in a nozzle). The tin drops out the bottom of the cyclone. Stationary vanes in the bottom of the cyclone will be used to recover some of the kinetic energy which remains in the tin (due to a velocity of at least $50 \mathrm{ft} / \mathrm{sec}$ as it comes out of the MHD channel and nozzle). The steam exits the cyclone separator through a top center port. This steam, which is at the exit pressure from the MHD channel (445 psia), is used to drive an impulse steam turbine wheel. The steam turbine is directly coupled to a mixed flow centrifugal tin pump that is fed from the tin outlet of the cyclone separator. Further study of the thermodynamics of this part of the process is necessary to obtain quantitative evaluations of state conditions so that the effects on 
system efficiency can be determined. It may be possible to have a single steam turbine (or parallel flow units) operating with inlet steam from the last MHD stage, to drive all of the tin pumps. A reduction in MHD stage 2 channel size is anticipated because of higher operating pressure levels if this type of separator/tin pump is selected during preliminary design.

The first stage cyclone separator has a five (5) gallon volume capacity (e.g., 8 inch ID, 24 inch length) and is to be rated for 1200 psig and $570^{\circ} \mathrm{F}$. The vessel will have a two inch schedule 80 tangential inlet for the two-phase mixture, a two inch schedule 80 steam outlet on the top head, and a $1 / 2$ inch schedule 80 outlet on the bottom conical head for the tin outlet.

The first stage tin lockout tank (see Figure 18) is 7.5 gallon capacity, which will provide a five minute time interval for tin collection at anticipated flow rates. It will have a 1200 psig design pressure at a design temperature of $570^{\circ} \mathrm{F}$. The tin inlet and outlet will be $1 / 2$ inch pipe connections on the top and bottom heads. Two $1 / 2$ inch pipe connections located on the side wall will be used for the liquid level control.

The first stage tin surge tank has 15 gallon capacity at a design pressure of 1200 psig and design temperature of $570^{\circ} \mathrm{F}$ (see Figure 19). This horizontal tank is to have a $1 / 2$ " pipe dip tube type outlet, two $1 / 2^{\prime \prime}$ pipe connections on top for the tin inlet and a pressure relief port, two 1/2" pipe connections on one head for liquid level and a $1 / 2$ inch pipe drain on the bottom. 
The first stage tin recirculating (side stream) pump is to have a flow capacity of 1 gallon per minute at a differential head of 1000 psi. Case pressure rating is $1200 \mathrm{psig}$ at $570^{\circ} \mathrm{F}$. A high chrome steel or heavy chrome plated steel case and impeller is recommended. A motor drive of $2.5 \mathrm{hp}$ is required.

The first stage oxide removal unit is to be a "heat cleaned glass" filter cartridge rated at 10 micron absolute with a 1 gallon per minute flow of tin at a pressure drop less than 10 psid. Case pressure rating will be 1200 psig at $570^{\circ} \mathrm{F}$. System operation has not been defined yet to the extent which dictates whether a dual (replaceable) alternate filter cartridge system or a multiple filter cartridge system (which has sufficient total capacity for a proposed run) will be designed for the system.

A five gallon tin expansion tank (which is also used for damping hydraulic shock) rated at conditions of 1200 psig and $570^{\circ} \mathrm{F}$ will be provided in the first stage tin return line. Inlet and pressure relief connections will be $1 / 2^{\prime \prime}$ pipe (see Figure 20). Valve $\# 3$ is a three inch stop valve which is used for the initial fill operation of the first stage tin system; it is rated 600" ASA which is serviceable to 1200 psig at $550^{\circ} \mathrm{F}$. The valve flow coefficient (Cv) is 110 . Valve $\# 2$ is a three inch check valve (600非 ASA rating) which automatically opens when the first stage tin filling operation is completed. 
The first stage horizontal tin dump tank has a 45 gallon capacity, a design pressure rating of $1200 \mathrm{psig}$ at a design temperature of $570^{\circ} \mathrm{F}$ (see Figure 21). It has a three inch schedule 80 pipe tin outlet (dip tube), two 1 inch pipe connections on top for gas pressurization and gas relief/venting, two $1 / 2$ inch pipe connections on top for pressure and temperature sensors, two $1 / 2$ 1nch pipe connections on an end head for liquid level sensing, and a 1/2 inch pipe connection on the bottom for a drain.

The first stage tin piping is $31 / 2$ inch schedule 80 .

Design of the hydrogen scavenging unit will be done during preliminary design.

\subsection{MHD Stage 2 System}

Additional electrical power (between 25 and $100 \mathrm{KW}$ ) is extracted from the second stage MHD device through which the second stage tin and steam flow. The apparatus which is required to accomplish the tin-steam mixing functions, tin $\mathrm{f} 111$, and tin oxide cleanup operations are described in the following narrative.

The second stage 0 to $60 \mathrm{KW}$ electric superheater (see Figure 22) will be used only when the first stage MHD device is bypassed. The steam generator would then be operated at nominal 1000 psia saturated steam conditions. The steam from the outlet of the steam generator is routed through the steam reheater, that is internal to the boiler, following isenthalpic expansion to lower pressure (e.g., 300 psia). The steam temperature drop due to expansion is partially regained in 
the reheater. The electric power to the superheater is adjusted to raise the 300 psia steam up to approximately $545^{\circ} \mathrm{F}$. The second stage electric superheater consists of a 3 inch schedule 80 pipe section (see Figure 22) welded to a $3^{\prime \prime}$ by $3^{\prime \prime}$ by $2^{\prime \prime}$ tee on one end which is, in turn, welded to a flange. The opposite end of the pipe section is welded to a $3^{\prime \prime}$ by 2 " concentric reducer. Four standard nine foot long ( $8 \mathrm{ft}$ heated) $15 \mathrm{KW}$ electric heaters are inserted into the $3^{\prime \prime}$ pipe section using a flanged connection. The heater elements are wrapped with $1 / 8^{\prime \prime}$ tubing on a $1 \mathrm{ft}$ helical pitch to provide radial spacing. The $1 / 8^{\prime \prime}$ tubing is spot welded to the heater sheaths at regular intervals to fasten the spacer tubing securely. Steam enters the superheater via the 2 inch leg of the tee and flows axially through the unit. The heated portion of the electric heaters are downstream of the steam inlet.

The tin-steam second stage mixer has rectangular shaped channels which converge from 4 " by 7 " dimensions to 2 " by $31 / 2^{\prime \prime}$ dimensions (see Figure 14). Four hundred and forty-eight tubes ( $1 / 8^{\prime \prime}$ OD by .015 inch wa11) converge from the large channel, where they are fastened into a tubesheet, into the small channel. The second stage tin flows through the inside of the tubes. The rectangular (4" by 7") inlet channel has a transition section from the 6 inch schedule 80 pipe which feeds tin to the mixer. Steam flows into the m-xer (outside of the tubes) from the side direction into the region where the tubes are splayed apart. This region allows room for the steam to be distributed evenly in a lateral direction so that a uniform axial flow will be obtained in the cusp regions that are formed between the tubes (see Section $A$, Figure 14). The external pressure boundaries of the mixer will be 
formed from plate sections welded together and stiffened with external rings as required to withstand the design pressure of $1200 \mathrm{psig}$ at $570^{\circ} \mathrm{F}$.

The second stage rectangular MHD channel has not been defined at the present time except in approximate internal dimensions. The inlet dimensions are approximately $2.5^{\prime \prime}$ by $4 "$. Length is approximately $30 "$. Outlet dimensions are approximately 6" by 4". Fluid dynamic constraints as represented by void fraction (V.F.) limits are similar to stage 1 conditions (i.e., V.F. in $\cong 0.6$ and V.F. out $\cong 0.8$ ). The cryogenic refrigeration system, magnets, magnet power supply, and air cooled heat exchanger for the refrigeration system ( $f a n$ coil $\mathrm{HX} \# 2$ ) have not been defined at the present time.

Electrical power from the second stage MHD generator will be dissipated inside a variable resistance water cooled load (see Figure 15) that is identical to the one which was described for the first stage generation system. The expansion tank, fan coil heat exchanger (非), water pump, electrical insulators and piping are also identical to those described for the stage 1 system.

The second stage nozzle is designed and constructed in a manner identical to the first stage nozzle, though dimensions are larger (see figure 16). The rectangular flow cross section of the nozzle at the inlet has dimensions of approximately 6" by 4". The length of the nozzle is 18". The outlet dimensions are approximately $6 "$ by $51 / 2 "$. Note again that the nozzle design is a function of the separator design requirements and could change from the example given if the separator design chang from the preferred example. 
The second stage separator (of the inverted bowl design) will have an identical case and bowl as the first stage separator (see Figure 17). The two foot diameter bowl will rotate with a peripheral velocity of approximately $100 \mathrm{ft} / \mathrm{sec}$. A $10 \mathrm{hp}$ motor is required to spin the unit up to speed. The pitot-tube tin scoop has an inlet hole diameter of approximately 1 inch. The outlet from the tin scoop mates with the six inch schedule 80 pipe of the second stage tin loop.

The second stage cyclone separator has a fifteen (15) gallon capacity (e.g., 12" dia. $x$ 36" long) and is to be rated for 1200 psig at $570^{\circ} \mathrm{F}$. This vessel will have $3^{\prime \prime}$ schedule 80 tangential inlet on the side wall and a $3^{\prime \prime}$ schedule 80 steam outlet in the top head. The tin outlet in the bottom conical head will be $1^{\prime \prime}$ schedule 80 pipe.

The second stage tin lockout tank (see Figure 18) is to have 20 gallon capacity to provide a 5 minute retention time for the anticipated tin flow rate. Design pressure is 1200 psig at a design temperature of $570^{\circ} \mathrm{F}$. The tin inlet and outlet on the top and bottom heads will be $1 "$ pipe connections. Two $1 / 2$ inch pipe connections on the side wall will be used for the liquid level control.

The second stage tin surge tank (see Figure 19) is to have 40 gallon capacity with a pressure rating of 1200 psig at a design temperature of $570^{\circ} \mathrm{F}$. This horizontal tank is to have a $1^{\prime \prime}$ pipe dip tube type out1et, two 1 inch pipe connections on top for the tin inlet and the pressure relief port, two $1 / 2$ inch pipe connections on one end head for liquid level control, and a $1 / 2$ " pipe connection on the bottom for a drain. 
The second stage tin recirculating (side stream) pump is to have a flow capacity of 3 gallons per minute at a differential head of 1000 psi. Except for the increased flow capacity and power requirement, it will have identical structural and material compatibility requirements as the first stage pump.

The second stage oxide removal unit is to have a 3 gallon per minute flow capacity. Other design considerations are identical with the first stage unit.

The second stage tin expansion and hydraulic shock damping tank is to have fifteen gallon capacity at a design pressure of 1200 psig and design temperature of $570^{\circ} \mathrm{F}$. Other design parameters are identical to the first stage unit.

Valve \#4 (shown in Figure 2) is a 6 inch stop valve which is used in the initial fill operation of the second stage tin system; it is rated 600 \# ASA which is serviceable to $1200 \mathrm{psig}$ at $550^{\circ} \mathrm{F}$. The valve flow coefficient (CV) is to be 400 . Valve \#10 is a 6 inch check valve (600非 ASA rating) which automatically opens at the conclusion of the second stage tin filling operation.

The second stage tin dump tank is to have 100 gallon capacity at a design pressure rating of $1200 \mathrm{psig}$ and design temperature of $570^{\circ} \mathrm{F}$ (see Figure 21). It has a 6 inch schedule 80 dip tube tin outlet, two $11 / 2$ inch pipe connections on top for gas pressurization and gas relief/venting, two $1 / 2$ inch pipe connections on top for pressure and temperature sensors, two $1 / 2$ inch pipe connections on one end head for 
for liquid level sensing, and a $1 / 2$ inch pipe connection on the bottom for a drain.

The second stage tin piping is 6 inch schedule 80 . NOTE: All piping has been sized by rough calculation; sizes will be re-evaluated during preliminary design.

Conceptual design of the hydrogen scavenging unit has not been done.

\subsection{Miscellaneous System Components}

Trace heating and insulation will be provided on all system piping and vessels. The pipe trace heaters will be metal sheathed (inconel or stainless stee1) magnesium oxide insulated electric resistance wire. Two parallel heater elements will be provided on each pipe section for redundancy; in case of heater failure, one heater will be capable of heating the section to operating temperature $\left(550^{\circ} \mathrm{F}\right)$ in a reasonable period of time $(4 \mathrm{hrs})$. Insulation will be low conductivity preformed semi-cylindrical sections with two layers and staggered joints, taped and painted (such as Kaylo 10). Sufficient thickness of insulation will be provided ( 2 to 4 inches) to reduce heat losses to levels which can be accommodated with the wrapped on electrical resistance heaters. Heaters for vessels will be clamped-on band type electrical resistance units of sufficient capacity to accommodate heat losses and the stipulated heat up time ( $4 \mathrm{hrs}$ ). Detailed description of the various electrical heaters is given in the Electrical Section of this document. Some of the small fill and drain lines for the tin and steam systems have been omitted from the above discussion. 


\section{SECTION III}

3. SYSTEM LIMITATIONS, SET POINTS AND PRECAUTIONS

The steam system and tin loop components of both stages will be designed for 1200 psig operation at $570^{\circ} \mathrm{F}$ except for the hotwells and condenser/boiler she11 which will be designed for 100 psig operation. Direct connected pressure relief valves will be provided on all vessels which can be subjected to overpressurization by stop valves. Set points relate to liquid level controls and electrical heater overtemperature. These set points will be manual with optional computer control.

Precautions relate to overpressurization of system components, overtemperature of system components, and tin wear-through of piping. Overpressurization will be avoided by proper sizing and pressure set points of automatic steam pressure relief valves in critical components and by placement of pressure transducers at strategic locations which activate alarms and/or automatic shutdown functions. Thermocouples will be used to monitor and control critical components such as electric heater elements. Tin wear-through of piping components (e.g., elbows) will be monitored and alarmed by using partial wall drill through "gauges" with pressure transducer indication. 


\section{SECTION IV}

\section{OPERATION}

Operational considerations relate to startup, steady state, and shutdown procedures. These procedures are discussed in some detail in the following paragraphs.

\subsection{Startup}

Starting with a cold inerted (nitrogen or argon gas) system, trace heaters are turned on and temperatures are monitored to bring system components (except the steam generator) and piping to temperature. Auxiliary water supply pumps are turned on for feedwater supplies and cooling circuits. Tin is melted, storage and surge tanks are filled to appropriate levels. Water levels are established in the steam generator and hot wells. Referring to Figure 2, throttle valve $\equiv_{1}$ and bypass valve 非 17 are closed. Power is increased in increments to the steam generator while monitoring pressure and liquid level. If necessary, water is bled down from the bottom of the steam generator to compensate for liquid expansion. Steam is bypassed through valve $\# 17$ to the regenerators and condenser boiler. Steady operation of the feedwater and heat rejection systems is attained by manual control of pressures and water level set points, heating inputs and steam flow rates.

Throttle valve $\# 31$ is closed and throttle valve 11 is opened to pressurize the steam and tin systems of the MHD 1oops. As throttle valve \#31 is opened, the bypass valve $\#_{17}$ is closed to establish steam flow throughout the two MHD systems. Perturbations in the feedwater system are allowed to dampen out. 
To initiate operation of the first stage MHD system, tin dump tank \#1 is pressurized, and the separator is brought up to speed. Throttle valve $\|_{1}$ is partially closed to permit pressure and flow matchings in MHD channe1 \#1 as tin valve $\# 3$ is opened. Tin pump \#1 is started. Tin and steam flow together through the first stage generator. As steam pressure is reduced in stage $\|_{1}$, the flows can be matched to design. Tin is separated and repressurized in the separator/diffuser, reheated and returned to the inlet as check valve $\left.\right|_{2}$ opens automatically. Tin valve $\# 3$ is closed when the tin flow system is filled. The tin side stream will operate automatically. When the first stage has been brought to steady state operation with respect to flows and pressure levels, the MHD generator can be loaded by application of the magnetic field. This will result in changes in valve \#1 position and electric load \#1 resistance.

The second stage can be brought into operation in a manner similar to stage \#1. The components of stage 2 are identical in function to stage 1 , though pressures and flow rates are different.

\subsection{Steady State}

Trace heaters are not operated during steady state operation. In nominal steady state operation, the steam generator supplies $1 \mathrm{lbm} / \mathrm{sec}$ (3600 $\mathrm{lbm} / \mathrm{hr})$ of saturated steam at $1000 \mathrm{psia}$. This steam is superheated $10^{\circ} \mathrm{F}$ for flow measurement in a venturi meter. At steady operation of the system, throttle valve 11 will be wide open, valve $\|_{30}$ is closed, stop valve $\$ 4$ (for bleed steam regenerative heating) is open, stop valve $\# 29$ is open, valve \#42 is closed, throttle valve $\# 28$ is full 
open, valve \#31 is full open and the feedwater system valves are modulated according to the respective liquid level controls.

In steady state operation, each MHD generator is expected to produce from 25 to $100 \mathrm{KW}$ of electrical power depending upon the applied magnetic field strength and resistive load.

\section{3 Shutdown}

By shutting down the electrical heaters in the steam generator, the steaming rate will coast down according to the rate of decrease in power and the heat capacity of the steam generator assembly. The rate of coast down in pressure (and consequent saturation temperature) within the steam generator must be limited either by electrical power input and/or by throttle valve 非 setting to prevent excessive thermal shock to the bottom tube sheet. The tin flow will cease as steam flow is cut because the nozzles which accelerate the tin will cease to operate. The separators will be allowed to coast down without motor power. The tin will drain back into the respective dump tanks $\|_{1}$ and $\#_{2}$ when valves \#3 and \#14 are opened. Check valves $\# 2$ and $\# 10$ wi11 have to have sma11 bleed orifices for draining lines. Trace heaters must be used to keep the lines and vessels hot until water can be drained from the system and an inert gas purge is used to dry out the system to preclude oxide formation on internal surfaces. For long down time periods, a11 heaters can be turned off. 
$\mathrm{V}-1$

SECTION $V$

5. CASUALTY EVENTS AND RECOVERY PROCEDURES

This topic has not been addressed in the conceptual design phase. 
VI-1

SECTION VI

6. MAINTENANCE

This topic has not been addressed in the conceptual design phase. 


\section{APPENDIX INDEX}

\section{A A. REFERENCES}

A B . DRAWINGS

A C. INSTRLMENT LIST 


\section{APPENDIX A A}

\section{REFERENCES}

1. "Two Fluid MHD Cycle for Nuclear-Electric Power Conversion," by David Elliott, Jet Propulsion Laboratory, Pasadena, Ca., ARS Journal, June 1962. 

A-3

APPENDIX A B

DRAWINGS 



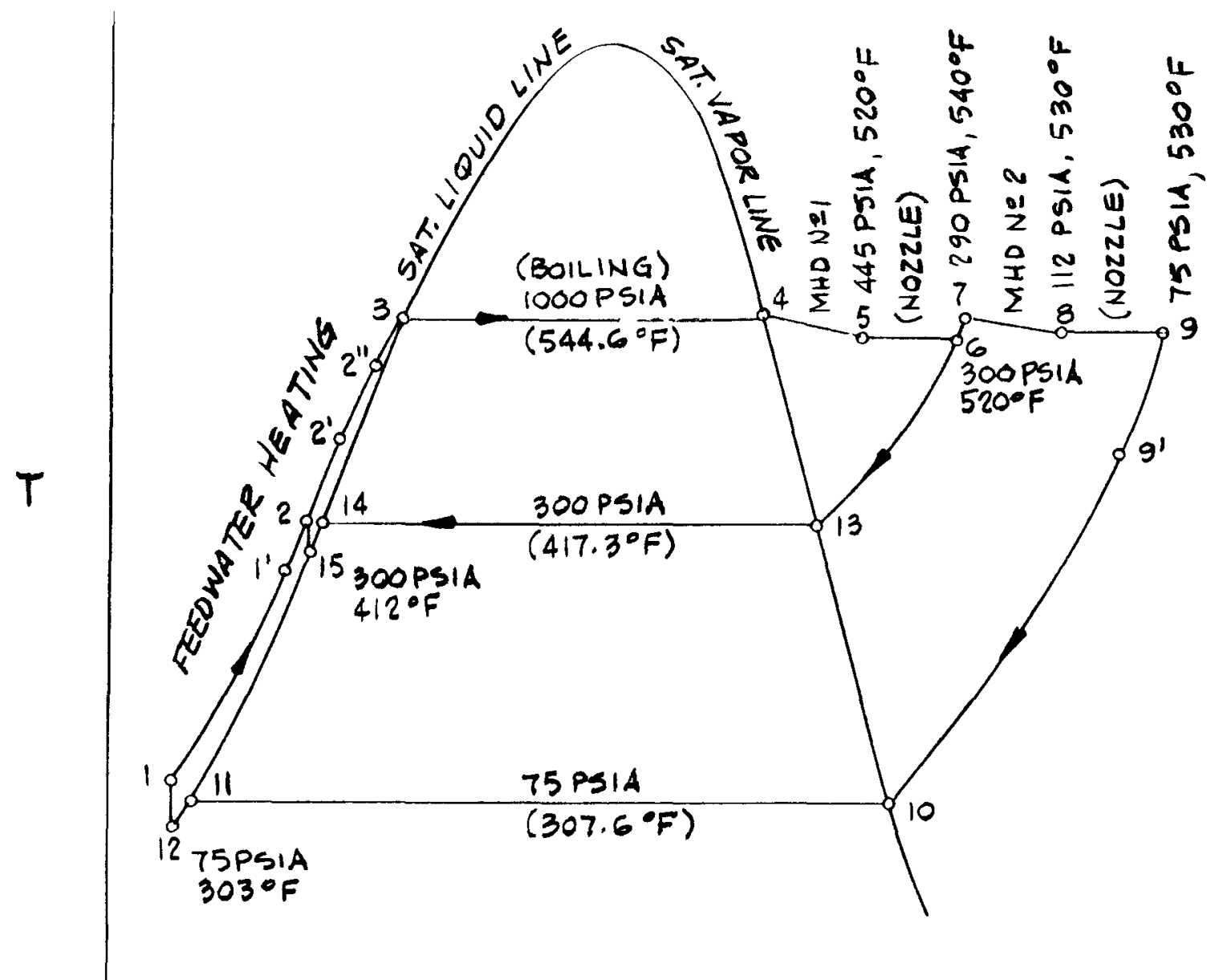

$s^{\prime}$

TWO STAGE MHD TIN/STEAM RANKINE CYCLE WITH REGENERATIVE FEEDWATER HEATING

FIGURE № 1 

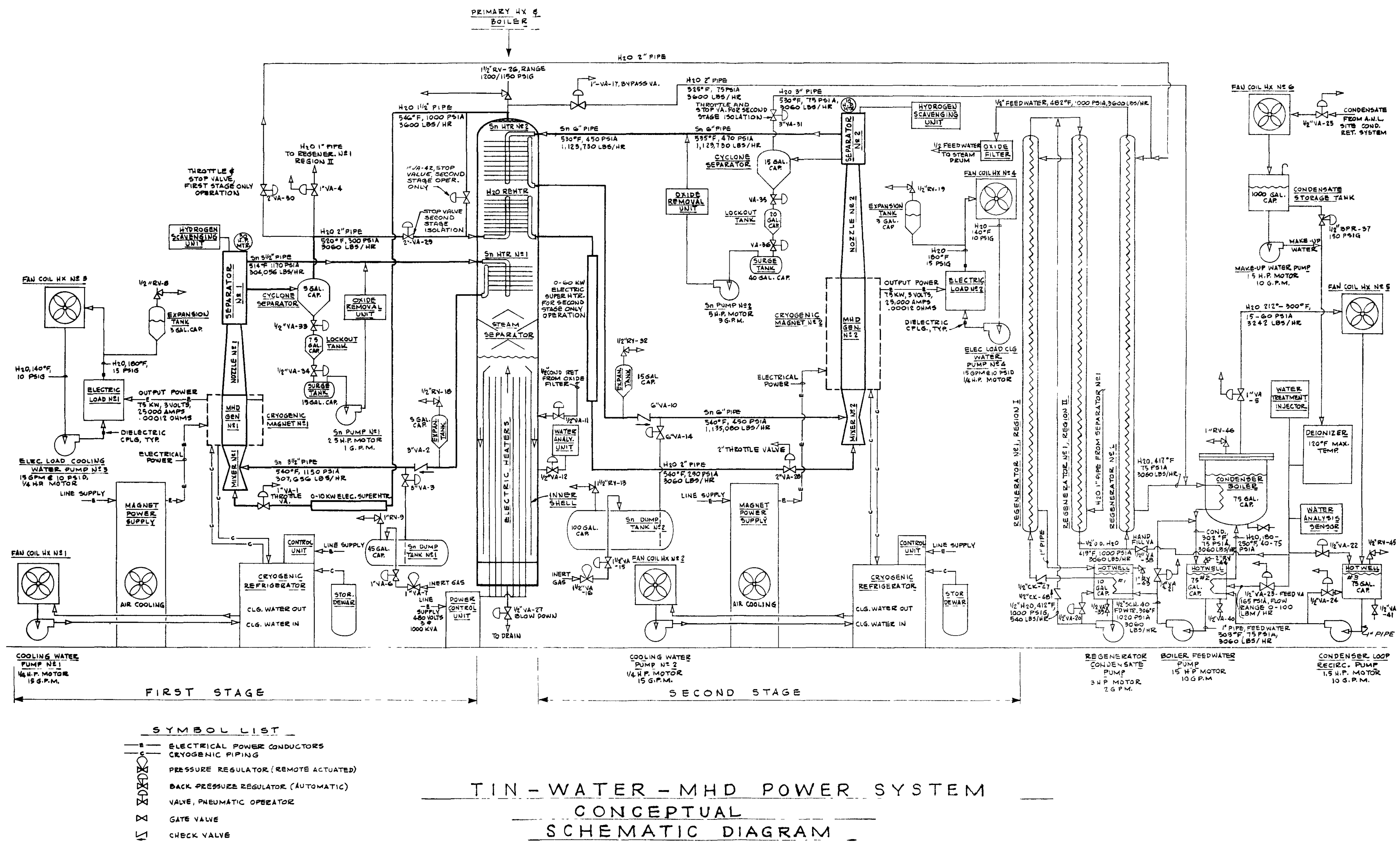

TIN - WATER - MHD POWER SYSTEM CONCEPTUAL
SCHEMATIC DIAGRAM - 


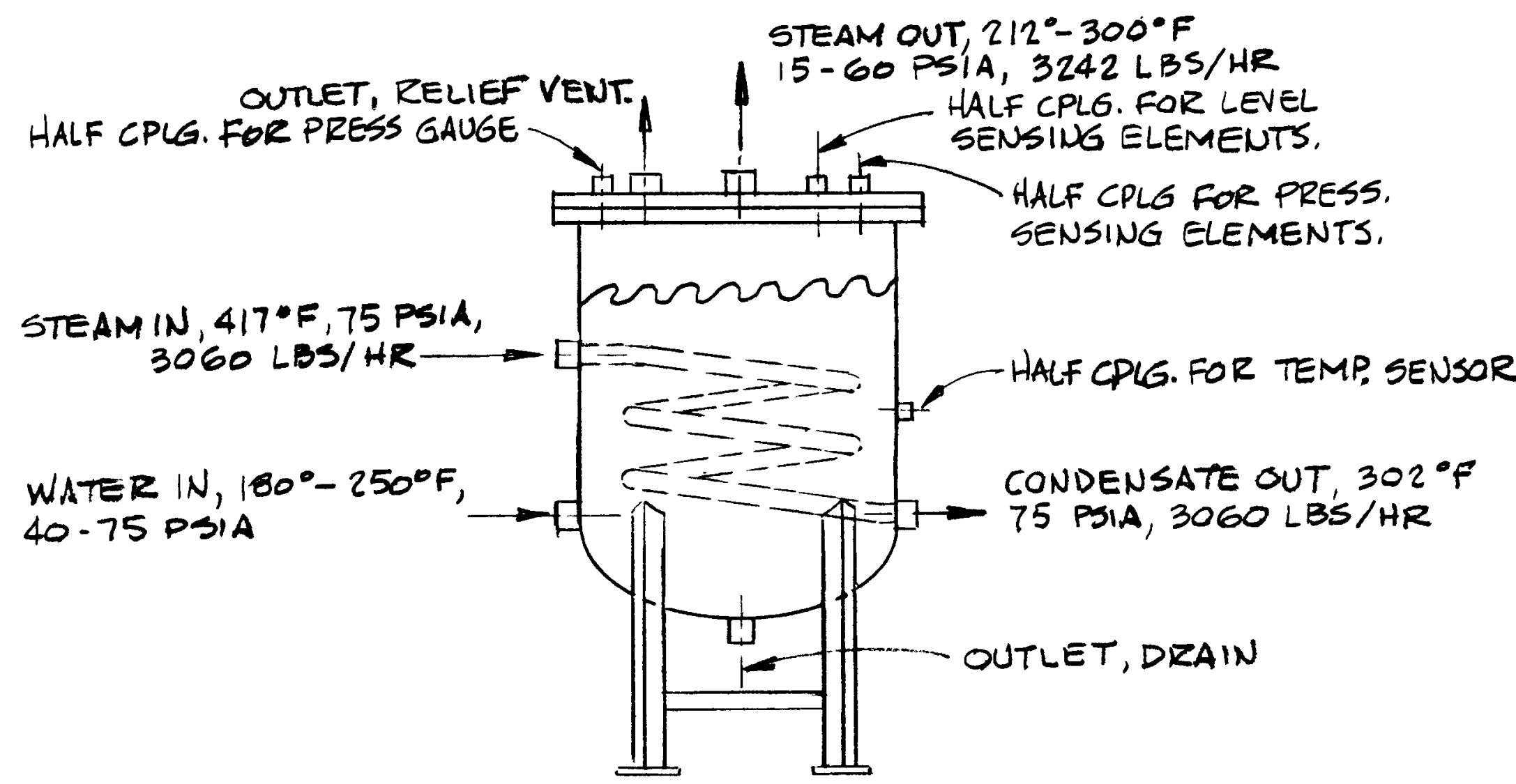

ONE, CONDENSER-BOILER

CHARACTERISTICS:

PS SHELL, 100 PSIA Q $\frac{B T U}{H R} 3,400,000$

$\triangle P$ TUBE 1200 PSIA

$\triangle P T U B E O$

AREA TUBE, 80 SQ. FT.

FIGURE NOS 


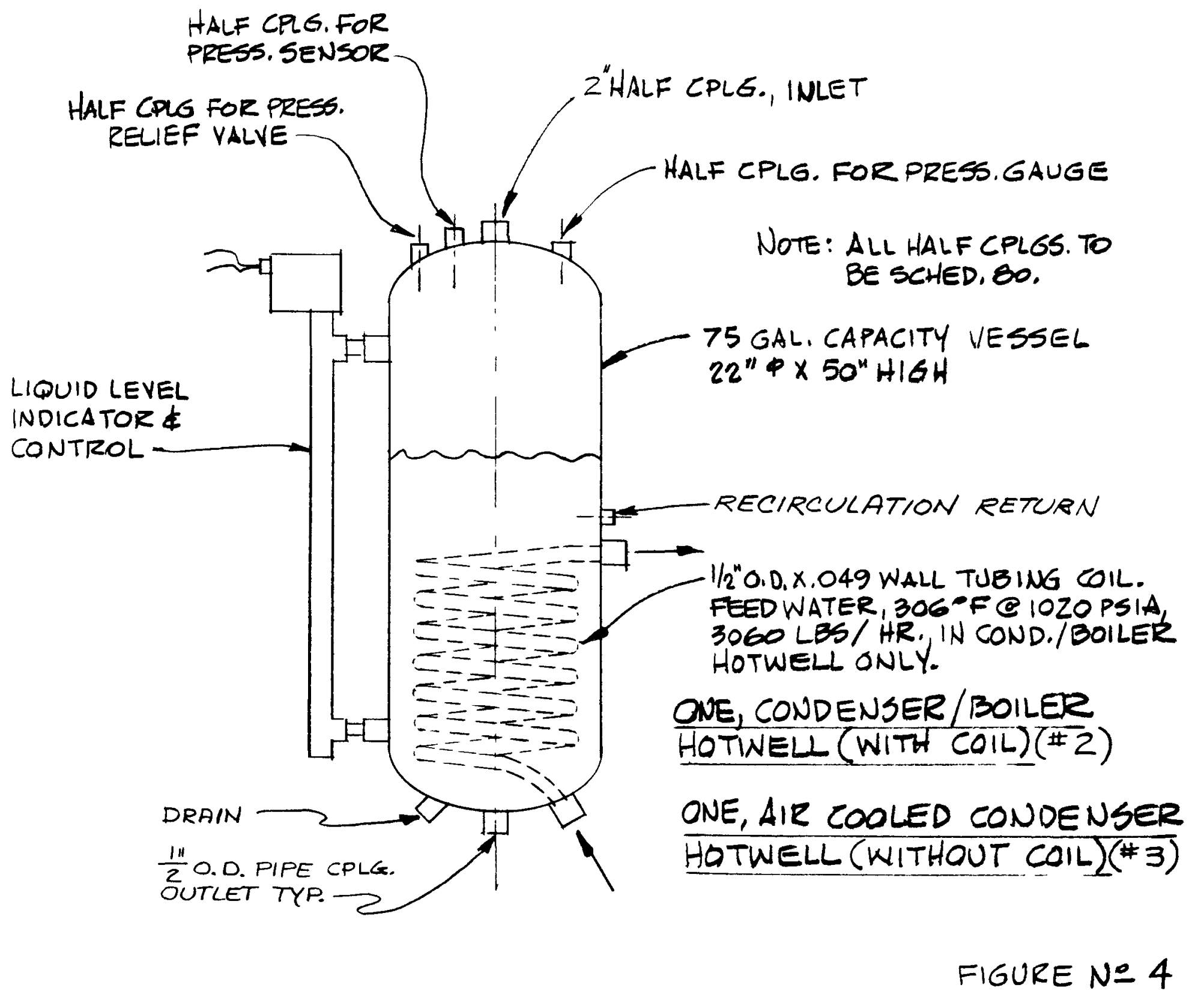


HALF CPLG. FOR PRESS. SENSOR HALF CPLG. FOK PRESS. RELIEF VALVE.

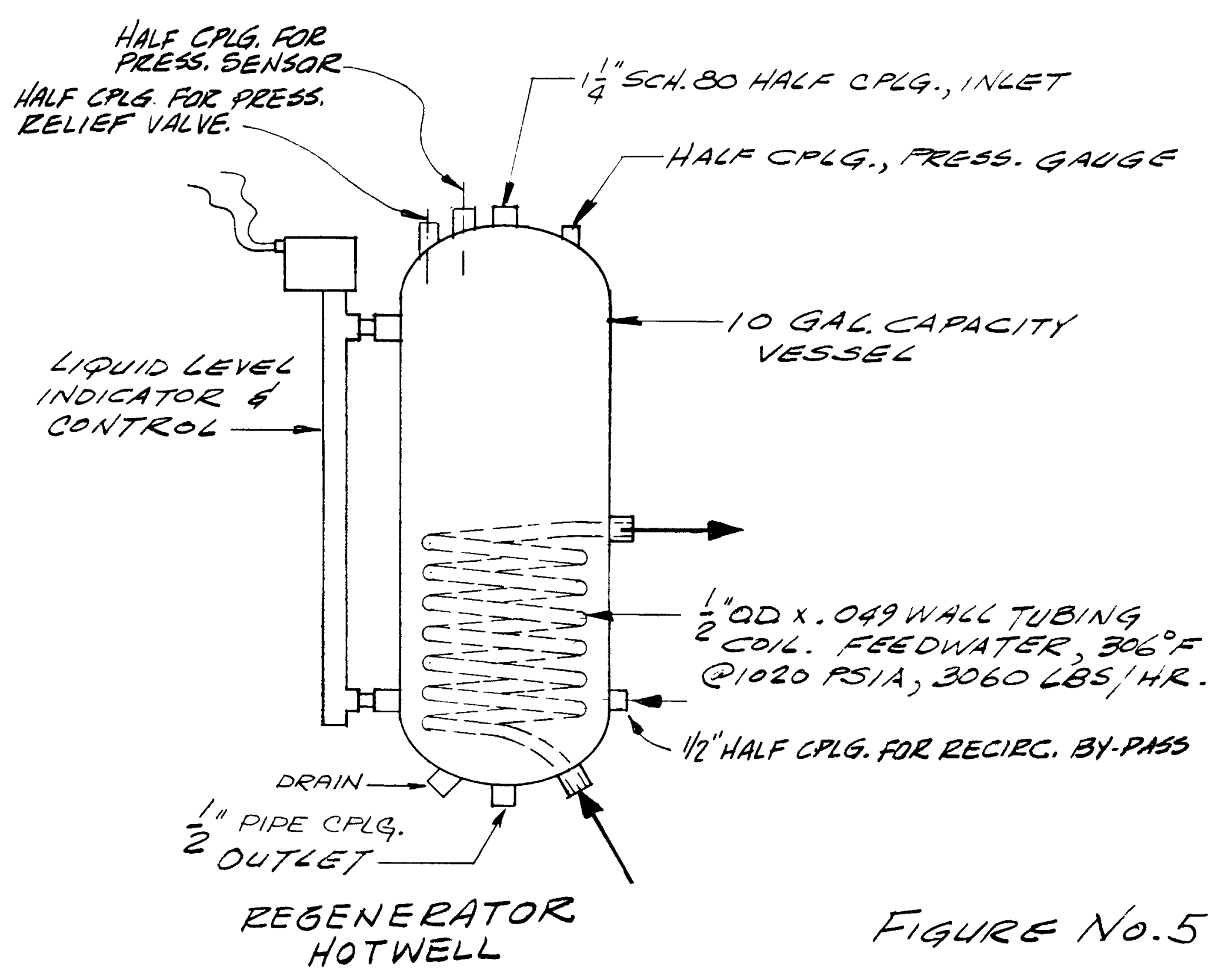



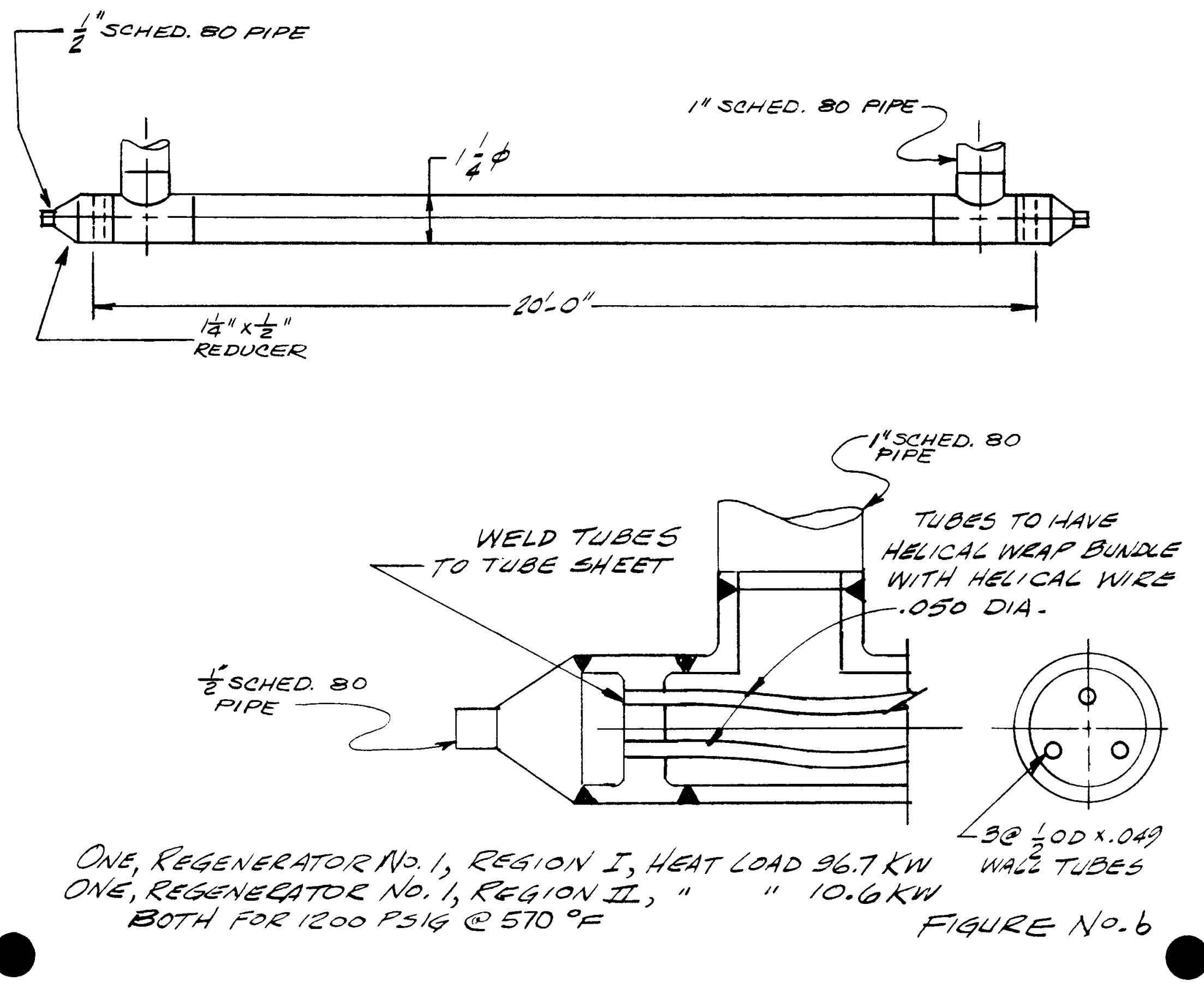

ONE, REGENERATORNO.1, REGION I, HEAT LOAD $96.7 \mathrm{KW}$ ONE, REGENERATOE NO.", PEGIONZI," "10.6KW BOTH FOR 1200 PSIG 570 OF FIGURE NO.6 

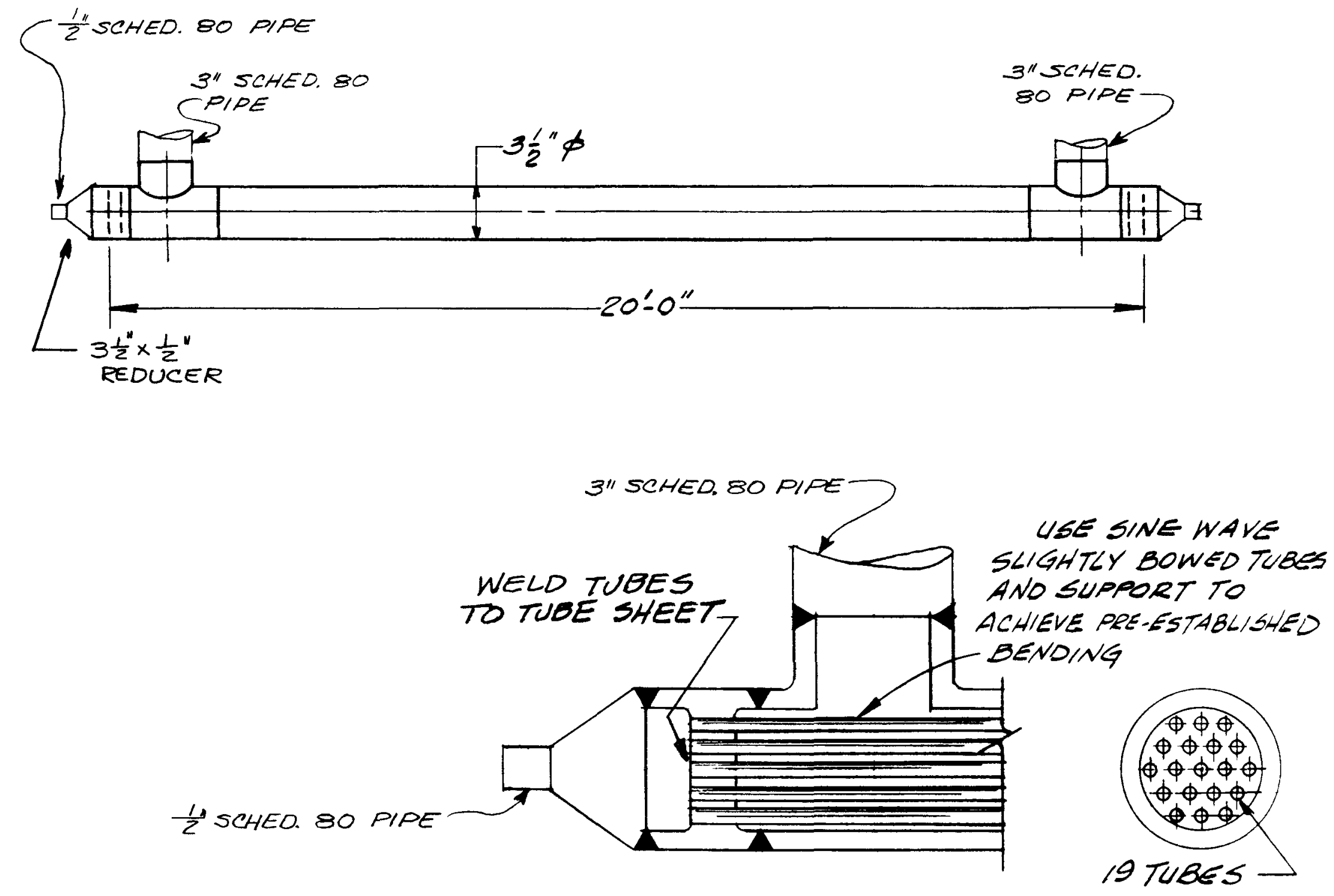

ONE, REGENERATOR No. 2 AGURE No.7 


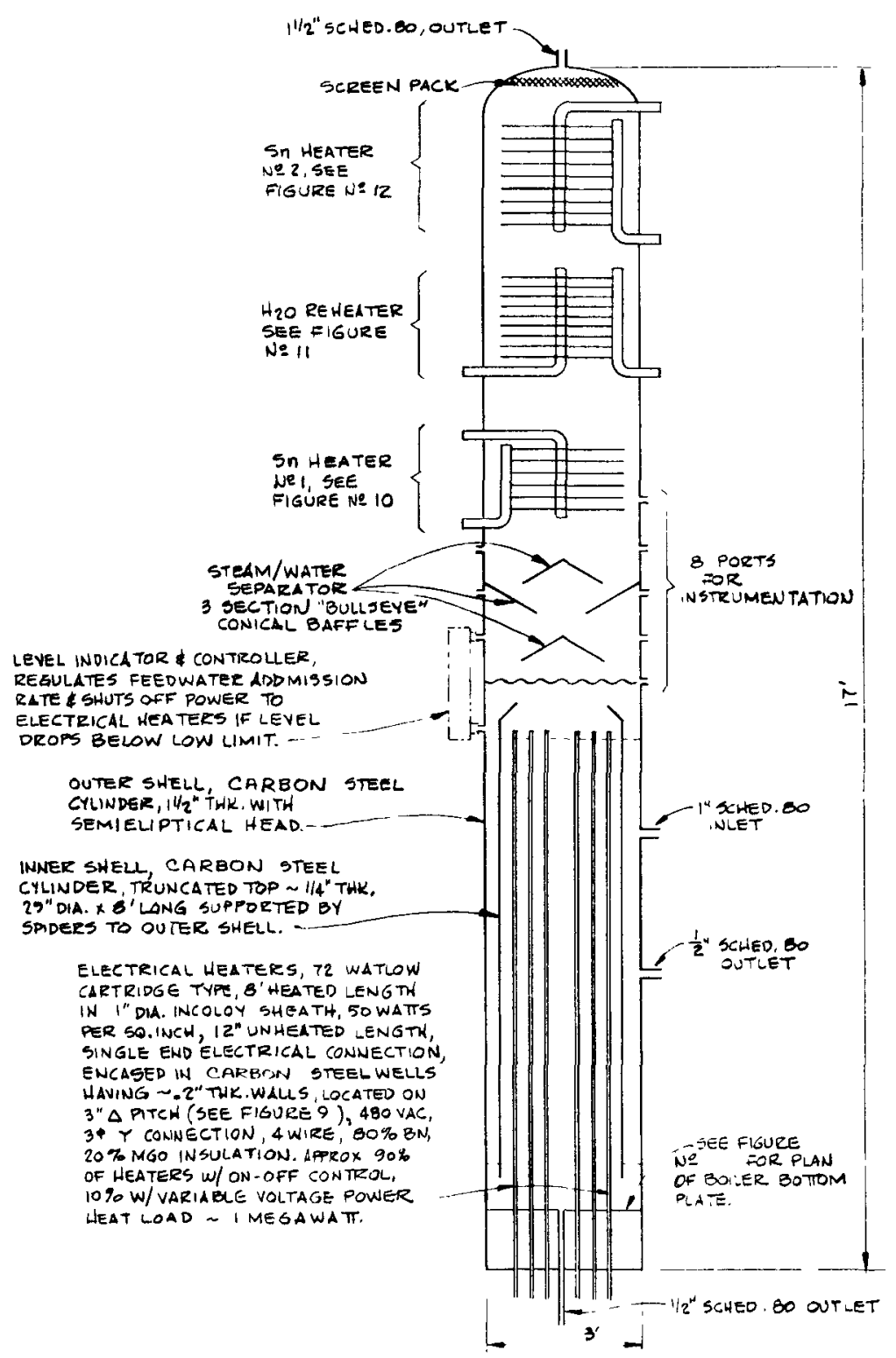
BOILER CHARACTERISTILS
$567^{\circ} \mathrm{F}, 1200$ PSIA
31 CU.FT. VOLUME
3600 LBS/HE STEAM
STEAM TET STEAM
ARST STAGE TIN HTR. 484,399 BTU/HR
SECONO " " " "
" " " "
STEAM REHEATER 35,500 BTU HR.
H.T. AREA 40 SQ.FT.
TOTAL 3,546,400 BTU/HR



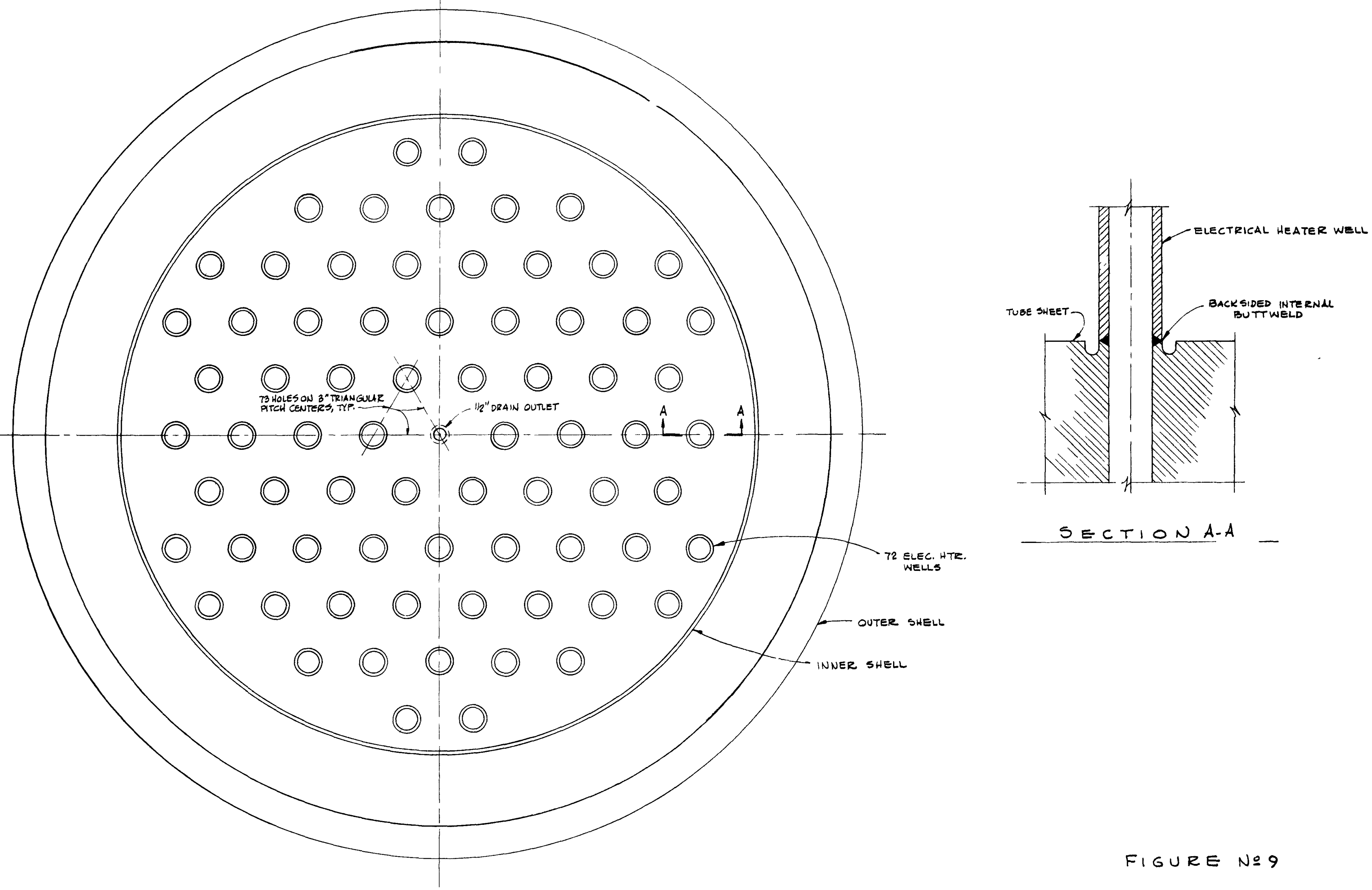


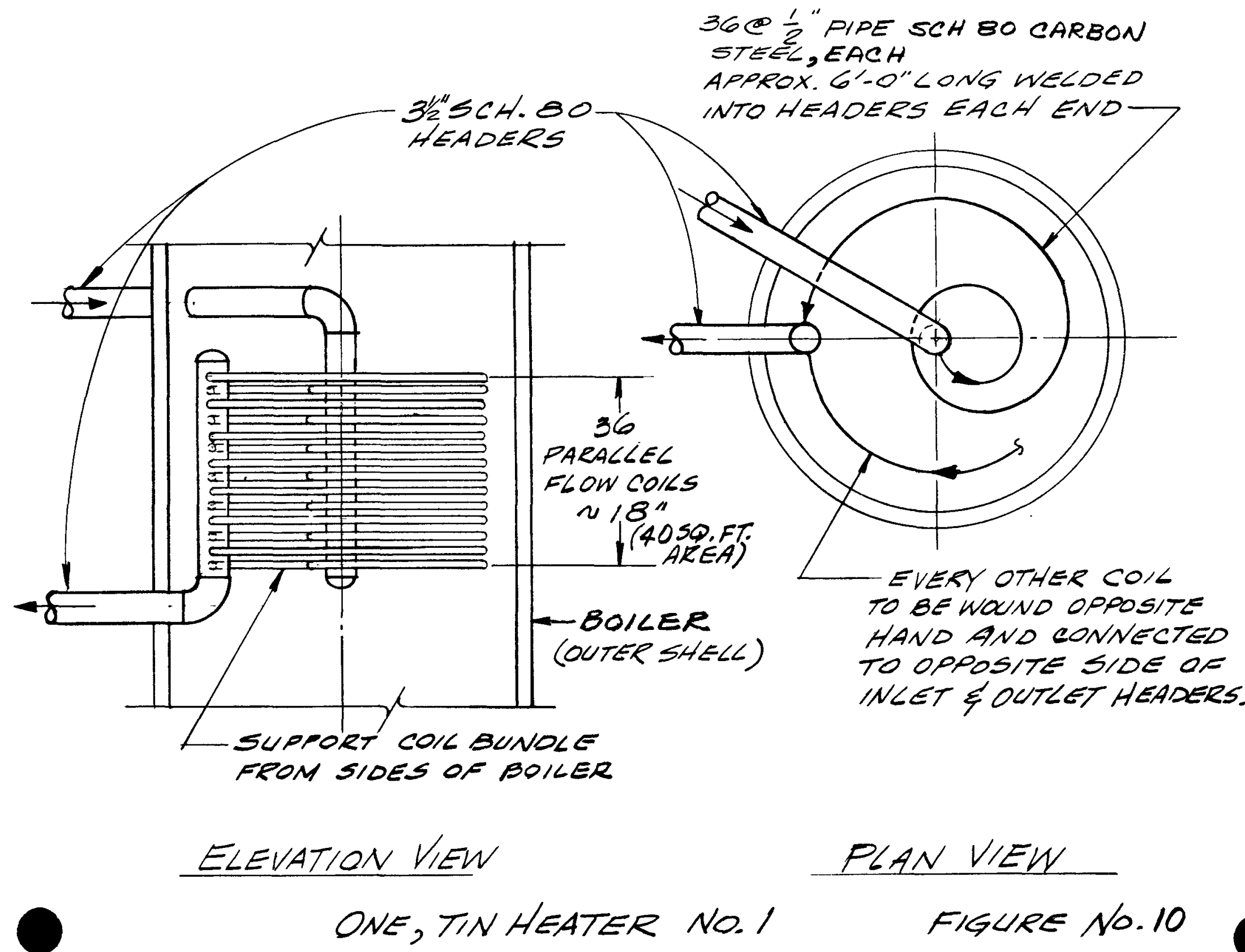




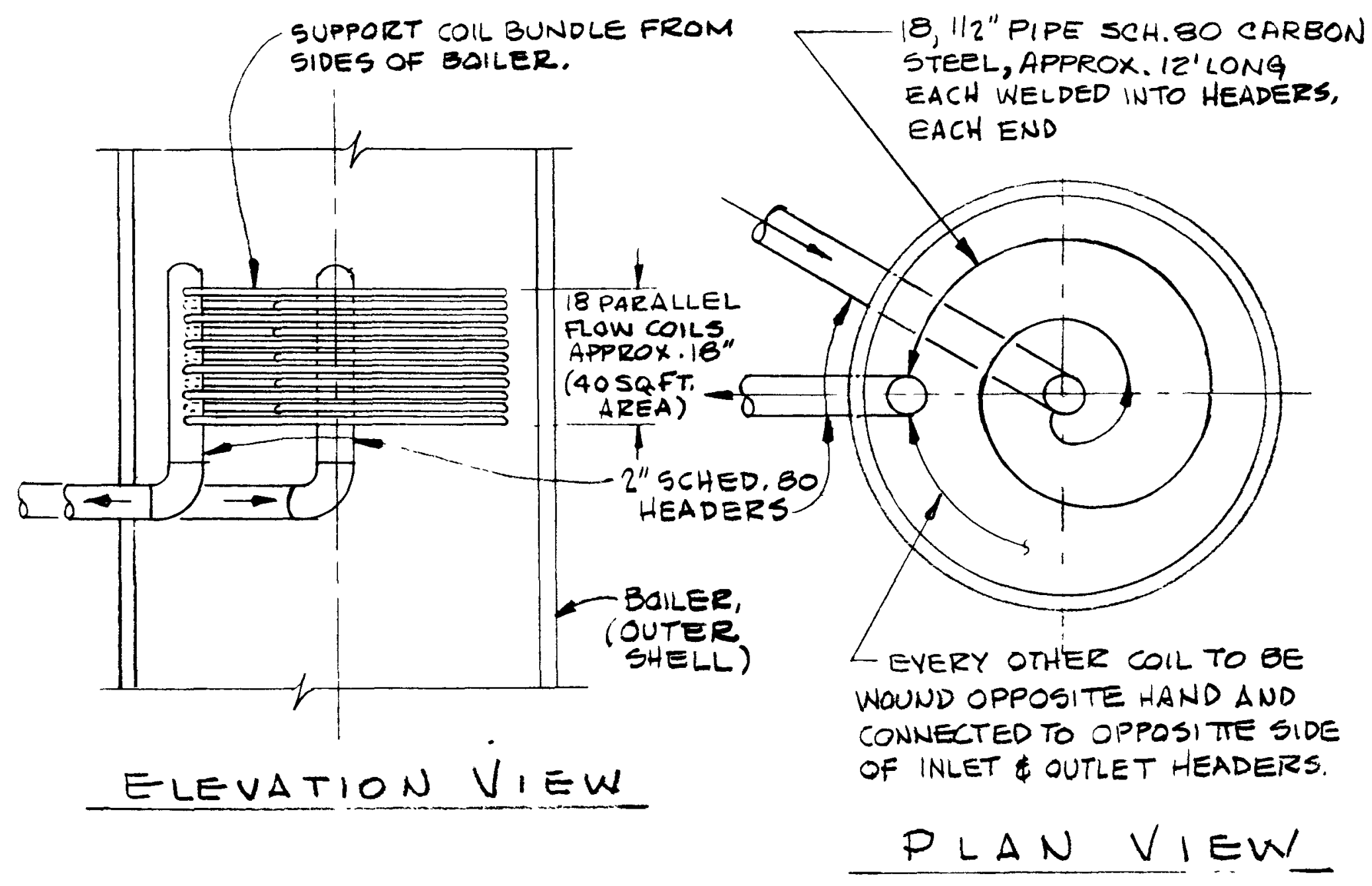

ONE, STEAM REHEATER

FIGURE NEII 


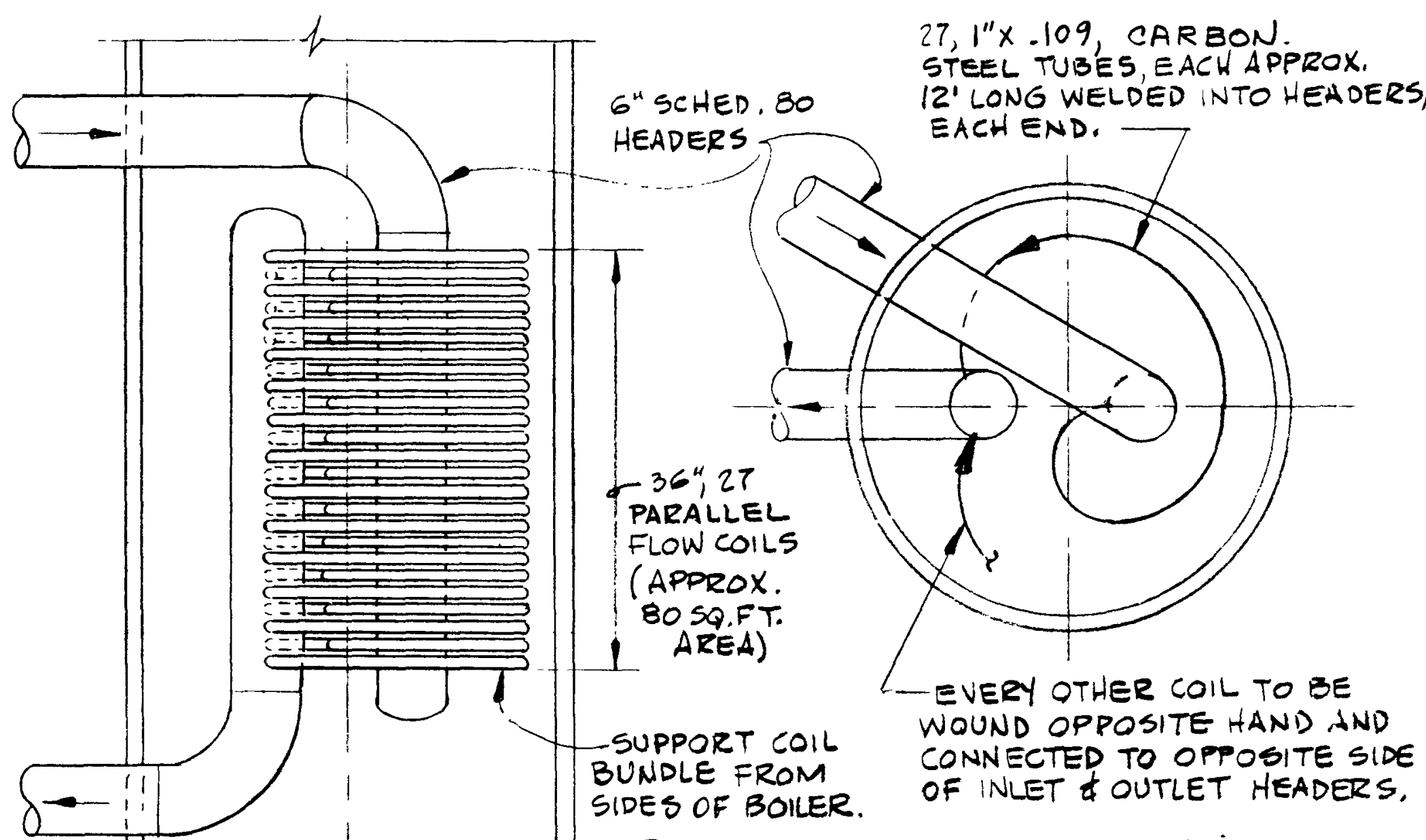

ELEVATION VIEW

ONE, TIN HEATER NO?

F) GURENOIZ 


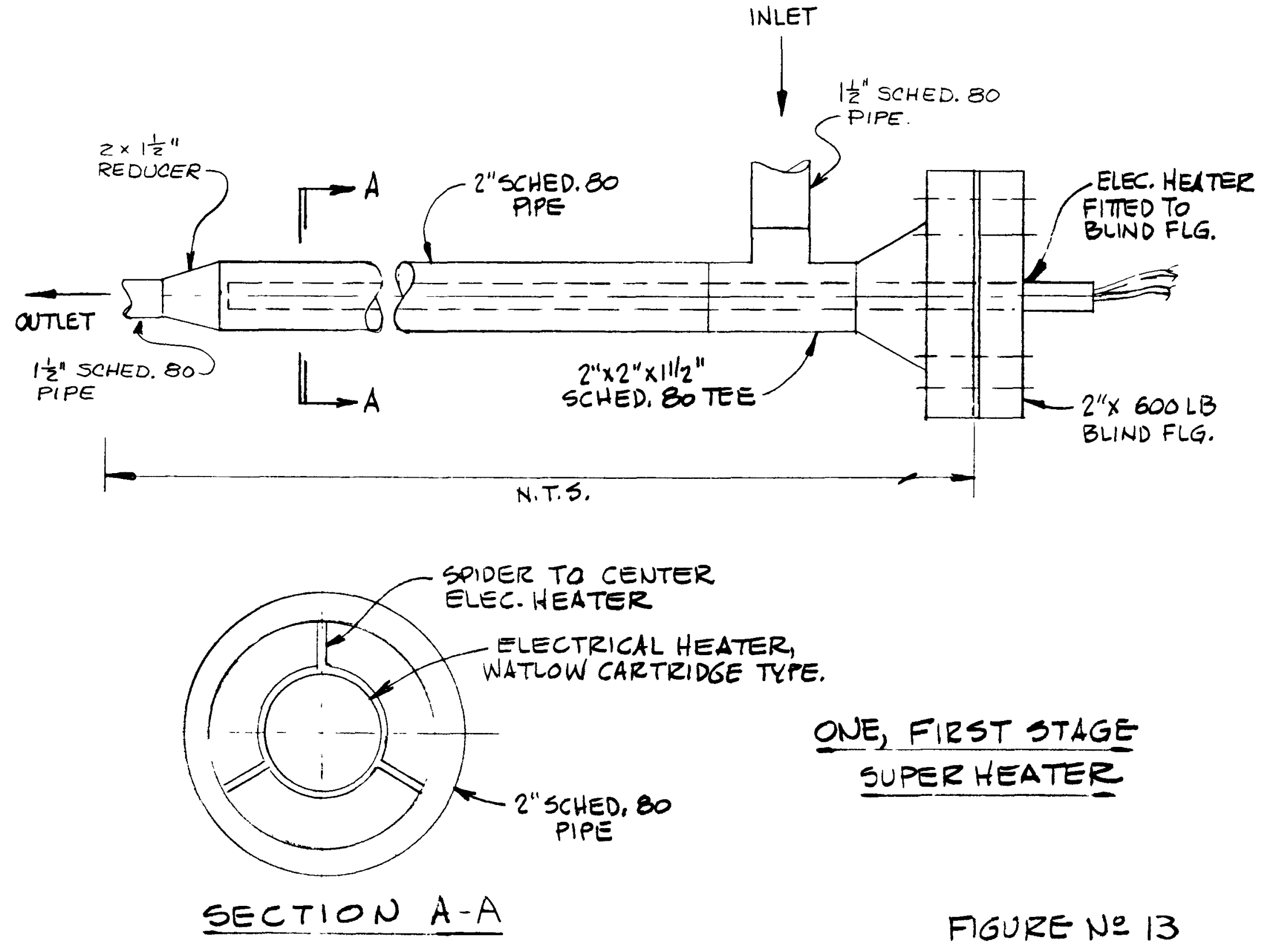




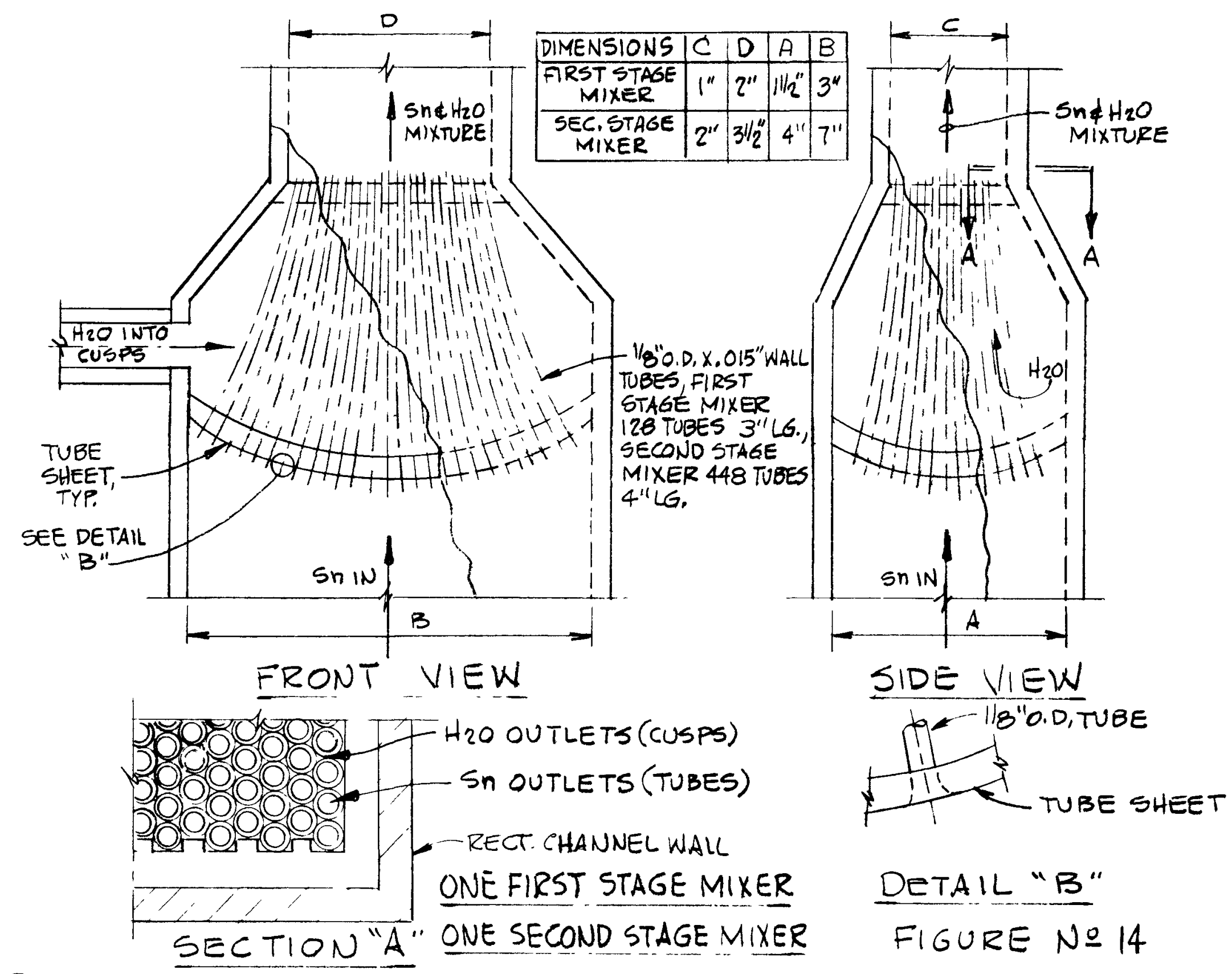


A-19

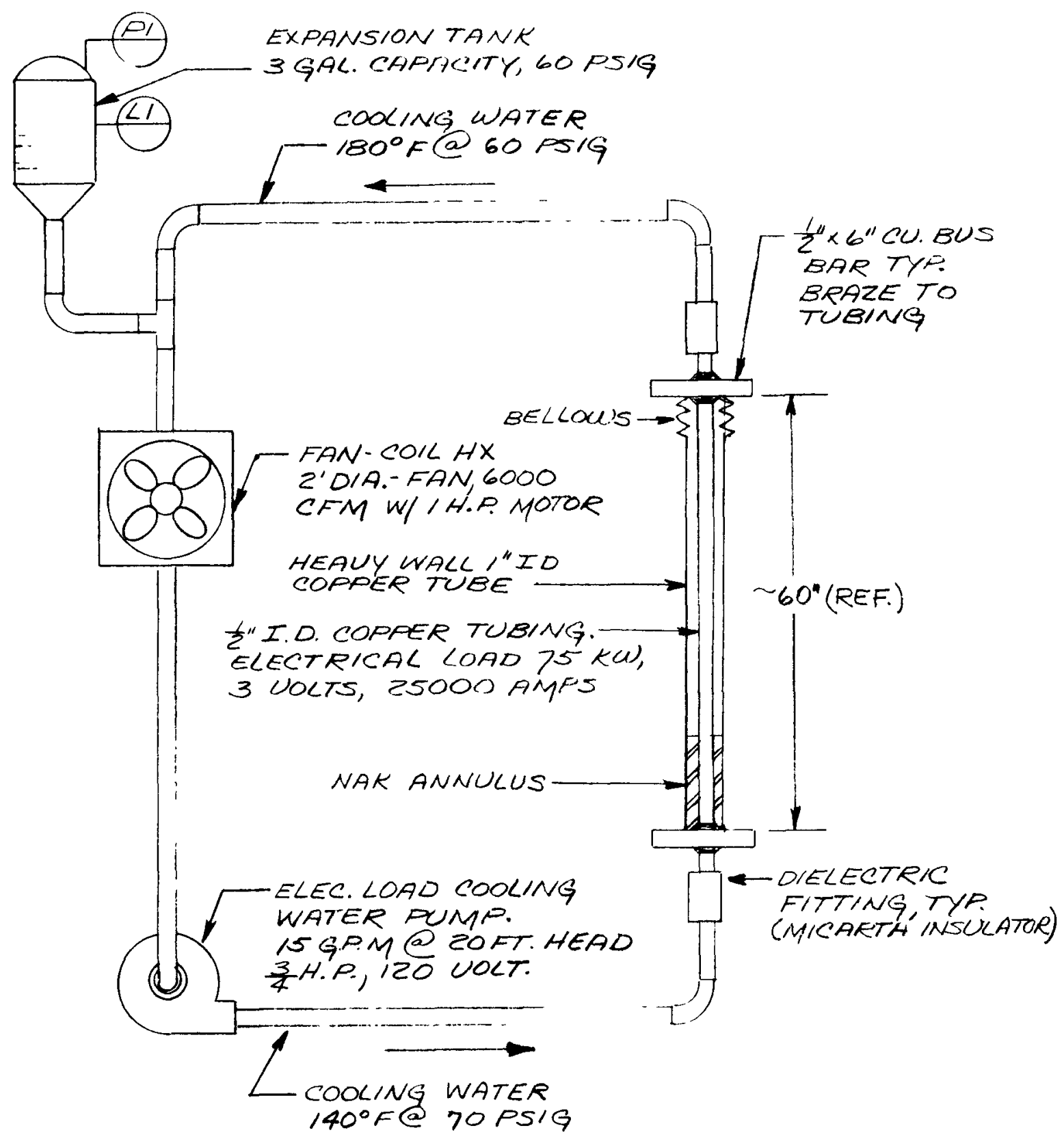

$$
\frac{\text { ELECTRICAL LOADS }}{2 \text { SYSTEMS REDO }}
$$

FIgURe No. 15 


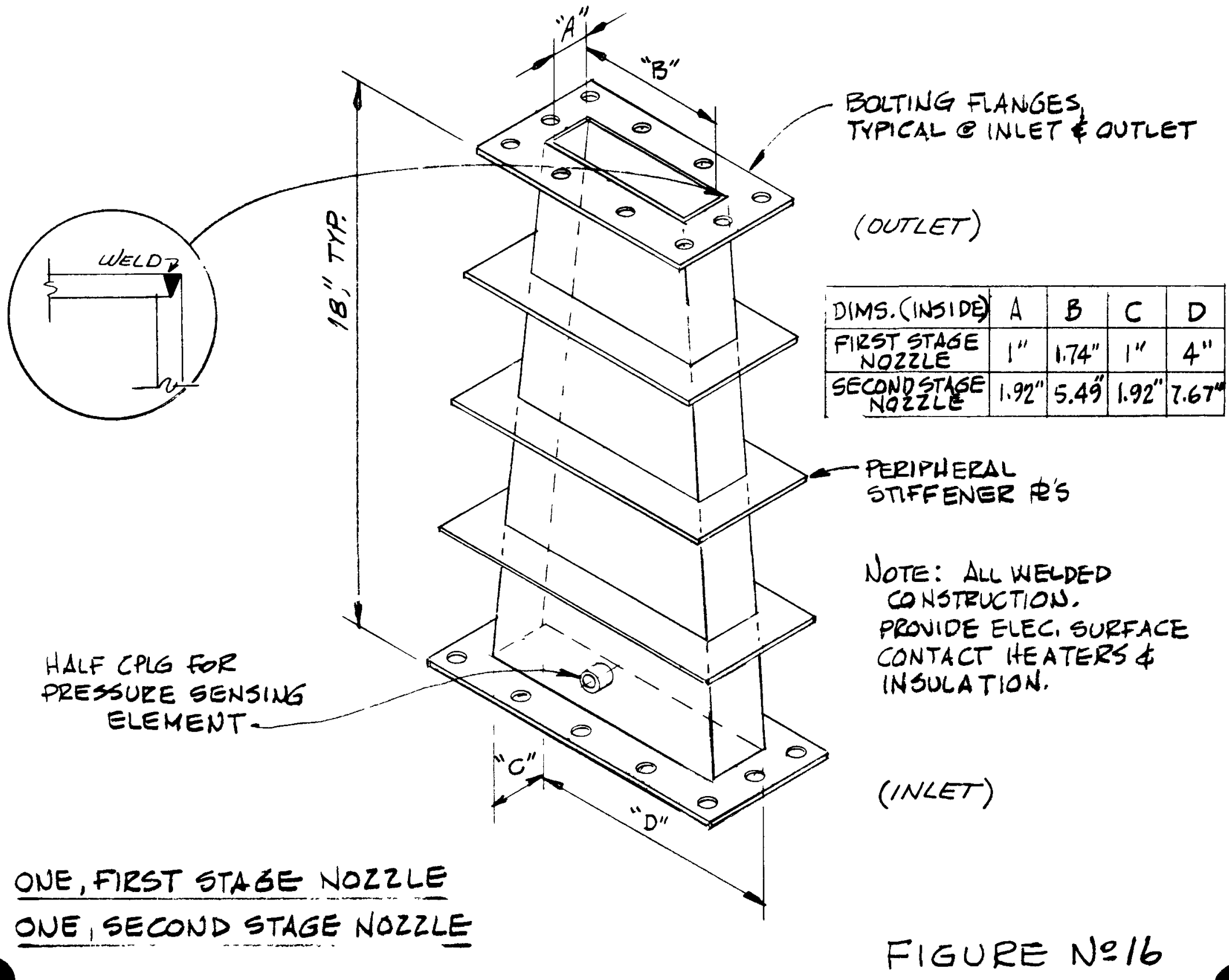




\section{CHARACTERISTICS:}

\section{FIRST STAGE,}

$\mathrm{H}_{2} \mathrm{O}-\mathrm{Sn}$ INLET, H2O-SW MIXTUEE, 445 PSIA, VOIO FRACTION 0.8 , MASS RATTO 1 H2O/85.46 $5 \mathrm{n}$, Sn e 520\% 304,056 LBS/HR, 175 FT/SEC VEL. H20 $520^{\circ} \mathrm{F}, 3600$ LBS/HR, 175 FT/SEC VEL. CROSS SECTION AREA OF FLOW $1 \frac{3}{4}$ SQ. IN. SI OUTLET, $514^{\circ}$ F, 117.0 PSIA 304056 LBS/HR Sn OUTLET, S14 F, IIT.O PSIA, 304,056 LBS/HR
5 FT. SECC.VEL., D. 432 LBM/CU.FT.

H20 OUTLET $520^{\circ} \mathrm{F}, 300$ PSIA, 3600 LBS/HR, 15OFT/SEC. VEL.

\section{SECOND STAGE}

HZO-SN INLET, H2O-SN MIXTURE, $I Z$ PSIA, VOID FRACTION 0.8 , MASS RATIO .85 HzO/315 Sn

Sn @ 530 $\mathrm{F}, 1,123,730 L B S / H R, 100 \mathrm{FT} / \mathrm{SEC}, \mathrm{VEL}$ HZO E $530^{\circ}$, 3060 LBS/HR, 100 FT./SEC. VEL. CROSS SECTION AREA OF FLOW SO. $1 \mathrm{~N}$.

Sn OUTET, 535\%, 320 PSIA, 1,123,730 LBS/HR 5FT./sEC.VEL., P: 432 LBM/CU. FT. H2O OUTLET, $530^{\circ} \mathrm{F}, 3060$ LBS/HR, 75 PSIA,
$150 \mathrm{FT} / \mathrm{SEC}$. VEL.
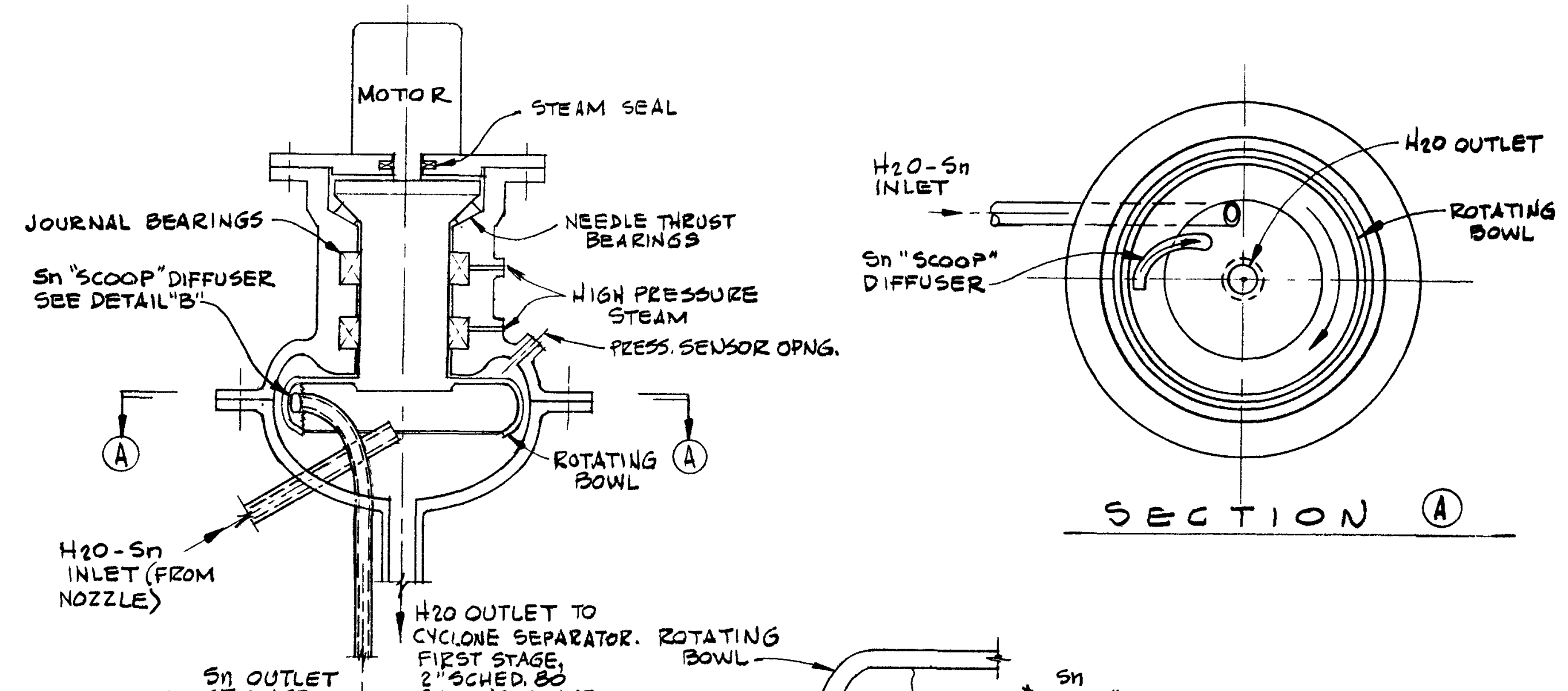

SIR OUTLET $31 / 2 "$ SCHED.80 SECONOSTAGE, SECOND STAGE

SECTION THRU SEPARATOR - DIFFUSER

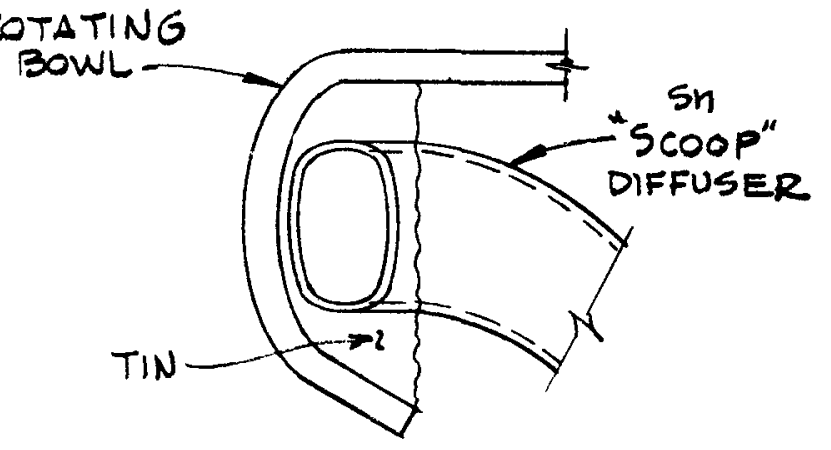

ONE SEPARATOR-DIFFUSER FIRST STAGE,

ONE, SEPARATOR-DIFFUSER, SECOND STAGE 
$81: N \quad \exists \quad 091 \exists$

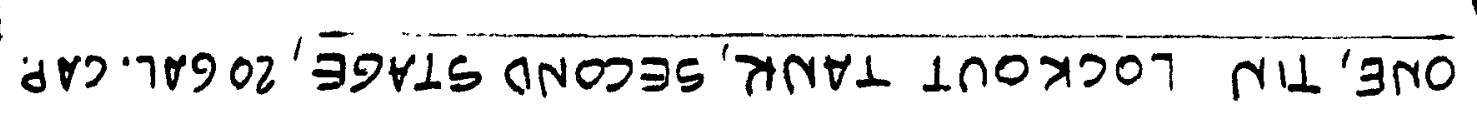

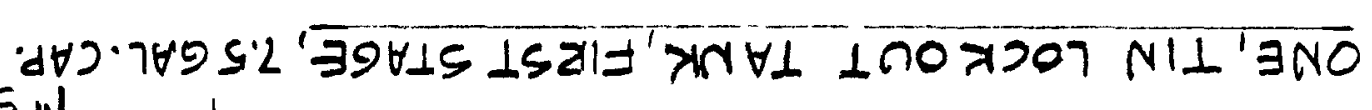

(2 36015$) \perp \exists 21008 \cdot 03 H 125$ in 1

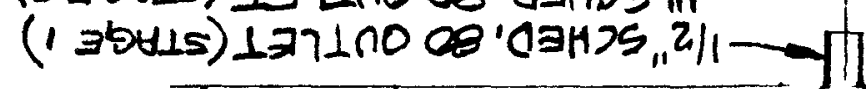

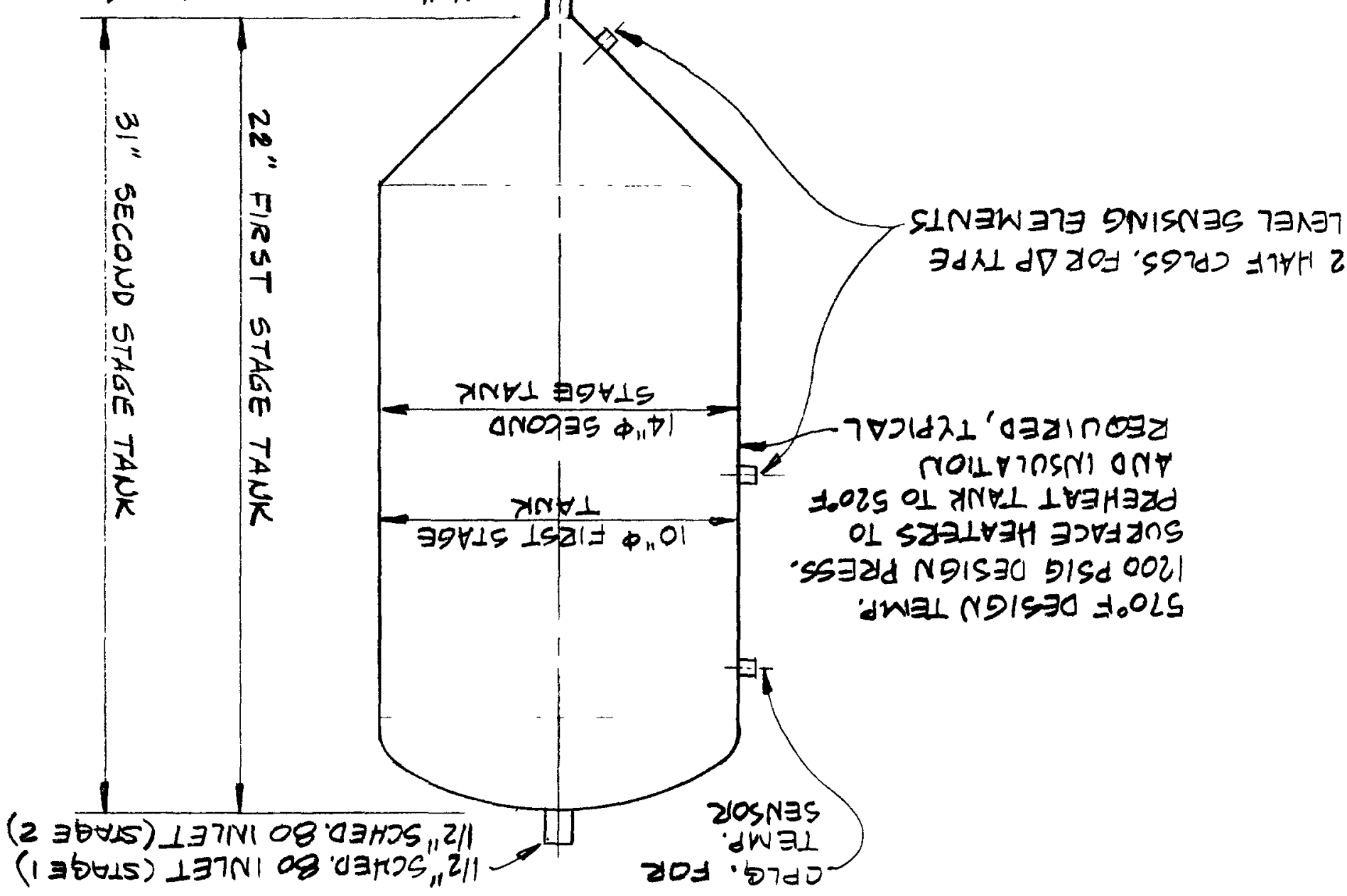




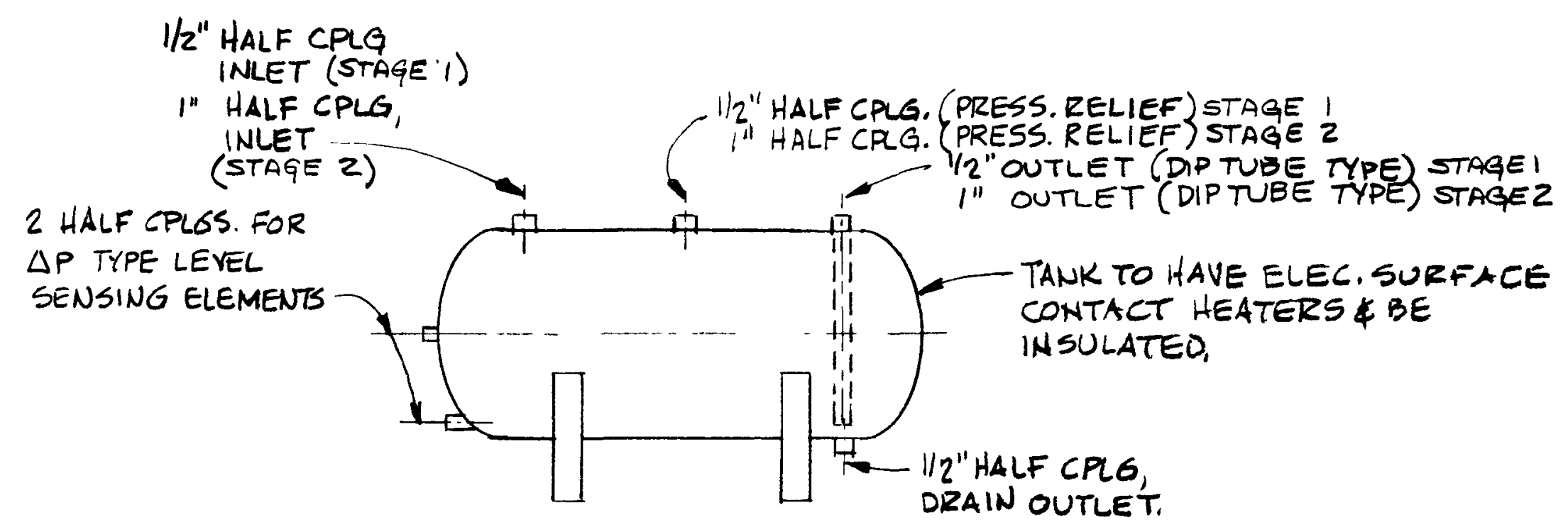

CHARACTERISTICS:

FIRST STAGE TANK;

15 GAL CAPACITY

1200 PSIG DESIGN PRESS.

300 PSIG NOM. OPER. PRESS.

DESIGN TEMP. $570^{\circ} \mathrm{F}$

NOM. OPER, TEMP. $520^{\circ} \mathrm{F}$

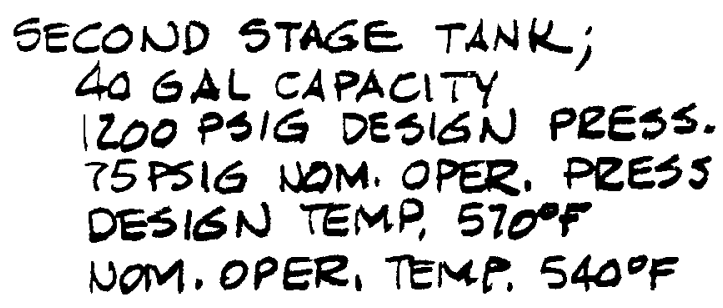

ONE, FIRST STAGE, TIN SURGE TANK ONE, SECOND STAGE, TIN SURGE TANIL 


\section{Oz -}

ThNA Nolsh

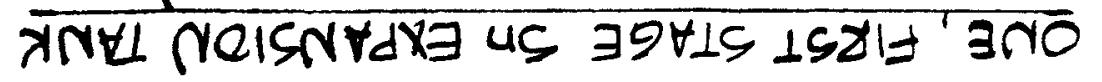

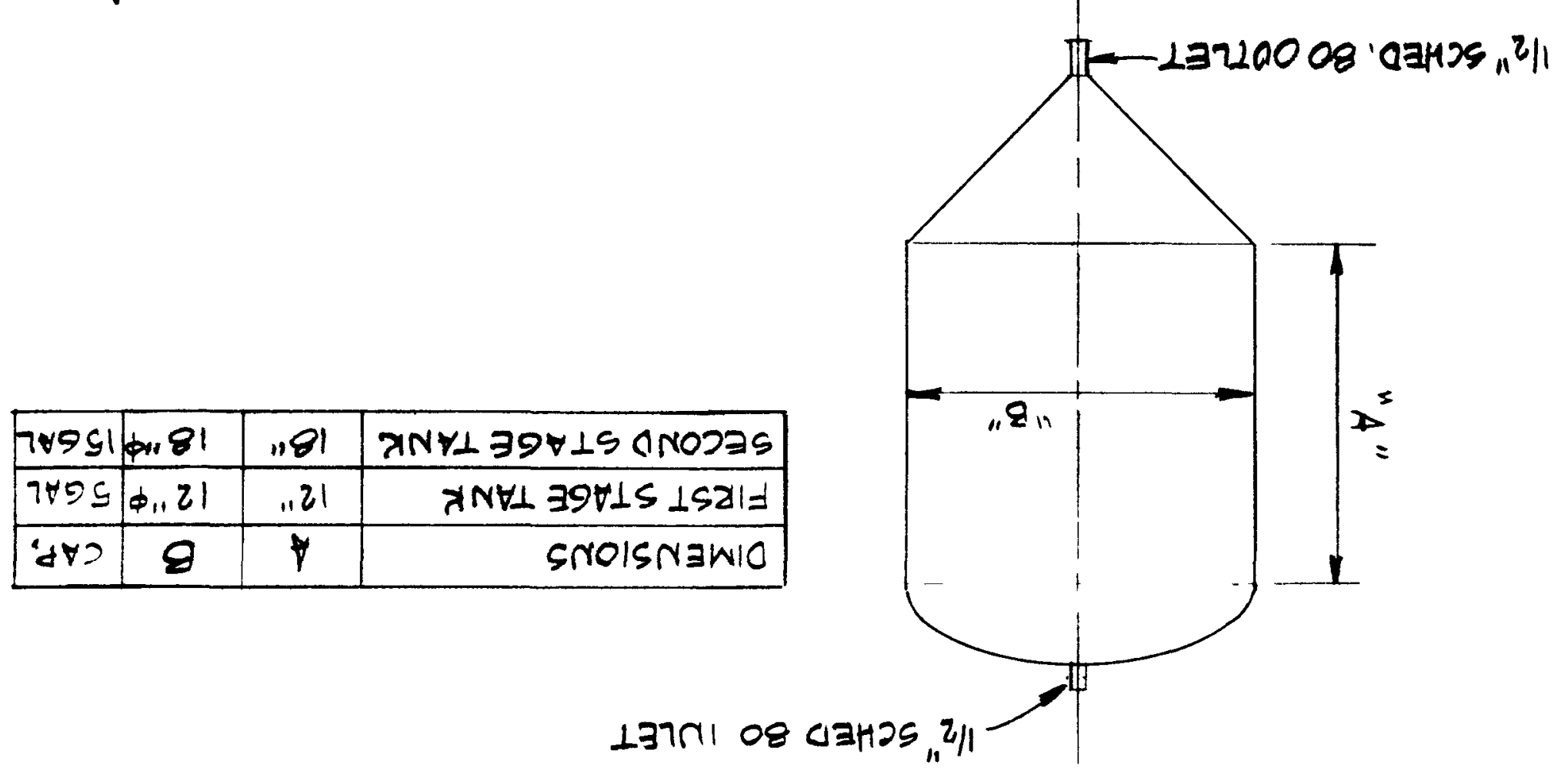


CHARACTERISTICS

FIRST STAGE TANK:

45 GAL. VOLUME, $4 \mathrm{~kW}$ HEATING REQ'D.
SECOND STAGE TANK

100 GALONVOLUME, $8 \mathrm{KW}$

HEATING REQ'D.

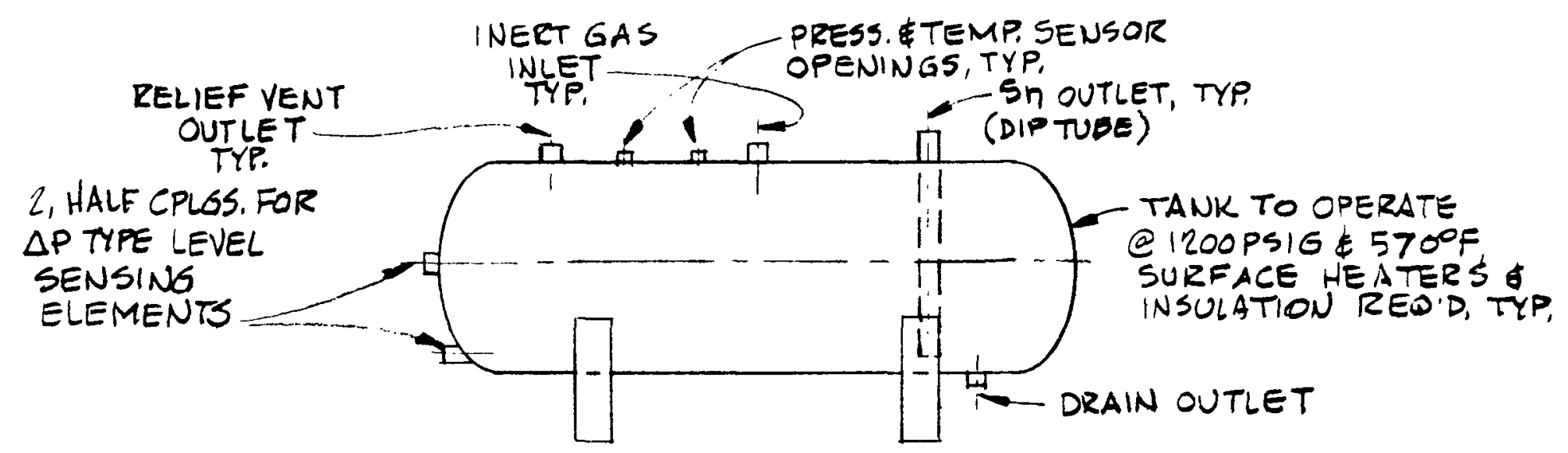

ONE, FIRST STAGE TIN DUMP TANK

ONE, SE GOND STAGE TIN DUMP TANK

FIGURE NO LI 


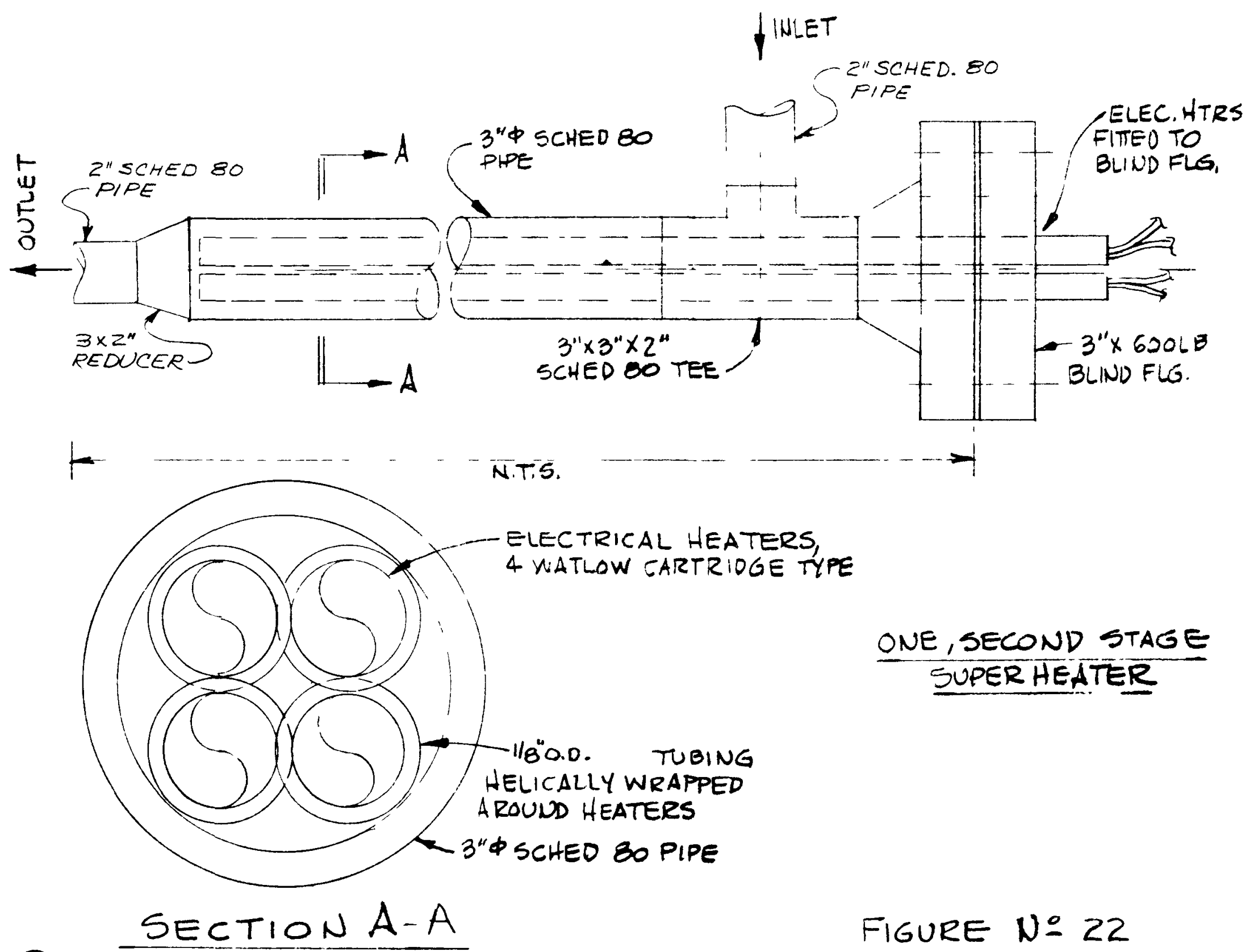




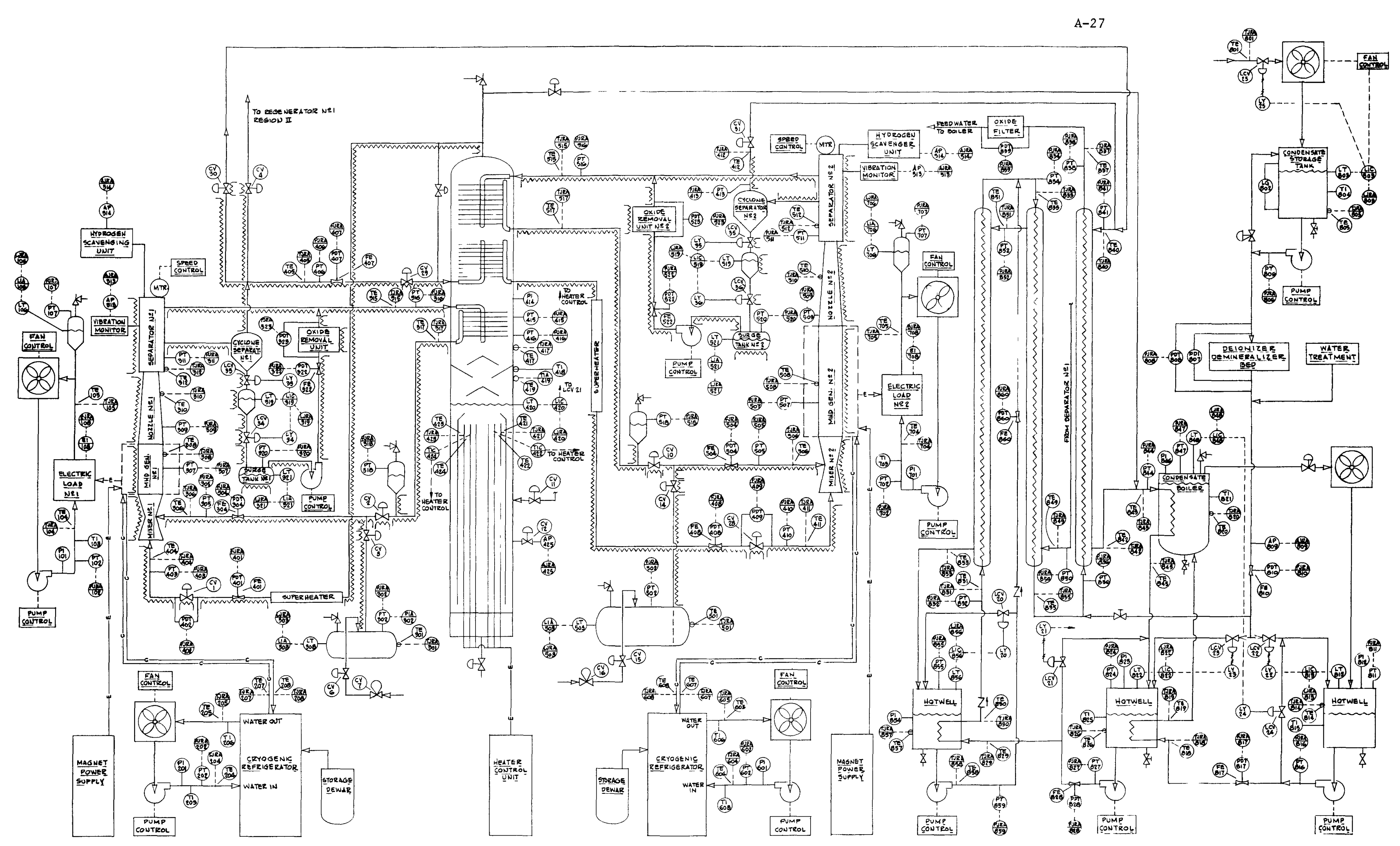

Nores:

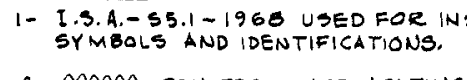

TIN-WATER MHD POWER SYSTEM -

2- Mam denotes trace heating.

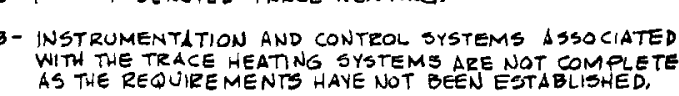
CONCEPTUAL P\&1 DIAGRAM - 

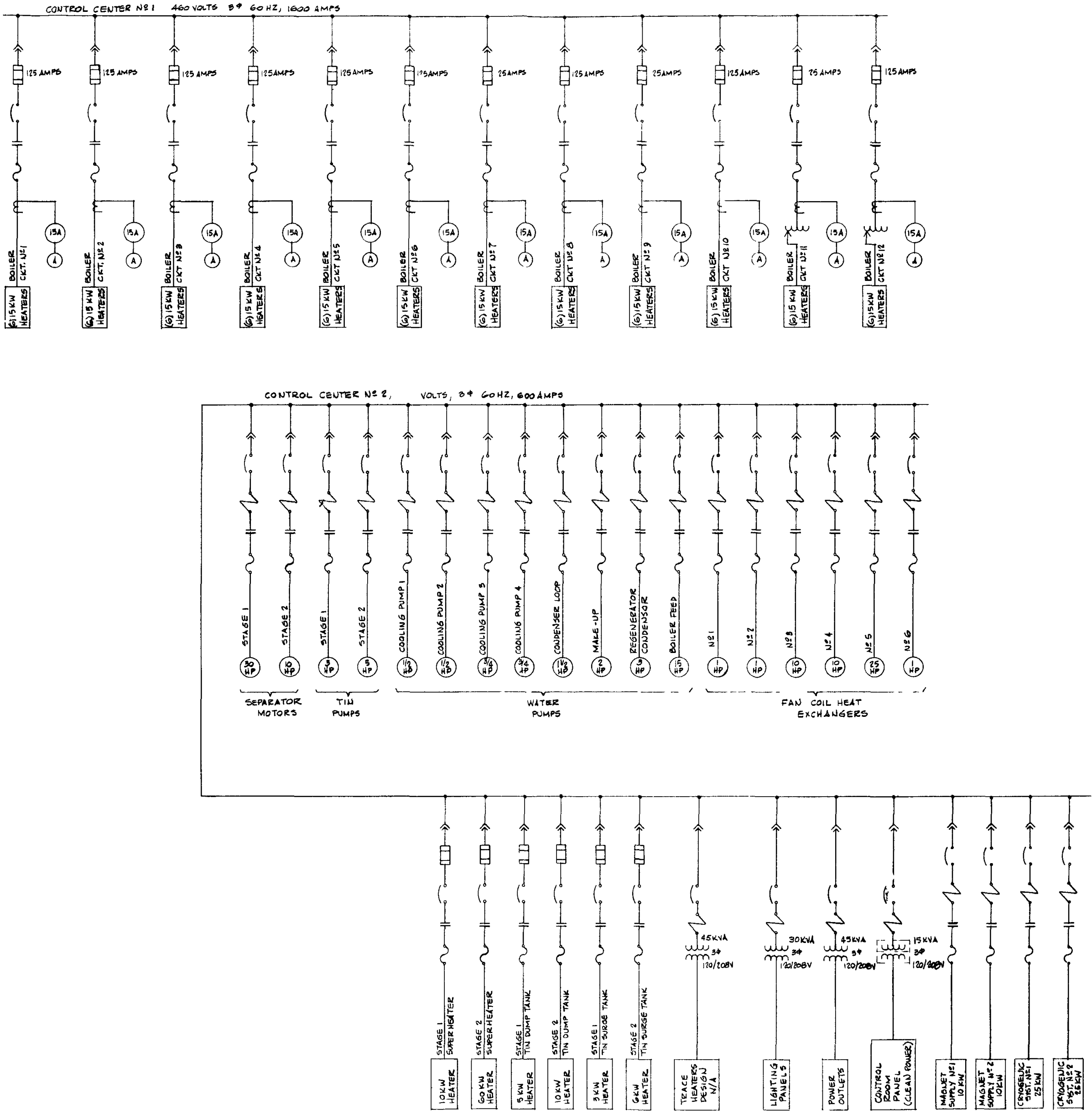
A-29

APPENDIX $A C$

INSTRUMENT LIST 
Sensing

Element

P1-101

PT-102

T1-103

$\mathrm{TE}-104$

TE-105

LT-106

PT-107

EI-108

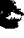

P1-201

PT-202

T1-203

TE-204

$\mathrm{TE}-205$

T1-206

TE-207
Type

Bourdon Pressure Gage

Strain Gage Pressure

Transducer

Dial Thermometer

Thermocouple (Type K)

Surface Mount

Thermocouple (Type K) $\quad 40-200^{\circ} \mathrm{F}$

Surface Mount

Capacitance Type Probe

0-20 inches

0-30 psig

train Gage Pressure

Transducer

Voltmeter

Bourdon Pressure Gage

Strain Gage

Dial Thermometer

Thermocouple (K)

Surface Mount

Thermocouple (K)

Surface Mount

Dial Thermometer

hermocouple (T)

urface Mount

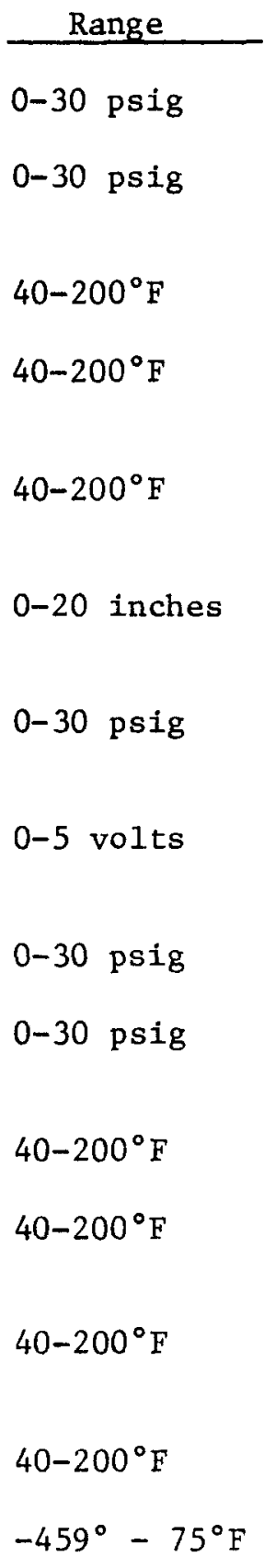

Accuracy

$3 \%$

$1 \%$

$3 \%$

$1 \%$

$1 \%$

$3 \%$

$1 \%$

$1 \%$

$3 \%$

$1 \%$

$3 \%$

$1 \%$

$1 \%$

$3 \%$

$1 \%$
Function

Indicate pressure.

Indicate pressure and alarm.

Indicate temperature.

Indicate temperature and alarm.

Indicate temperature and alarm.

Indicate level and alarm.

Indicate pressure.

Indicate voltage.

Indicate pressure.

Indicate pressure and alarm.

Indicate temperature.

Indicate temperature and alarm.

Indicate temperature and alarm.

Indicate temperature.

Indicate temperature and alarm.
Where

Indicated

Local

CRT Terminal

Local

CRT Terminal

CRT Terminal

CRT Terminal \& control panel

CRT Terminal

CRT Termina1 \& control panel

Local

CRT Termina1

Local

CRT Terminal

CRT Terminal

Loca1

CRT Termi 
Sensing

Element

TE-208

TE-301

PT-302

LT-303

FE-304

PT -305

PT-307

TE-308

PT-309

TE-310

PT -311

$\mathrm{TE}-312$
Type

Thermocouple (T)

Surface Mount

Thermocouple (K) (Thermowe11)

Force-Balance

(Tantalum Diaphragm)

Force-Balance

Diff. Pressure

Transducer

Flow Tube

Force-Balance

(Tantalum Diaphragm)

Thermocouple (K)

Surface Mount

Force-Balance

(Tantalum Diaphragm)

The rmocouple (K)

(Thermowe11)

Force-Balance

(Tantalum Diaphragm)

The rmocouple (K)

(Thermowe11)

Force-Balance

(Tantalum Diaphragm)

Thermocouple (K)

(Thermowe11)
Range

$-459^{\circ}-75^{\circ} \mathrm{F}$

$40^{\circ}-600^{\circ} \mathrm{F}$

0-1200 psia

0-30 inches

$0-100 \mathrm{lbs} / \mathrm{sec}$

(tin)

0-1200 psia

$40^{\circ}-600^{\circ} \mathrm{F}$

0-1200 psia

$40^{\circ}-600^{\circ} \mathrm{F}$

0-1200 psia

$40^{\circ}-600^{\circ} \mathrm{F}$

0-1200 psia

$40^{\circ}-600^{\circ} \mathrm{F}$

$1 / 2 \%$
Function

where

Indicated

CRT Terminal

Indicate temperature and alarm.

Indicate temperature and alarm.

Indicate pressure and alarm.

Indicate level and alarm.

CRT Terminal \& control panel.

Indicate flow and alarm.

CRT Terminal

Indicate pressure and alarm.

Indicate temperature and alarm.

Indicate pressure and alarm.

Indicate temperature and alarm.

Indicate pressure and alarm.

Indicate temperature and alarm.

Indicate pressure and alarm.

Indicate temperature and alarm.

CRT Termina1

CRT Terminal

CRT Terminal

CRT Terminal

CRT Terminal

CRT Terminal

CRT Terminal

CRT Terminal 
Indicate amount of vibration and alarm.

Indicate amount of hydrogen liberated and alarm.

$\begin{array}{ll}\text { TE-315 } & \text { Thermocouple (K) } \\ \text { (Surface Mount) }\end{array}$

PT-316

Force-Balance (Tantalum Diaphragm)

TE-317 Thermocoup1e (K) (Surface Mount)

PT-318

Force-Balance (Tantalum Diaphragm)

LT-319

PT -320

LT -321

PDT-323

\section{Force-Balance}

Transducer

Force-Balance (Tantalum Diaphragm)

Force-Balance Diff. Pressure

Transducer

Force Balance
(Diff. Pressure

Flow Tube $40^{\circ}-600^{\circ} \mathrm{F}$

0-1200 psia

$40^{\circ}-600^{\circ} \mathrm{F}$

0-1200 psia

0-20 inches

0-1200 psia

0-20 inches

$0-51 \mathrm{bs} / \mathrm{sec}$

(Tin)

$0-50$ psia
$1 / 2 \%$

$1 \%$

$1 / 2 \%$

$1 \%$

$3 \%$

$1 \%$

$3 \%$

$3 \%$

$1 \%$
Indicate temperature and alarm.

Indicate pressure and alarm.

Indicate temperature and alarm.

Indicate pressure and a1arm.

Indicate level and control valves 33 and 34 .

Indicate pressure and a1arm.

Indicate level and alarm.

Indicate flow.

Indicate Diff. pressure and alarm.
Where

Indicated

CRT Terminal \& control panel

CRT Terminal \& control panel

CRT Terminal

CRT Terminal

CRT Terminal

CRT Terminal

CRT Terminal \& control panel

CRT Terminal

CRT Terminal \& control panel

CRT Terminal

CRT Terminal

NOTE: All 300 series pressure sensors, level sensors, and flow sensors are exposed to tin. Tin is very corrosive to sta ss steels and inconel, which more sensors use as their interface medium. Tantalum appears to be an acc able substitute. 
Flow Tube.

Strain Gage Pressure

Transducer

TE-404

The rmocouple (K)

Surface Mount

TE-405

The rmocouple (K)

Surface Mount

PT-406

Strain Gage Pressure

Transducer

FE-407

FE-408

Flow Tube

Flow Tube

PDT-409

PT -410

$\mathrm{TE}-411$

$\mathrm{TE}-412$

PT -413
Strain Gage Diff.

Pressure Transducer

Strain Gage Pressure Transducer

Thermocouple (K)

Surface Mount

Thermocouple (K)

Surface Mount

Strain Gage Pressure

Transducer

Range

$0-2 \mathrm{lbs} / \mathrm{sec}$

(Steam)

0-500 psia

0-1200 psia

Accuracy

$3 \%$

$1 \%$

$1 \%$

$40^{\circ}-600^{\circ} \mathrm{F}$

$40^{\circ}-600^{\circ} \mathrm{F}$

0-1200 psia

$1 \%$

$0-2 \mathrm{lbs} / \mathrm{sec}$

(Steam)

$0-2 \mathrm{lbs} / \mathrm{sec}$

(Steam)

0-500 psia

0-1200 psia

$40^{\circ}-600^{\circ} \mathrm{F}$

$40^{\circ}-600^{\circ} \mathrm{F}$

0-1200 psia

$1 / 2 \%$

$1 \%$
Function

Indicate mass flow of steam and alarm.

Indicate diff. pressure and alarm.

Indicate pressure and alann.

Indicate temperature and alarm.

Indicate temperature and alarm.

Indicate pressure and alarm.

Indicate mass flow of steam and alarm.

Indicate mass flow of steam and alarm.

Indicate diff. pressure and alarm.

Indicate pressure and alarm.

Indicate temperature and alarm.

Indicate temperature and alarm.

Indicate pressure and
Where

Indicated

CRT Terminal

CRT Terminal

CRT Terminal

CRT Terminal

CRT Terminal

CRT Terminal

CRT Terminal

CRT Termina1

CRT Terminal

CRT Terminal

CRT Terminal alarm.

CRT Terminal

CRT Terminal 


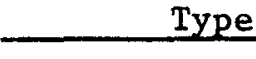

Thermocouple (K) (Thermowe11)

Force-Balance

Force-Balance Diff. Pressure Transducer

Flow Tube

Force-Balance

Surface Mount

Force-Balance

Thermocouple (K)

Thermowe11

Force-Balance

Thermocouple (K)

The rmowe11

Force-Balance

Vibration Monitor
Thermocouple (K)

\section{Range}

$40^{\circ}-600^{\circ} \mathrm{F}$

0-600 psia

0-30 inches

$0-500 \mathrm{lbs} / \mathrm{sec}$

(Tin)

0-600 psia

$40^{\circ}-600^{\circ} \mathrm{F}$

0-600 psia

$40^{\circ}-600^{\circ} \mathrm{F}$

$1 / 2 \%$

0-600 psia

$40^{\circ}-600^{\circ} \mathrm{F}$

0-600 psia

$40^{\circ}-600^{\circ} \mathrm{F}$

$1 / 2 \%$
$3 \%$

$1 \%$

$1 / 2 \%$

$1 \%$

$1 \%$

\section{$1 / 2 \%$}

$1 \%$

$\%$

$\%$

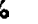

(1)

\section{Function}

Indicate temperature and alarm.

Indicate pressure and alarm.

Indicate level and alarm.

Indicate flow and alarm.

Indicate pressure and alarm.

Indicate temperature and alarm.

Indicate pressure and alarm.

Indicate temperature and alarm.

Indicate pressure and alarm.

Indicate temperature and alarm.

Indicate pressure and alarm.

Indicate temperature and alarm.

Indicate amount of vibration and alarm.
Where

Indicated

CRT Termina1

CRT Terminal

CRT Terminal \& control panel

CRT Terminal \& control pane1

CRT Terminal

CRT Terminal

CRT Terminal

CRT Terminal

CRT Terminal

CRT Terminal

CRT Termina1

CRT Terminal

CRT Terminal \& control 
Range

AP-514

TE-515 Thermocouple (K) Surface Mount

PT-516

TE-517

Thermocouple (K) Surface Mount

PT-518 Force-Balance

LT-519

PT -520

LT-521

FE-522

Force-Balance Diff. Pressure Transducer

Force-Balance

Force-Balance Diff. Pressure Transducer

\section{Flow Tube}

Force-Balance

$$
40^{\circ}-600^{\circ} \mathrm{F}
$$

0-600 psia

$40^{\circ}-600^{\circ} \mathrm{F}$

0-600 psia

$0-20$ inches

$0-600$ psia

0-20 inches

$0-10 \mathrm{lbs} / \mathrm{sec}$

(Tin)

PDT-523
0-50 psia
Accuracy

$1 / 2 \%$

$1 \%$

$1 / 2 \%$

$1 / 2 \%$

$3 \%$

$1 \%$

$3 \%$

$3 \%$

$1 \%$
Function

Indicate amount of

liberated hydrogen and

alarm.

Indicate temperature and alarm.

Indicate pressure and alarm.

Indicate temperature and alarm.

Indicate temperature and alarm.

Indicate level and control valves 35 and 36 .

Indicate pressure and alarm.

Indicate level and alarm.

Indicate flow and alarm.

Indicate Diff. Pressure and alarm.
Where

Indicated

CRT Terminal \& control panel

CRT Terminal

CRT Terminal

CRT Termina1

CRT Terminal

CRT Terminal

CRT Terminal

CRT Terminal \& control panel

CRT Terminal

CRT Termina1

NOTE: All 500 series pressure sensors, level sensors and flow sensors are exposed to tin. 


\begin{tabular}{|c|c|c|c|c|c|}
\hline $\begin{array}{l}\text { Sensing } \\
\text { Element }\end{array}$ & Type & Range & Accuracy & Function & $\begin{array}{l}\text { Where } \\
\text { Indicated }\end{array}$ \\
\hline$P 1-601$ & Bourdon Pressure Gage & $0-30$ psig & $3 \%$ & Indicate pressure. & Local \\
\hline $\mathrm{PT}-602$ & $\begin{array}{l}\text { Strain Gage Pressure } \\
\text { Transducer }\end{array}$ & $0-30$ psig & $1 \%$ & $\begin{array}{l}\text { Indicate pressure and } \\
\text { alarm. }\end{array}$ & CRT Terminal \\
\hline $\mathrm{T} 1-603$ & Dial Thermometer & $40^{\circ}-200^{\circ} \mathrm{F}$ & $3 \%$ & Indicate temperature. & Local \\
\hline $\mathrm{TE}-604$ & $\begin{array}{l}\text { Thermocouple (K) } \\
\text { Surface Mount }\end{array}$ & $40^{\circ}-200^{\circ} \mathrm{F}$ & $1 \%$ & $\begin{array}{l}\text { Indicate temperature and } \\
\text { alarm. }\end{array}$ & CRT Terminal \\
\hline TE-605 & $\begin{array}{l}\text { Thermocouple (K) } \\
\text { Surface Mount }\end{array}$ & $40^{\circ}-200^{\circ} \mathrm{F}$ & $1 \%$ & $\begin{array}{l}\text { Indicate temperature and } \\
\text { alarm. }\end{array}$ & CRT Terminal \\
\hline $\mathrm{T} 1-606$ & Dial Thermometer & $40^{\circ}-200^{\circ} \mathrm{F}$ & $3 \%$ & Indicate temperature. & Local \\
\hline $\mathrm{TE}-607$ & $\begin{array}{l}\text { Thermocouple ( } \mathrm{T}) \\
\text { Surface Mount }\end{array}$ & $-459^{\circ}-75^{\circ} \mathrm{F}$ & $1 \%$ & $\begin{array}{l}\text { Indicate tempeature and } \\
\text { alarm. }\end{array}$ & CRT Terminal \\
\hline $\mathrm{TE}-608$ & $\begin{array}{l}\text { Thermocouple (T) } \\
\text { Surface Mount }\end{array}$ & $-459^{\circ}-75^{\circ} \mathrm{F}$ & $1 \%$ & $\begin{array}{l}\text { Indicate temperature and } \\
\text { alarm. }\end{array}$ & CRT Terminal \\
\hline P1-701 & Bourdon Pressure Gage & $0-30$ psig & $3 \%$ & Indicate pressure. & Local \\
\hline PT -702 & $\begin{array}{l}\text { Strain Gage Pressure } \\
\text { Transducer }\end{array}$ & $0-30$ psig & $1 \%$ & $\begin{array}{l}\text { Indicate pressure and } \\
\text { alarm. }\end{array}$ & CRT Terminal \\
\hline $\mathrm{T} 1-703$ & Dial Thermometer & $40^{\circ}-200^{\circ} \mathrm{F}$ & $3 \%$ & Indicate temperature. & Loca1 \\
\hline $\mathrm{TE}-704$ & $\begin{array}{l}\text { Thermocouple (K) } \\
\text { Surface Mount }\end{array}$ & $40^{\circ}-200^{\circ} \mathrm{F}$ & $1 \%$ & $\begin{array}{l}\text { Indicate temperature and } \\
\text { alarm. }\end{array}$ & CRT Terminal \\
\hline $\mathrm{TE}-705$ & $\begin{array}{l}\text { Thermocouple (K) } \\
\text { Surface Mount }\end{array}$ & $40^{\circ}-200^{\circ} \mathrm{F}$ & $1 \%$ & $\begin{array}{l}\text { Indicate temperature and } \\
\text { alarm. }\end{array}$ & CRT Terminal \\
\hline $\mathrm{LT}-706$ & Capacitance Type Probe & $0-20$ inches & $3 \%$ & Indicate level and alarm. & $\begin{array}{l}\text { CRT Terminal \& } \\
\text { control panel }\end{array}$ \\
\hline $\mathrm{PT}-707$ & $\begin{array}{l}\text { Strain Gage Pressure } \\
\text { Transducer }\end{array}$ & $0-30$ psig & $1 \%$ & $\begin{array}{l}\text { Indicate pressure and } \\
\text { alarm. }\end{array}$ & CRT Termi \\
\hline
\end{tabular}


Surface

0-50 inches

$3 \%$

0-50 inches

Dial Thermometer

TE-805

Thermocouple (K)

Thermowell

PT-806

Strain Gage Pressure Transducer

PD1-807

Bourdon Differential Pressure Gage

PDT-808

Strain Gage Diff. Pressure Transducer

AP-809

FE-810

\section{Flow Tube}

PT-811

Strain Gage Pressure Transducer

P1-812

LT -813

Bourdon Pressure Gage

Capacitance Probe

TE-814 $40^{\circ}-200^{\circ} \mathrm{F}$

$1 / 2 \%$

$40^{\circ}-200^{\circ} \mathrm{F}$

0-200 psia

0-50 psia

0-50 psia (Water)
$0-2 \mathrm{lbs} / \mathrm{min}$
Thermocouple (K)

The rnowe 11
Indicate voltage.

Indicate temperature and alarm.

Indicate leve1.

Indicate level, control LCV25; alarm.

Indicate temperature.

Indicate temperature and alarm.

Indicate pressure and alarm.

Indicate pressure.

Indicate diff. pressure and alarm.

Indicate water purity.

Indicate flow and alarm.

Indicate pressure and alarm.

Indicate pressure.

Indicate level; control LCV22; alarm.

Indicate temperature and alarm.
Where Indicate

CRT Terminal \& control panel

CRT Terminal

Local

CRT Terminal \& control panel

Loca1

CRT Terminal

CRT Terminal

Local

CRT Terminal

CRT Terminal \& control panel

CRT Terminal

CRT Terminal

Loca1

CR'T Terminal \& control panel

CRT terminal 
Sensing

Element

T1-815

PT-816

FE-817

TE-818

TE-819

TE-820

T1-821

LT -822

P 1-823

PT-824

T1-825

TE- 826

PT-827

FE- 828

TE-829

Transducer

Flow Tube
Flow Tube

Type

Dial Thermometer

Strain Gage Pressure

Thermocouple (K)

Surface Mount

Thermocouple (K)

Surface Mount

Thermocouple (K)

The rmowell

Dial Thermometer

Capacitance Probe

Bourdon Pressure Gage

Strain Gage Pressure

Transducer

Dial Thermometer

Thermocouple (K)

Thermowell

Strain Gage Pressure

Transducer

0-1200 psia

$0-2 \mathrm{lbs} / \mathrm{sec}$

$40^{\circ}-600^{\circ} \mathrm{F}$

$1 / 2 \%$

Accuracy

$3 \%$

$1 \%$

$3 \%$

$1 / 2 \%$

$1 / 2 \%$

$1 / 2 \%$

$3 \%$

$3 \%$

$3 \%$

$1 \%$

$3 \%$

$1 / 2 \%$

$1 \%$

$\%$

Thermocouple (K)

Surface Mount

\section{Function}

Indicate temperature.

Indicate pressure and alarm.

Indicate flow and alarm.

Indicate temperature and alarm.

Indicate temperature and alarm.

Indicate temperature and alarm.

Indicate temperature.

Indicate level; control LCV23; alarm.

Indicate pressure.

Indicate pressure and alarm.

Indicate temperature.

Indicate temperature and alarm.

Indicate pressure and alarm.

Indicate flow and alarm.

Indicate temperature and alarm.
Where

Indicated

Local

CRT Terminal

CRT Termina1

CRT Terminal

CRT Terminal

CRT Terminal

Local

CRT Termina1 \& control panel

Local

CRT Terminal

Local

CRT Terminal

CRT Terminal

CRT Terminal

CRT Termi 


\section{Sensing}

Element

TE-830

TE-831

PT-832

$\mathrm{TE}-833$

PT-834

$\mathrm{TE}-835$

PT -836

TE-837

PT-838

PDT-839

TE-840

PT-841

TE-842
Type

Thermocouple (K)

Surface Mount

Thermocouple (K)

Surface Mount

Strain Gage Pressure

Transducer

Thermocouple (K)

Surface Mount

Strain Gage Pressure

Transducer

Thermocouple (K)

Surface Mount

Strain Gage Pressure

Transducer

Thermocouple (K)

Surface Mount

Strain Gage Pressure

Transducer

Strain Gage Diff.

Pressure Transducer

Thermocouple (K)

Surface Mount

Strain Gage

Pressure Transducer

Thermocouple (K)

Surface Mount

\begin{tabular}{|c|c|}
\hline Range & Accura \\
\hline $40^{\circ}-600^{\circ} \mathrm{F}$ & $1 / 2 \%$ \\
\hline $40^{\circ}-600^{\circ} \mathrm{F}$ & $1 / 2 \%$ \\
\hline $0-1200$ psia & $1 \%$ \\
\hline $40^{\circ}-600^{\circ} \mathrm{F}$ & $1 / 2 \%$ \\
\hline $0-1200$ psia & $1 \%$ \\
\hline $40^{\circ}-600^{\circ} \mathrm{F}$ & $1 / 2 \%$ \\
\hline $0-1200$ psia & $1 \%$ \\
\hline $40^{\circ}-600^{\circ} \mathrm{F}$ & $1 / 2 \%$ \\
\hline $0-1200$ psia & $1 \%$ \\
\hline $0-50$ psia & $1 \%$ \\
\hline $40^{\circ}-600^{\circ} \mathrm{F}$ & $1 / 2 \%$ \\
\hline $0-1200$ psia & $1 \%$ \\
\hline $40^{\circ}-600^{\circ} \mathrm{F}$ & $1 / 2{ }^{\circ}$ \\
\hline
\end{tabular}

$1 / 2 \%$

$12 \%$

$12 \%$

$2 \%$

$1 \%$

$2 \%$

$1 \%$

$1 / 2 \%$

$1 / 2 \%$

\section{Function}

Indicate temperature and alarm.

Indicate temperature and alarm.

Indicate pressure and alarm.

Indicate temperature and alarm.

Indicate pressure and alarm.

Indicate temperature and alarm.

Indicate pressure and alarm.

Indicate temperature and alarm.

Indicate pressure and alarm.

Indicate diff. pressure and alarm.

Indicate temperature and alarm.

Indicate pressure and alarm.

Indicate temperature and alarm.
Where

Indicated

CRT Terminal

CRT Terminal

CRT Terminal

CRT Terminal

CRT Terminal

CRT Terminal

CRT Terminal

CRT Terminal

CRT Terminal

CRT Termina1

CRT Terminal

CRT Terminal

CRT Terminal 
Strain Gage

Pressure Transducer

TE-845

Thermocouple (K)

Surface Mount

P1-846

PT-847

LT-848

TE-849

PT-850

TE-851

PT -852

TE-853

P 1-854

PT-855
Bourdon Pressure Gage

Strain Gage

Pressure Transducer

Capacitance Probe

Thermocouple (K)

Surface Mount

Strain Gage

Pressure Transducer

Thermocouple (K)

Surface Mount

Strain Gage

Pressure Transducer

Thermocouple (K)

Surface Mount

Bourdon Pressure Gage

Strain Gage

Pressure Transducer
Range

$40^{\circ}-600^{\circ} \mathrm{F}$

0-1200 psia

Accuracy

$1 / 2 \%$

$1 \%$

$40^{\circ}-600^{\circ} \mathrm{F}$

$1 / 2 \%$

0-100 psig

0-100 psia

0-25 inches

$3 \%$

$40^{\circ}-600^{\circ} \mathrm{F}$

$1 / 2 \%$

0-1200 psia

$1 \%$

$40^{\circ}-600^{\circ} \mathrm{F}$

$1 / 2 \%$

0-1200 psia

$1 \%$

$40^{\circ}-600^{\circ} \mathrm{F}$

0-1000 psig

0-1000 psia

0-10 inches
Function

Indicate temperature and alarm.

Indicate pressure and alarm.

Indicate temperature and alarm.

Indicate pressure.

Indicate pressure and alarm.

Indicate level; control LCV 24; alarm.

Indicate temperature and alarm.

Indicate pressure and alarm.

Indicate temperature and alarm.

Indicate pressure and alarm.

Indicate temperature and alarm.

Indicate pressure.

Indicate pressure and alarm.

Indicate leve1; control LCV20; and alarm.
Where

Indicated

CRT Termina1

CRT Terminal

CRT Terminal

Loca1

CRT Terminal

CRT Terminal \& control panel

CRT Terminal \& f control panel

CRT Terminal

CRT Terminal

CRT Terminal

CRT Terminal

Local

CRT Terminal

CRT Term 
Sensing

Elements

TE-857

TE-858

FE-860
Type

Thermocouple (K)

The rmowe11

Thermocouple (K)

Surface Mount

Strain Gage

Pressure Transducer

Flow Tube

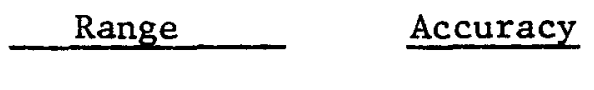

$40^{\circ}-600^{\circ} \mathrm{F}$

$40^{\circ}-600^{\circ} \mathrm{F}$

0-1200 psia

$0-1 \mathrm{bb} / \mathrm{min}$
$1 / 2 \%$

$1 \%$

$3 \%$
Where

Indicated

Indicate temperature and alarm.

Indicate temperature and alarm.

Indicate pressure and alarm.

Indicate flow and alarm.
CRT Terminal

CRT Terminal

CRT Termina1

CRT Terminal 
APPENDIX B

Tin-Water MHD Program Plan Task Descriptions

(abridged)

Task No. 1.0 Project Management

Work Statement

Full time management effort will be required for general program activities such as the following:

a. Overall coordination of effort.

b. Integration of results of related two-phase 1iquid-metal work into the $\mathrm{Sn}-\mathrm{H}_{2} \mathrm{O}$ project.

c. Arrangement for vendor participation in component development efforts and participation in liaison activities.

d. Interfacing with scientific staff relative to system and component analytical studies.

e. Interfacing with ANL Materials Science Division on tin oxidation reduction and materials compatibility studies.

f. Preparation of documents and reports.

g. Planning of program activities and schedules.

h. Review and approval of engineering output.

Task No. 2.0 Conceptual Design

Work Statement

Conceptual effort will be required in connection with further refinement of the system and some of its components. In general, this will be accomplished along with parametric and trade-off studies, by both computer and hand methods, interacting with concurrent design inputs, 
Predominantly, the components requiring conceptual design effort are the injector-mixer, MHI) generator and nozzle-separator-diffuser units. Also required will be conceptual designs for experimental test facilities for the above components.

Although they are of more straightforward nature, conceptual design of the steam components is also necessary. This will be accomplished concurrently with the preliminary design.

Task No. 3.0 Research and Development Work Statement

The research and development activities will be closely associated with the conceptual and preliminary design phases. Because of the integrated time-frame-relationship between design phases some $R \& D$ efforts will also be associated with the detailed design phase.

The objectives of the $R \& D$ activities will be as follows:

a. To support the system and component design efforts.

b. To contribute to two-phase liquid metal technology in generaal.

c. To develop computational and analytical tools to facilitate future advanced system design.

d. To provide high confidence levels for operation of the completed system and its components.

The task objectives will be accomplished by the following activities:

a. Performance of cycle studies to optimize system parameters within the practical restrictions imposed by the ongoing design. Typical of these restrictions might be: size, economy, materials, stress, nolse, voltage output and safety considerations.

b. Contributions to test planning and test equipment conceptual design. 


\begin{abstract}
c. Operation of test equipment including planning of detailed experimental procedures, acquiring data, correlating results with extsting theory and drafting compatible mathematical models.
\end{abstract}

Task No. 4.0 Preliminary Design

Work Statement

Preliminary design work will be performed on the system and its components as soon as individual conceptual designs are completed or as soon as $R \& D$ requirements are satisfied, as the case might be. Since the various system components will required differing amounts of conceptual and $R \& D$ effort there will be an integrated time schedule for commencement of preliminary design of individual components.

The work of this task will involve engineering, design and drafting activities covering the mechanical, fluid-dynamic, thermodynamic structural and electrical aspects of design. Engineering calculations in support of the design, including stress analyses will be included in the workscope. Activities of this task will interact closely with $R \& D$ efforts. Task output will be in the form of design layouts and outline specifications, supported as appropriate by information from vendors.

Task No. 5.0 Final Design Work Statement

Final design work will be performed on the system and its components as the respective preliminary design and safety reviews are completed. le work of this task will involve engineering, design, and drafting activities. Essentially, the activities will center about preparing detailed drawings and specifications from the layout drawings developed in the preliminary design phase. 
Scheduling, of the various tasks will depend upon the availability of information from research activities to enable the establishment of materials of construction, sizes, and other parameters necessary to finalize all specifications.

The task output will consist of complete engineering packages, including detail drawings, assembly drawings, detail specifications, engineering calculations in support of the design and all other information necessary for construction.

Task No. 6.0 Construction Work Statement

This task pertains only to construction of the 1 MW Prototype Power System and includes most activities occurring between completion of final design and operation of the system. This includes preparation of work packages, bidding, contract administration, fabrication quality control delivery, installation and checkout.

Intiation of the construction phase in general will be dependent upon favorable results from the $R \& D$ activities at designated decision points and the availability of construction funds.

Initiation of construction activities for the various untts and subsystems will, in general, be contingent upon completion of design and safety reviews for those units and subsystems. Exceptions will involve certain units whose final design completions are on critical paths because of a need to incorporate results of $R \& D$ activities affecting, for instance only one design variable. The preliminary designs of these few components will be completed to advanced status.

The task output will be the completed prototype power system which has been checked out and is ready for operation. 
Task No. 7.0 Power System Operation

Work Statement

This task will commence after the power system has been completely installed, tested and approved for formal operation. The activities included in the formal operation phase will be dedicated to demonstrating the operational characteristics of such a system. Various tests will be planned and executed to facilitate this objective.

The system will also be used as a facility for developing component design refinements within its practical capability for accepting design modifications. Therefore, planning for such modifications will be an activity within this task.

Mathematical models will be refined in accordance with test results and reports will be prepared. 


\section{Criteria}

The basic policy for cost estimating is provided in the Engineering Policy and Practices Manual ENG-PPM-C-2 ${ }^{[1]}$ and guidance document ENG/CP 0218. [2]

Costs for the $1 \mathrm{MW}$ Prototype Power System for which conceptual designs have been completed were subjected to a"detailed"material and labor estimating procedure. A contingency of $20 \%$ was applied to those estimates. Components of the power system such as the MHD generator, injector-mixer, nozzle-separator-diffuser, superconducting magnets, cryogenics, etc. were subject to "study" estimates in which comparisons were made with engineering equipment of somewhat similar type, size and complexity whose costs were known. A contingency of $20 \%$ was applied to those costs also.

"Study" type estimates were applied, in general to the $R \& D$ program. Since this program is relatively labor-intensive, reflecting a number of task assignments, no contingency was applied.

Vendor consultations were employed in connection with some components to facilitate both design and construction. Preliminary vendor quotations (Informal) were used whenever possible.

Argonne's Central Shops assistance was utilized in estimating some fabrication costs.

Installation and erection costs were based on current CPFF (cost plus fixed fee) contract work preformed at ANL. The hourly rate is $\$ 20$ per hour. It includes direct labor, fringe benefits, ANL administration, smal1 tools, contractor administration and contractor's fee. It covers all categories of work, including pipefitting, ironwork, electrical, 
carpentry, insulation, millwright, etc. This was escallated as appropriate to the year in which a particular task was to be performed.

Escalation was applied to current labor and material costs in accordance with ENG/CP $0241^{[3]}$ dated December 27, 1974. In accordance with that directive the following escalation schedule was used for materials and services: FY 75-76, $12 \%$; FY 76-77, $10 \%$; al1 succeeding years, $6.5 \%$. ANL labor rates were escalated $8 \%$ yearly. Escalation was applied to each individual labor rate or material or service rate as appropriate to the year in which the cost was scheduled to be incurred. Contingencies were applied to total category costs for each fiscal year.

Cost estimation has been based on the use of low-carbon steel for the entire system. The ultimate choice of materials, however, will be determined by a materials research program. A need to use other than carbon steel for the tin circulation system for example could result in higher costs and material procurement problems.

\section{Estimate Sheets}

There are two sets of estimate sheets. One set is for a single-stage power system and the other is for a two-stage power system. The cost figures for the two-stage system represent increments which must be added to the costs for a single-stage system to arrive at total costs for a two-stage system.

The estimate sheets are arranged by fiscal year, each year's sheets being preceeded by a summary sheet. The program categories are defined by numbers ( 1 through 8 on the yearly summary sheets). Fach program task or activity on the detailed estimate sheets is identified as to category by a number along the left hand margin. The categories appear on the summary sheets essentially in the same order in which they appear on the program plan network. 


\section{$\mathrm{C}-3$}

The totals appearing in the right hand columns of the summary sheets include contingencies applied to the sums of labor and materials as appropriate. These are the figures summarized in Tables $\mathrm{V}-1$ and $\mathrm{V}-2$. 


\section{REFERENCES}

1. Argonne National Laboratory, Engineering Division Policy and Procedure Manua1, Procedure No. ENG-PPM-C-2,"Construction Project Cost Estimating."

2. Argonne National Laboratory, Engineering Division memorandum ENG/CP0218 of November 20, 1974, "Estimating Information," H. Korbus to Distribution.

3. Argonne National Laboratory, Engineering Division memorandum ENG/CP0241 of December 27, 1974, "Estimating Information," H. Korbus to Distribution. 
Component

Valves

Piping and fittings

Electrical heating elements

Primary $\mathrm{Hx}$ and Boller

Mixer

MHD Channe1s

Magnets and Power Supply

Cryogenics

Nozzle-Separator-Diffuser*

Electrical Loads*

Oxide Removal Unit*

Cyclone Separators

Tin Surge Tank

Tin Dump Tanks

Steam Regenerators

Steam Condenser

Experimental Facilities*

Tin Expansion Tanks

Superheaters

Heat Rejection System

Deaeration Unit
Reference

Valtek, Inc.

Means Construction Estimating Handbook

Watlow Electrical Manufacturing Company

ANL, Central Shops and engineering experience

ANL, Centra1 Shops

ANL experience

ANL experience

ANL experience

Engineering judgement

Engineering judgement

Engineering judgement

ANL, Central Shops

ANL, Central Shops

ANL, Central Shops

ANL, Central Shops

ANL, Central Shops

Engineering judgement

Engineering experience

Engineering experfence

Engineering experience

Engineering experience 
Reference List - Mechanica1 (cont)

Component

Drafting and Design

Erection and installation

Pumps

Tin

\section{Reference}

Engineering experience and Engineering Div. standard criteria

Means Construction Estimating Handbook and current CPFF rate

Perry Engineering Handbook

Wa11 Street Journal

Mechanical component costs were gathered by L. Carlson, ANL Engineering Division. 
Component

Control Centers

Powerstats

Conduit

Wire

Contro1 Components (meters, switches, etc.)

Pressure indicator with alarm

Transformers

Isolation Transformer

Electropneumatic Converters

Manual Controllers

Valve Drive Mechanisms

Signal Wire

Square Duct

Gaphic Pane1

Electronic cabinets, racks, terminal strips, blowers, consoles, etc.

Thermocouple Assemblies

Dial Thermometers

Surface Mounted Thermocouples

Terminal Boards

Thermocouple References

Bourdon Pressure Gauges

crain Gauge Transducers

Power Supply $\underline{\text { Reference }}$

Westinghouse Catalog

Superior Flect. Co.

Means Construction Cost Data

Means Construction Cost Data

Allied Control Co. catalog

Engineering experience

Means Construction Cost Data

Topaz Electronics catalog

Leeds \& Northrup catalog

Leeds \& Northrup catalog

Leeds \& Northrup catalog

Allied Control Co. catalog

Square D Co. catalog

Engineering Experience

Amco Eng. Co. catalog

Leeds \& Northrup catalog

Claud S. Gordon Co. catalog

Claud S. Gordon Co. catalog

Claud S. Gordon Co, catalog

Acromag, Inc. catalog

Enerpac Div. catalog

Bel1 \& Howell catalog

Hewlett-Packard catalog 
Component

Force Balances

Flow Instruments

Level Indicators

Different1al Pressure Transmitters

Vibration Monitors

PH Monitors

Conductivity Monitors

Hydrogen Monitors

Computer

Real Time Clock

Disk Pack

Magnetic Tape Unit

Alpha-Numeric Termina1

Drum Plotter

Plotting Scope

In-Out Expander \& System

Analog Input System
Reference

Taylor Inst. Co. catalog

Taylor Inst. Co. catalog

Endress \& Houser catalog

Taylor Inst. Co. catalog

Be11 \& Howe11 catalog

Leeds \& Northrup catalog

Engineering judgement

Engineering judgement

Digital Equipment Corp.

Digltal Equipment Corp.

Digital Equipment Corp.

Digital Equipment Corp.

Computer Communications Inc.

Calcomp

Hewlett-Packard

Computer Prod. Inc.

Computer Prod. Inc.

Electrical component costs were gathered by T. Zinneman, ANL Engineering Division. 


\section{EST IMATE WORK SHEET}

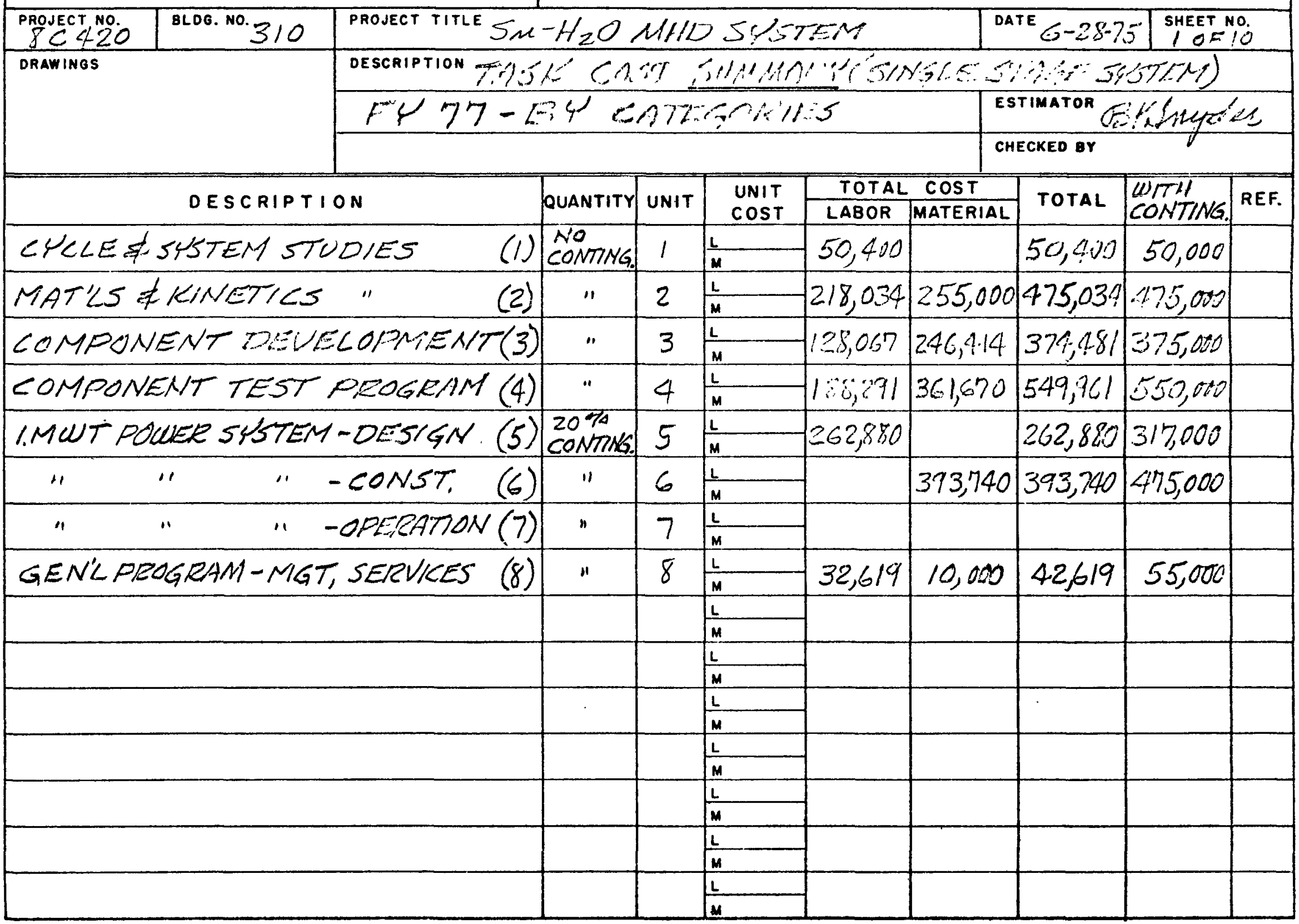




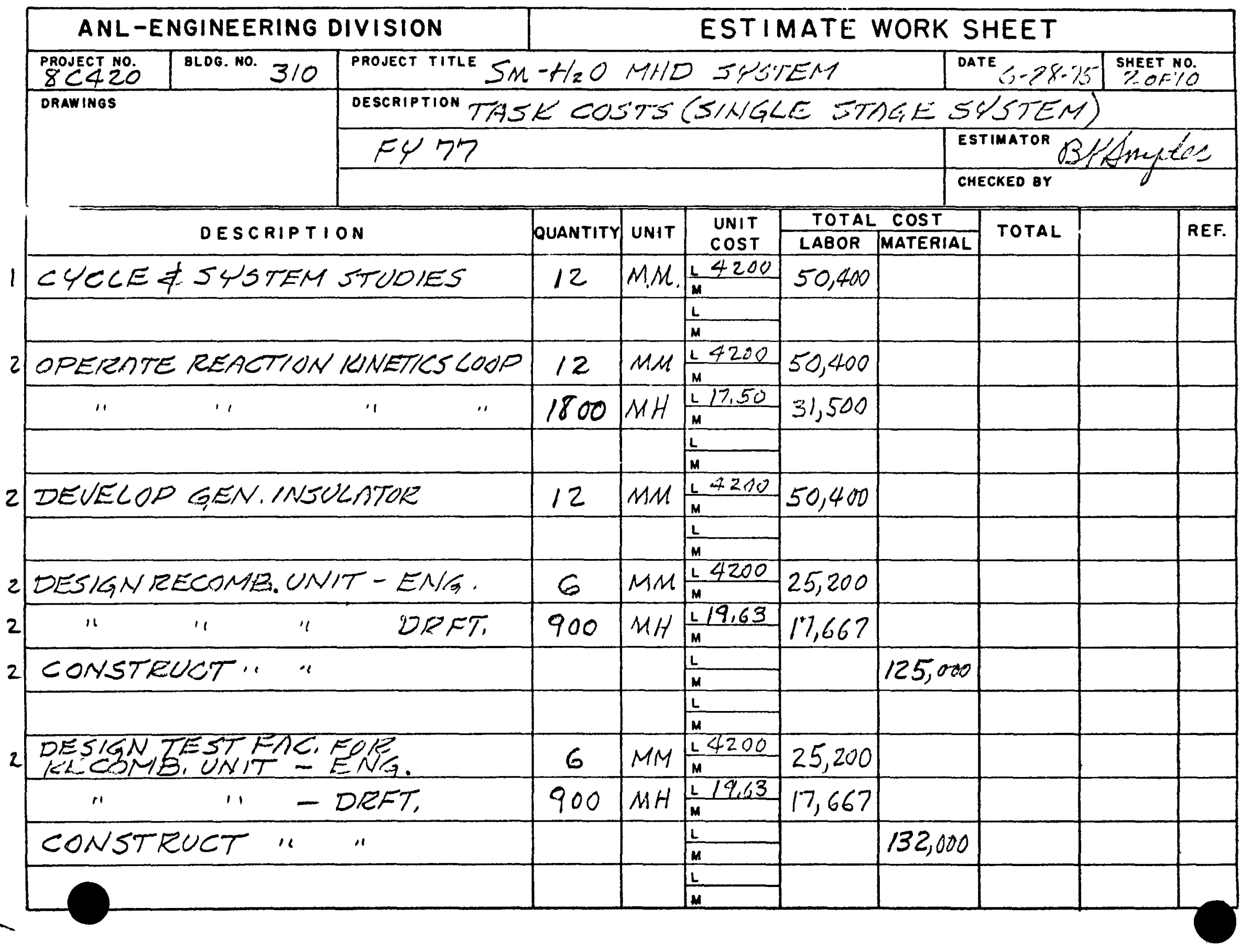




\begin{tabular}{|c|c|c|c|c|c|c|c|c|c|c|}
\hline & \multicolumn{3}{|c|}{ ANL-ENGINEERING DIVISION } & \multicolumn{7}{|c|}{ ESTIMATE WORK SHEET } \\
\hline & $8 C^{\text {PRQSECT }} 420$ & BLOG. NO. 310 & \multirow{2}{*}{\multicolumn{8}{|c|}{ 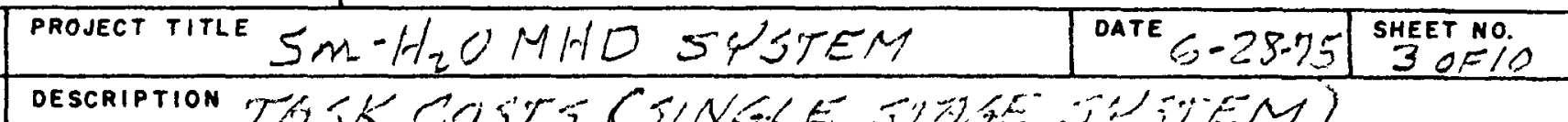 }} \\
\hline \multirow{3}{*}{\multicolumn{3}{|c|}{\begin{tabular}{|l} 
DRAMINGS \\
DRA \\
\end{tabular}}} & & & & & & & & \\
\hline & & & \multicolumn{6}{|c|}{ FY 77} & \multicolumn{2}{|c|}{ 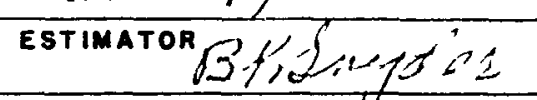 } \\
\hline & & & & & & & & & CHECKED BY & \\
\hline & \multicolumn{3}{|c|}{ DESCRIPTION } & QUANTITY & UNIT & $\begin{array}{l}\text { UNIT } \\
\text { COST }\end{array}$ & \multicolumn{2}{|c|}{ 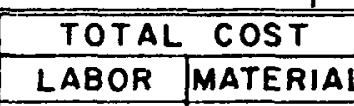 } & A TOTAL & REF. \\
\hline 4 & \multicolumn{3}{|c|}{ NaK-N TEST FAC,-PRELIM,DES. (2) "E" } & 160 & MH & $\frac{19,63}{M}$ & 3140 & & & \\
\hline 4 & $"$ & " & "ENG. & 4 & MM & $\frac{14200}{M}$ & 16,800 & & & \\
\hline 4 & $" 1$ & "FINAL & DES. (2) "D" & 80 & MH & $\frac{L 19.63}{M}$ & 1,570 & & & \\
\hline$4 \longdiv { 1 }$ & $"$ & 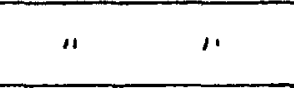 & $"(6) " C "$ & 60 & $\mathrm{MH}$ & $\frac{L 19.63}{M}$ & 1,178 & & & \\
\hline \multirow{2}{*}{$\begin{array}{l}4 \\
4\end{array}$} & " & " " " & ENG & 2 & MM & $\frac{1200}{M}$ & 8,400 & & & \\
\hline & " & ." & "CONSTRUCT & & & & & 170,000 & & \\
\hline 4 & $"$ & "OPERATT & $E 15 \% W \% 5 T$ & 3 & MM & $\angle 4200$ & 12,600 & & & \\
\hline \multirow{2}{*}{4} & $\begin{array}{l}\text { DES/GNM } \\
\text { LOOP FOK }\end{array}$ & $\begin{array}{l}\text { DD'STO REA } \\
\text { e SMnLL SSAR }\end{array}$ & $\begin{array}{l}\text { TION KINETIES } \\
\text { ETHST-ENG }\end{array}$ & 2 & $M M$ & 24200 & 8,400 & & & \\
\hline & $1 " \quad 1$ & " & " DRFT, & 200 & $\mathrm{MH}$ & $\frac{219.63}{M}$ & 4000 & & & \\
\hline \multirow[t]{6}{*}{4} & CONSTRUS & CT MODIFICA & TIONS FOR" & & & $\frac{L}{M}$ & & 30,640 & & \\
\hline & & & & & & $\frac{L}{M}$ & & & & \\
\hline & & & & & & $\frac{L}{M}$ & & & & \\
\hline & & & & & & $\frac{L}{M}$ & & & & \\
\hline & & & & & & $\frac{L}{M}$ & & & & \\
\hline & & & & & & & & & & \\
\hline
\end{tabular}


1

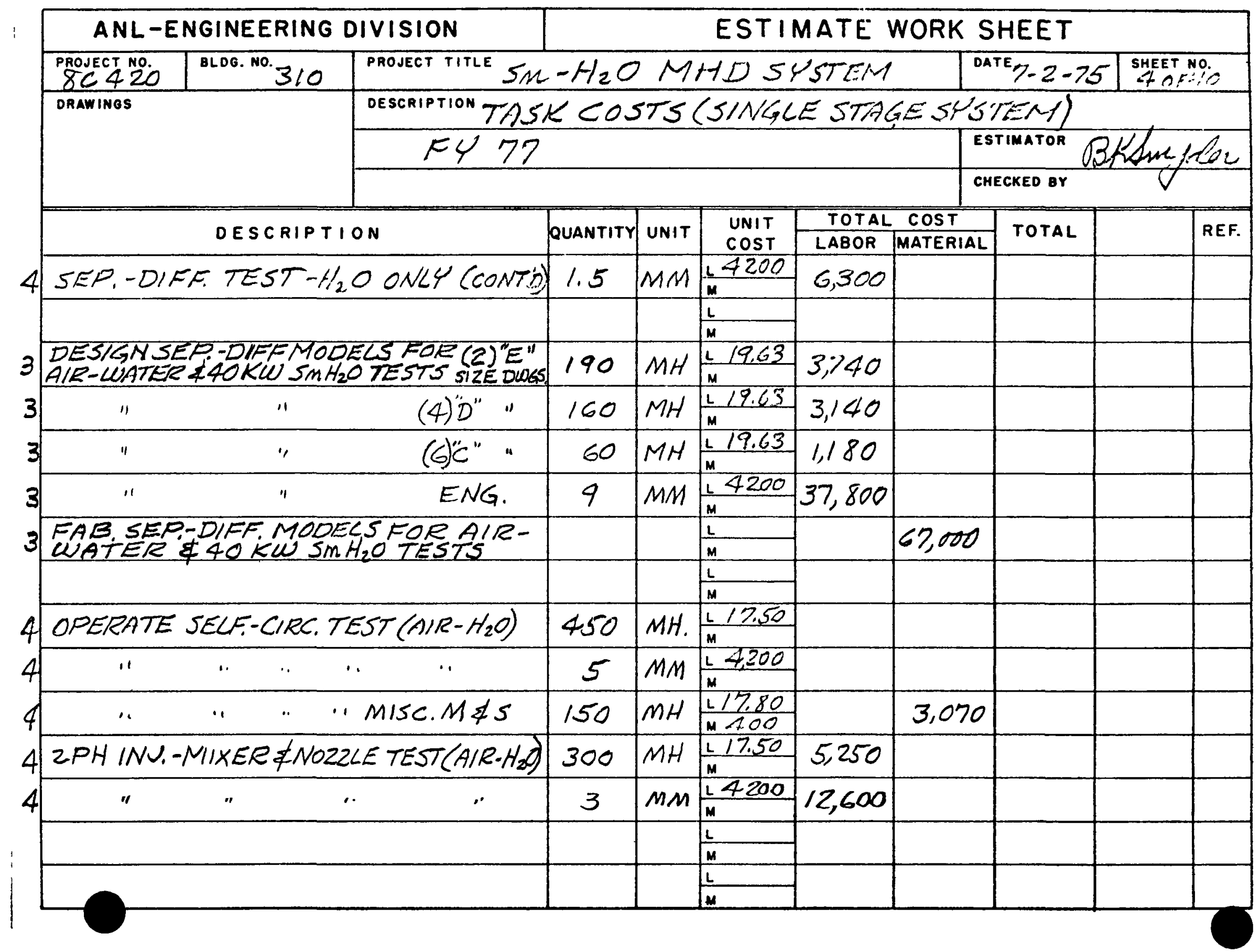




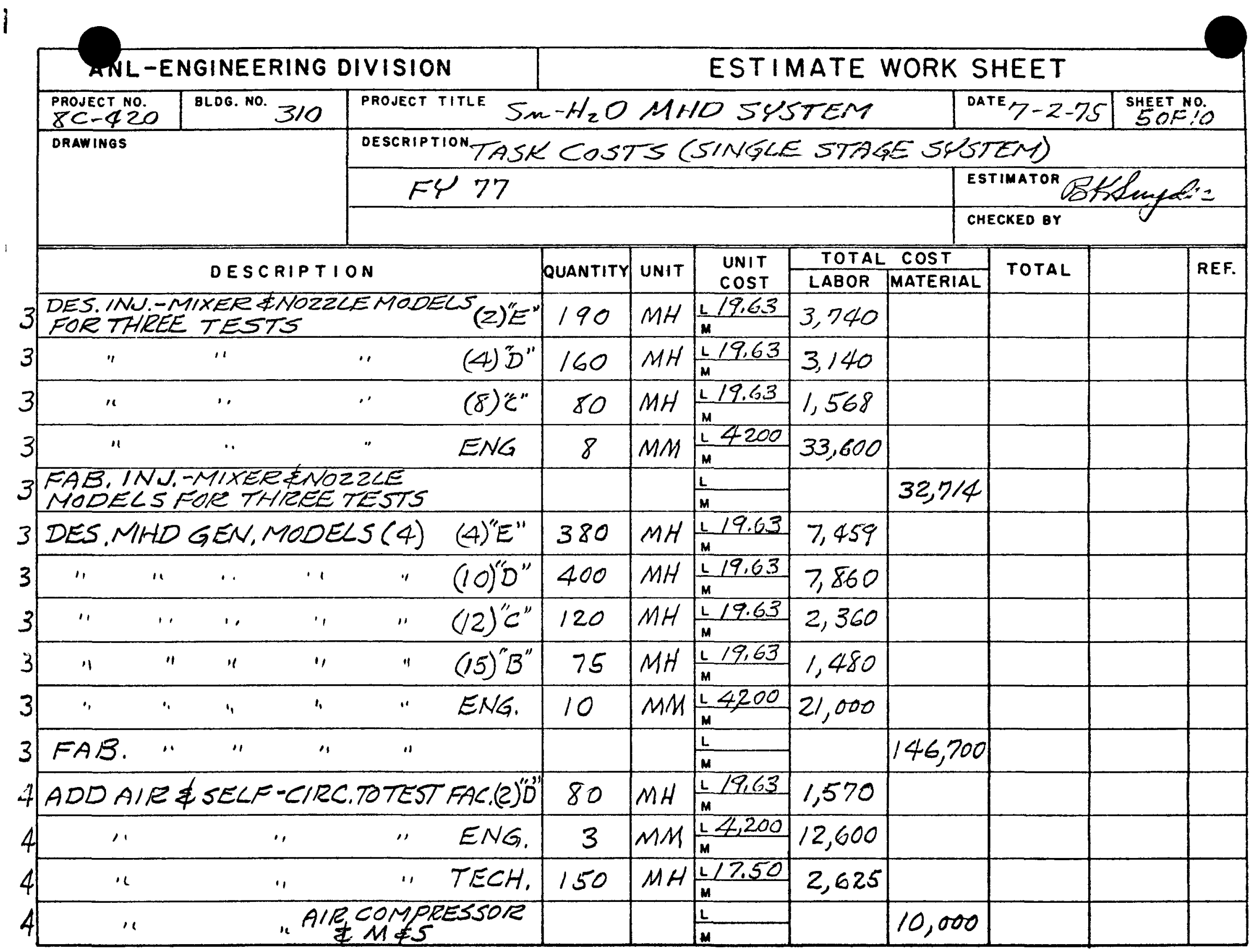




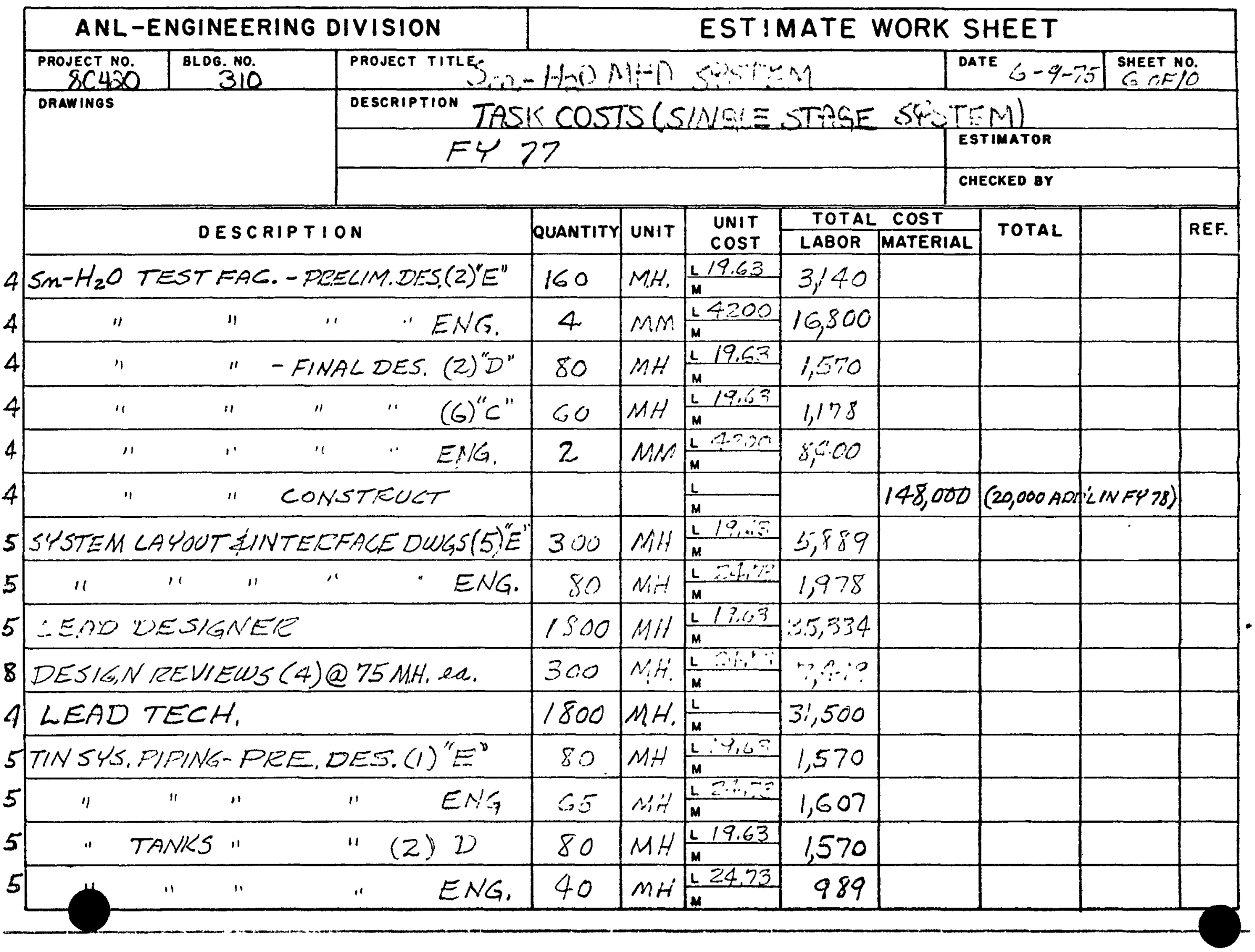




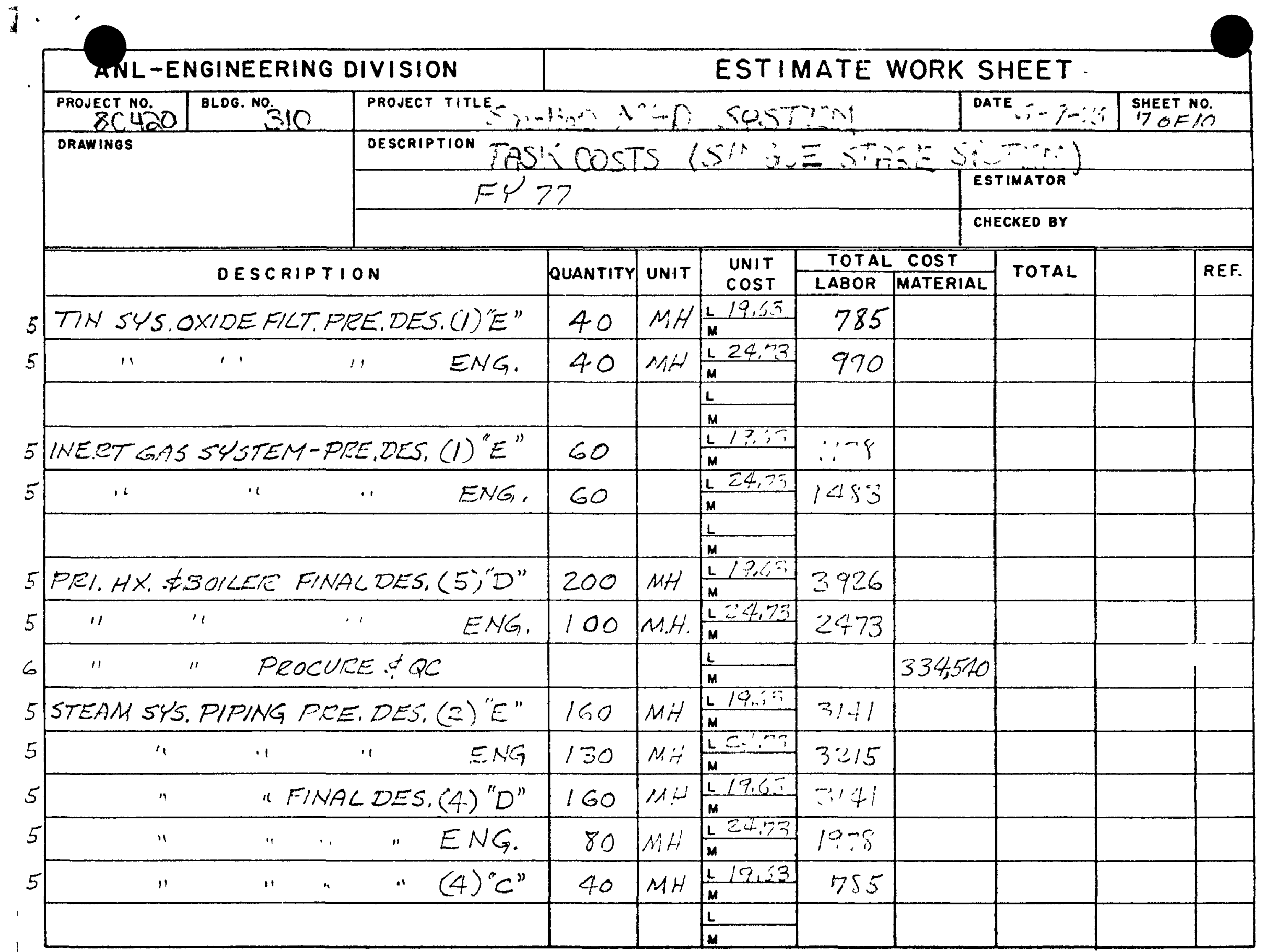




\begin{tabular}{|c|c|c|c|c|c|c|c|c|}
\hline \multicolumn{2}{|c|}{ ANL-ENGINEERING DIVISION } & \multicolumn{7}{|c|}{ ESTIMATE WORK SHEET } \\
\hline \begin{tabular}{|l|l|} 
PROJECT NOO & BLDG. NOO \\
SOO & 3NO \\
\end{tabular} & \multicolumn{6}{|c|}{ PROJECT TITLE $S_{m}-\mathrm{H} 2 \mathrm{~N}$ MHD STITSOM } & \multicolumn{2}{|c|}{\begin{tabular}{ll|l} 
DATE & $6-9-75$ & SHEET NOO \\
$80 F i 0$
\end{tabular}} \\
\hline \multirow[t]{3}{*}{ DRAWINOS } & \multicolumn{8}{|c|}{ DESCRIPTION TASK COSTS (SINGLE STAGE SWSTEM) } \\
\hline & \multirow{2}{*}{\multicolumn{6}{|c|}{\begin{tabular}{|c|c|} 
FY & \\
\end{tabular}}} & \multicolumn{2}{|c|}{ Estimató } \\
\hline & & & & & & & \multicolumn{2}{|c|}{ CHECKEO \&Y } \\
\hline \multicolumn{2}{|c|}{ DESCRIPTION } & QuANTITY & UNIT & $\begin{array}{l}\text { UNIT } \\
\text { COST }\end{array}$ & TOTAL & COST & TOTAL & REF. \\
\hline DEAERATION UNIT & (Z) D"SIZE DWGS, & 80 & MH & $\frac{19.63}{M}$ & 1510 & & & \\
\hline " & $\equiv 3 \%$ & 40 & MH & $\mid \frac{1}{M}=4,23$ & 9.59 & & & \\
\hline & & & & L & & & & \\
\hline FEEECWATER SYS. FINAL & $(3)^{\prime \prime} D "$ & 120 & MH & \begin{tabular}{|l|l|}
19,63 \\
\end{tabular} & 2.356 & & & \\
\hline " $"$. & ENGG. & 150 & W:t & $\mid \frac{L 2 \pi m_{2} \mid}{M}$ & 3709 & & & \\
\hline & & & & & & & & \\
\hline CONDENSEK SYS. FINA & $A C D E S .(5) " D "$ & 200 & $M H$ & $\frac{-19,63}{M}$ & 3926 & & & \\
\hline ". & ENG. & 150 & $\mathrm{MH}$ & $\frac{124.23 \mid}{M}$ & 3709 & & & \\
\hline & & & & $\frac{L}{M}$ & & & & \\
\hline ZEGEN.HX, FINALDES. & (1)"D" & 40 & $M H^{\prime}$ & $\mid \frac{19,6)}{M}$ & 785 & & & \\
\hline " & $E N G$ & 40 & $M H$ & 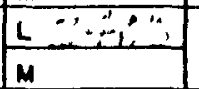 & 959 & & & \\
\hline REJECT HEAT SHS. DES & $(4)^{\prime \prime} D^{\prime \prime},(6)^{\prime \prime} C^{\prime \prime}$ & 220 & MH & $\frac{49,63}{M}$ & $43 / 9$ & & & \\
\hline$" 11$ & $\$ S P E C S-E N G$. & 160 & MH. & \begin{tabular}{|l|l|}
-24.75 \\
\end{tabular} & 3960 & & & \\
\hline LIQ. LEVEL CONTROLS & (3) $c^{\nu}$ & 30 & MH & \begin{tabular}{|l|l|}
4 \\
$M$
\end{tabular} & 590 & & & \\
\hline$\overline{11}$ & ENG. & 30 & $M H^{\prime}$ & $\frac{124.73}{4}$ & 742 & & & \\
\hline
\end{tabular}




\begin{tabular}{|c|c|c|c|c|c|c|c|c|c|c|}
\hline & $A N L-E I$ & NGINEERING & IVISION & \multicolumn{7}{|c|}{ ESTIMATE WORK SHEET } \\
\hline & $\begin{array}{l}\text { PROJECT NOO } \\
\text { 8C } 420 \text { ( }\end{array}$ & 8LOG. NO 310 & \multicolumn{6}{|c|}{ PROJECT TITLE $\operatorname{Snz}-H_{3} \mathrm{O} M \mathrm{MHO}, \mathrm{EM}$} & \multicolumn{2}{|c|}{ 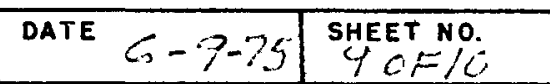 } \\
\hline \multirow{3}{*}{\multicolumn{3}{|c|}{$\begin{array}{l}\text { Dramings } \\
\end{array}$}} & \multicolumn{8}{|c|}{ OESCRIPTION TASK COSTS (SINGLE STAQF SPSYTIM) } \\
\hline & & & \multicolumn{6}{|c|}{\begin{tabular}{|l|l|l|l}
$f=\varphi$ & E \\
\end{tabular}} & \multicolumn{2}{|c|}{ ESTIMATOR } \\
\hline & & & & & & & & & \multicolumn{2}{|c|}{ CHECKED BY } \\
\hline \multicolumn{4}{|c|}{ DESCRIPTION } & QUANTIT & UNIT & $\begin{array}{l}\text { UNIT } \\
\text { COST }\end{array}$ & $\frac{T O T A L}{\text { TABOR }}$ & $\begin{array}{l}\text { COST } \\
\text { MATERIAL }\end{array}$ & TOTAL & REF. \\
\hline \multirow{2}{*}{5} & $\therefore E=E I G E P A$ & GTION UN/T-A & CELCDES, (1) "D" & 40 & MH & $\frac{19.63}{M}$ & 785 & & & \\
\hline & " & $" 1$ & ENG & 40 & MH & $\frac{1}{4} 24,73$ & 959 & & & \\
\hline 5 & & & & & & $\frac{2}{M}$ & & & & \\
\hline \multirow{2}{*}{$\begin{array}{l}5 \\
5\end{array}$} & ELECTRICA & $\angle \angle O A D-P R$ & L.DES. (2)"D" & 80 & MH & $\frac{19,6=1}{M}$ & 1570 & & & \\
\hline & & " & ENG. & 40 & $\mathrm{MH}$ & $\frac{L}{M}=4,7^{\prime}, 3$ & $98 ?$ & & & \\
\hline & & & & & & 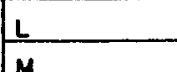 & & & & \\
\hline 5 & PEI. HX $\neq B 0: 4$ & LERELLCONT. & WNAS DES. (3)"E" & 240 & $M H$ & 419,63 & $47 / 2$ & & & \\
\hline \multirow{2}{*}{$\begin{array}{l}5 \\
6\end{array}$} & $"$ & " & ENG. & 240 & MH & $\frac{1 \% 20}{M}$ & 5936 & & & \\
\hline & " & "Froce & UE $\$ Q C .(10 \%)$ & & & $\frac{L}{M}$ & & 59,200 & & \\
\hline 5 & TOTAL SUSTE & EM ELECT, CON & T. PRE,DES.(2)"E" & 280 & M.H. & 419,3 & 5497 & & & \\
\hline \multirow[t]{2}{*}{5} & ' & " & $E N G_{1}$ & 160 & $M !$ & & 3957 & & & \\
\hline & & & & & & $\frac{L}{M}$ & & & & \\
\hline \multirow{2}{*}{5} & INST. SYS. & -PRELIDES, & $(3)^{\prime \prime} E^{\prime \prime}$ & 240 & $M \ddot{C}$ & 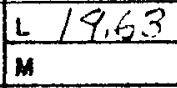 & 4212 & & & \\
\hline & " & $"$ & ENG. & 320 & MH & $\frac{124,53}{4}$ & 7914 & & & \\
\hline 5 & & & & & & $\frac{L}{4}$ & & & & \\
\hline
\end{tabular}




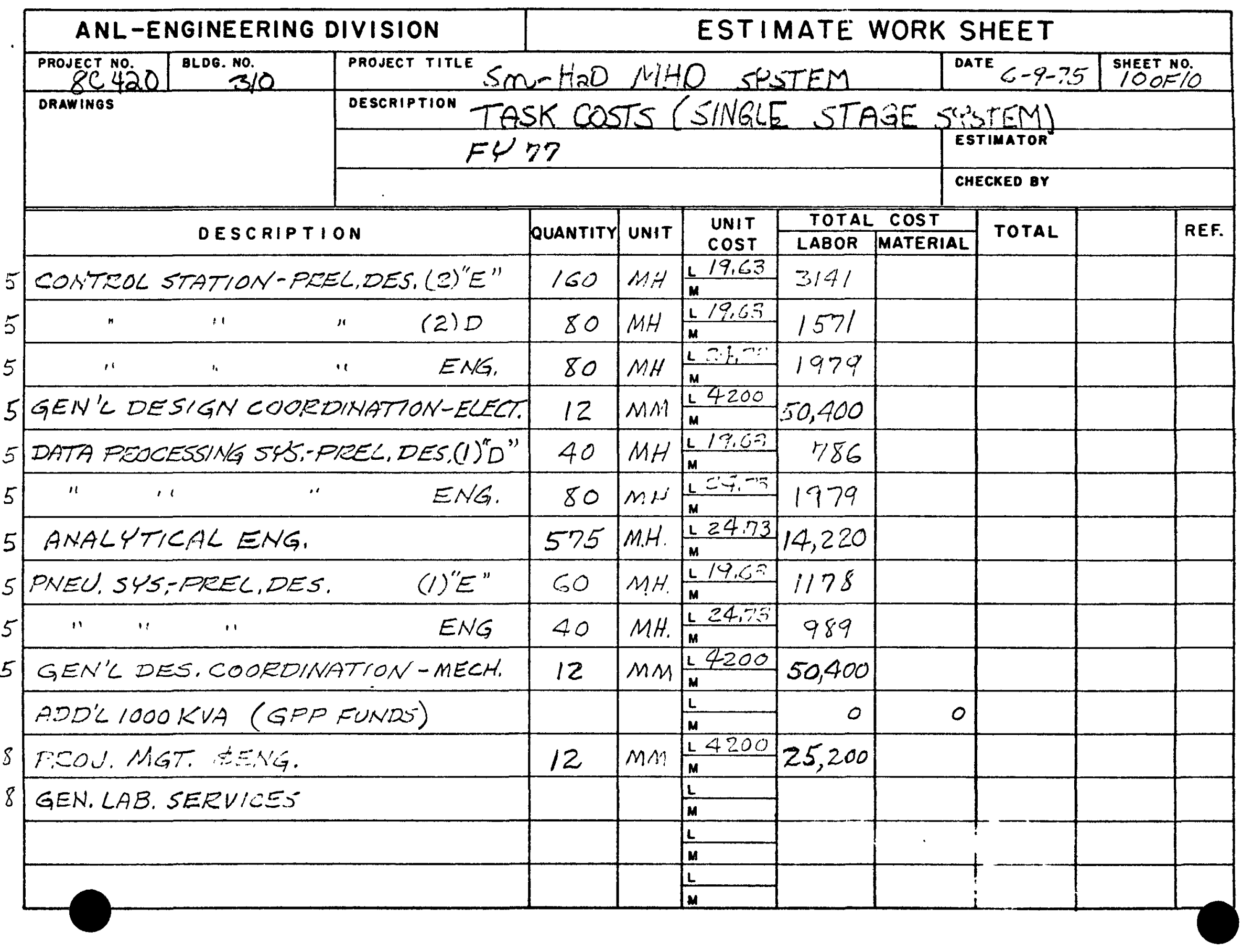




\begin{tabular}{|c|c|c|c|c|c|c|c|c|c|c|c|}
\hline$A N L-E$ & JGINEERING & IVISION & \multicolumn{9}{|c|}{ ESTIMATE WORK SHEET } \\
\hline $\begin{array}{l}\text { PROJECT NOO } \\
\triangle C\end{array} 4.20$ & BLOG. NO. & \multicolumn{6}{|c|}{ PROJECT TITLE SA $-1 / 20$ M//D SISTTEM } & \multicolumn{4}{|c|}{\begin{tabular}{|l|l} 
DATE $6-28-75$ & SHEET
\end{tabular}} \\
\hline \multirow{3}{*}{\multicolumn{2}{|c|}{ DRAWINGS }} & \multicolumn{10}{|c|}{ DESCRIPTION TASHE' COST SUMMAGOU (SIMGLE STIVEE SHSTEM) } \\
\hline & & \multirow{2}{*}{\multicolumn{6}{|c|}{ FY M - BY CATEGORIES }} & \multirow{2}{*}{\multicolumn{4}{|c|}{ 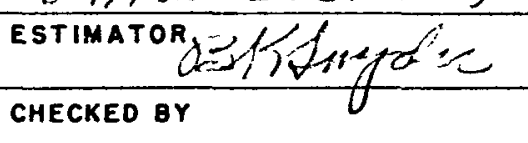 }} \\
\hline & & & & & & & & & & & \\
\hline \multirow{2}{*}{\multicolumn{3}{|c|}{ DESCRIPTION }} & \multirow{2}{*}{\multicolumn{2}{|c|}{ QUANTITY UNIT }} & \multirow{2}{*}{$\begin{array}{l}\text { UNIT } \\
\text { COST }\end{array}$} & \multicolumn{2}{|c|}{ TOTAL COST } & \multirow{2}{*}{\multicolumn{2}{|c|}{ L TOTAL }} & \multirow{2}{*}{ WONTING. } & \multirow{2}{*}{ REF. } \\
\hline & & & & & & LABOR & MATERIAL & & & & \\
\hline \multicolumn{3}{|c|}{ CYCLE \&SYSTEM STIDIES } & $\mid \begin{array}{l}\text { NO CON- } \\
\text { TIMEEXY }\end{array}$ & & $\frac{L}{M}$ & 54,132 & & & 54,432 & 55,000 & \\
\hline \multicolumn{2}{|c|}{ MATES \& KINETICS } & $(2)$ & $"$ & & L & 200,000 & & & 200,070 & 200,500 & \\
\hline \multicolumn{3}{|c|}{ COMPONENT DEVELOPMENT (3) } & $"$ & & $\frac{L}{M}$ & 197,316 & 3,00 & & 200,316 & 30,$0 ; 9$ & * \\
\hline \multicolumn{3}{|c|}{ COMPONENT TEST PROGICAM (A) } & $"$ & & $\frac{L}{M}$ & 237,006 & 28,00 & & 265,006 & $26,5,000$ & \\
\hline \multicolumn{3}{|c|}{ 1. MWT POWEL SYSTEMDESIGN (5) } & \begin{tabular}{|l|}
$20 \% \circ \mathrm{CON}$ \\
$\pi N^{\prime} G \in K C 4$
\end{tabular} & & $\frac{L}{M}$ & 259,335 & & & 259,335 & 312,000 & \\
\hline$" 1$ & $"$ & CONST. (6) & $" 1$ & & $\frac{L}{M}$ & & \multicolumn{2}{|c|}{$1,333,679$} & $1,333,679$ & $1,600,0 x$ & \\
\hline$"$ & $11-2$ & PERATION (†) & $"$ & & $\frac{L}{M}$ & & & & & & \\
\hline \multicolumn{3}{|c|}{ GEN'L PROGRAM-MGT, SERVICES (8) } & " & & $\frac{L}{M}$ & 36,285 & \multicolumn{2}{|c|}{18,000} & 54,288 & 65,000 & \\
\hline & & & & & L & & & & & & \\
\hline & & & & & $\frac{L}{M}$ & & & & & & \\
\hline & & & & & $\frac{L}{M}$ & & & & & & \\
\hline & & & & & $\frac{L}{M}$ & & & & & & \\
\hline & & & & & $\frac{L}{M}$ & & & & & & \\
\hline *WAS 25 & $0,000 \mathrm{NNPE}$ & LIMINARYS RE. & & & $\frac{L}{M}$ & & & & & & \\
\hline POFT & SUBMITTE & $0=-25-15$ & & & $\frac{L}{M}$ & & & & & & \\
\hline
\end{tabular}




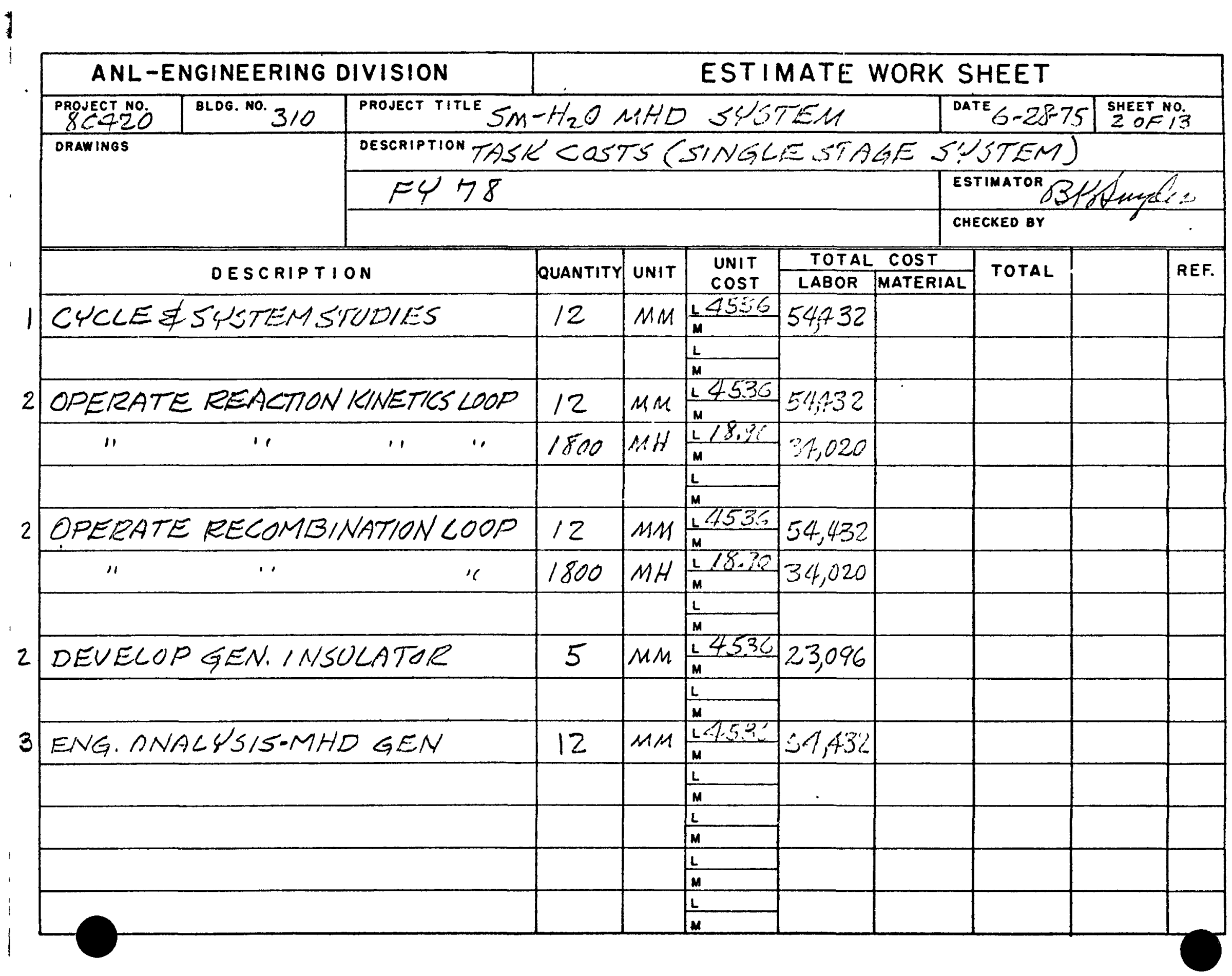




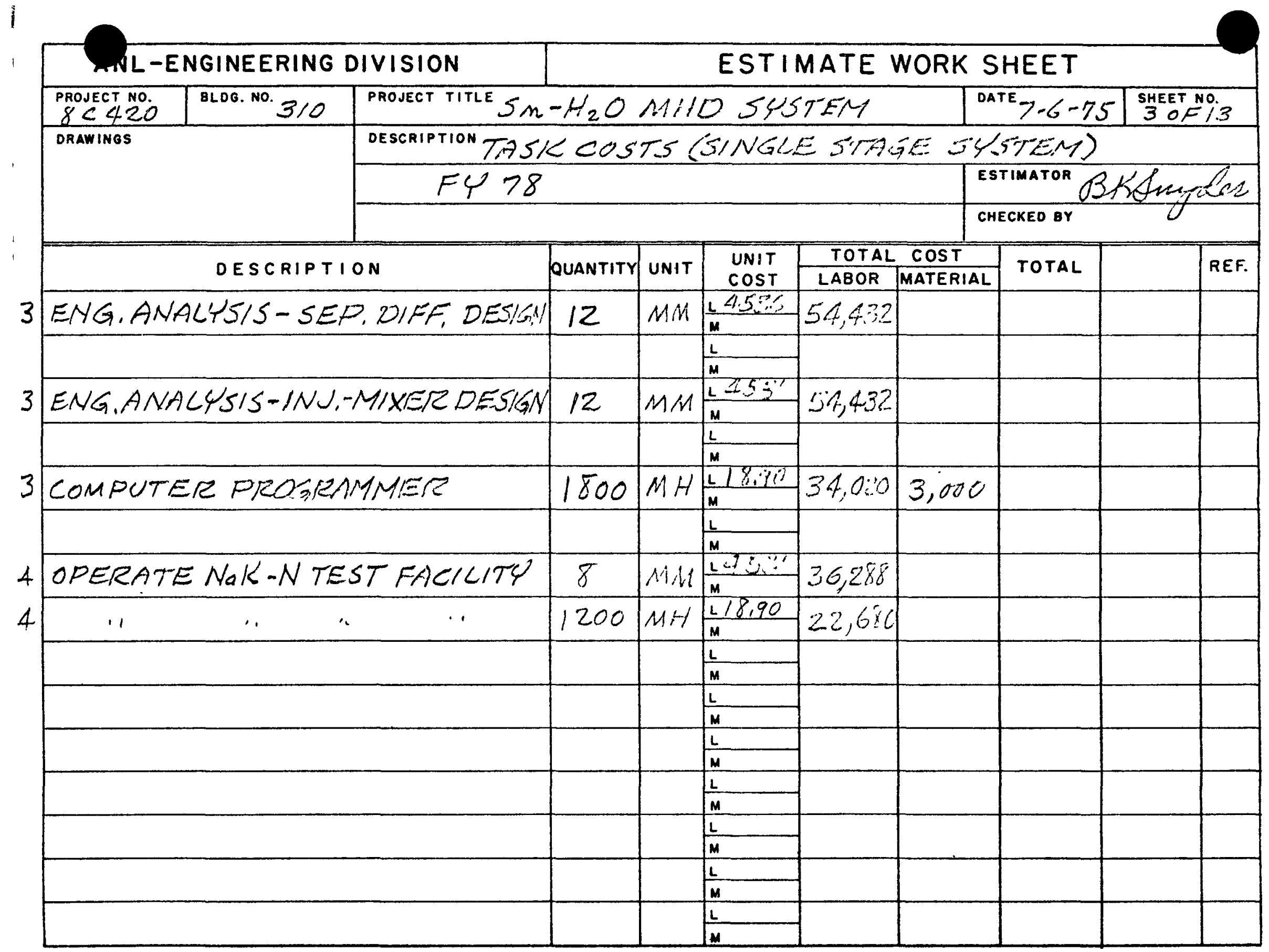




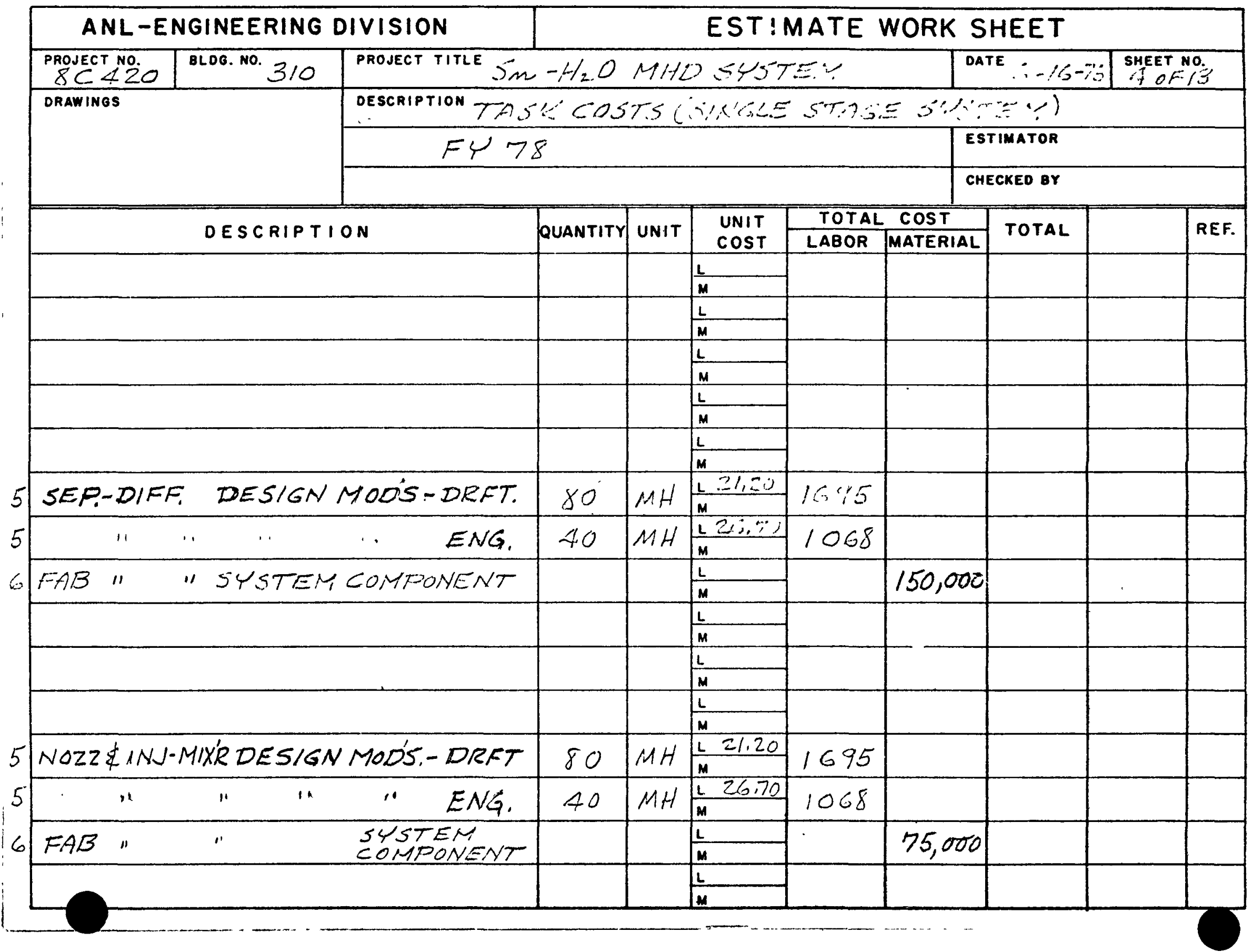




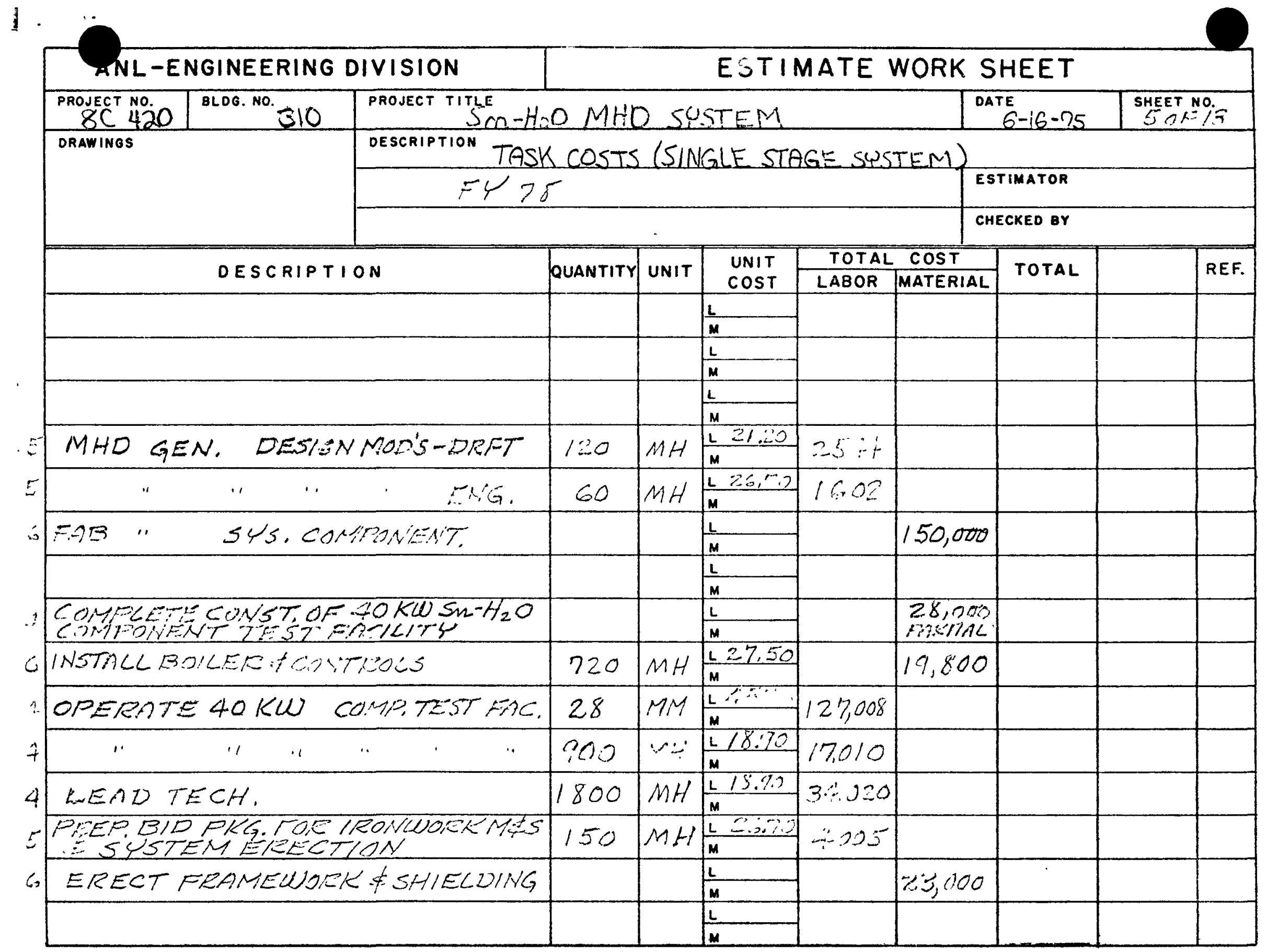




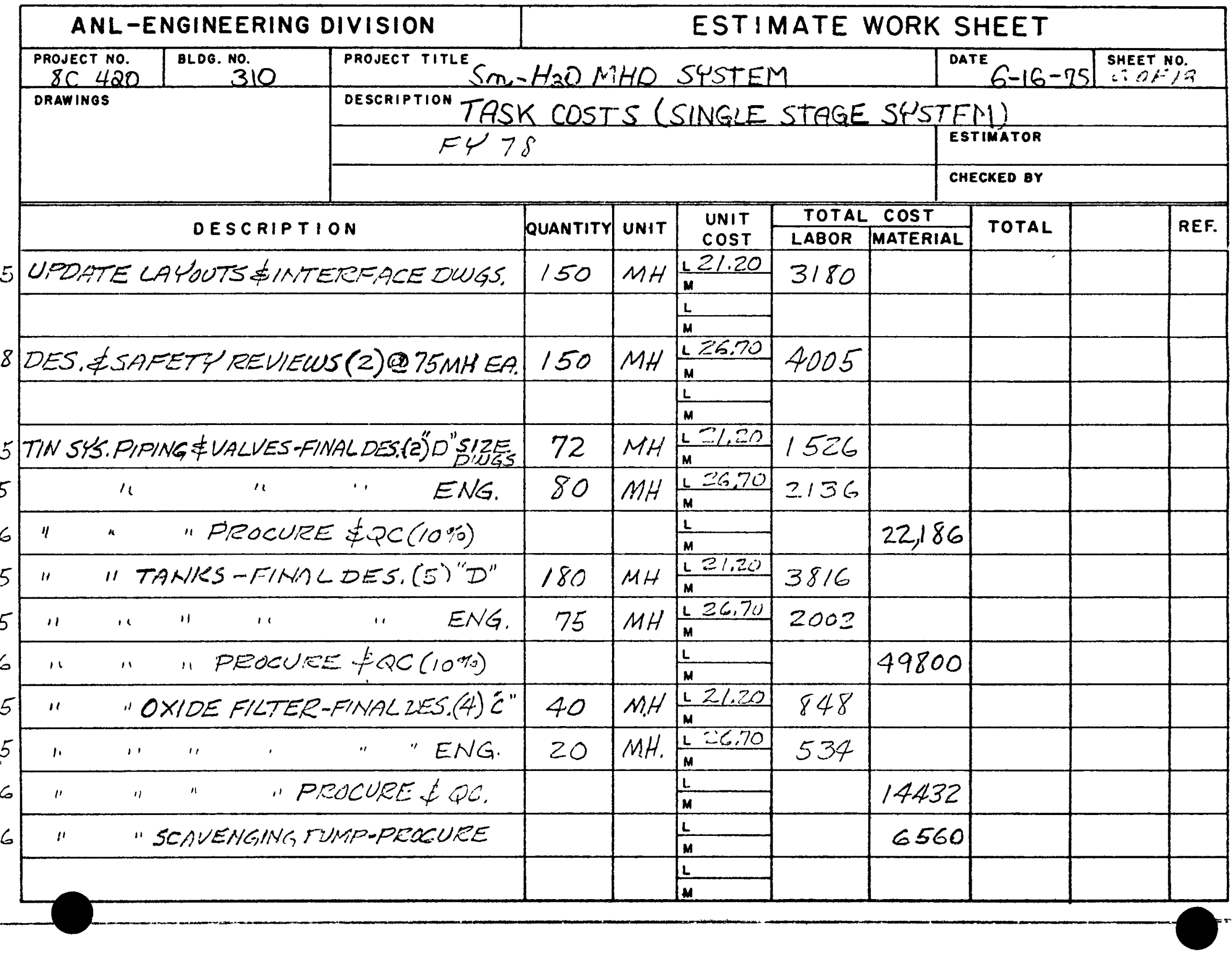




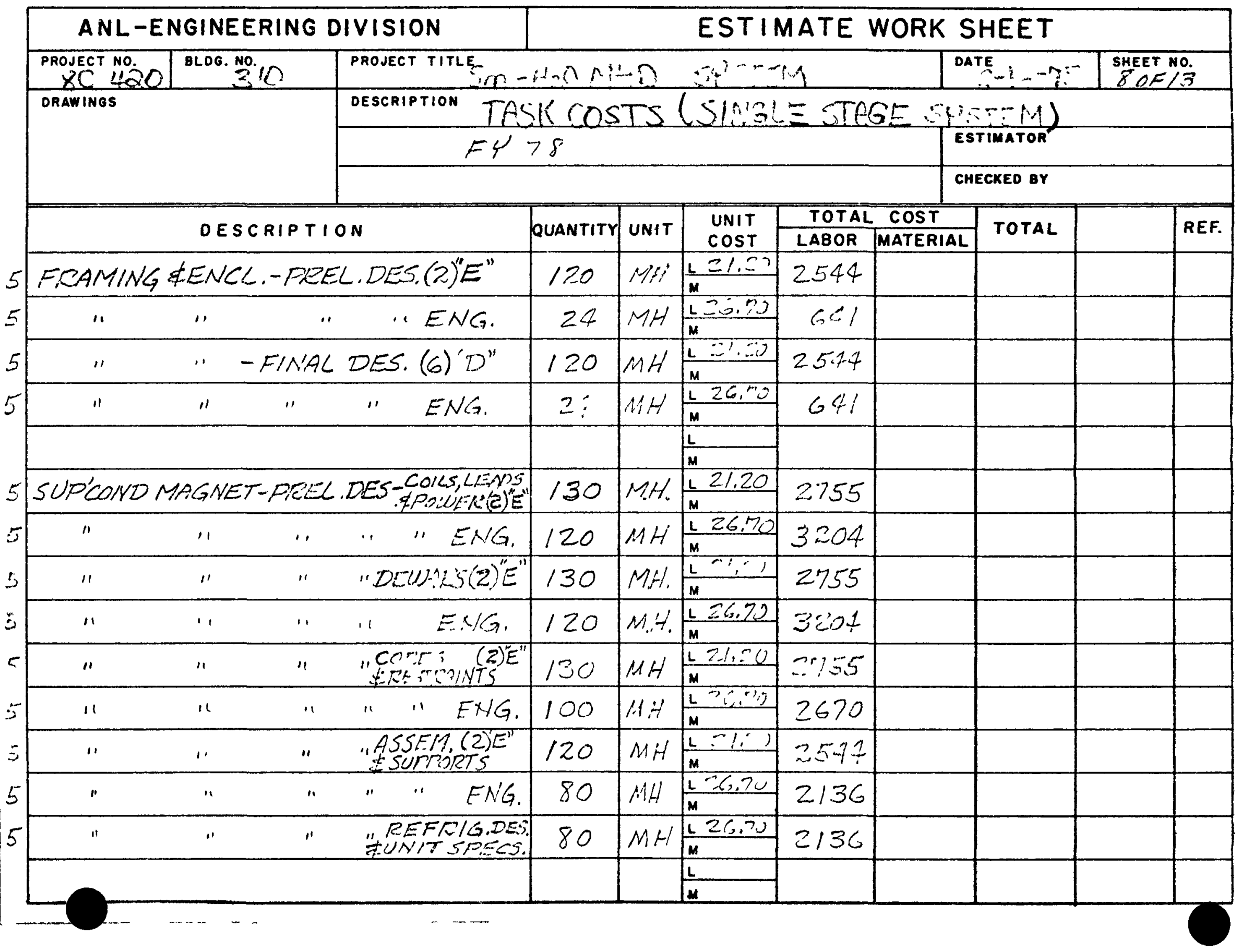




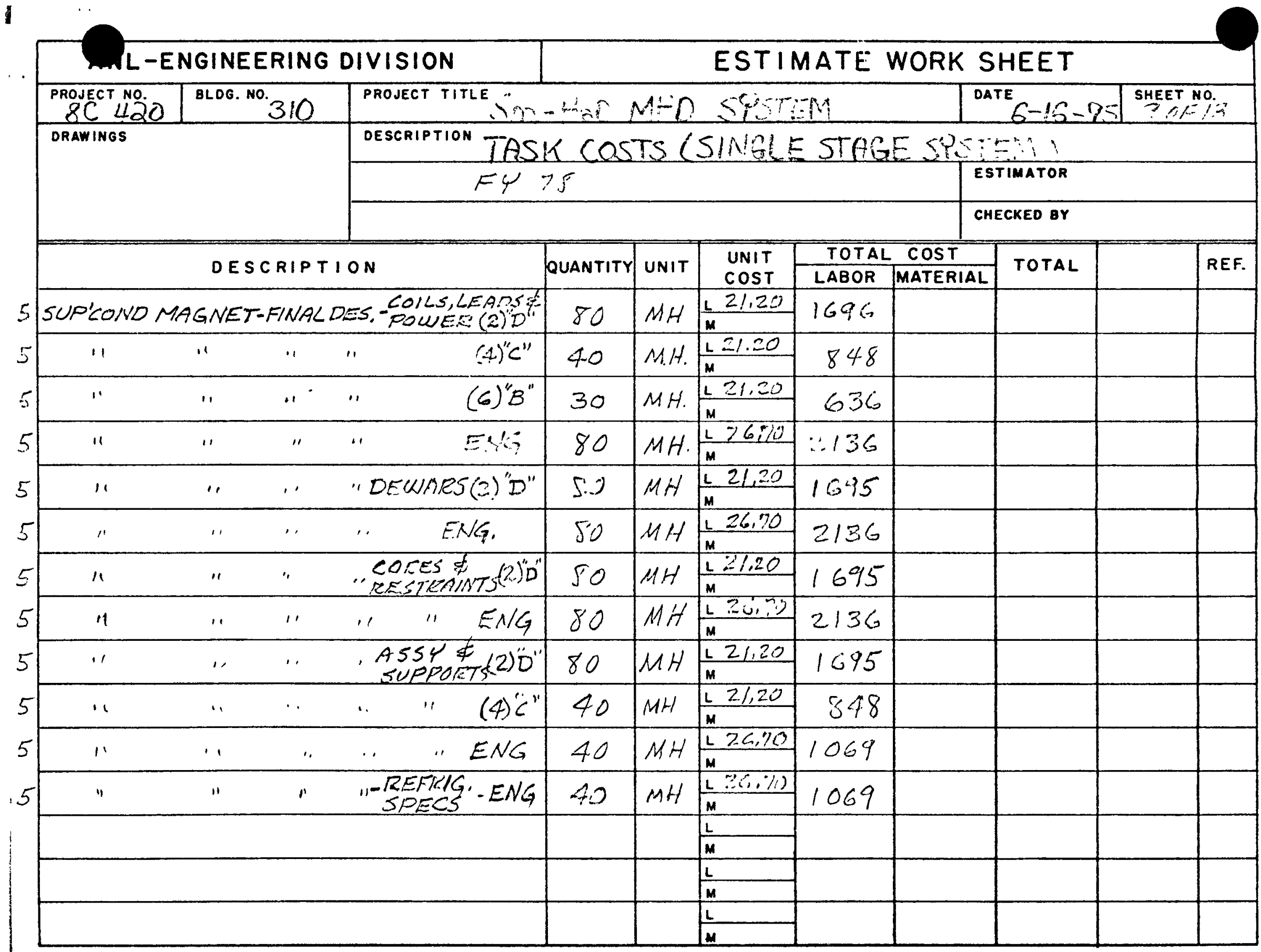




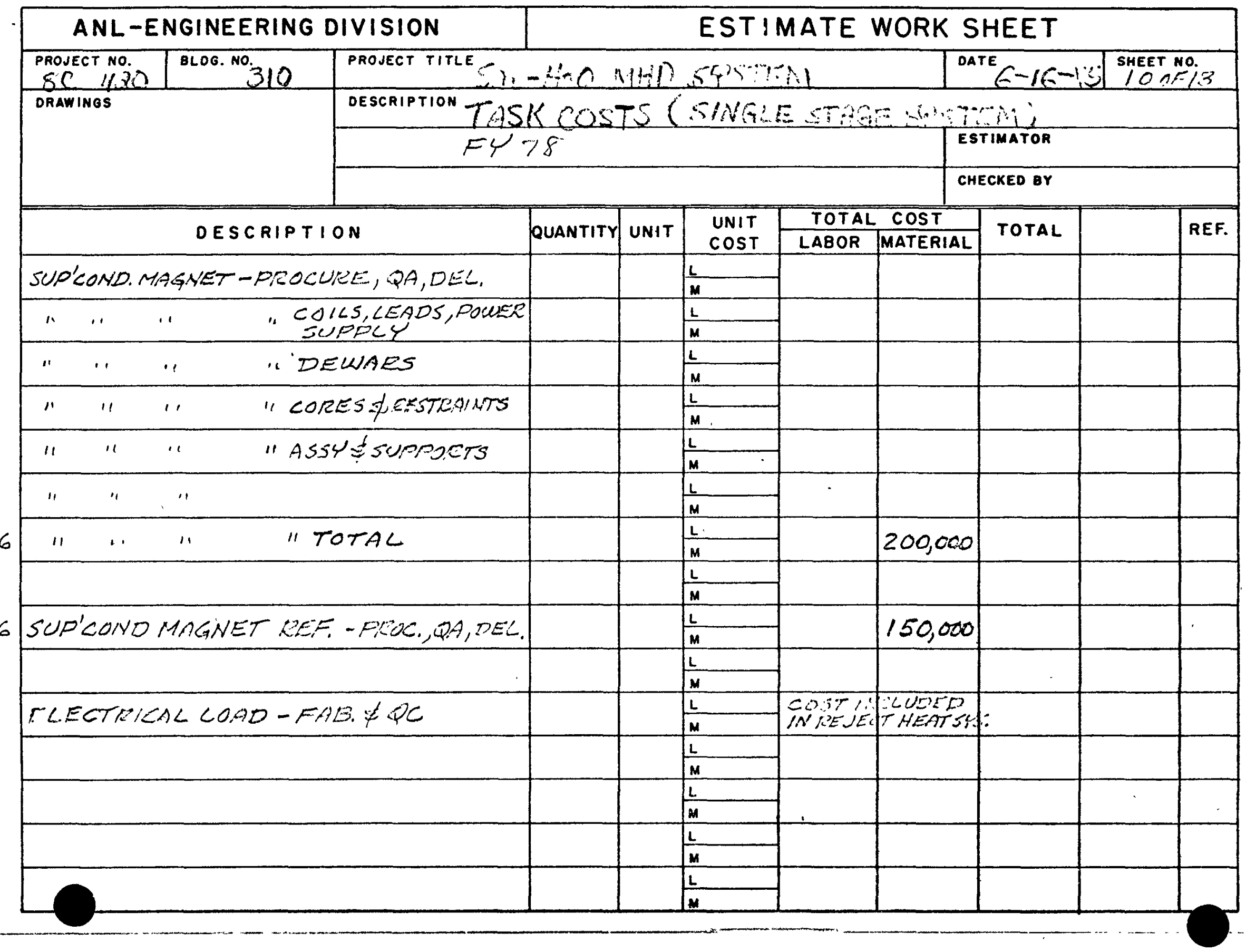




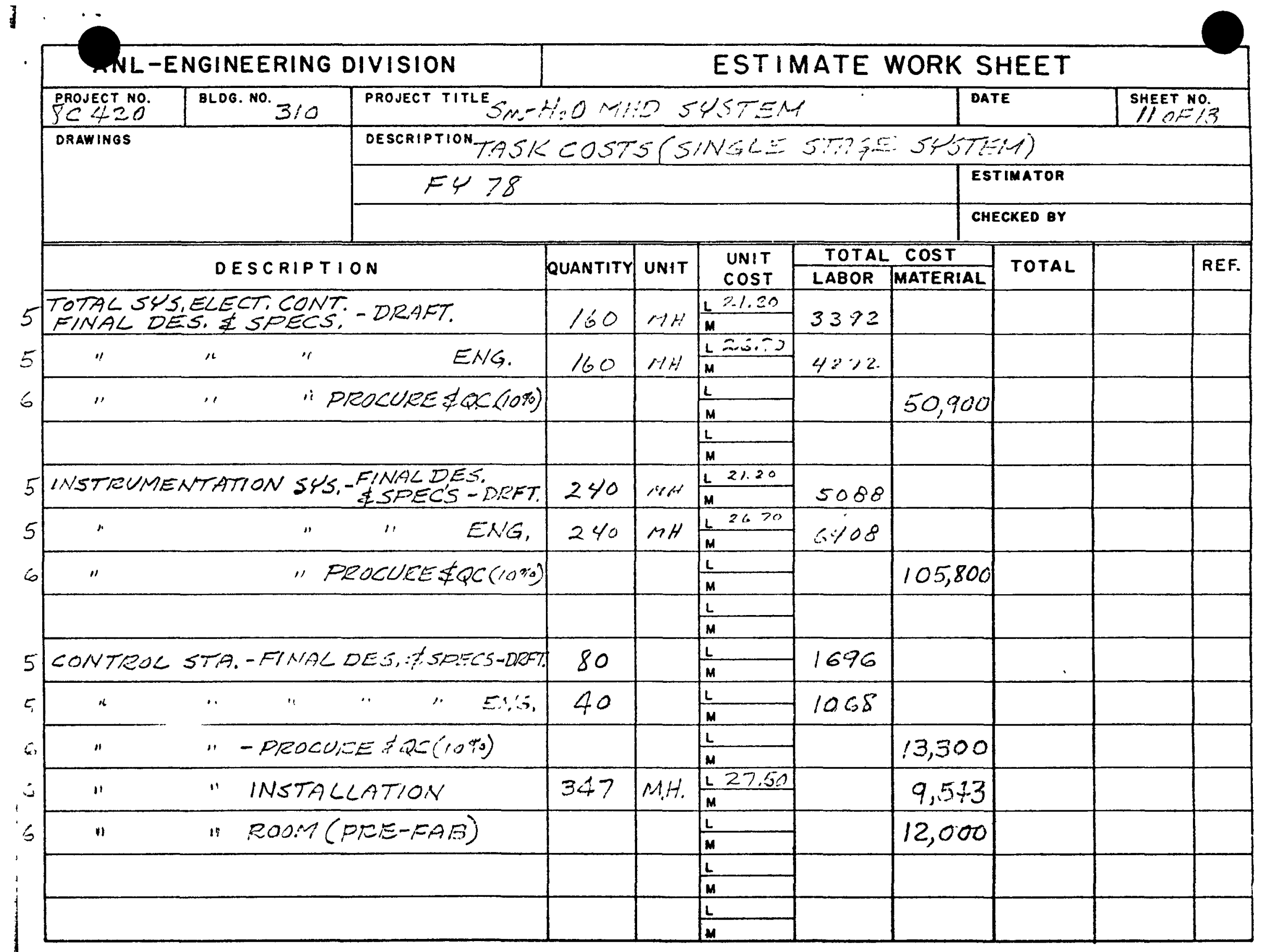




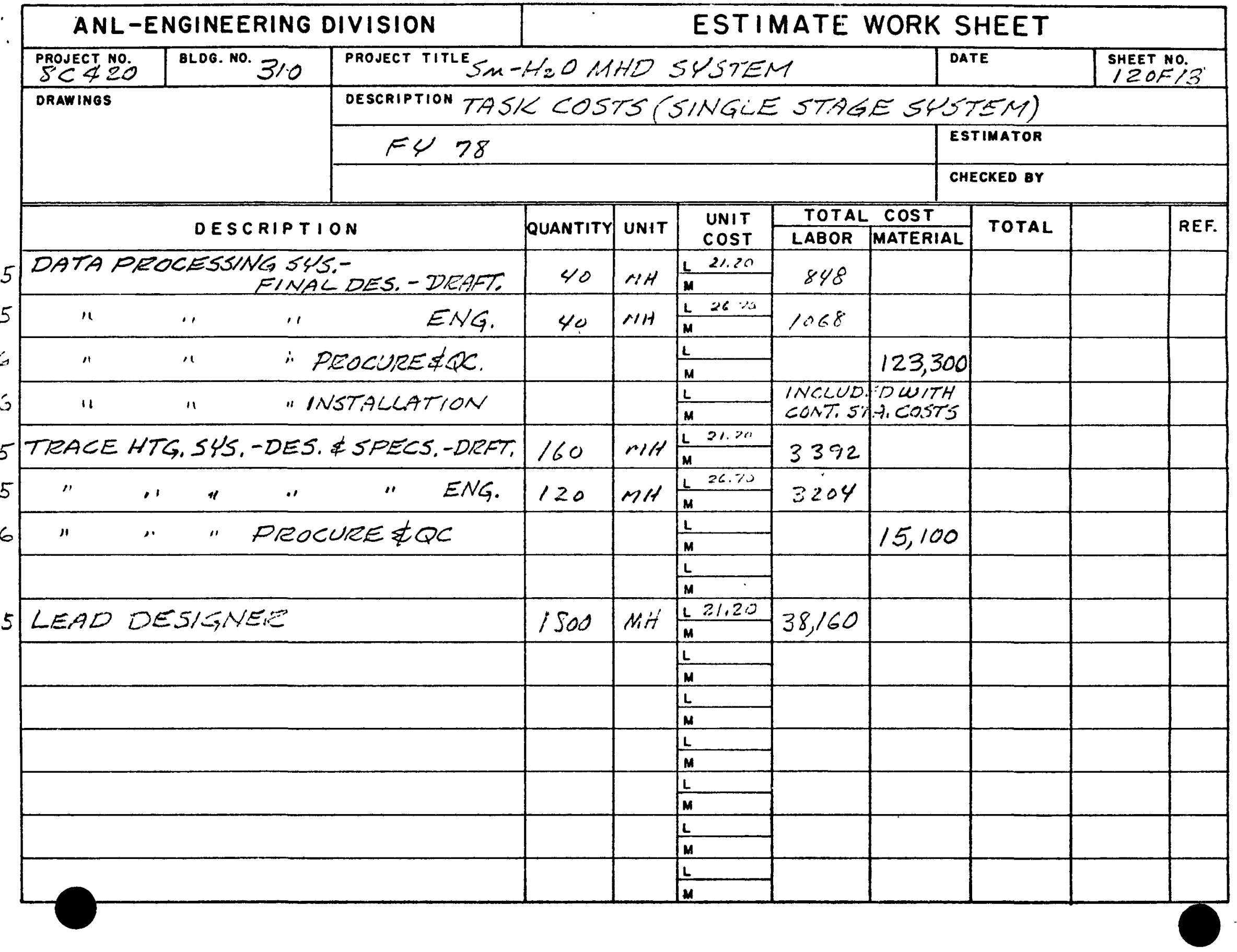




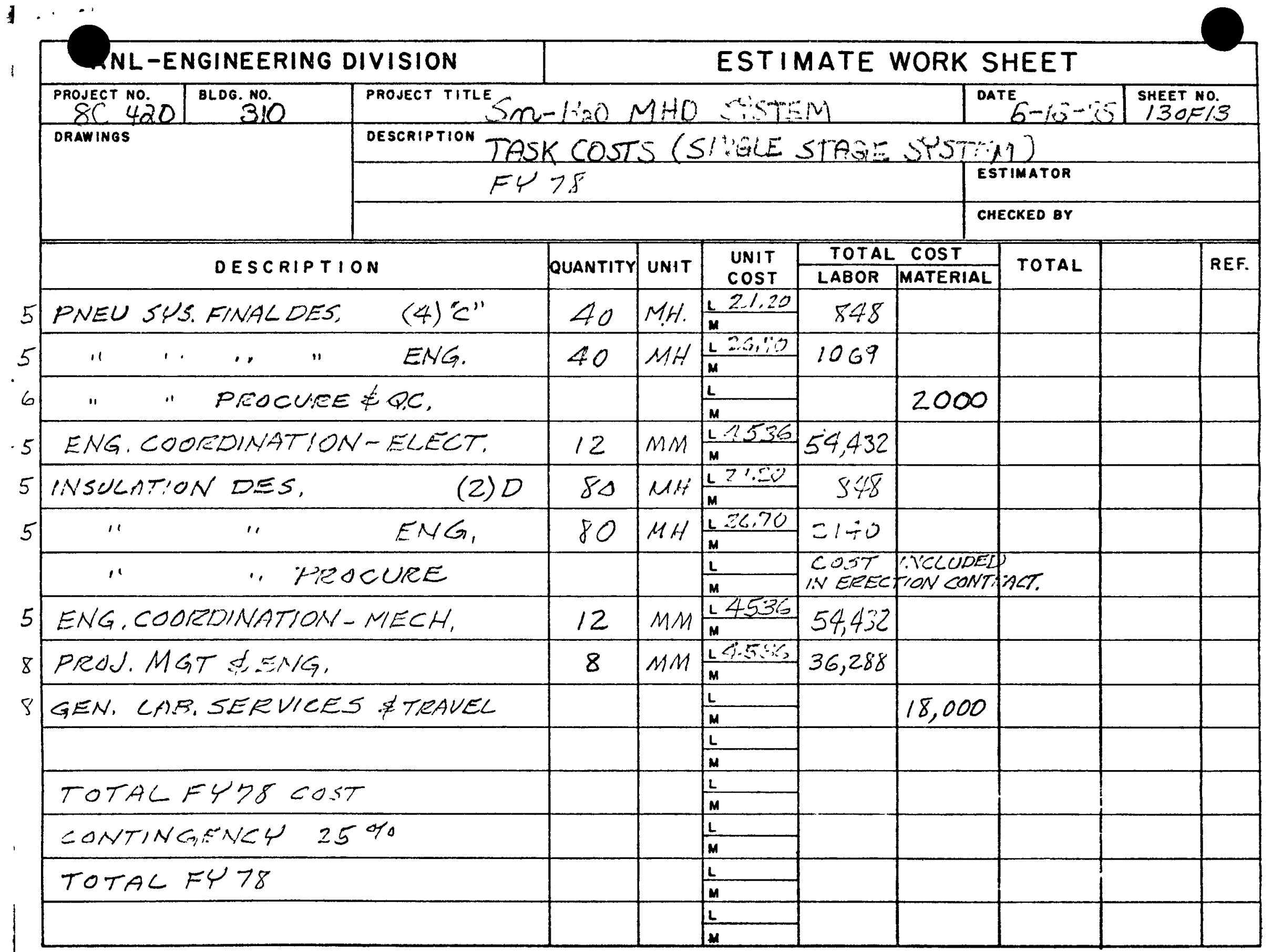




\section{EST I MATE WORK SHEET}

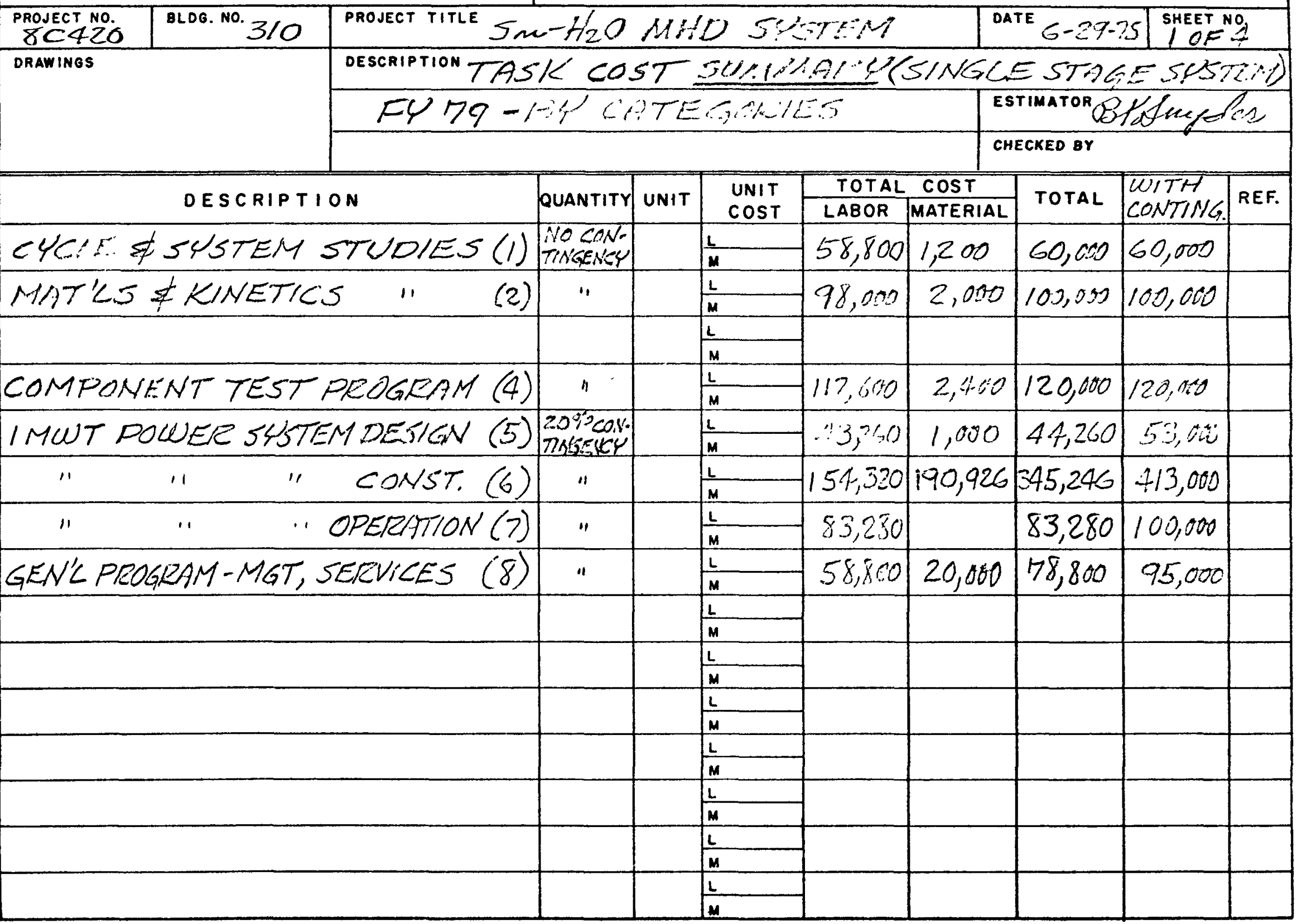




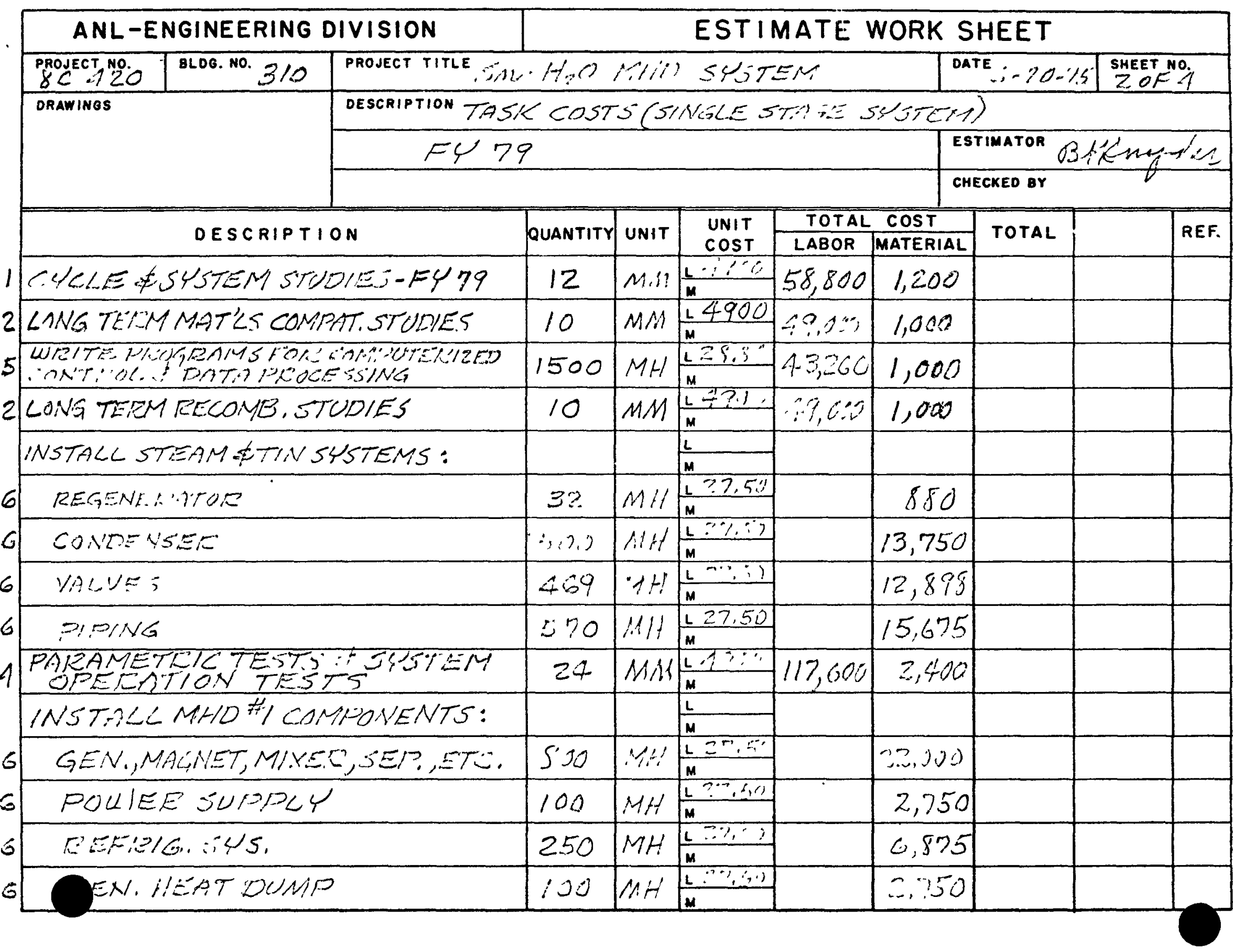




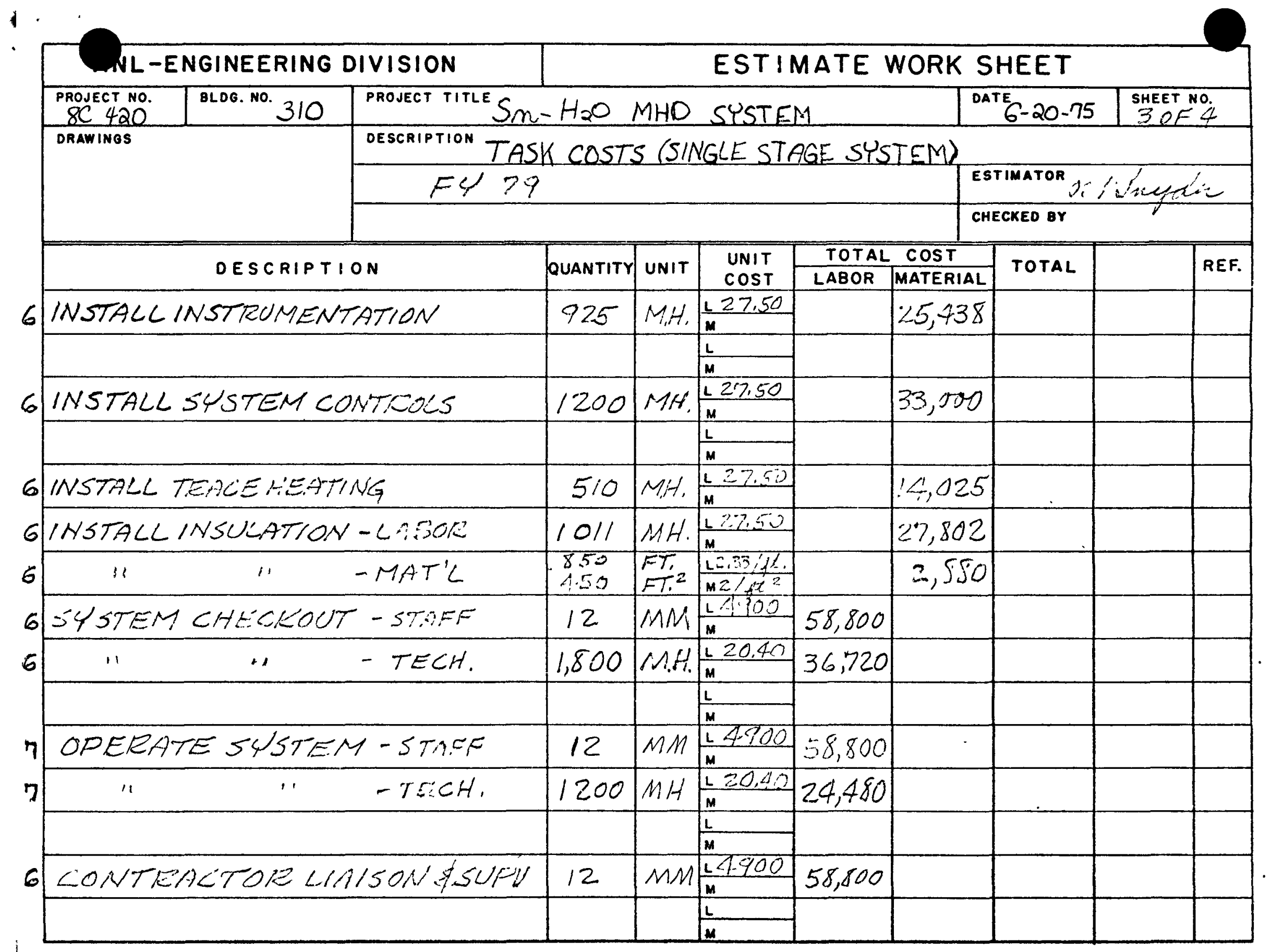




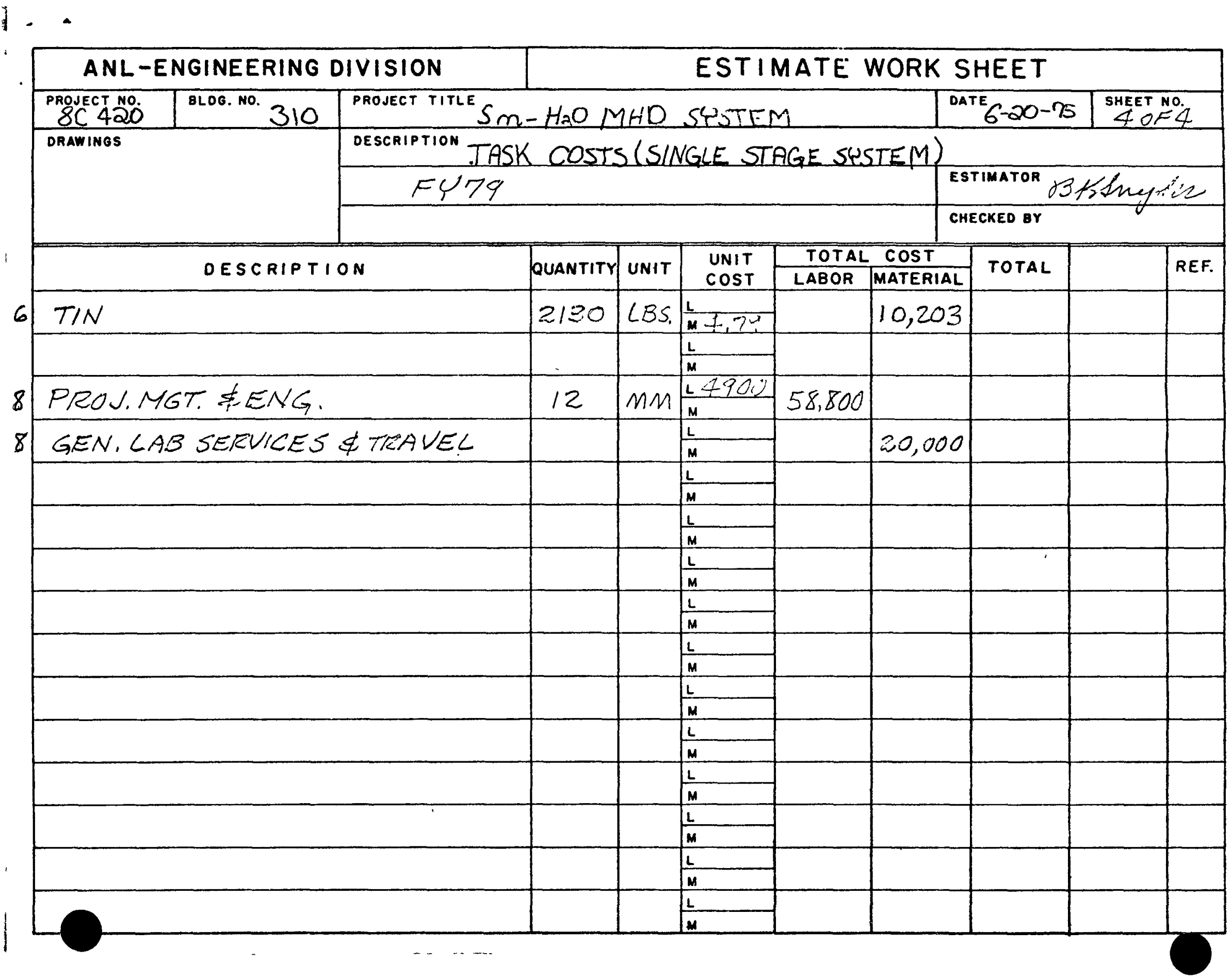




\begin{tabular}{|c|c|c|c|c|c|c|c|c|c|c|c|}
\hline NL-E & IGINEERING & DIVISION & \multicolumn{9}{|c|}{ ESTIMATE WORK SHEET } \\
\hline $\begin{array}{l}\text { PROJECT NO. } \\
S^{\prime} C \cdot 20\end{array}$ & BLOG. NO. 310 & \multicolumn{6}{|c|}{ 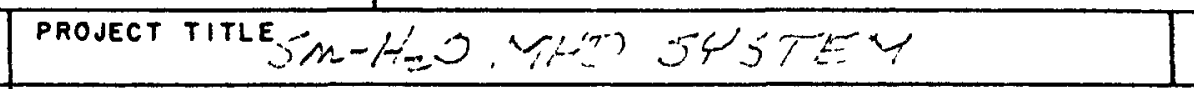 } & \multicolumn{4}{|c|}{ DATE $6-22.757^{\text {SHEET }}$ OFO } \\
\hline \multirow{3}{*}{\multicolumn{2}{|c|}{ DRAWINGS }} & \multicolumn{10}{|c|}{ 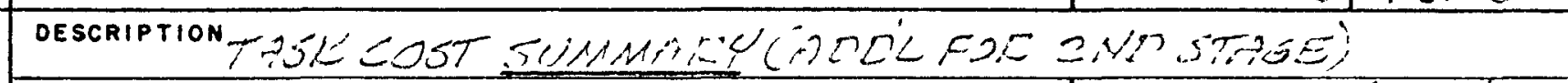 } \\
\hline & & \multicolumn{6}{|c|}{ FY $77-34$ CATtG\% } & \multicolumn{4}{|c|}{ 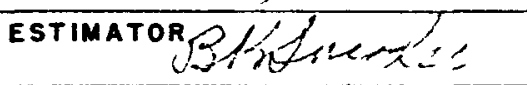 } \\
\hline & & & & & & & & \multicolumn{2}{|c|}{ CHECKED BY } & \\
\hline \multirow{2}{*}{\multicolumn{3}{|c|}{ DESCRIPTION }} & QUANTITY & UNIT & UNIT & TOTAL & $\cos T$ & & & wirti & REF. \\
\hline & & & & & $\cos T$ & LABOR & MATERIA & & TOTAL & CON & \\
\hline \multicolumn{3}{|c|}{ 1.MWT POWER SYSTEM-DESIGN (5) } & $\begin{array}{l}20 \% 5 \operatorname{CoN}- \\
\text { THESECY }\end{array}$ & & $\frac{L}{M}$ & $-1 \hat{2}, 2=1$ & & & $46,2=1$ & 53,000 & \\
\hline \multirow[t]{20}{*}{11} & $" 1$ & CONST. (6) & $"$ & & $\frac{L}{M}$ & & 14,43 & & 14,433 & 15,000 & \\
\hline & & & & & $L$ & & & & & & \\
\hline & & & & & $L$ & & & & & & \\
\hline & & & & & $M$ & & & & & & \\
\hline & & & & & $L$ & & & & & & \\
\hline & & & & & $M$ & & & & & & \\
\hline & & & & & $\frac{L}{M}$ & & & & & & \\
\hline & & & & & $L$ & & & & & & \\
\hline & & & & & $\frac{M}{L}$ & & & & & & \\
\hline & & & & & $M$ & & & & & & \\
\hline & & & & & $L$ & & & & & & \\
\hline & & & & & $\mid \frac{m}{L}$ & & & & & & \\
\hline & & & & & $M$ & & & & & & \\
\hline & & & & & $L$ & & & & & & \\
\hline & & & & & $M$ & & & & & & \\
\hline & & & & & $\frac{L}{M}$ & & & & & & \\
\hline & & & & & $L$ & . & & & & & \\
\hline & & & & & L & & & & & & \\
\hline & & & & & M & & & & & & \\
\hline & & & & & $L$ & & & & & & \\
\hline
\end{tabular}




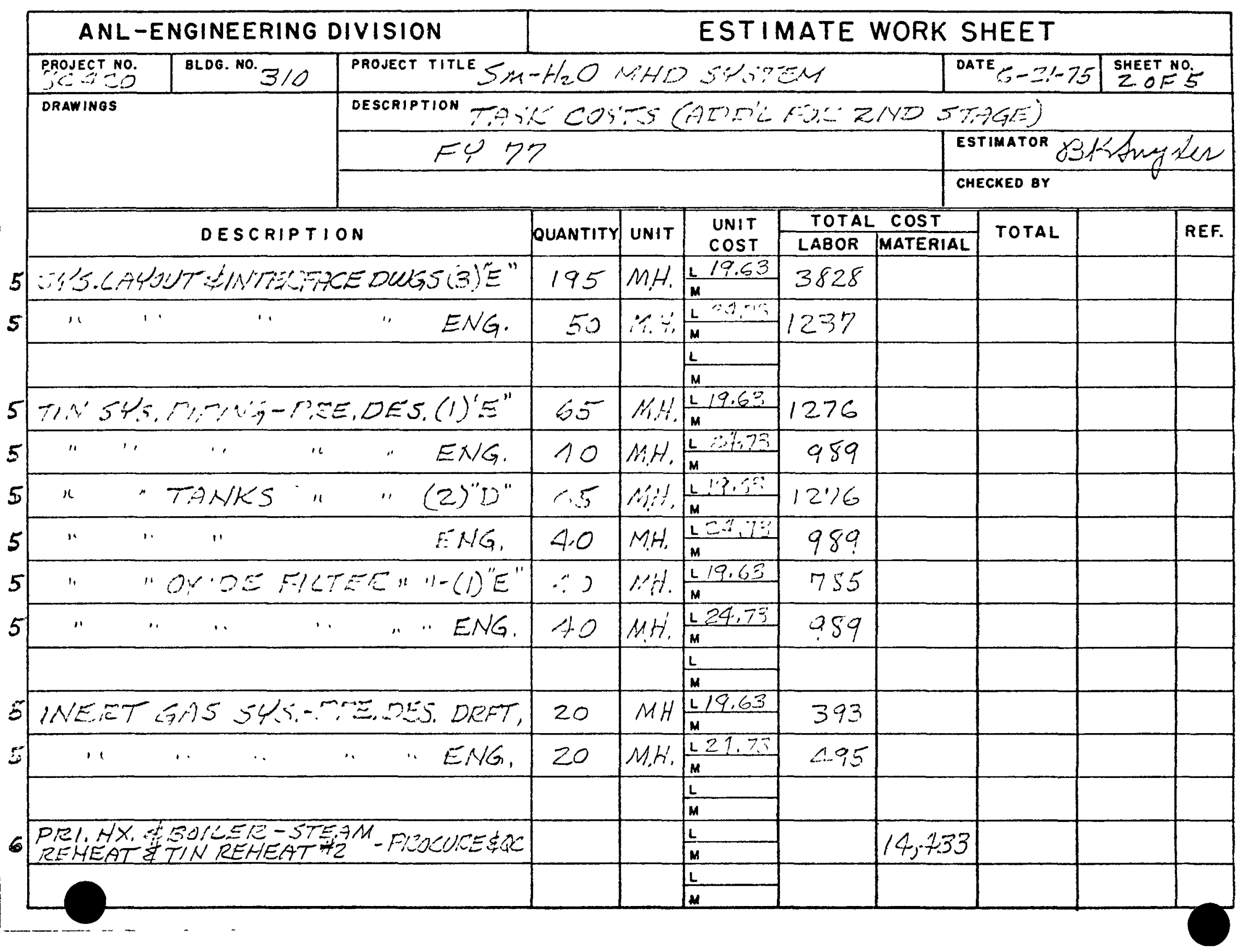




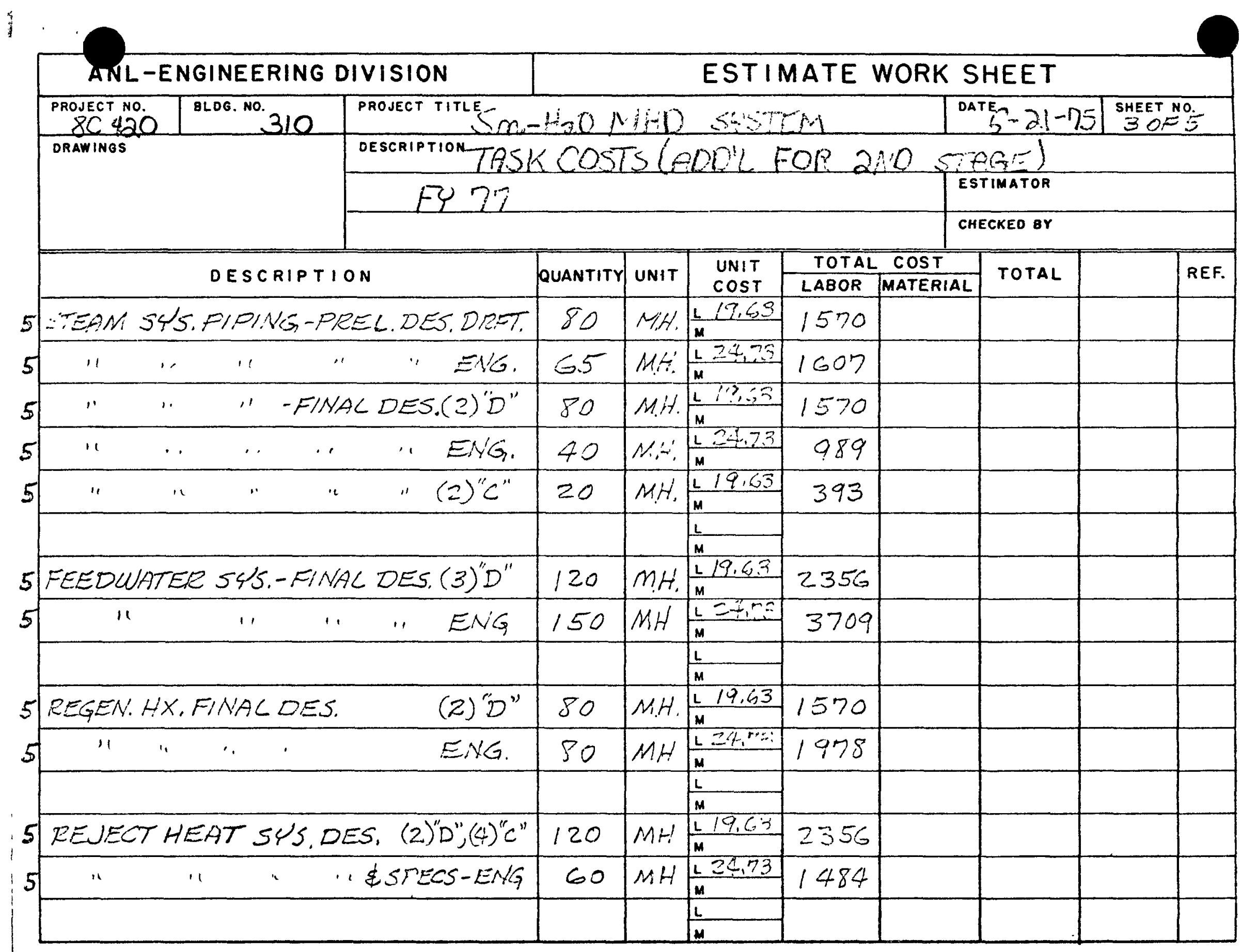




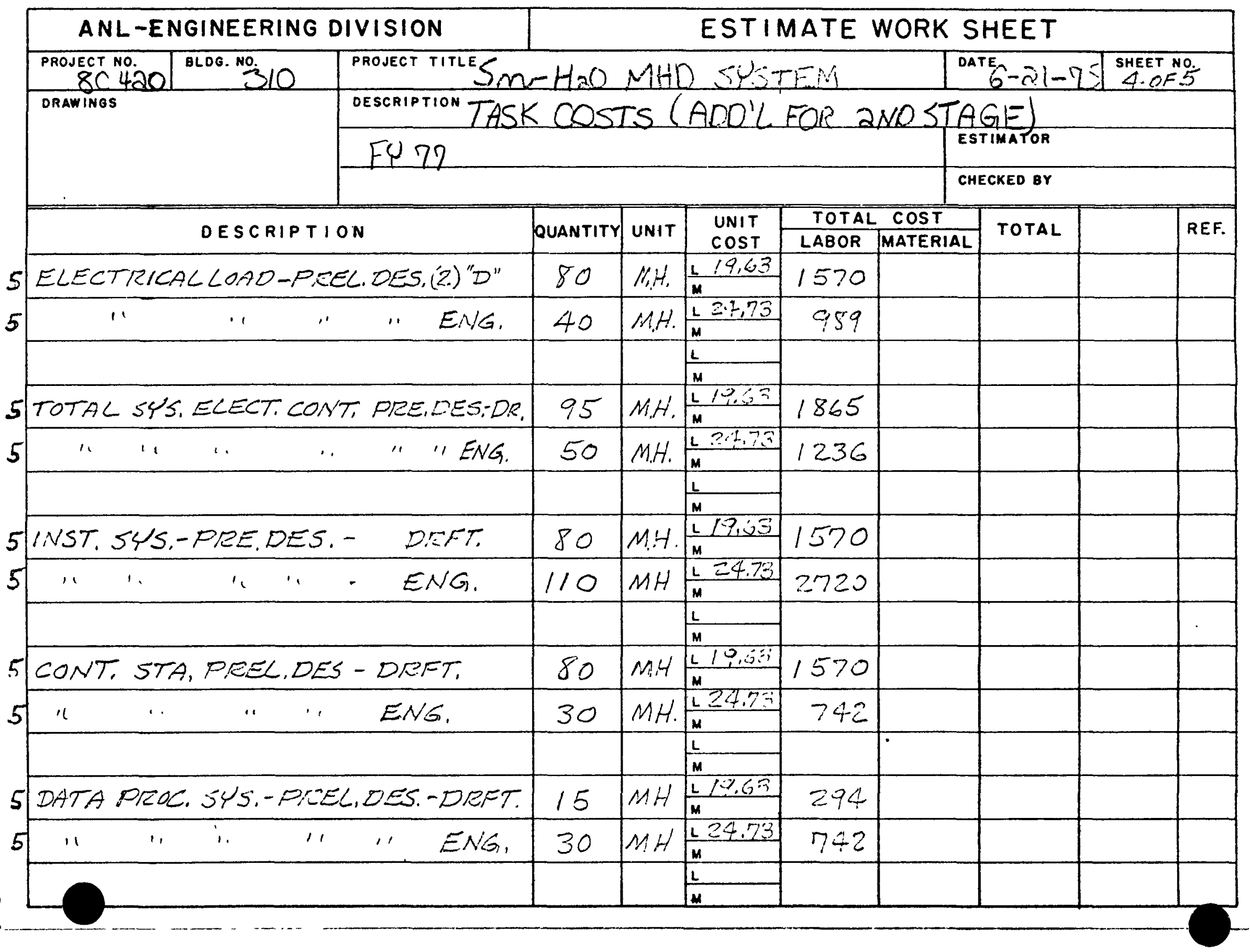




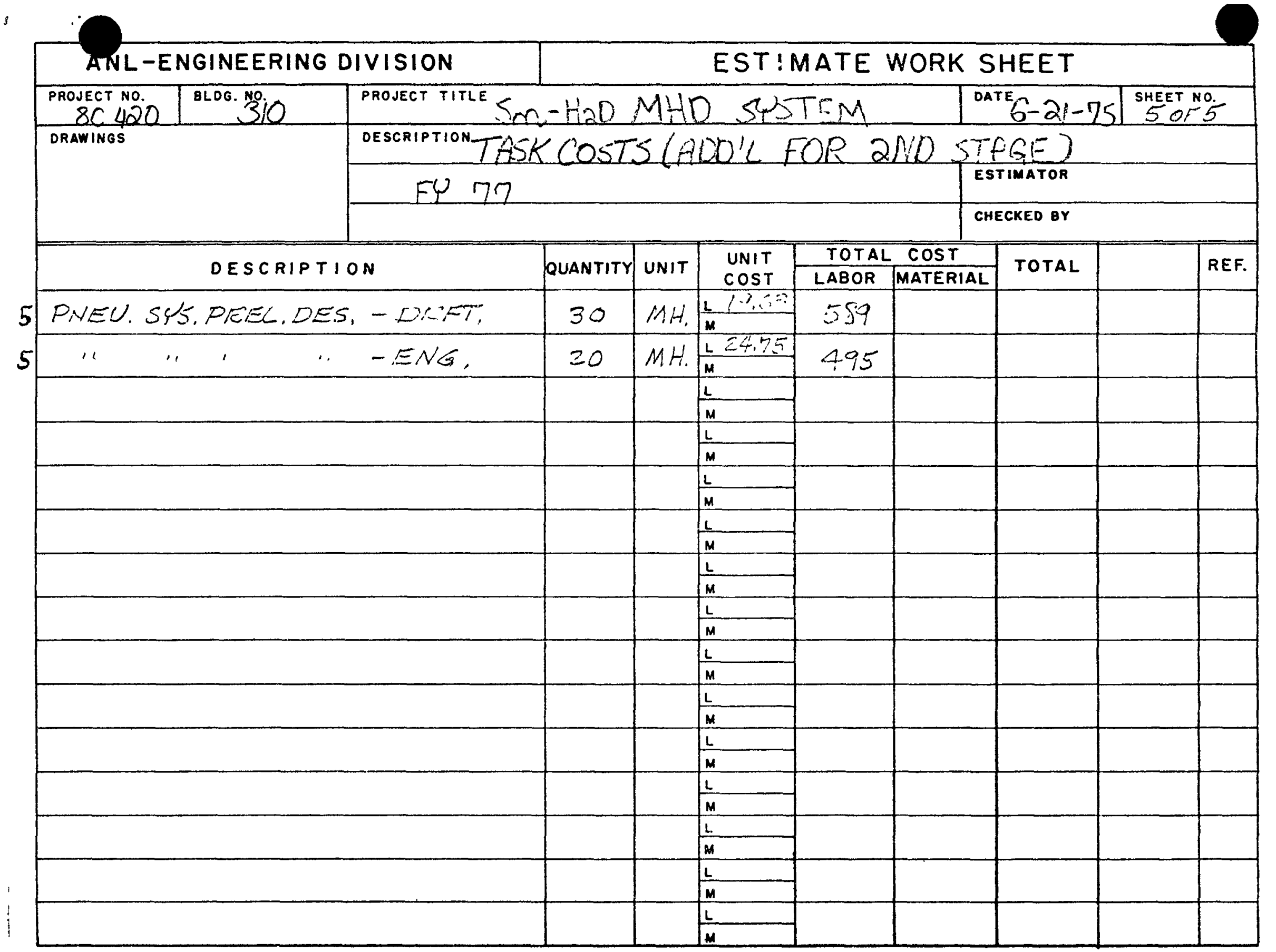




\begin{tabular}{|c|c|c|c|c|c|c|c|c|c|c|c|}
\hline ATNL-E & NGINEERINC & IVISION & \multicolumn{9}{|c|}{ ESTIMATE WORK SHEET } \\
\hline \begin{tabular}{|l} 
PROJECT NO \\
$S=120$ \\
\end{tabular} & BLOG. NO. 310 & \multicolumn{6}{|c|}{ PROJECT TITLE SM- 1120 N,HD STS:TEN } & \multicolumn{4}{|c|}{ 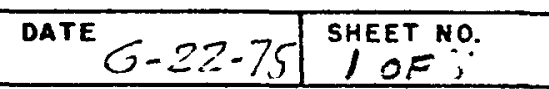 } \\
\hline \multirow{3}{*}{\multicolumn{2}{|c|}{\begin{tabular}{|l} 
DRAWINGS \\
\end{tabular}}} & \multicolumn{10}{|c|}{ 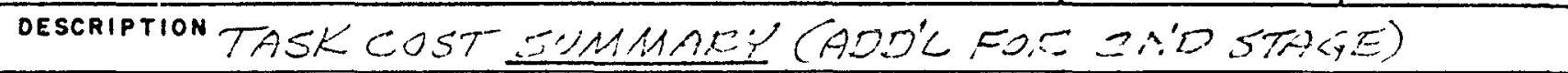 } \\
\hline & & \multicolumn{7}{|c|}{ FY 78 - BY CATEGCMEIES } & \multicolumn{3}{|c|}{ 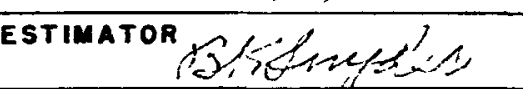 } \\
\hline & & & & & & & & \multicolumn{4}{|c|}{ CHECKED BY $Y$} \\
\hline \multirow{2}{*}{\multicolumn{3}{|c|}{ DESCRIPTION }} & \multirow{2}{*}{ QUANTITY } & \multirow{2}{*}{ UNIT } & \multirow{2}{*}{$\begin{array}{l}\text { UNIT } \\
\text { COST }\end{array}$} & \multirow{2}{*}{\multicolumn{3}{|c|}{ TOTAL COST }} & & \multirow{2}{*}{$\begin{array}{l}\text { CUITH } \\
\text { CONTING }\end{array}$} & \multirow{2}{*}{ REF. } \\
\hline & & & & & & & & & & & \\
\hline \multicolumn{3}{|c|}{ 1.MWT POWEE SYSTEM-DESIGN (5) } & $\begin{array}{l}20 \text { d } 2014 \\
\text { TINGENCY }\end{array}$ & & & 64,515 & & & 64,315 & $7 \%, 000$ & \\
\hline " & $" 1$ & $\angle O M S T .(6)$ & $" 1$ & & $\frac{L}{M}$ & 12,015 & \multicolumn{2}{|l|}{865,153} & 877,168 & $1,05.3000$ & * \\
\hline \multicolumn{3}{|c|}{ GEN'LPEOGRAM -MGT., SERVICES (8) } & \multirow[t]{2}{*}{." } & & $L$ & & \multicolumn{2}{|c|}{4,000} & 4,000 & 5,100 & \\
\hline & & & & & $\frac{L}{M}$ & & & & & & \\
\hline & & & & & L & & & & & & \\
\hline & & & & & $\frac{L}{M}$ & & & & & & \\
\hline & & & & & $L$ & & & & & & \\
\hline & & & & & $M$ & & & & & & \\
\hline & & & & & $\frac{L}{M}$ & & & & & & \\
\hline & & & & & $L$ & & & & & & \\
\hline & & & & & $L$ & & & & & & \\
\hline & & & & & $M$ & & & & & & \\
\hline & & & & & $\frac{L}{M}$ & & & & & & \\
\hline & & & & & $L$ & & & & & & \\
\hline & & & & & $M$ & & & & & & \\
\hline & & & & & $\frac{L}{M}$ & & & & & & \\
\hline * WAS 8 & $15,060 \mathrm{~N}:$ & 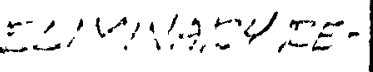 & & & $\frac{L}{M}$ & & & & & & \\
\hline$\Sigma)=F$ & 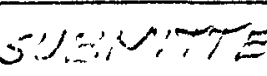 & $0-25.75$ & & & $\frac{L}{M}$ & & & & & & \\
\hline
\end{tabular}




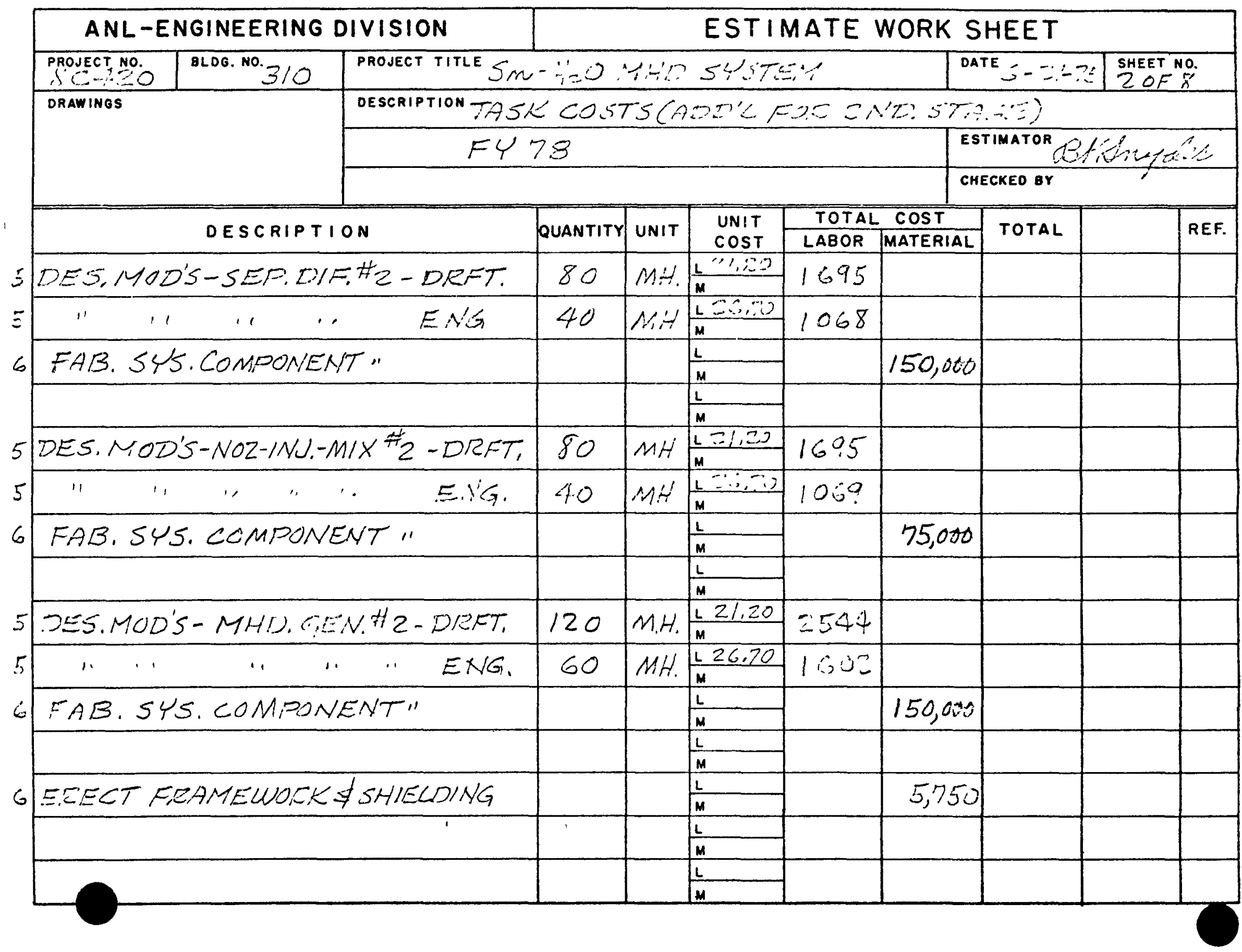




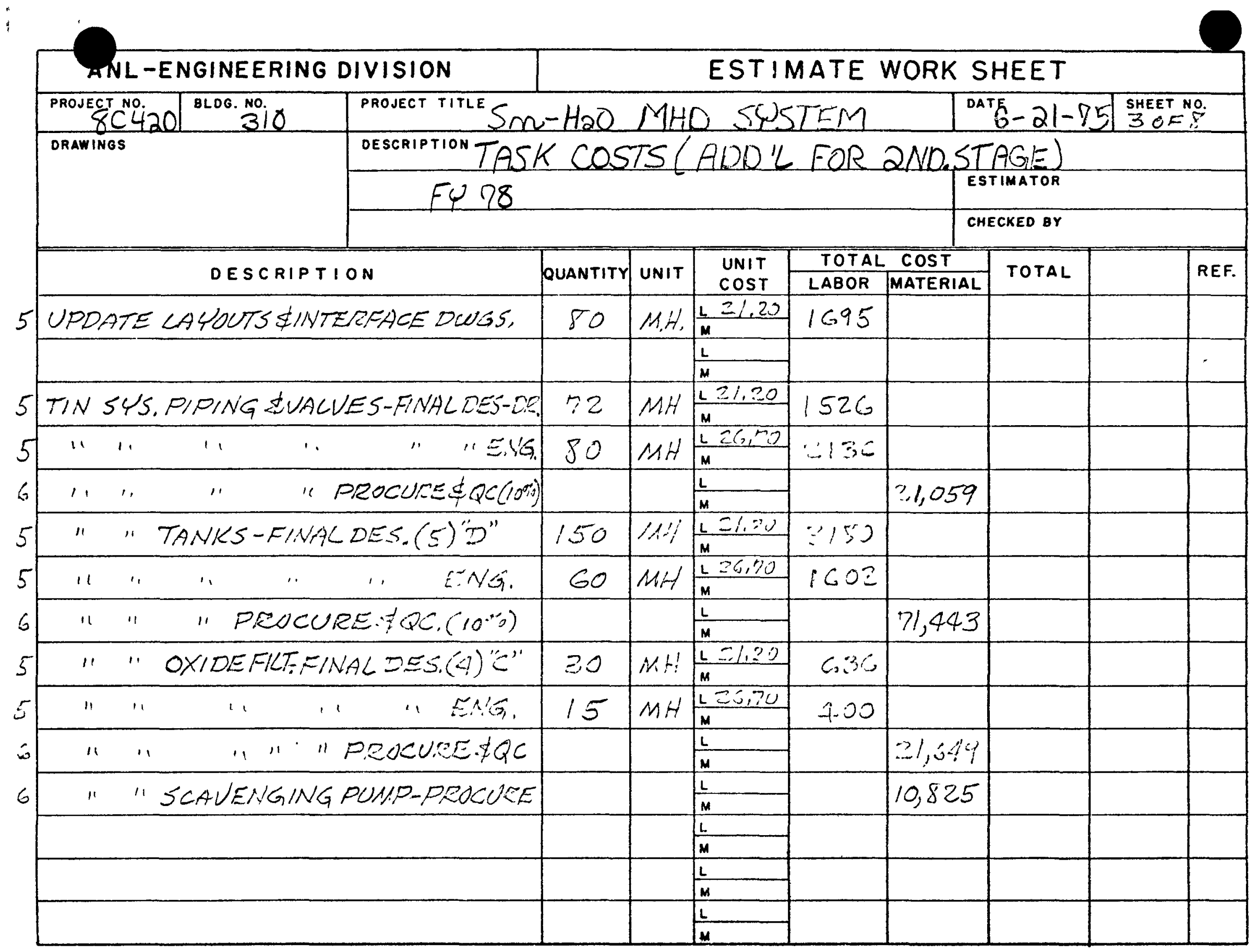




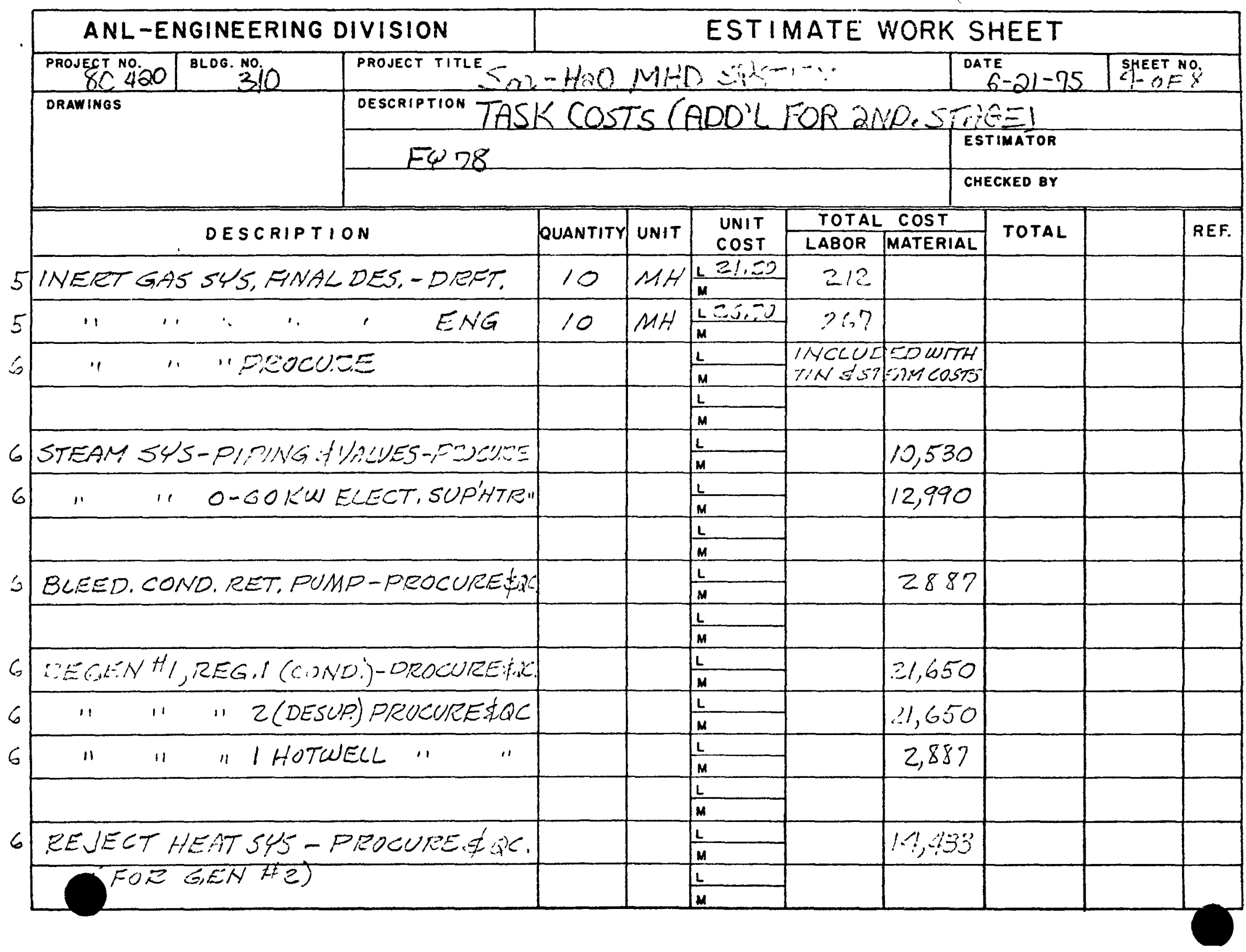




\begin{tabular}{|c|c|c|c|c|c|c|c|c|}
\hline \multirow{4}{*}{ 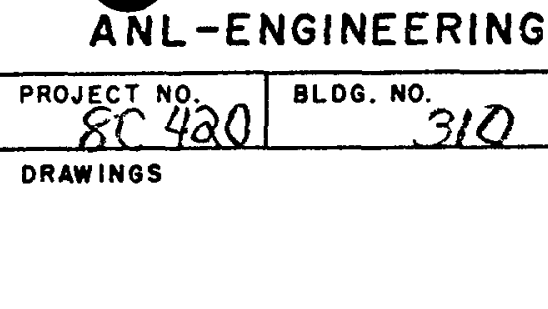 } & IVISION & \multicolumn{7}{|c|}{ ESTIMATE WORK SHEET } \\
\hline & \multicolumn{6}{|c|}{ 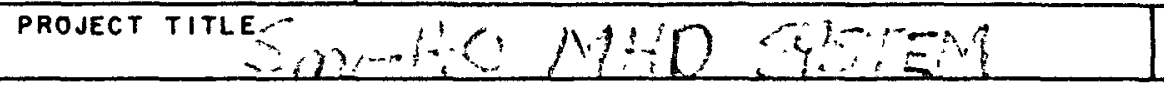 } & \multicolumn{2}{|c|}{ 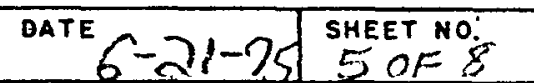 } \\
\hline & \multicolumn{8}{|c|}{ 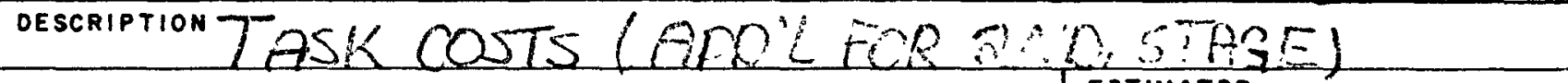 } \\
\hline & \multirow{2}{*}{\multicolumn{6}{|c|}{\begin{tabular}{l|l}
2 & \\
& 0
\end{tabular}}} & \\
\hline \multirow{2}{*}{\multicolumn{2}{|c|}{ OESCRIPTION }} & & & & & & & \\
\hline & & Quantitry u & UNIT & $\begin{array}{l}\text { UNIT } \\
\text { COST }\end{array}$ & $\begin{array}{lll}\text { TOTAL } \\
\text { LABOR } \\
\end{array}$ & $\begin{array}{cccc}\operatorname{COST} \\
\text { MATERIAL }\end{array}$ & TOTAL & REF. \\
\hline \multirow{2}{*}{\multicolumn{2}{|c|}{ FRAMING $\$$ DNCL - PRE, \&FINAL DES }} & $=5 \%$ ALD & & & 1,600 & & & \\
\hline & & & & & & & & \\
\hline \multicolumn{2}{|c|}{ SUP'COND.MAGNET \#Z:FEEF- } & & & $\frac{L}{M}$ & & & & \\
\hline \multicolumn{2}{|c|}{ COMPLETE PRELA FINIIL ZIES, } & $75 \% \circ \mathrm{OF}=$ & $\#$ & $\frac{L}{M}$ & 30,000 & & & \\
\hline & & & & & & & & \\
\hline \multicolumn{2}{|c|}{ SUP'COND. MAGNET \#Z PROCURE,QA } & & & & & 200,000 & & \\
\hline & & & & & & & & \\
\hline & & & & & & & & \\
\hline & & & & & & & & \\
\hline & & & & & & & & \\
\hline & & & & & & & & \\
\hline & & & & & & & & \\
\hline & & & & & & & & \\
\hline & & & & & & & & \\
\hline & & & & & & & & \\
\hline
\end{tabular}


ANL-ENGINEERING DIVISION

ESTIMATE WORK SHEET

\begin{tabular}{|c|c|c|c|c|}
\hline $\begin{array}{l}\text { PROJECT NO. } \\
S C \longleftrightarrow 2 O\end{array}$ & BLOG. NO. $3 / 0$ & PROJECT TITLE SM-AHDO MHAD SUSTEM & DATE & $\begin{array}{l}\text { SHEET NOD } \\
\text { COF OE }\end{array}$ \\
\hline DRAWINGS & & $O E$ & & \\
\hline
\end{tabular}

$$
\text { FS } 78
$$

- FOTAL SYSELECT. CONT. DRATT.

\begin{tabular}{|c|c|c|c|c|c|c|c|}
\hline \multirow{2}{*}{ DESCRIPTION } & \multirow{2}{*}{ QUANTITY } & \multirow{2}{*}{ UNIT } & \multirow{2}{*}{$\begin{array}{l}\text { UNIT } \\
\text { COST }\end{array}$} & \multicolumn{2}{|c|}{ TOTAL COST } & \multirow{2}{*}{ TOTAL } & \multirow{2}{*}{ REF. } \\
\hline & & & & LABOR & MATERIAL & & \\
\hline $\begin{array}{l}\text { TOTAL SYSELECTICONT: - DRAFT. } \\
\text { FINAL DES. S SPECS, - }\end{array}$ & 40 & $\mathrm{rH}$ & $L=1.20$ & 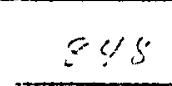 & & & \\
\hline " ENG. & 40 & $m / n$ & $\frac{L}{M}=6 .-2$ & 1168 & & & \\
\hline " "PROCUEE & & & $\frac{L}{M}$ & & $1,4,500$ & & \\
\hline & & & L & & & & \\
\hline 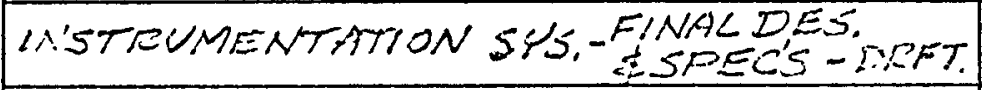 & 40 & $\mathrm{MH}$ & $\frac{21,20}{M}$ & $840^{\circ}$ & & & \\
\hline ENG & 40 & $M H$ & $\frac{26.1 .9}{M}$ & 1260 & & & \\
\hline$\because P R O C U E E \& Q C(10 \%)$ & & & $\frac{L}{M}$ & & 47,300 & & \\
\hline & & & L & & & & \\
\hline CONTROL STA. - FINAL DES, FS SPIECS-DOF. & 40 & M:'-' & $L: 1, \cdots$ & 578 & & & \\
\hline 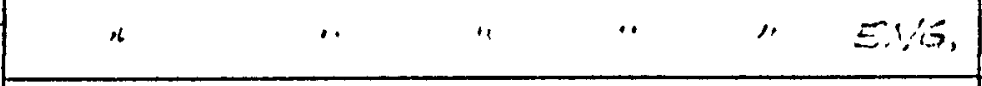 & 40 & $M H$ & $M$ & 1065 & & & \\
\hline$" \quad "$-PFOCUED $R Q R\left(10 r_{0}\right)$ & & & $\frac{L}{M}$ & & 2.201 & & \\
\hline " $"$ - INSTALLATION. & 40 & $A r i$ & $L$ & & 1100 & & \\
\hline & & & $\frac{L}{M}$ & & & & \\
\hline & & & $\frac{L}{M}$ & & & & \\
\hline & & & L & & & & \\
\hline
\end{tabular}

\begin{tabular}{|c|c|c|c|c|c|c|c|}
\hline \multirow{2}{*}{ DESCRIPTION } & \multirow{2}{*}{ QUANTITY } & \multirow{2}{*}{ UNIT } & \multirow{2}{*}{$\begin{array}{l}\text { UNIT } \\
\text { COST }\end{array}$} & \multicolumn{2}{|c|}{ TOTAL COST } & \multirow{2}{*}{ TOTAL } & \multirow{2}{*}{ REF. } \\
\hline & & & & LABOR & MATERIAL & & \\
\hline $\begin{array}{l}\text { TOTAL SYSELECT.CONT. - DRAFT. } \\
\text { FINAL DES. S SPECS. - }\end{array}$ & 40 & $r \mu$ & $L 21.20$ & $2 ! s$ & & & \\
\hline " EN/G. & 40 & $m$ & $L=5.70$ & 1168 & & & \\
\hline 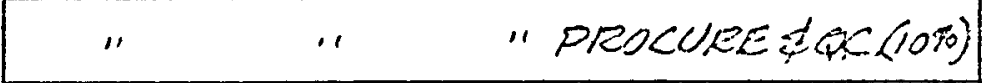 & & & \begin{tabular}{|l}
$L$ \\
$M$
\end{tabular} & & 14,500 & & \\
\hline & & & 2 & & & & \\
\hline 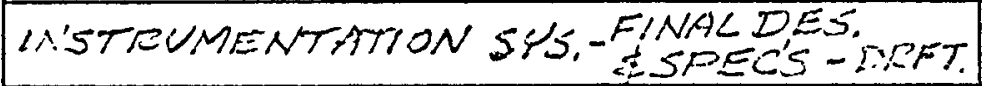 & 40 & $\mathrm{MH}$ & $\frac{21,20}{M}$ & $840^{\circ}$ & & & \\
\hline " $\quad$ ENG, & 40 & $\mathrm{MH}$ & $\frac{26.19}{M}$ & 1260 & & & \\
\hline$\because P P O C U E E \neq Q C(10 \%)$ & & & $\frac{L}{M}$ & & 47,300 & & \\
\hline & & & $\frac{L}{M}$ & & & & \\
\hline CONTPOL STA. - FINAL DES, SF SPECS-DNF. & 40 & $M: \div$ & $\mathrm{L}=1, \cdots$ & 548 & & & \\
\hline$" \quad " \quad$ " & 40 & $m g$ & 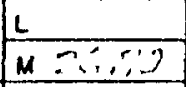 & 1065 & & & \\
\hline$" \quad "$ - PEOCUEE \&QR $\left(100_{0}\right)$ & & & L & & 2.300 & & \\
\hline " $"$ - INSTALLATION. & 40 & Ari & $L$ & & 1100 & & \\
\hline & & & $\frac{L}{M}$ & & & & \\
\hline & & & $L$ & & & & \\
\hline & & & $\frac{L}{M}$ & & & & \\
\hline
\end{tabular}

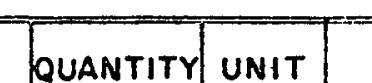

ESTIMATOR

CHECKED BY 


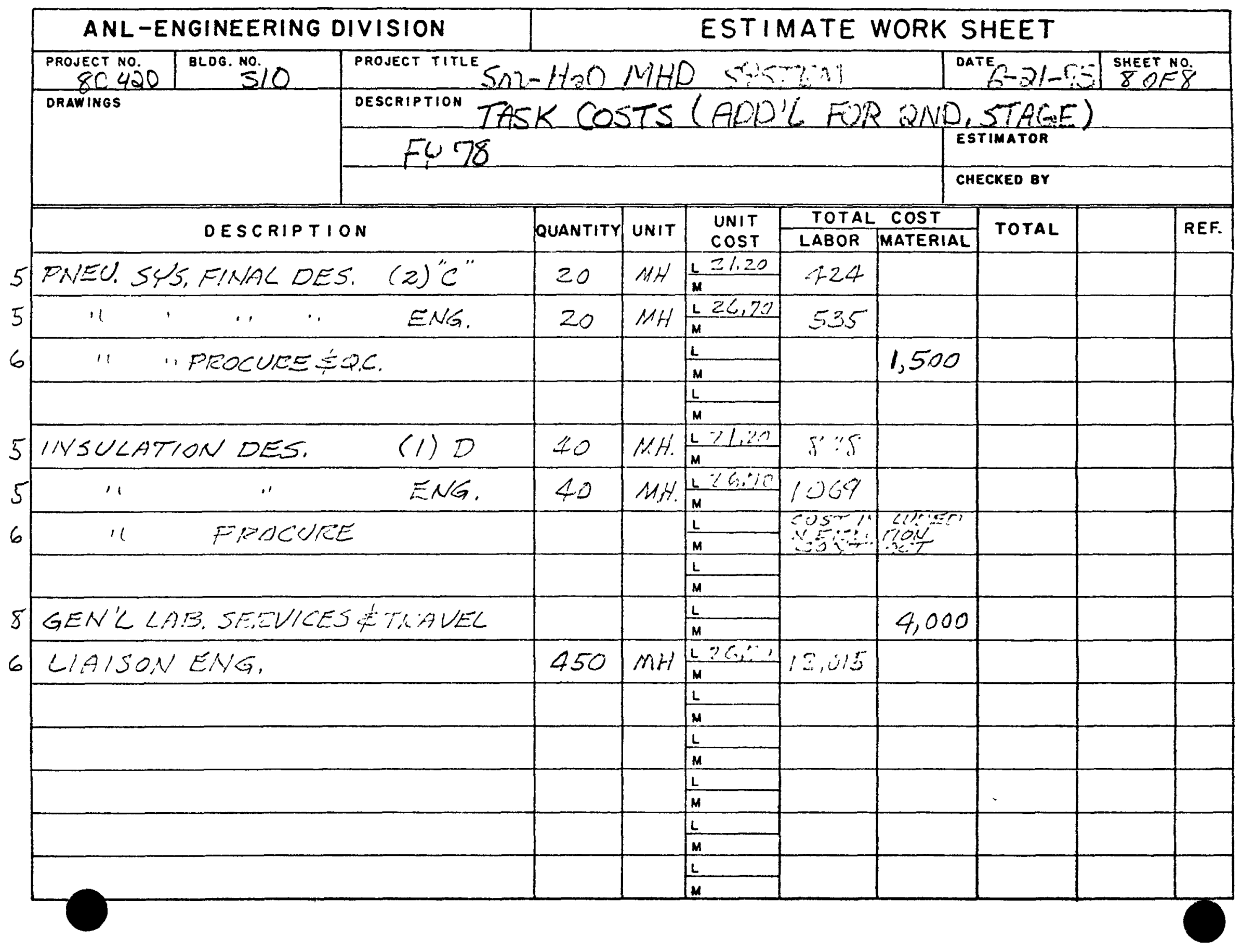




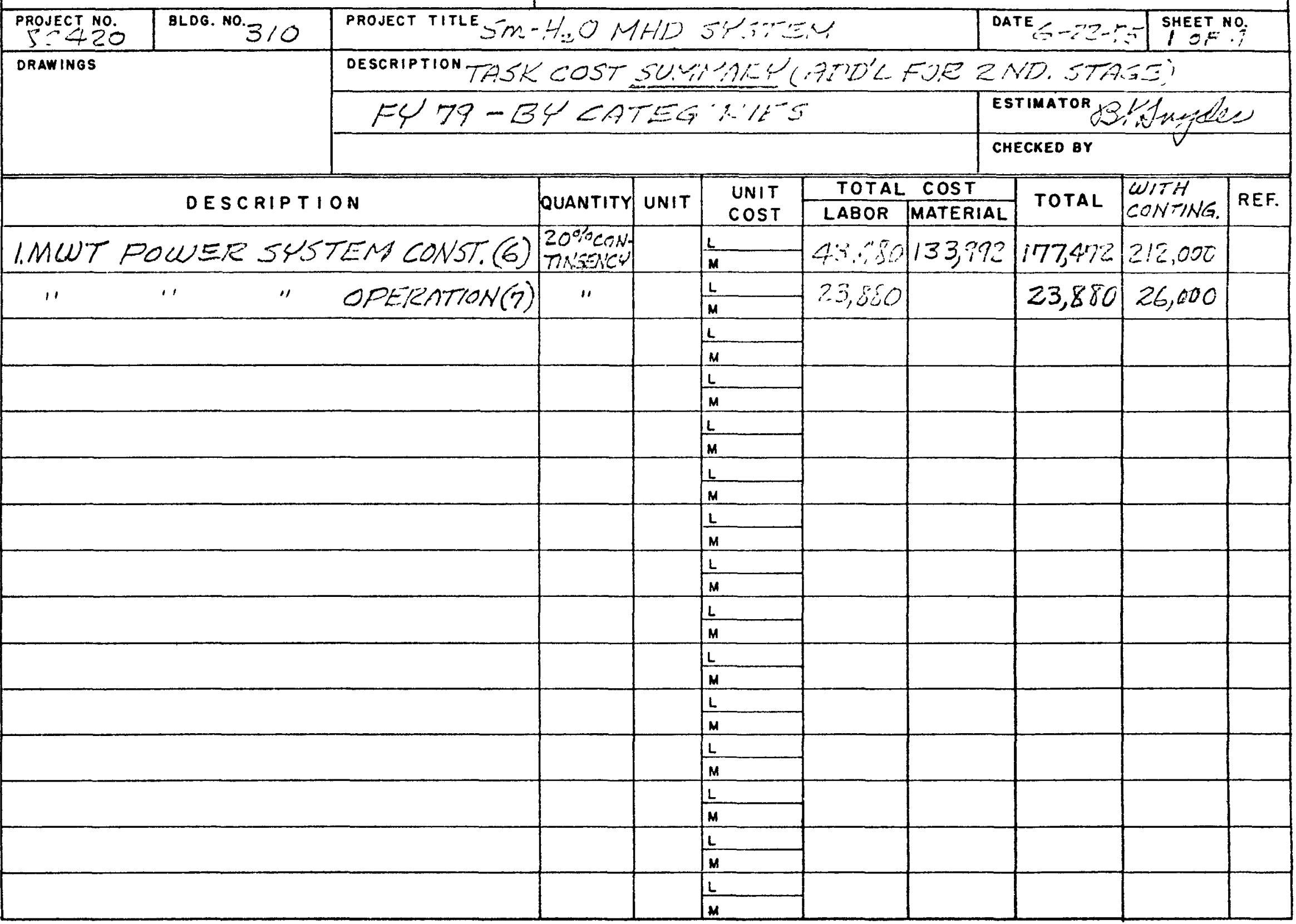




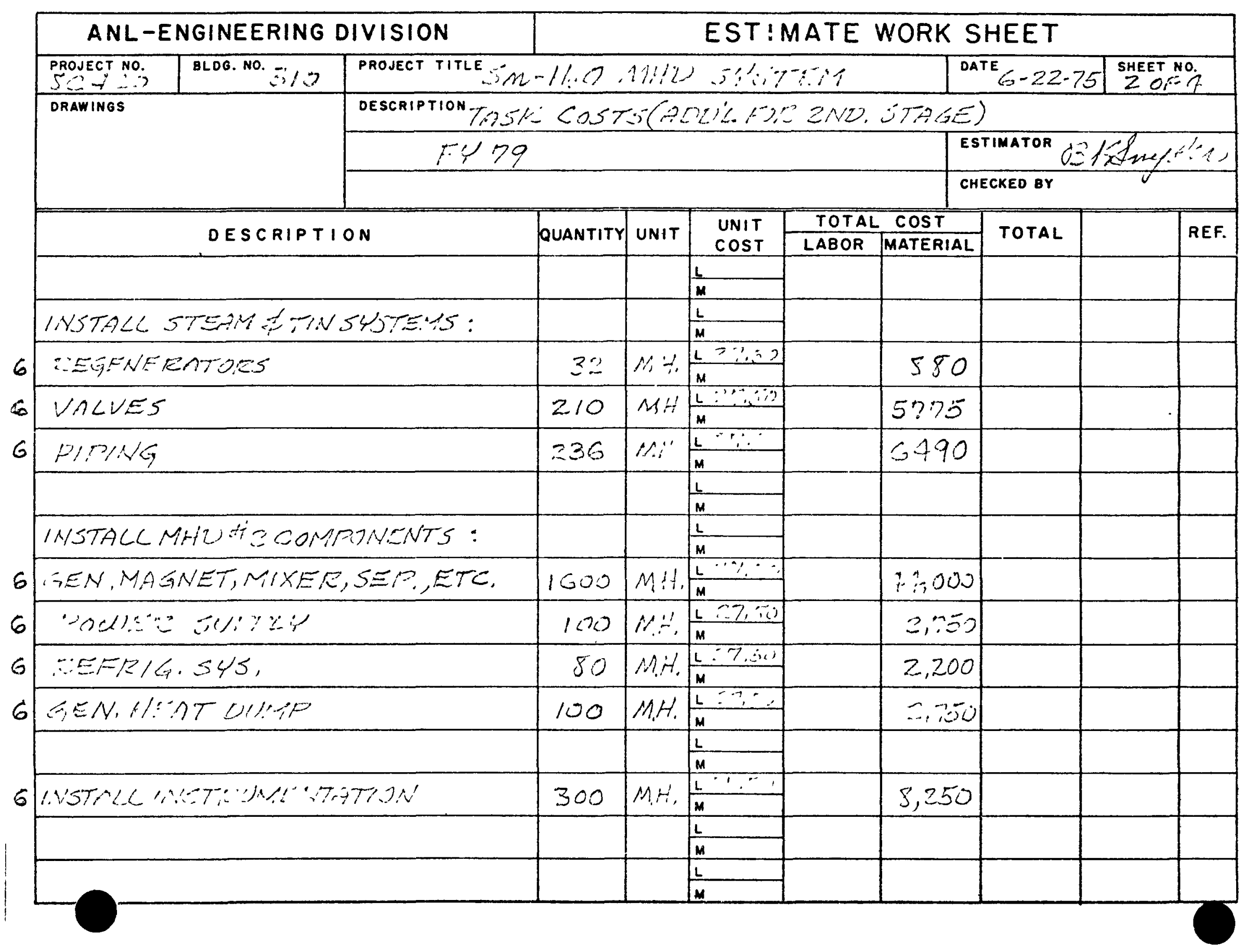




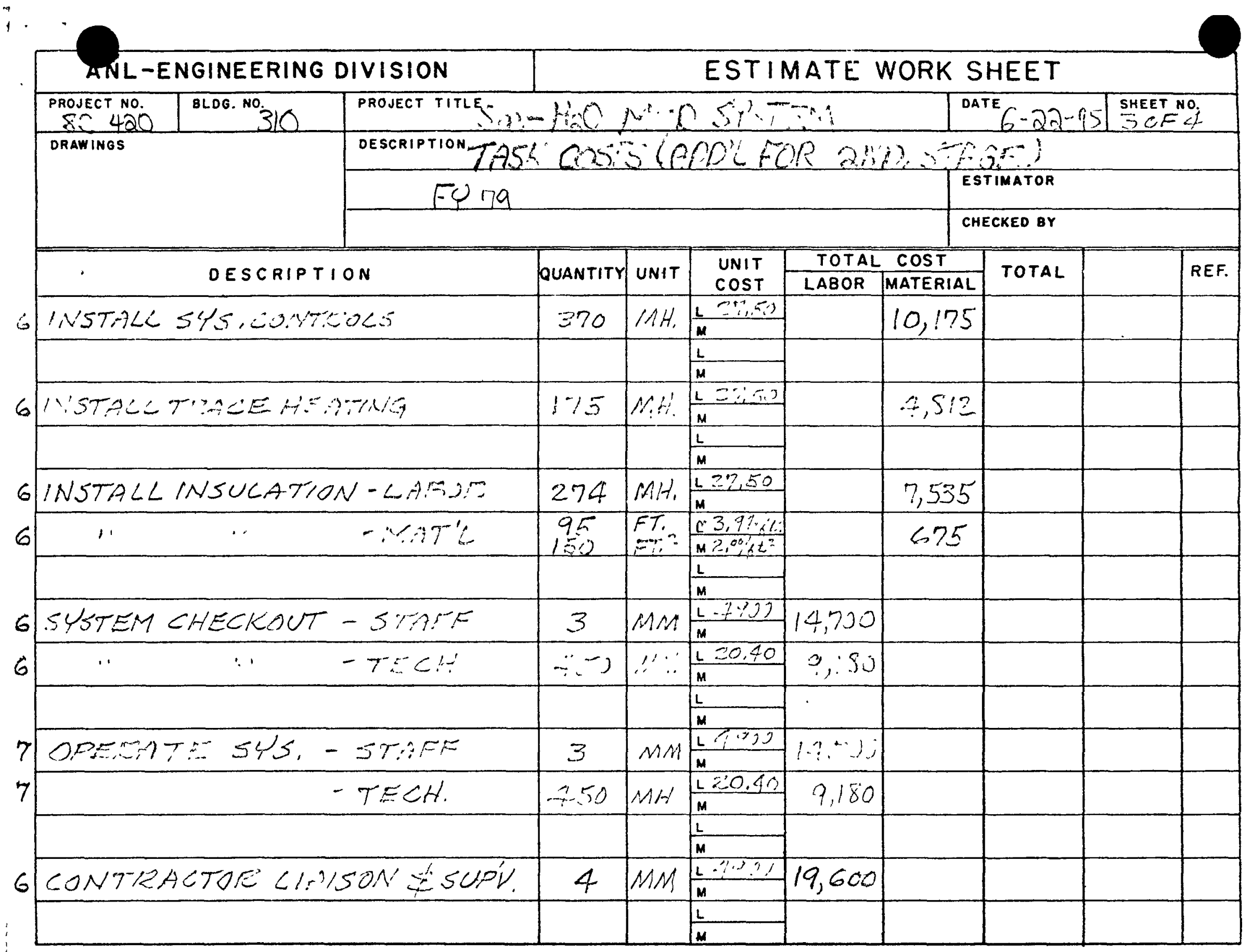




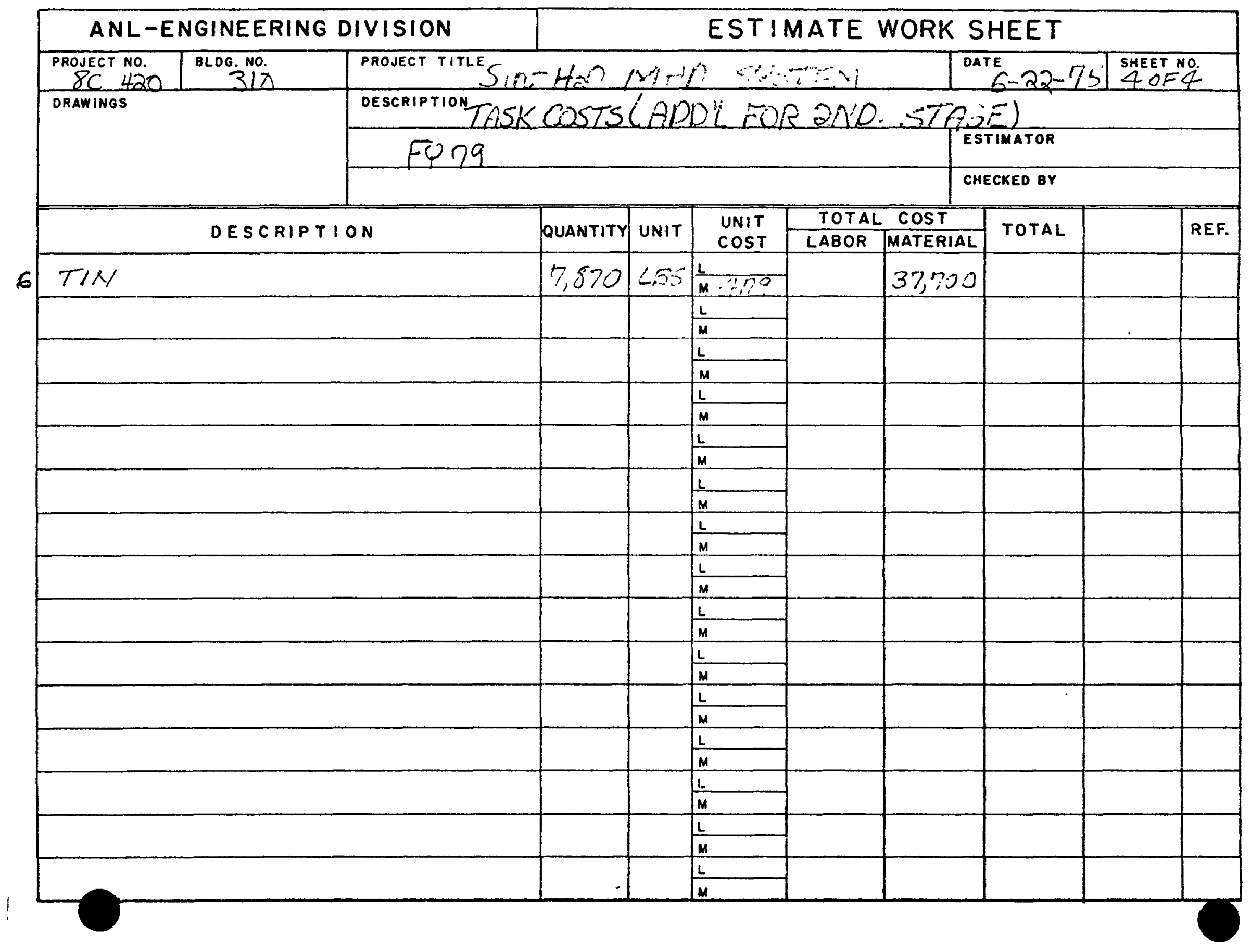


19. Keywords (cont)

prototype power system steam system components

$\mathrm{R} \& \mathrm{D}$ program

reaction kinetics

separator superconducting magnets

system design description

test facilities tin oxide

tine pump

20. Abstract (contd.)

it also possesses the potential for increased system. reliability and reduced noise levels, since the few rotating parts are of small size and will rotate at relatively low velocity.

The FY 75 activities included cycle and system studies, pre-conceptual design studies and development of detailed program plans. Volume I describes the results of the cycle and system studies and tin-water oxidation studies conducted in FY 75 .

This volume, Volume II, concerns itself with the description of a conceptua reference design for a $1 \mathrm{MW}$ (thermal) $\mathrm{Sn}-\mathrm{H}_{2} \mathrm{O}$ MHD Prototype Power System, the program plan for the $R \& D$, design and construction of such a system and time schedules and budgets corresponding thereto.

A summary of the conceptual reference design of the prototype power system, its major features and operational characteristics are given.

The overall program plan is described. Subsections describe, in detail, the materials and reaction-kinetics studies program and the component development and testing program.

Also, the overall program schedule is presented. Salient program features such as constraints, critical paths, manpower loadings and program buildup are discussed.

The management plan, including an organization chart is presented, Overa11 program budgets are developed by category for each of the four fiscal pears, 1976 through 1979, for both a single stage system and a double stage system. Also included is an analysis of some budgetary characteristics of the program.

The Conceptual System Design Description of the 1 MW Prototype Power System is presented. This is the reference design upon which the program plan, task descriptions and, the program budgets were based. It describes a twostage system. However, provisions are incorporated which would permit construction of only portions of the system required for operation of a single stage. An abridged version of the major program task descriptions upon which the program schedules and cost estimates were based is included, as are detailed cost estimate sheets and cost estimating criteria. 